\author{
UNIVERSIDADE DE SÃO PAULO \\ ESCOLA DE ENGENHARIA DE SÃO CARLOS \\ DEPARTAMENTO DE HIDRAULICA E SANEAMENTO
}

Sarah Regina Vargas

\title{
Influência da concentração de nutrientes na \\ Interação entre duas espécies fitoplanctônicas isoladas do Reservatório de Itupararanga - S.P.
}



Sarah Regina Vargas

\title{
Influência da concentração de nutrientes na Interação entre duas espécies fitoplanctônicas isoladas do Reservatório de Itupararanga - S.P.
}

\author{
Dissertação apresentada à Escola de Engenharia de \\ São Carlos, da Universidade de São Paulo, como \\ parte dos requisitos para obtenção do Título de \\ Mestre em Hidráulica e Saneamento.
}

Orientador: Professora Titular Maria do Carmo Calijuri

São Carlos

2012 
AUTORIZO A REPRODUÇÃO E DIVULGAÇÃO TOTAL OU PARCIAL DESTE TRABALHO, POR QUALQUER MEIO CONVENCIONAL OU ELETRÔNICO, PARA FINS DE ESTUDO E PESQUISA, DESDE QUE CITADA A FONTE.

Ficha catalográfica preparada pela Seção de Tratamento da Informação do Serviço de Biblioteca - EESC/USP

Vargas, Sarah Regina
V297i Influência da concentração de nutrientes na interação entre duas espécies fitoplanctônicas isoladas do

Reservatório de Itupararanga-SP / Sarah Regina Vargas ; orientador Maria do Carmo Calijuri. -- São Carlos, 2012.

Dissertação (Mestrado - Programa de Pós-Graduação em Hidráulica e Saneamento) -- Escola de Engenharia de São Carlos da Universidade de São Paulo, 2012.

1. Reservatórios. 2. Cianobactéria. 3. Clorofícea. 4. Saxitoxina. 5. Competição por recurso limitado. 6. Níveis tróficos. I. Título. 


\section{FOLHA DE JULGAMENTO}

Candidata: Licenciada SARAH REGINA VARGAS.

Título da dissertação: "Influência da concentração de nutrientes na interação entre duas espécies fitoplanctônicas isoladas do reservatório de Itupararanga - S.P.".

Data da defesa: 22/03/2012

\section{Comissão Julgadora:}

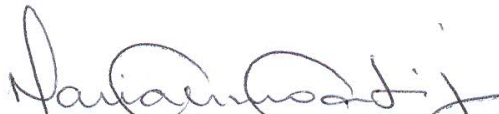

Profa. Titular Maria do Carmo Calijuri (Orientadora)

(Escola de Engenharia de São Carlos/EESC)

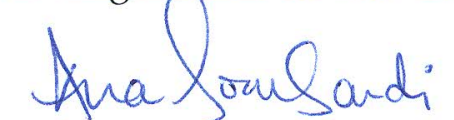

Prof ${ }^{a}$. Dr ${ }^{a}$. Ana Teresa Lombardi

(Universidade Federal de São Carlos/UFSCar)

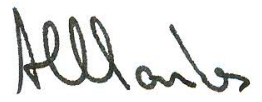

Prof. Dr. André Cordeiro Alves dos Santos

(Universidade Federal de São Carlos/UFSCar)

\section{Resultado:}

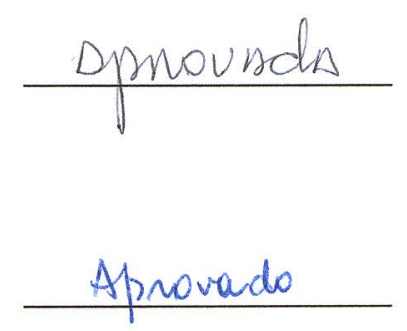

Aprovaso

Coordenador do Programa de Pós-Graduação em Engenharia Hidráulica e Saneamento:

Prof. Titular Edson Cezar Wendland

Presidente da Comissão de Pós-Graduação:

Prof. Associado Paulo Cesar Lima Segantine 
Dedico este trabalho aos meus pais Nelson $e$ Lindalva, por me apoiarem e ajudarem durantes estes anos; aos meus irmãos Lívia e Pedro, pelo amor e carinho; e ao Ricardo pelo amor, paciência e atenção em todos os momentos. 



\section{AGRADECIMENTOS}

Primeiramente agradeço à Deus, pela oportunidade, saúde e força na realização deste trabalho.

À minha família, pelo amor, apoio, compreensão e dedicação por toda a minha vida, obrigada por sempre acreditarem em mim.

Ao Ricardo Benini, pelo amor, companheirismo, atenção e incentivo durante a realização desta pesquisa. Por estar sempre ao meu lado, me ouvindo e aconselhando nos momentos mais difíceis.

À professora Maria do Carmo Calijuri, pela oportunidade de fazer parte do seu grupo de pesquisa, por acreditar e confiar no meu trabalho e contribuir com seus ensinamentos que ajudaram no meu amadurecimento profissional.

Às agências de fomento Capes, pela concessão de bolsa, e FAPESP, pelo suporte financeiro ao Projeto Temático (08/55636-9).

Aos pesquisadores do BIOTACE, Flávia, Raquel, Davi, Lorena, Juliana e Roger, pelas ajudas e momentos de descontração.

Às técnicas do BIOTACE, Adriana e Luci, que muito me ensinaram com dedicação e paciência.

Aos amigos Dr. André Cordeiro Alves Dos Santos, Ms. Simone Pereira Casali, Dra. Adriana C. P. Miwa e Dra. Patrícia Bortoleto de Falco, pelos conselhos, correções e sugestões que tanto me ajudaram no desenvolvimento desta pesquisa.

Ao amigo e Ms. Paulo Vagner dos Santos que tanto me ensinou, aconselhou e ajudou com muita paciência, carinho e dedicação, muito obrigada.

Aos meus saudosos amigos de colégio e graduação pela compreensão da minha ausência e pela contribuição com as descontrações, com carinho e atenção, nos momentos difíceis da minha pesquisa.

Aos técnicos Waldomiro Antônio Filho e José Roberto Maramarque, e pesquisadores Dra. Flávia Bottino e Davi Cunha, pela realização, com dedicação, do trabalho de campo para a coleta de água do Reservatório de Itupararanga no início da minha pesquisa.

Ao técnico Júlio César Trofino do Laboratório de Saneamento da EESC/USP, pela disponibilidade em fazer e ensinar a análise de detecção de microcnutrientes.

À aluna de mestrado Laís Américo Soares do Laboratório de Microbiologia Ambiental da UFSCar - Campus Sorocaba, pela realização da análise de bactérias nitrificantes. 
Aos funcionários da Pós-Graduação do Departamento de Hidráulica e Saneamento Maria Auxiliadora C. Altieri Pin, Pavlovna Damião Rocha Bueno, Rosemeire A. de Jesus, Flávia G. Canova, Fernanda M. Struzziatto e André Canale Garcia, obrigada pela atenção e eficiência.

E por fim, mas não com menor importância, aos examinadores de qualificação e defesa, Prof. Dr. André Cordeiro Alves Dos Santos e Prof ${ }^{a}$. Dra. Ana Tereza Lombardi, pelas pertinentes contribuições para a elaboração desta pesquisa e dissertação.

Enfim, à todos aqueles que contribuíram com a minha formação e amadurecimento profissional, para que eu pudesse me manter firme nesta jornada, para se encerrar mais uma fase da minha vida e ter inicio a uma nova, o meu muito obrigada! 
Não faças do amanhã o sinônimo de nunca, nem o ontem te seja o mesmo que nunca mais. Teus passos ficaram. Olhes para trás... mas vá em frente, pois há muitos que precisam que chegues para poderem seguir-te. 



\section{RESUMO}

VARGAS, S.R. Influência da concentração de nutrientes na interação entre duas espécies fitoplanctônicas isoladas do Reservatório de Itupararanga, SP. 2012. 148 f. Dissertação (Mestrado) - Escola de Engenharia de São Carlos, Universidade de São Paulo, São Carlos, 2012.

O Reservatório de Itupararanga, no interior do estado de São Paulo, tem como principal finalidade geração de energia elétrica e o abastecimento público, além de área de lazer e pesca. O crescimento urbano e agrícola em torno do corpo hídrico tem alterado a qualidade da água favorecendo a proliferação de cianobactérias. Estudos preliminares da comunidade fitoplanctônica demonstraram a dominância da cianofícea Cylindrospermopsis raciborskii e da clorofícea Monoraphidium contortum. Com o objetivo de investigar o nível trófico do reservatório e sua influência na dominância destas espécies, foram realizados ensaios de interação entre estes microrganismos sob diferentes concentrações de fósforo, simulando o reservatório em três diferentes níveis tróficos: oligotrófico, mesotrófico e supereutrófico. Também foi determinada a produção de saxitoxina pela cianobactéria. No ambiente oligotrófico a C. raciborskii apresentou diminuição do volume celular, aumento da produção de saxitoxina e senescência em interação com o M. contortum. Nos ambientes mesotrófico e supereutrófico, a cianobactéria não apresentou diferenças no crescimento e na produção de saxitoxina, comparado ao seu controle, quando em interação com a clorofícea. $\mathrm{O}$ mesmo não foi observado para M. contortum nestes dois níveis de trofia, pois teve seu crescimento prejudicado nas interações com $C$. raciborskii. As velocidades específicas de crescimento de $M$. contortum foram crescentes conforme o aumento da trofia, e as da C. raciborskii decrescentes. As concentrações de clorofila-a também foram crescentes conforme o aumento de trofia, e diminuíram no final dos experimentos. O consumo de ortofosfato foi semelhante na simulação dos três ambientes e o consumo do nitrato, foi maior quanto mais elevado o nível trófico. A partir dos resultados, foram feitas previsões das espécies fitoplanctônicas dominantes regidas pelo nível trófico do reservatório, que contribuirão nas medidas de conservação e manejo deste ecossistema aquático.

Palavras-chave: Cianobactéria. Clorofícea. Saxitoxina. Competição por recurso limitado. Níveis tróficos. 



\begin{abstract}
VARGAS, S.R. Influence of nutrient concentration in the interaction between two phytoplankton species isolated from the Reservoir Itupararanga, SP. 2012. $148 \mathrm{f}$. Master's Degree Dissertation - Escola de Engenharia de São Carlos, Universidade de São Paulo, São Carlos, 2012.

The Reservoir Itupararanga within the state of São Paulo, whose main purpose is public supply, besides electricity generation, and recreational areas and fishing. The urban growth and agriculture around the water body has changed its quality, favoring the growth of cyanobacteria. Preliminary studies of phytoplankton showed a dominance of cyanophyceae Cylindrospermopsis raciborskii and clorofícea Monoraphidium contortum. In order to investigate the trophic level of the reservoir and its influence on the dominance of these species, tests of the interaction between these microorganisms under different phosphorus concentrations were performed, simulating the reservoir in three different trophic levels: oligotrophic, mesotrophic and supereutrophic. The production of saxitoxin by the cyanobacteria was also defined. In the oligotrophic C. raciborskii showed a decrease of cell volume, increased production of saxitoxin and senescence in interaction with $M$. contortum. In mesotrophic and supereutrofic environments, the cyanobacteria did not show differences in growth and production of saxitoxin, compared to their control when interacting with the chlorophycea. The same was not observed for M. contortum in these two trophic levels, as its growth was affected by the interactions with $C$. raciborskii. The specific growth rates of $M$. contortum were growing with increasing trophic, and those of C. raciborskii decreasing. The chlorophyll-a concentrations were also growing with increasing trophic, and decreased at the end of the experiments. The orthophosphate consumption was similar in the three simulation environments and consumption of nitrate was greater the higher the trophic level. From the results, were made estimates of the dominant phytoplankton species was governed by the trophic level of the reservoir, which will help in the conservation and management of this aquatic ecosystem.
\end{abstract}

Keywords: Cyanobacteria. Clorofícea. Saxitoxin. Competition for limited resource. Trophic levels. 



\section{LISTA DE FIGURAS}

Figura 1: Ciclo do Fósforo (modificado de BRAGA et al., 2005; ODUM, 1988) ..................31

Figura 2: Ciclo do Nitrogênio (modificado de BRAGA et al., 2005; ODUM, 1988)............. 32

Figura 3: Cylindrospermopsis raciborskii à esquerda $e$ Monoraphidium contortum à direita, isoladas do Reservatório de Itupararanga $(200$ x). Escala de $20 \mu$ para ambas as espécies..... 38

Figura 4: Localização do Reservatório de Itupararanga (SECCHIN, em andamento). 44

Figura 5: Fluxograma de apresentação das principais etapas desenvolvidas no projeto de pesquisa. Experimento - Exp.; Oligotrófico - Oligo; Mesotrófico - Meso; Supereutrófico Super. Total de 63 Erlenmeyers em cada experimento, sendo 9 do Bloco 1 e 54 do Bloco 2. 45

Figura 6: Estações de amostragem das coletas do Reservatório de Itupararanga. EC1 - eixo central ; EC2 - eixo central 2; EC3 - eixo central 3; BR1 - braço 1; BR2 - braço 2; BR3 braço 3; BR4 - braço 4; Trans - transição dos rios para o reservatório.

Figura 7: Esquema dos experimentos realizados em triplicata para cada ensaio de simulação de trofia. $\mathrm{Cr}$ - monocultura de Cylindrospermopsis raciborskii; Int - Interação das duas espécies; Mc - monocultura de Monoraphidium contortum. Bloco 1 representa unidades experimentais para amostragem de densidade, biovolume e toxina. Bloco 2 representa unidades experimentais para amostragem de nutrientes e clorofila-a. Monoculturas correspondem aos controles das duas espécies.

Figura 8: Exposição dos blocos 1 e 2, totalizando 63 Erlenmeyers em cada simulação de trofia.

Figura 9: Comunidade fitoplanctônica do Reservatório de Itupararanga após enriquecimento em meio de cultura em aumento de 200x. A - Cylindrospermopsis raciborskii; B Monoraphidium contortum.

Figura 10: Curvas de crescimento das cepas de $M$. contortum e C. raciborskii baseadas nas médias da densidade $\left(10^{4}\right.$.ind. $\left.\mathrm{ml}^{-1}\right)$ e do biovolume $\left(10^{7} \cdot \mu \mathrm{m}^{3} \cdot \mathrm{ml}^{-1}\right)$. Barras verticais indicam o desvio padrão $(n=3)$.

Figura 11: Curvas de crescimento de C. raciborskii e $M$. contortum baseadas nas médias do biovolume $\left(10^{5} \cdot \mu \mathrm{m}^{3} \cdot \mathrm{ml}^{-1}\right)$ na simulação do ambiente Oligotrófico. Mc cont. - M. contortum controle; Mc int. - M. contortum interação; Cr cont. - C. raciborskii controle; Cr int. $-C$. raciborskii interação. Barras verticais indicam o desvio padrão ( $\mathrm{n}=3$ ).

Figura 12: Curvas de crescimento de C. raciborskii e $M$. contortum baseadas nas médias do biovolume $\left(10^{5} \cdot \mu \mathrm{m}^{3} \cdot \mathrm{ml}^{-1}\right)$ na simulação do ambiente Mesotrófico. Mc cont. - M. contortum 
controle; Mc int. - M. contortum interação; Cr cont. - C. raciborskii controle; Cr int. - C. raciborskii interação. Barras verticais indicam o desvio padrão $(\mathrm{n}=3)$.

Figura 13: Curvas de crescimento de C. raciborskii e $M$. contortum baseadas nas médias do biovolume $\left(10^{5} \cdot \mu \mathrm{m}^{3} \cdot \mathrm{ml}^{-1}\right)$ na simulação do ambiente Supereutrófico. Mc cont. $-M$. contortum controle; Mc int. - M. contortum interação; Cr cont. - C. raciborskii controle; Cr int. - C. raciborskii interação. Barras verticais indicam o desvio padrão $(n=3)$. .70

Figura 14: Média dos volumes celulares $\left(\mu \mathrm{m}^{3}\right)$ de $M$. contortum $(\mathrm{Mc})$ e C. raciborskii $(\mathrm{Cr})$ na simulação do ambiente oligotrófico. " $x$ " indica máximo e mínimo, retângulo a maior concentração dos volumes e $\square$ dentro do retângulo a média do volume celular $(n=3) \ldots \ldots \ldots \ldots . . .75$

Figura 15: Média dos volumes celulares $\left(\mu \mathrm{m}^{3}\right)$ de M. contortum $(\mathrm{Mc})$ e C. raciborskii $(\mathrm{Cr})$ na simulação do ambiente mesotrófico. " $x$ " indica máximo e mínimo, retângulo a maior concentração dos volumes e $\square$ dentro do retângulo a média do volume celular $(n=3)$.

Figura 16: Média dos volumes celulares $\left(\mu \mathrm{m}^{3}\right)$ de $M$. contortum $(\mathrm{Mc})$ e C. raciborskii $(\mathrm{Cr})$ na simulação do ambiente supereutrófico. " $x$ " indica máximo e mínimo, retângulo a maior concentração dos volumes e $\square$ dentro do retângulo a média do volume celular $(n=3)$. .78

Figura 17: Média da concentração de clorofila-a $\left(\mu \mathrm{g} . \mathrm{L}^{-1}\right)$ da soma dos controles, $M$. contortum e C. raciborskii, e da interação, na simulação do ambiente oligotrófico. As barras verticais indicam o desvio padrão $(n=3)$.

Figura 18: Média da concentração de clorofila-a $\left(\mu \mathrm{g} . \mathrm{L}^{-1}\right)$ da soma dos controles, $M$. contortum e C. raciborskii, e da interação, na simulação do ambiente mesotrófico. As barras verticais indicam o desvio padrão $(n=3)$.

Figura 19: Média da concentração de clorofila-a $\left(\mu \mathrm{g} . \mathrm{L}^{-1}\right)$ da soma dos controles, $M$. contortum e C. raciborskii, e da interação, na simulação do ambiente supereutrófico. As barras verticais indicam o desvio padrão $(n=3)$.

Figura 20: Controle C. raciborskii dia 0. Aumento de 400x. Escala de 15 ㅍ..................139

Figura 21: Controle C. raciborskii dia 7. Aumento de 200x. Escala de $40 \mu \mathrm{m}$. ..................139

Figura 22: Controle C. raciborskii dia 15. Aumento de 400x. Escala de $10 \mu \mathrm{m}$.................139

Figura 23: Controle $M$. contortum dia 0. Aumento de 400x. Escala de $20 \mu \mathrm{m} . . . \ldots \ldots \ldots \ldots \ldots . . . . . . .140$

Figura 24: Controle M. contortum dia 7. Aumento de 400x. Escala de $20 \mu \mathrm{m} \ldots \ldots \ldots \ldots \ldots \ldots \ldots . . . . . . .140$

Figura 25: Controle $M$. contortum dia 15. Aumento de 400x. Escala de $10 \mu \mathrm{m} . . . \ldots \ldots \ldots \ldots \ldots . . . . .140$

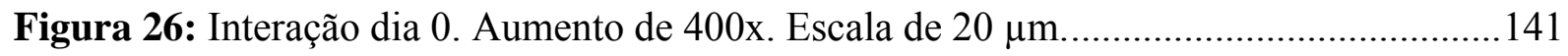

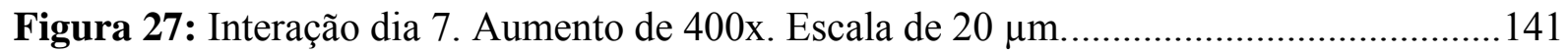

Figura 28: Interação dia 15. Aumento de 400x. Escala de 15 m......................................141 
Figura 29: Controle C. raciborskii dia 0. Aumento de 400x. Escala de $15 \mu \mathrm{m}$. 142

Figura 30: Controle C. raciborskii dia 7. Aumento de 200x. Escala de $20 \mu \mathrm{m}$. 142

Figura 31: Controle C. raciborskii dia 15. Aumento de 200x. Escala de $20 \mu \mathrm{m}$. 142

Figura 32: Controle M. contortum dia 0. Aumento de 400x. Escala de $15 \mu \mathrm{m}$. 143

Figura 33: Controle M. contortum dia 7. Aumento de 400x. Escala de $15 \mu \mathrm{m}$. 143

Figura 34: Controle M. contortum dia 15. Aumento de 400x. Escala de $15 \mu \mathrm{m}$. 143

Figura 35: Interação dia 0. Aumento de 200x. Escala de $20 \mu \mathrm{m}$. 144

Figura 36: Interação dia 7. Aumento de 200x. Escala de $20 \mu \mathrm{m}$. 144

Figura 37: Interação dia 15. Aumento de 200x. Escala de $20 \mu \mathrm{m}$. 144

Figura 38: Controle C. raciborskii dia 0. Aumento de 200x. Escala de $20 \mu \mathrm{m}$. 145

Figura 39: Controle C. raciborskii dia 7, com heterocito. Aumento de 200x. Escala de $20 \mu \mathrm{m}$.

Figura 40: Controle C. raciborskii dia 15, com heterocito. Aumento de 400x. Escala de 15 $\mu \mathrm{m}$. 145

Figura 41: Controle M. contortum dia 0. Aumento de 400x. Escala de $20 \mu \mathrm{m}$. 146

Figura 42: Controle M. contortum dia 7. Aumento de 400x. Escala de $15 \mu \mathrm{m}$. 146

Figura 43: Controle M. contortum dia 15. Aumento de 400x. Escala de $15 \mu \mathrm{m}$. 146

Figura 44: Interação dia 0. Aumento de 200x. Escala de $20 \mu \mathrm{m}$. 147

Figura 45: Interação dia 7, C. raciborskii com heterocito. Aumento de 400x. Escala de 20 $\mu \mathrm{m}$.

Figura 46: Interação dia 15, C. raciborskii com heterocito. Aumento de 200x. Escala de 20 $\mu \mathrm{m}$. 



\section{LISTA DE TABELAS}

Tabela 1 - Classificação e características das principais cianotoxinas e gêneros potencialmente produtores (SIVONEN \& JONES, 1999; CALIJURI et al. 2006).

Tabela 2 - Inóculo e biovolume iniciais das culturas de C. raciborskii e $M$. contortum para cada ambiente simulado

Tabela 3 - Comparação da média dos macronutrientes e micronutrientes do Reservatório de Itupararanga e do meio de cultura ASM - 1 padrão, em mg. $\mathrm{L}^{-1}$

Tabela 4 - Concentrações de fósforo utilizadas para as simulações dos graus de trofia do Reservatório de Itupararanga e o índice de estado trófico (IET) conforme Lamparelli, 2004. 55

Tabela 5 - Classificação do Estado Trófico - IET - de Reservatórios segundo Lamparelli (2004)

Tabela 6 - Comparação das velocidades específicas de crescimento ( $\mu$ ) (média com desvios padrão, $\mathrm{n}=3$ ), de $M$. contortum $(\mathrm{Mc})$ e C. raciborskii $(\mathrm{Cr})$, e C. raciborskii nos três ambientes simulados: oligotrófico, mesotrófico e supereutrófico

Tabela 7 - Comparação dos tempos de duplicação (Td) (média com desvios padrão, $\mathrm{n}=3$ ), de M. contortum $(\mathrm{Mc})$ e C. raciborskii $(\mathrm{Cr})$, e C. raciborskii nos três ambientes simulados: oligotrófico, mesotrófico e supereutrófico

Tabela 8 - Médias dos biovolumes iniciais e finais de M. contortum (Mc) e C. raciborskii (Cr) $\left(10^{5} \cdot \mu \mathrm{m}^{3} \cdot \mathrm{ml}^{-1}\right)$, com desvios padrão $(\mathrm{n}=3)$, nos três ambientes simulados

Tabela 9 - Médias, com desvios padrão ( $\mathrm{n}=3$ ), dos volumes celulares de $M$. contortum nos controles e nas interações, nos dias 0,7 e 15 , nos ambientes simulados

Tabela 10 - Médias, com desvios padrão (n=3), dos volumes celulares de C. raciborskii nos controles e nas interações, nos dias 0,7 e 15, nos ambientes simulados 80

Tabela 11 - Médias, com desvios padrão $(n=3)$, das concentrações de ortofosfato $\left(\mu \mathrm{g} . \mathrm{L}^{-1}\right)$ da simulação do ambiente oligotrófico, nas culturas (Cult.) controle de C. raciborskii $(\mathrm{Cr}-$ cont.), controle de $M$. contortum (Mc - cont.) e interação

Tabela 12 - Médias, com desvios padrão $(n=3)$, das concentrações de ortofosfato $\left(\mu \mathrm{g} . \mathrm{L}^{-1}\right)$ da simulação do ambiente mesotrófico, nas culturas (Cult.) controle de C. raciborskii $(\mathrm{Cr}-$ cont.), controle de M. contortum (Mc - cont.) e interação

Tabela 13 - Médias, com desvios padrão $(n=3)$, das concentrações de ortofosfato $\left(\mu \mathrm{g} . \mathrm{L}^{-1}\right)$ da simulação do ambiente supereutrófico, nas culturas (Cult.) controle de C. raciborskii $(\mathrm{Cr}-$ cont.), controle de M. contortum (Mc - cont.) e interação 
Tabela 14 - Médias, com desvios padrão $(n=3)$, das concentrações de ortofosfato $\left(\mu \mathrm{g} . \mathrm{L}^{-1}\right)$ da simulação dos ambientes oligotrófico, mesotrófico e supereutrófico, nas culturas (Cult.) controle de C. raciborskii ( $\mathrm{Cr}$ - cont.), controle de $M$. contortum ( $\mathrm{Mc}$ - cont.) e interação, com comparação das culturas em cada dia de análise

Tabela 15 - Médias, com desvios padrão $(n=3)$, das concentrações de nitrato $\left(\mathrm{mg} . \mathrm{L}^{-1}\right)$ da simulação do ambiente oligotrófico, nas culturas (Cult.) controle de C. raciborskii $(\mathrm{Cr}-$ cont.), controle de $M$. contortum (Mc - cont.) e interação

Tabela 16 - Médias, com desvios padrão $(n=3)$, das concentrações de nitrato $\left(\mathrm{mg} . \mathrm{L}^{-1}\right)$ da simulação do ambiente mesotrófico, nas culturas (Cult.) controle de C. raciborskii $(\mathrm{Cr}-$ cont.), controle de M. contortum (Mc - cont.) e interação

Tabela 17 - Médias, com desvios padrão $(n=3)$, das concentrações de nitrato $\left(\mathrm{mg} . \mathrm{L}^{-1}\right)$ da simulação do ambiente supereutrófico, nas culturas (Cult.) controle de C. raciborskii ( $\mathrm{Cr}$ cont.), controle de M. contortum (Mc - cont.) e interação

Tabela 18 - Médias, com desvios padrão $(n=3)$, das concentrações de nitrato $\left(\mathrm{mg} . \mathrm{L}^{-1}\right)$ da simulação dos ambientes oligotrófico, mesotrófico e supereutrófico, nas culturas (Cult.) controle de C. raciborskii ( $\mathrm{Cr}$ - cont.), controle de M. contortum ( $\mathrm{Mc}$ - cont.) e interação, com comparação das culturas em cada dia de análise

Tabela 19 - Relação N:P inicial e final de cada cultura nos ambientes simulados baseada na média das concentrações de nitrato e ortofosfato $(\mathrm{n}=3)$ nos controles de $M$. contortum $(\mathrm{Mc}-$ controle) e de C. raciborskii ( $\mathrm{Cr}$ - controle) e interação.

Tabela 20 - Média, com desvio padrão $(n=3)$, das concentrações de saxitoxina por biovolume $\left(10^{-10} \mu \mathrm{g} . \mu \mathrm{m}^{-3}\right)$ das culturas (Cult.) controle de C. raciborskii (Cr - cont.) e interação (Int.), nos três ambientes simulados, oligotrófico (oligo), mesotrófico (meso) e supereutrófico (super)

Tabela 21 - Comparação das médias, com desvios padrão $(n=3)$, das concentrações de saxitoxina $\left(\mu \mathrm{g} . \mathrm{L}^{-1}\right)$ entre os controles de C. raciborskii e entre as interações, nas diferentes simulações de níveis tróficos 100

Tabela 22 - Síntese dos resultados, médias com desvios padrão $(\mathrm{n}=3)$, das culturas controle (Cont.) e interação (Int.), nos três ambientes simulados: oligotrófico (oligo), mesotrófico (meso) e supereutrófico (super) 103

Tabela 23 - Composição do meio de cultura WC

Tabela 24 - Composição da solução de metais do meio de cultura WC

Tabela 25 - Composição da solução de vitaminas do meio de cultura WC.

Tabela 26 - Composição do meio de cultura ASM-1. 
Tabela 27 - Composição do meio de cultura para determinação de bactérias oxidadoras de amônia e nitrito. 136

Tabela 28 - Composição das soluções ferro quelante e metais traço. 136 



\section{SUMÁRIO}

1. INTRODUÇÃ

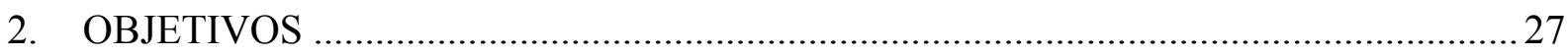

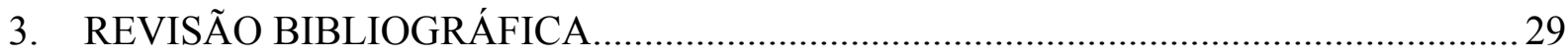

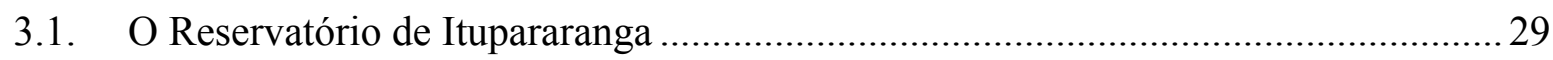

3.2. Nutrientes e Comunidade Fitoplanctônica...........................................................29

3.3. Caracterização das espécies utilizadas nesta pesquisa ......................................... 37

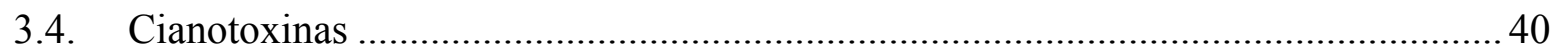

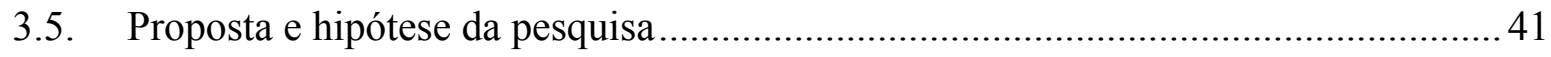

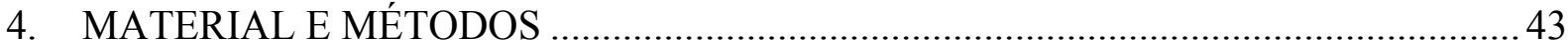

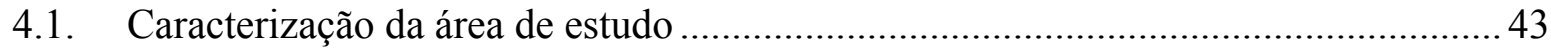

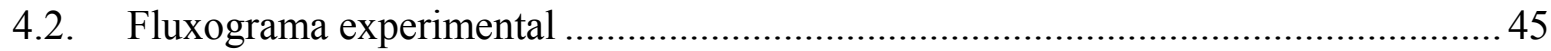

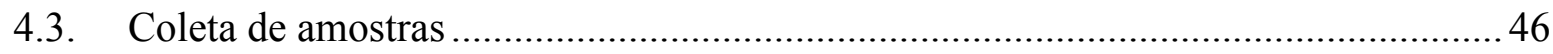

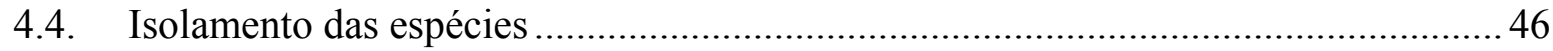

4.5. Triagem das cepas e testes de cultivo da cianobactéria e da clorofícea..................... 48

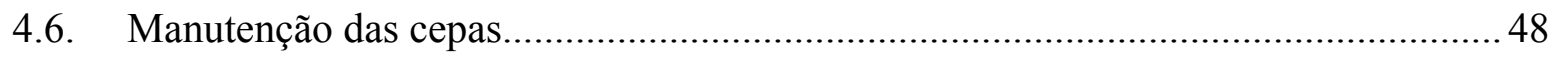

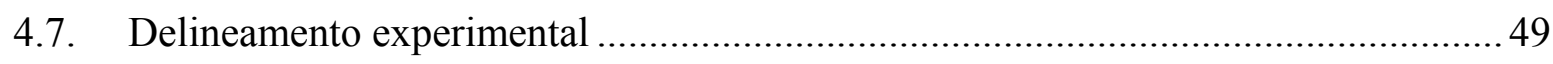

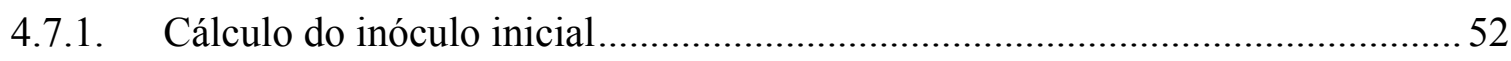

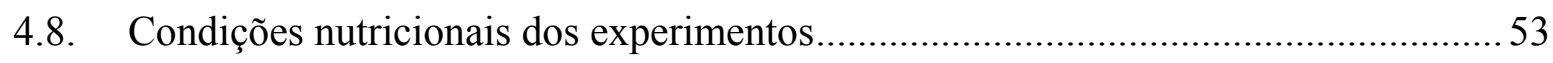

4.8.1. Modificações do meio ASM-1 para a simulação de trofia .................................. 54

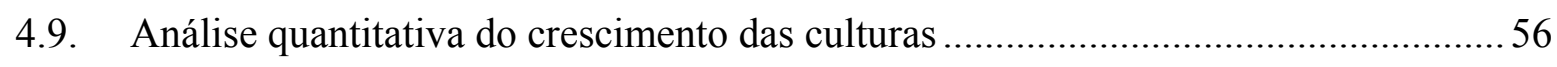

4.10. Análise de nutrientes dissolvidos e clorofila-a ................................................5 57

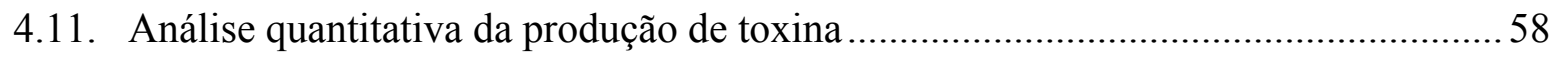

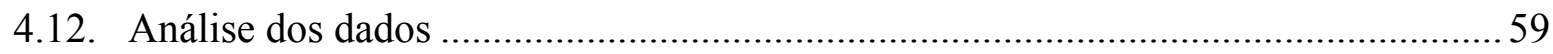

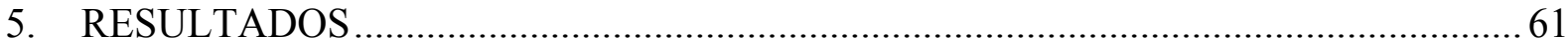


5.1. Isolamento e caracterização do crescimento das cepas de C. raciborskii e $M$.

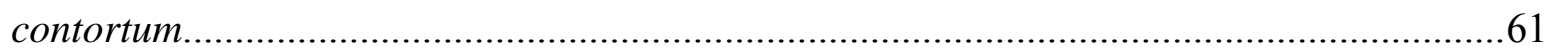

5.2. Ensaios de interação: comparação dos parâmetros bióticos e físico-químicos ..........64

5.2.1. Caracterização do crescimento das cepas nas simulações de trofia.....................64

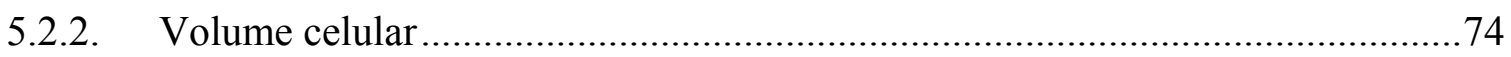

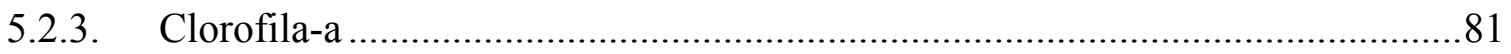

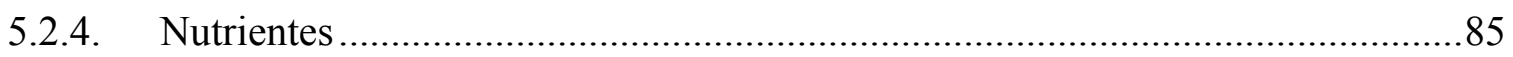

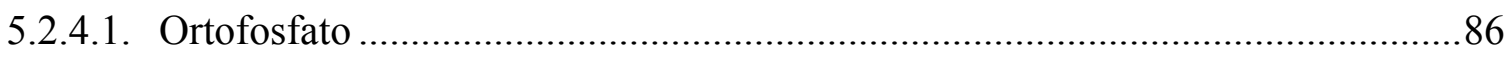

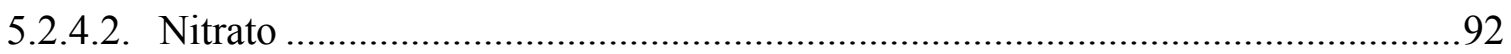

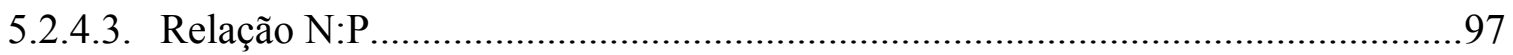

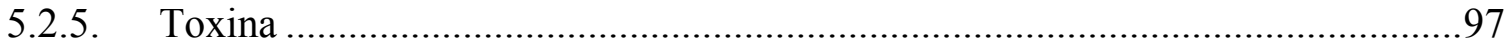

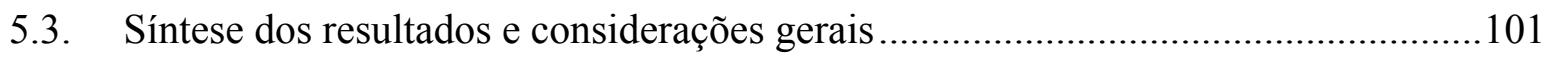

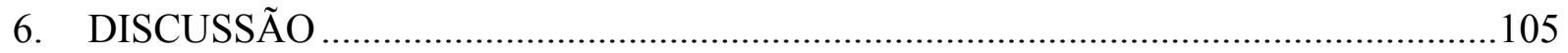

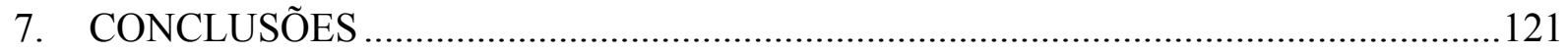

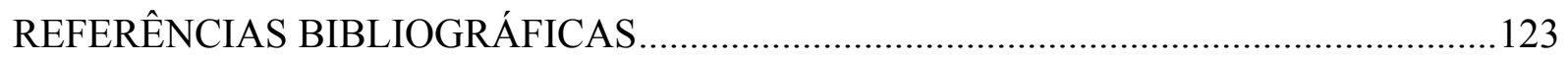

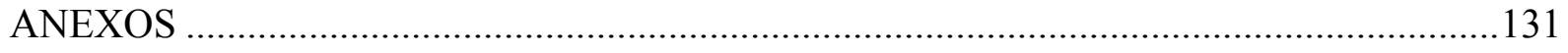

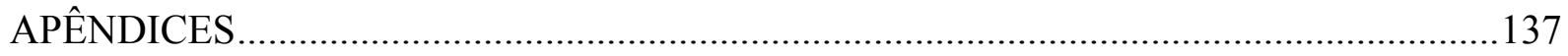




\section{INTRODUÇÃO}

O Reservatório de Itupararanga é de grande interesse ecológico e econômico no estado de São Paulo por estar inserido em uma Área de Proteção Ambiental (APA Itupararanga) e ser manancial de abastecimento de água para cidades da região. Os diversos usos da água deste corpo hídrico, aliados à crescente urbanização, conseqüente despejo irregular de efluentes domésticos e práticas de agricultura em torno do reservatório, tem diminuído a qualidade da água, podendo caracterizá-lo como mesotrófico.

Como principal conseqüência das ações antrópicas, observa-se o aumento da concentração de nutrientes na água do reservatório, principalmente de nitrogênio e fósforo, que tem impacto na proliferação de microrganismos, principalmente cianobactérias, como constatado em Itupararanga, aumentando então, a sua biomassa.

Esses nutrientes, que por um lado contribuem para a proliferação de alguns organismos fitoplanctônicos, também podem limitar o crescimento de outros em função de suas concentrações na água. As concentrações de nutrientes e a relação entre nitrogênio e fósforo podem determinar a composição da comunidade fitoplanctônica e controlar a biomassa destes organismos nos ecossistemas aquáticos, assim como interferir na competição entre eles.

A comunidade fitoplanctônica e as alterações desta comunidade podem ser influenciadas também por outras condições do ambiente, como fatores de luminosidade, nível trófico, temperatura, $\mathrm{pH}$, entre outros, os quais, quando favoráveis à uma espécie, permitem seu melhor desenvolvimento. Portanto, a competição entre diferentes espécies ocorre quando as condições ambientais impõem fatores limitantes, que podem favorecer ou prejudicar determinada espécie e permitir o seu prevalecimento ou exclusão da comunidade.

O domínio da cianobactéria Cylindrospermopsis racisborkii no Reservatório de Itupararanga, em alguns períodos, ainda não foi justificado. Para outros ambientes, há evidências na literautura de que o sucesso competitivo desta espécie é devido à capacidade de migração na coluna da água, tolerância à baixa luminosidade, resistência à herbivoria pelo zooplâncton, fixação do nitrogênio atmosférico, capacidade de armazenamento de fósforo, entre outros. 
A presença desta cianobactéria nos reservatórios é preocupante por ser uma espécie potencialmente tóxica, hábil a produção de cilindrospermopsina e saxitoxina, o que se constitui grave problema de saúde pública, pois o Reservatório de Itupararanga é utilizado para o abastecimento público.

Além da referida espécie, há abundância da clorofícea Monoraphidium contortum que, por ser de grupo diferente da cianobactéria C. raciborskii, desperta o interesse pela investigação dos fatores que estariam conduzindo a competição entre tais espécies, bem como a síntese de toxinas pela cianobactéria.

Para esclarecer estas questões foram realizados experimentos a fim de investigar a influência da concentração de fósforo, nitrogênio e micronutrientes no desenvolvimento das espécies, em monoculturas e em interação. Para adquirir resultados mais próximos ao ambiente estudado nesta pesquisa, C. raciborskii e $M$. contortum foram obtidas a partir do isolamento e cultivo destes organismos do próprio Reservatório de Itupararanga.

As concentrações de nutrientes estabelecidas simularam diferentes cenários para este ecossistema aquático em função dos seus níveis de trofia: oligotrófico, mesotrófico e supereutrófico. Dessa forma, foi possível analisar, comparar e descrever as respostas de $C$. raciborskii e de $M$. contortum em limitação de recursos. 


\section{OBJETIVOS}

O objetivo desta pesquisa foi analisar o efeito da modificação das concentrações de fósforo e conseqüente alteração da razão $\mathrm{N}: \mathrm{P}$, em ensaios de interação entre Cylindrospermopsis raciborskii e Monoraphidium contortum, simulando o Reservatório de Itupararanga em três diferentes níveis tróficos, com o intuito de:

- caracterizar o crescimento das espécies sob variadas condições nutricionais;

- verificar o efeito da interação nos parâmetros de crescimento dos microrganismos e na produção de saxitoxina pela C. raciborskii;

- determinar a vantagem competitiva das espécies em ambiente oligotrófico, mesotrófico e supereutrófico através de simulações laboratoriais. 


\section{REVISÃO BIBLIOGRÁFICA}

\subsection{O Reservatório de Itupararanga}

Reservatórios são sistemas aquáticos artificiais com diversas funções quanto ao uso, como navegação, abastecimento doméstico e industrial, irrigação, aqüicultura, recreação e lazer, harmonia paisagística e geração de energia elétrica (VON SPERLING, 1996).

Entre os reservatórios do Estado de São Paulo de grande relevância encontra-se o Reservatório de Itupararanga, em cujo entorno há presença de fragmentos florestais em bom estado de conservação e diversas nascentes e corpos hídricos que abastecem o reservatório, que é responsável pelo abastecimento do município de Sorocaba e região (BEU et al., 2011).

Com o objetivo de proteger os recursos hídricos, bem como a diversidade biológica e o ordenamento da ocupação na região, foi criada a Área de Proteção Ambiental (APA) de Itupararanga pela Lei Estadual no ${ }^{\circ} 10.100$ (SÃO PAULO, 1998).

A bacia do Reservatório de Itupararanga vem sofrendo degradação ambiental devido à especulação imobiliária, com avanço de ocupação por loteamentos e chácaras, que reduzem a cobertura vegetal e aumentam a produção de efluentes domésticos, além das atividades agrícolas que predominam na região, por ser uma das principais da economia (BEU et al., 2011).

Segundo CETESB (2010), o Reservatório de Itupararanga oferece ótima qualidade de água ao abastecimento público, embora já comece a apresentar problemas com seu estado trófico, com dados que o classificam como mesotrófico e, em alguns pontos no mês de julho, como eutrófico, o que requer urgência de pesquisas no local, dada a importância deste manancial à região e à Bacia Hidrográfica do Sorocaba e Médio Tietê.

\section{2. $\quad$ Nutrientes e Comunidade Fitoplanctônica}

Como observado no Reservatório de Itupararanga e em diversos outros corpos hídricos, a alteração da qualidade da água pode ser proveniente, principalmente, da interferência do homem, devido à forma como o solo é usado e ocupado e as consequências 
ocasionadas aos ecossistemas aquáticos, como o aumento da concentração de nutrientes e impurezas nas águas (BRAGA et al., 2005; VON SPERLING, 1996).

Calijuri et al. (2006) afirmaram que a elevação de nutrientes essenciais para a comunidade fitoplanctônica, como fósforo, nitrogênio, carbono e ferro, pode contribuir para o processo de eutrofização do corpo hídrico. As principais consequências a mudança da qualidade da água, são aumento da biomassa do fitoplâncton e das macrófitas aquáticas, diminuição da concentração de oxigênio dissolvido e da transparência da água, mortandade de peixes, florações de cianobactérias, entre outros.

O fósforo diretamente disponível para o metabolismo dos organismos, sem necessidade de conversões a formas mais simples, é o ortofosfato, que pode ter origem da dissolução de compostos do solo, da decomposição da matéria orgânica, de despejos de esgotos industriais e urbanos, detergentes, excrementos de animais e fertilizantes. É um elemento indispensável para o crescimento do fitoplâncton, mas quando em excesso contribui para a eutrofização (VON SPERLING, 1996).

Segundo Wetzel (1993), o desenvolvimento do fitoplâncton, tanto em ambiente natural quanto em culturas, depende da quantidade de fósforo que há disponível. Vários estudos foram realizados com algas de água doce para verificar a tolerância à este nutriente, e verificou-se que o fitoplâncton pode se desenvolver em uma gama de tolerância abaixo ou acima de $20 \mu \mathrm{g} . \mathrm{L}^{-1}$ de $\mathrm{PO}_{4}{ }^{-3}$, dependendo da espécie.

O ciclo do fósforo é lento e ocorre por meio da erosão da litosfera, a qual é a principal reserva deste nutriente, ocorrendo a liberação na forma de fosfatos que serão consumidos pelos produtores e direcionados para a hidrosfera, onde serão assimilados pelo fitoplâncton (Figura 1) (BRAGA et. al., 2005). Hoje, ressalta-se a grande contribuição de fósforo aos sistemas hídricos através de fertilizantes, detergentes e áreas de mineração. 


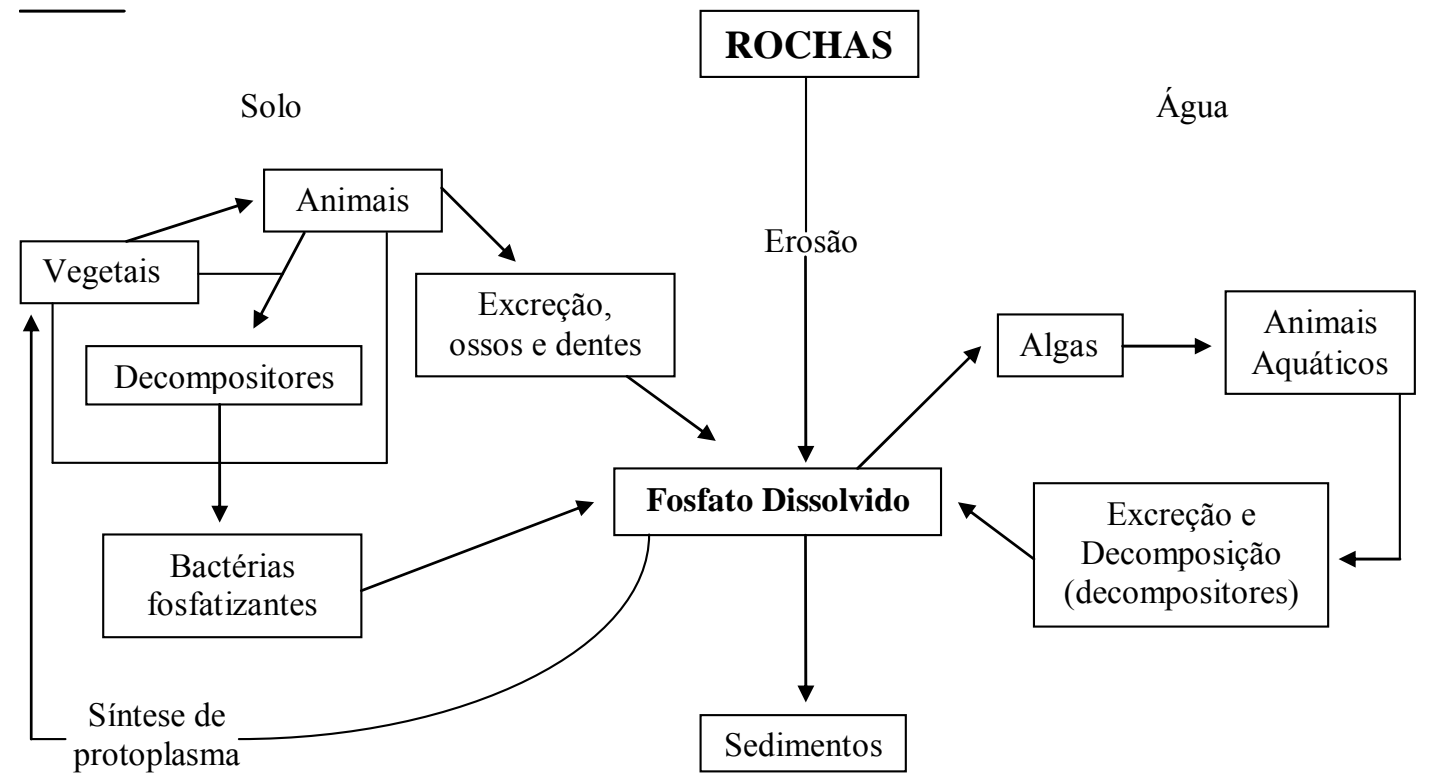

Figura 1: Ciclo do Fósforo (modificado de BRAGA et al., 2005; ODUM, 1988)

As fontes de nitrogênio nos corpos hídricos são diversas, sendo as principais os esgotos urbanos e industriais, excrementos animais, fertilizantes, e compostos biológicos de origem natural. Assim como o fósforo, o nitrogênio é indispensável para o crescimento das algas e, quando em excesso, também contribui para o crescimento destes organismos (PIVELI \& KATO, 2006; VON SPERLING, 1996).

Segundo Braga et al. (2005), a principal forma do nitrogênio para consumo pelos produtores e assimilação pelo fitoplâncton é o nitrato, $\mathrm{NO}_{3}{ }^{-}$, que pode ter origem da decomposição da matéria orgânica ou ainda por ação das bactérias nitrificantes.

O ciclo do nitrogênio pode ser observado na Figura 2, no qual ocorre a fixação de nitrogênio atmosférico por bactérias e cianobactérias; amonificação; nitrificação, correspondente a conversão do nitrogênio molecular fixado a nitrito e a nitrato, por bactérias aeróbias; e desnitrificação, por bactérias anaeróbias (BRAGA et al., 2005; PIVELI \& KATO, 2006). 


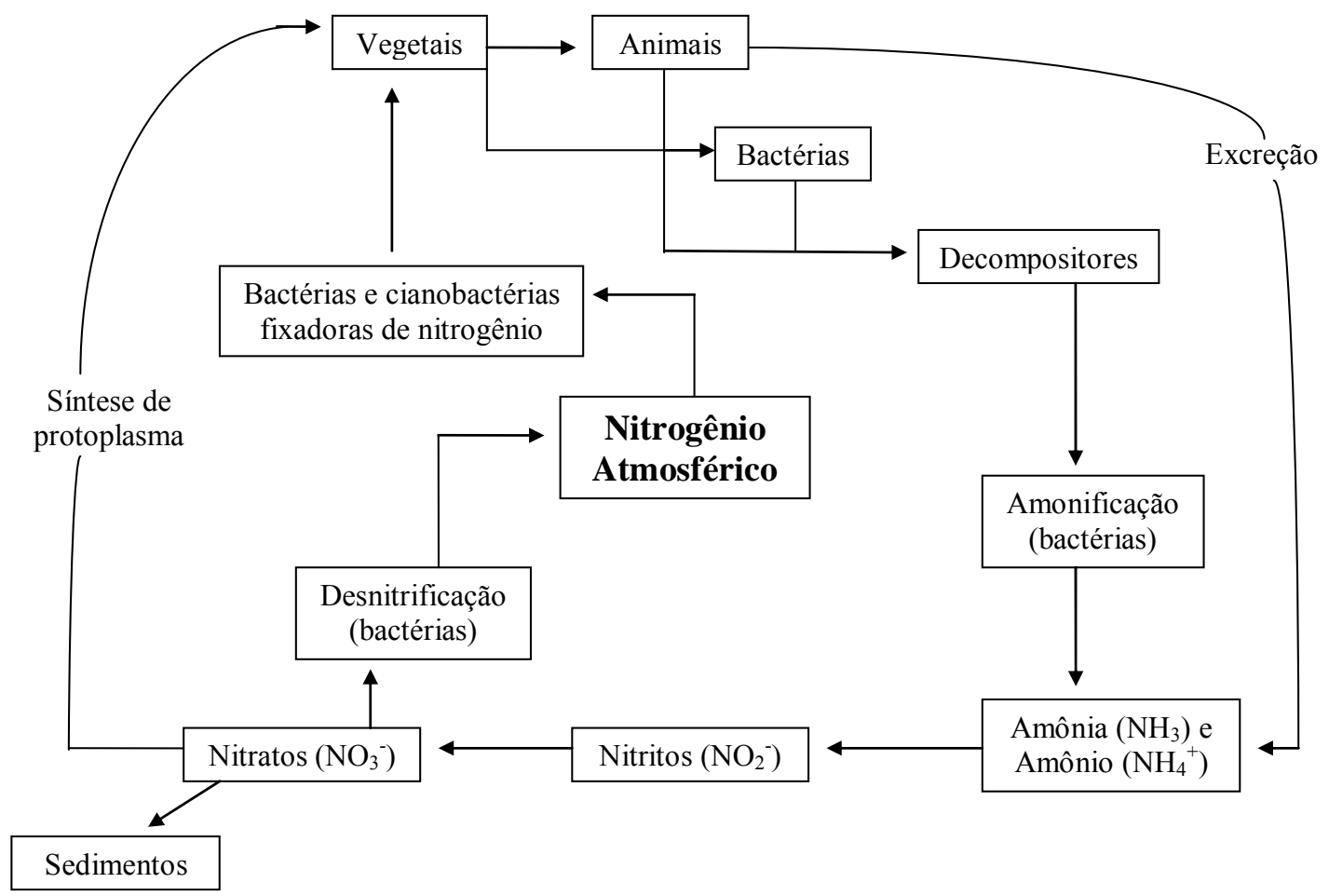

Figura 2: Ciclo do Nitrogênio (modificado de BRAGA et al., 2005; ODUM, 1988)

Em relação ao carbono, a maior parte de sua ocorrência na água doce esta sob a forma de produtos de equilíbrio do ácido carbônico, $\mathrm{H}_{2} \mathrm{CO}_{3}$. O fitoplâncton precisa de uma fonte de carbono de disponibilidade imediata e abundante na água para manter o seu desenvolvimento, pois o carbono inorgânico é um dos principais nutrientes do metabolismo fotossintético destes organismos (WETZEL, 1993).

Além dos macronutrientes citados, os organismos fitoplanctônicos necessitam de oligonutrientes (CALIJURI et al., 2006) ou, chamados também, de micronutrientes, para a sua nutrição, que correspondem ao ferro, manganês, zinco, cobre, boro, cobalto, molibdênio, silício, cloro e vanádio. Os ciclos desses elementos, em sua maioria, são regulados por alterações em seus estados de oxidação-redução, que são dirigidos pelos metabolismos fotossintético e bacteriano (WETZEL, 1993).

Para avaliar a qualidade da água em relação ao enriquecimento por nutrientes, bem como o seu efeito sobre o crescimento excessivo de algas, foi elaborado o Índice de Estado Trófico (IET), que classifica os corpos de água em diferentes graus de trofia. Vários trabalhos foram desenvolvidos estabelecendo diferentes valores limites de fósforo, clorofila- $a$ e disco de secchhi dentro de cada classificação (LAMPARELLI, 2004).

No geral, os graus de trofia e suas características são: oligotrófico, quando o ambiente é constituído por águas claras, com baixa concentração de nutrientes e produtividade; 
mesotrófico, quando o ambiente possui características intermediárias entre oligotrófico e eutrófico; e eutrófico, quando o ambiente tem elevada produtividade e alta concentração de nutrientes (BRAGA et al., 2005; VON SPERLING, 1996).

O cálculo mais atual do IET foi proposto por Lamparelli (2004), modificado a partir de Carlson (1977), no qual é considerado apenas as concentrações de fósforo total e clorofila$a$, para classificar os corpos hídricos em ultraoligotrófico, oligotrófico, mesotrófico, eutrófico, supereutrófico e hipereutrófico.

Portanto, de acordo com o que foi relatado e diante do atual contexto mundial de escassez e degradação da qualidade da água, devido, principalmente, ao acelerado crescimento demográfico, aumento da demanda por água potável e impactos gerados pelas atividades antrópicas, vê-se a importância da gestão integrada dos recursos hídricos (CALIJURI et al., 2010).

Dentre as medidas necessárias para o gerenciamento dos recursos hídricos no Brasil, destaca-se o monitoramento ambiental a partir de normas e leis, como a Resolução CONAMA 357/05 (BRASIL, 2005) que estabelece os padrões de qualidade dos corpos de água e os padrões de emissão de lançamento de efluentes, através de limites para a concentração de alguns parâmetros, como os nutrientes; e a Portaria MS nº. 2914 do Ministério da Saúde (BRASIL, 2011), a qual estabelece procedimentos de controle e vigilância da qualidade da água destinada ao abastecimento público.

Entre as comunidades biológicas que são afetadas pelo grau de trofia, uma das mais importantes é a fitoplanctônica, pois esta é a base da cadeia alimentar nos ecossistemas aquáticos (CALIJURI et al., 2006). O fitoplâncton é constituído por microalgas e cianobactérias nos ecossistemas aquáticos com poder limitado de locomoção. Devido à isso, sua distribuição ocorre principalmente a partir do movimento de turbulência da água. São seres unicelulares, isolados ou coloniais, com enorme variedade de formas e reprodução sexual e assexual (TORTORA et al., 2003; WETZEL, 1993).

Os mais abundantes e diversos organismos do fitoplâncton são algas das classes das diatomáceas, euglenofitas, e clorofitas, somados às cianobactérias (TORTORA et al., 2003). Devido à diferentes modos de vida, estes organismos respondem de modo distinto à luz, temperatura e regime de nutrientes (WETZEL, 1993), podendo ocorrer numa enorme variedade de ambientes situados praticamente em todas as longitudes, latitudes e altitudes do globo (BICUDO, 2006). 
Mesmo com diversos modos de vida, propriedades fisiológicas próprias e com diferentes tolerâncias aos fatores abióticos, há a coexistência de várias espécies de fitoplâncton em ecossistemas aquáticos. Em determinadas situações, espécies de uma comunidade tornam-se dominantes e outras se tornam raras, como por exemplo, quando fatores combinados ao ótimo para determinada espécie, favorecem-na, contribuindo com o seu desenvolvimento e produtividade máximos (WETZEL, 1993).

A regulação do desenvolvimento e a alteração da estrutura da comunidade fitoplanctônica são resultantes de interações de fatores físicos, químicos e biológicos, como luz, temperatura, concentração dos nutrientes inorgânicos e dos micronutrientes orgânicos, competição pelos recursos, predação e parasitismo por outros indivíduos. Mas a competição entre uma espécie e outra é relativa, uma vez que as condições físicas e bióticas podem ser alteradas no ambiente e modificar o desenvolvimento das espécies (CALIJURI et al., 2006; WETZEL, 1993).

Segundo Calijuri et al. (2006), a mudança desta comunidade em reservatórios deve-se à hidrodinâmica diferenciada em função da localização, a principal finalidade do sistema, morfometria, ciclo hidrológico, que determinam os diferentes tempos de residência da água, a ciclagem de materiais e a perda de biomassa.

Entre os fatores abióticos, a concentração dos nutrientes e sua estequiometria são um dos principais fatores que alteram a produção fotossintética e influenciam de forma direta na densidade, biomassa e composição desta comunidade de acordo com a sua disponibilidade (CALIJURI et al., 2006; KENESI et al., 2009), influenciando na competição entre esses organismos.

Em grande parte dos sistemas aquáticos tropicais, o crescimento das algas é regulado pela disponibilidade do fósforo, o qual, em determinadas situações, pode ser o fator limitante (KENESI et al., 2009). Fósforo e nitrogênio influem de forma direta na constituição estrutural das células fitoplanctônicas e, portanto, podem interferir no seu desenvolvimento (TAVARES \& ROCHA, 2003).

Fator limitante, segundo Odum (1988), é o material essencial para o desenvolvimento de um organismo estar disponível em quantidades que se aproximam da necessidade mínima. Este conceito é também conhecido como a Lei do mínimo de Liebig. Von Sperling (1996) explica que um nutriente é limitante para uma dada população quando um nutriente essencial para ela limita o seu crescimento. 
Segundo Wetzel (1993), o fósforo é o componente nutricional e estrutural menos abundante na natureza se comparado a outros, por isso é o elemento que por mais vezes pode limitar a produtividade biológica.

Tratando-se da competição por recurso limitado, é uma interação entre duas ou mais espécies que se sobrepõem em um determinado ecossistema, em que o crescimento e sobrevivência delas são afetados, causando diminuição na taxa reprodutiva, estresse fisiológico e até mesmo a morte de determinada espécie. Além disso, a competição pode provocar adaptações seletivas nas espécies para facilitar a coexistência delas em determinado local com recurso limitado, como por exemplo, em sistemas abertos, onde a probabilidade de coexistência é maior (ODUM, 1988; WETZEL, 1993). Segundo Sommer (1988), a partir de pesquisa experimental e teórica, afirma que, mesmo em competição, as espécies são capazes de coexistir.

A exclusão competitiva e mais intensa tem ocorrência mais provável em sistemas onde a imigração e emigração de espécies são reduzidas ou ausentes. Exemplo deste fato ocorre em culturas laboratoriais, ilhas, ou situações naturais que existam barreiras substanciais a entradas e saídas. A completa exclusão competitiva raramente ocorre em ecossistemas naturais, sendo mais provável, a coexistência de espécies (ODUM, 1988; HUSTON, 1979).

Para verificar se em um lago o crescimento do fitoplâncton está sendo limitado por fósforo ou nitrogênio, Thomann e Mueller (1987) sugeriram o critério da relação de nitrogênio e fósforo (N:P), a qual, quando for maior que 10 a limitação ocorre por fósforo, e quando menor é o nitrogênio que atua como fator limitante.

Em pesquisa realizada por Lee e Jones-Lee (1998), os fatores limitantes para o crescimento de algas em reservatórios foram discutidos. Quando a relação da concentração de nitrogênio inorgânico (amônia e nitrato) com ortofosfato for superior a 7,5:1, o ambiente é limitado por fósforo. Mas relatam também que devem ser consideradas as concentrações desses elementos na água: concentrações abaixo de $2 \mu \mathrm{g} . \mathrm{L}^{-1}$ de ortofosfato e $15 \mu \mathrm{g} . \mathrm{L}^{-1}$ de nitrogênio são consideradas limitantes.

Portanto, os fatores limitantes ambientais são variáveis importantes que determinam e condicionam o crescimento do fitoplâncton e, por isso, são considerados fatores seletivos na ecologia destes organismos (REYNOLDS, 1984), fato que implica na necessidade de estudos sobre condições que favorecem o desenvolvimento de determinadas espécies em um corpo hídrico. 
Em um lago da China, foi realizada pesquisa em laboratório da interação entre Microcystis aeruginosa (cianobactéria) e Scenedesmus quadricauda (clorofícea) sob três diferentes relações de N:P. Como resultado, foi observado que as duas espécies em culturas puras foram favorecidas com altos níveis de fósforo e nitrogênio, mas quando em cultura mista, a menor relação de N:P favoreceu o crescimento da $M$. aeruginosa, enquanto que a maior beneficiou a S. quadricauda (ZHU et al., 2010).

Vuorio et al. (2005) estudaram o impacto do enriquecimento com nutrientes em comunidade fitoplanctônica do Mar Báltico, com relação N:P de 1:1 e 7:1. Na segunda relação, a produção primária e a biomassa foram superiores à primeira, principalmente da clorofícea Monoraphidium contortum. O enriquecimento com nutrientes não teve efeito significativo na biomassa total de cianobactérias fixadoras de nitrogênio e nenhum efeito sobre a toxicidade deste grupo de organismos.

Contudo, nem sempre o desenvolvimento da comunidade fitoplanctônica requer a relação comum N:P de 16:1, como descrito por Redfield (1958), pois cada espécie possui sua exigência nutricional e seus fatores fisiológicos próprios, como cinética de absorção de nutrientes, assimilação e capacidade de armazenamento do nutriente (TILMAN et al., 1982).

Um exemplo é o que ocorre com as cianobactérias fixadoras de nitrogênio, em que o fósforo é o principal fator limitante para seu crescimento, e este crescimento é favorecido por baixa relação N:P (SMITH, 1983; STAL et al., 2003).

Diversas pesquisas de interações entre organismos fitoplanctônicos foram desenvolvidas almejando o entendimento da competição por uso de recursos. Rodrigo et al. (2009) estudou as características de crescimento de oito espécies fitoplanctônicas em culturas simulando ambiente oligotrófico e eutrófico, e observou que as clorofíceas apresentam melhor crescimento no ambiente eutrófico, enquanto as cianobactérias no oligotrófico. Hyenstrand et al. (2000) pesquisaram a competição entre clorofícea e cianobactéria em diferentes formas de fornecimento de nitrogênio inorgânico. Através desta, verificou que o nitrogênio inorgânico fornecido em pequenos pulsos e em alta frequência favorecem a cianobactéria Synecoccus ssp e grandes pulsos com baixa frequência a clorofícea Scenedesmus ssp., apresentando melhores desempenhos com o fornecimento de amônia e nitrato, respectivamente. Kim et al. (2007), analisaram o efeito da limitação de nutrientes e da relação N:P no crescimento do fitoplâncton e afirmaram que as cianobactérias são favorecidas com a adição de fósforo nas culturas e a baixa relação N:P.

Interações entre cianobactérias foram realizadas por De Nobel et al. (1997) a partir de ensaios de competição por fósforo entre duas cianobactérias fixadoras de nitrogênio, e Santos 
(2009), que estudou a interação entre duas cianobactérias e as implicações em seus crescimentos, bem como a produção de toxinas.

Além destes estudos, há outros que demonstram a influência da limitação por fósforo no crescimento, na eficiência fotossintética e na morfologia da cianobactéria Cylindrospermopsis raciborskii, como por exemplo, os desenvolvidos por Ferreira (2007) e Kenesi et al. (2009).

\subsection{Caracterização das espécies utilizadas nesta pesquisa}

Cylindrospermopsis raciborskii (Figura 3) é uma cianobactéria que, segundo Bicudo e Menezes (2006), se apresenta como talo filamentoso e microscópico, denominados tricomas, que são isolados e podem se apresentar de forma reta, espiral, sigmóide e curva, sem a presença de bainha mucilaginosa. As células são cilíndricas e os heterocistos são sempre terminais e solitários, responsáveis pela fixação do nitrogênio atmosférico. $\mathrm{O}$ acineto é a célula de resistência da espécie, por sua vez, são elípticos, oblongos ou cilíndricos, dependendo da espécie, e ocorrem de forma isolada. A reprodução ocorre a partir da fragmentação do tricoma ou, também, pela germinação do acineto.

O grupo das cianobactérias, conforme Reynolds (1988) é classificado como espécies S-estrategistas ("stress" tolerantes), que se caracterizam por serem organismos grandes, com baixas atividade metabólica, taxa de crescimento e relação área/volume, além de serem espécies capazes de sobreviver em ambientes com baixa concentração de nutrientes.

Segundo Saker et al. (2003), C. raciborskii tem se tornado cada vez mais predominante nas águas doces do mundo, fato preocupante na perspectiva de qualidade da água, por se tratar de uma espécie hábil à produção das toxinas cilindrospermopsina e saxitoxina. Padisák (1997) afirmou que a espécie ocorre desde reservatórios oligotróficos em regiões subtropicais até em lagos hipereutróficos tropicais.

O gênero Cylindrospermopsis é muito comum nas regiões tropicais, mas algumas espécies podem ocorrer em regiões temperadas (BICUDO \& MENEZES, 2006), como é o caso da C. raciborskii, devido à sua elevada eficácia na atividade fotossintética, na absorção de carbono inorgânico dissolvido, na absorção e transformação do fósforo inorgânico e à baixa exigência de luz, o que permitiu a invasão da espécie de águas tropicais para as de clima temperado (PADISÁK, 1997; WU et al., 2009). 


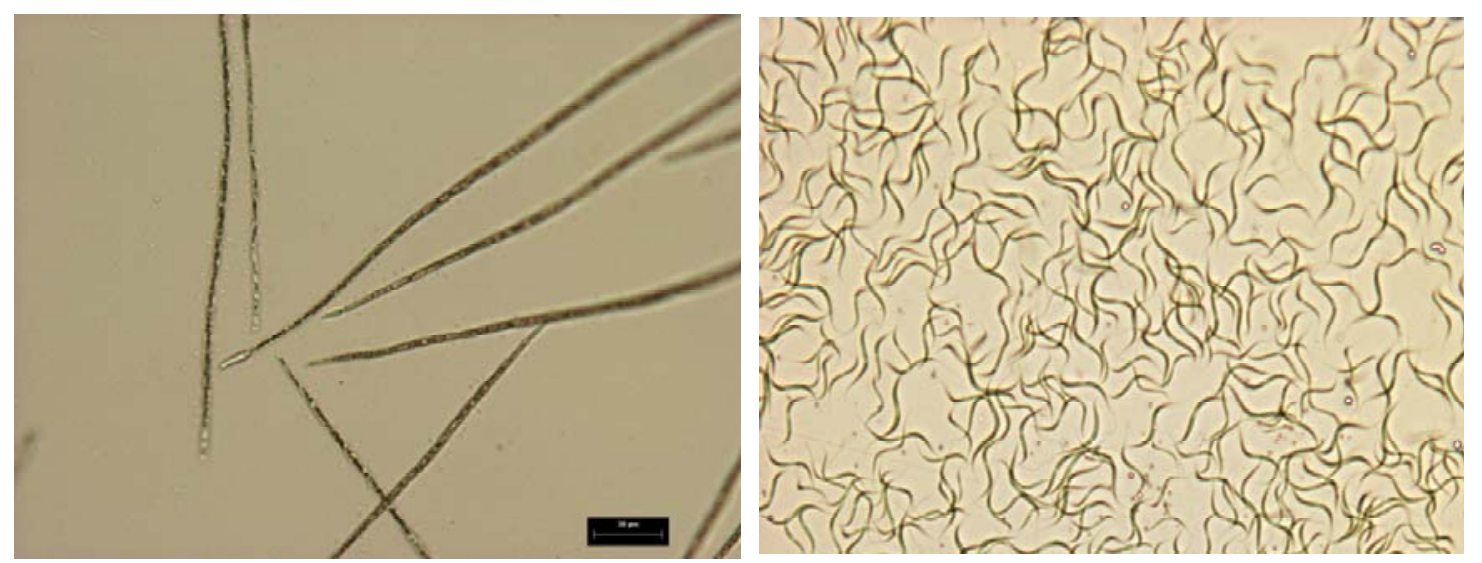

Figura 3: Cylindrospermopsis raciborskii à esquerda $e$ Monoraphidium contortum à direita, isoladas do Reservatório de Itupararanga (200 x). Escala de $20 \mu$ para ambas as espécies.

Além desses fatores, Padisák (1997) e Chellappa et al. (2008) atribuíram o sucesso ecológico da C. raciborskii às capacidades de migração da espécie na coluna de água, alta absorção de amônia e fixação do nitrogênio atmosférico, como também a resistência à herbivoria.

Briand et al. (2002) relataram que, em um pequeno lago da França, as principais variáveis que influenciaram o abundante crescimento da espécie foram temperatura da água e do ar, insolações, e a concentração de nutrientes, pois a deficiência de nitrogênio e a baixa concentração de fósforo no meio pode ser fator seletivo para o favorecimento desta espécie.

Diversos trabalhos têm descrito forte relação entre concentrações de fósforo e predomínio de Cylindrospermopsis spp. Bouvy et al. (2000) analisando a comunidade de 39 reservatórios no semi-árido do nordeste brasileiro, encontrou grande correlação entre o estado trófico, principalmente quanto às concentrações de fósforo e o predomínio de Cylindrospermopsis raciborskii.

O gênero Monoraphidium (Komárková-Legnerová, 1969) é o mais presente em todas as regiões do mundo entre as clorococales, umas das ordens do grupo das clorofíceas. Inclui 21 espécies que já foram coletadas em quase todo o mundo em ambiente oligotróficos e mesotróficos (BICUDO \& MENEZES, 2006).

Em relação à Monoraphidium contortum (Figura 3), é uma clorofícea de célula alongada e solitária, raramente estão unidas, mas podem estar por um curto período devido ao processo de reprodução. Possui formato de meia lua, diminuindo sua espessura à partir de seu centro até as pontas da célula. Apresenta cloroplasto pariental, cobrindo quase toda a parede 
celular e não possui pirenóides. Sua reprodução ocorre a partir de autósporos (BICUDO \& MENEZES, 2006; TREBON \& PRAHA, 1983).

Segundo Makulla e Sommer (1993), no lago Krummsee, na Alemanha, esta espécie é típica e dominante, mas os autores reportaram não haver relação da proporção de N:P com o biovolume relativo desta espécie. Em estudos realizados a partir do modelo Monod, não foram obtidos resultados satisfatórios de uma relação da dependência da taxa de crescimento de M. contortum com o nitrogênio como fator limitante (SOMMER, 1989).

Um dos fatores que poderiam contribuir para o sucesso da espécie, segundo Padisák et al. (2006), é o excesso de salinidade para água doce, que delimita o número de espécies fitoplanctônicas e contribui para o desenvolvimento das espécies tolerantes. Entre as tolerantes, $M$. contortum é uma das espécies que tem como vantagem, além da tolerância à salinidade, efetiva captação de luz. Happey-Wood (1988) afirma que o gênero Monoraphidium domina em ambientes turbulentos com grandes disponibilidade de nutrientes e luz.

Sommer (1989) verificou, em um lago hipereutrófico no norte da Alemanha, que a dominância de $M$. contortum foi favorecida por baixas concentrações de nitrogênio e amônia e altas temperaturas, e que as clorofíceas, de modo geral, tiveram o nitrogênio como fator limitante.

A partir da nova classificação funcional fitoplanctônica por códons, ainda em discussão, $M$. contortum e as demais espécies do gênero são classificadas no códon X1, caracterizado por algas de ambiente raso e de transição do eutrófico para o hipereutrófico (PADISÁK et al., 2008). Segundo Reynolds (1988), as clorofíceas pertencem ao grupo Cestrategistas (competidoras), no qual as espécies são pequenas, com alta relação área/volume e atividade metabólica, e exploram ambientes saturados de nutrientes e luz. Além disso, são organismos que, ao encontrarem condições ideais, possuem habilidade para dominar o ambiente e excluir outras espécies.

No entanto, são necessários estudos mais aprofundados da coexistência de $M$. contortum com a C. raciborskii, a fim de averiguar quais fatores, como a concentração dos nutrientes, influenciam no sucesso e competição dessas espécies no Reservatório de Itupararanga. 


\subsection{Cianotoxinas}

Várias espécies de cianobactérias que formam florações são hábeis à produção de toxinas, denominadas cianotoxinas. As principais cianotoxinas e suas respectivas classificações encontram-se na Tabela 1. Alguns pesquisadores acreditam que as cianotoxinas tem função protetora contra o grazing pelo zooplâncton, ou ainda, estão relacionadas às condições de crescimento ou à competição por recursos (CALIJURI et al., 2006).

Tabela 1 - Classificação e características das principais cianotoxinas e gêneros potencialmente produtores (SIVONEN \& JONES, 1999; CALIJURI et al. 2006)

\begin{tabular}{|c|c|c|c|}
\hline \multirow{2}{*}{ Grupo de toxina } & \multirow{2}{*}{ Toxina } & Alvo primário & Gêneros de cianobactérias \\
\hline & & em mamíferos & produtoras \\
\hline \multirow{4}{*}{ Peptídeos cíclicos } & & & Microcystis, Anabaena, \\
\hline & Microcistina & Fígado & Planktothrix, Nostoc, \\
\hline & & & Hapalosiphon, Anabaenopsis \\
\hline & Nodularina & Fígado & Nodularia \\
\hline \multirow{7}{*}{ Alcalóides } & \multirow{2}{*}{ Anatoxina-a } & \multirow{2}{*}{ Nervo sináptico } & Anabaena, Planktothrix, \\
\hline & & & Aphanizomenon \\
\hline & Anatoxina-a (s) & Nervo sináptico & Anabaena \\
\hline & Aplisiotoxina & Pele & $\begin{array}{l}\text { Lyngbya, Schizothrix, } \\
\text { Planktothrix }\end{array}$ \\
\hline & Cilindrospermopsina & Fígado & $\begin{array}{l}\text { Cylindrospermopsis, } \\
\text { Aphanizomenon,Umezakia }\end{array}$ \\
\hline & Lyngbyatoxina-a & $\begin{array}{c}\text { Pele, trato } \\
\text { gastrointestinal }\end{array}$ & Lyngbya \\
\hline & Saxitoxina & Nervo axônico & $\begin{array}{l}\text { Anabaena, Aphanizomenon, } \\
\text { Lyngbya, Cylindrospermopsis }\end{array}$ \\
\hline Lipopolissacarídeos & LPS & $\begin{array}{l}\text { Qualquer contato. } \\
\text { Potencial irritante }\end{array}$ & Todos \\
\hline
\end{tabular}

Segundo Sivonen e Jones (1999), na floração de cianobactérias, por uma ou mais espécies, pode haver cepas tóxicas e não-tóxicas. Uma cepa corresponde a um subgrupo genético específico, com características ligeiramente diferentes, dentro de uma espécie em particular.

Há duas hipóteses para o aparecimento e predomínio de cepas tóxicas, que está relacionado à presença de algum estressor ambiental ou à dinâmica populacional e à competição entre as populações. Porém, ainda não há uma explicação de quais fatores estão ligados à produção de toxina pelas cianobactérias (CALIJURI et al., 2006).

A presença de cianotoxinas nas águas de abastecimento no Brasil é um problema crescente e de grande preocupação, pois já foram registrados casos de intoxicação, como por 
exemplo, o ocorrido em Caruaru (PE) no ano de 1996 (CARMICHAEL et al., 2001) e no Rio de Janeiro onde ocorreu a intoxicação de pacientes que faziam hemodiálise (SOARES et al., 2006). No geral, as cianotoxinas podem afetar o sistema nervoso, o fígado, a pele e, ainda, inibir a síntese de proteínas (FERREIRA, 2007).

A fim de monitorar e controlar a concentração de cianotoxinas nos corpos hídricos brasileiros foi estabelecida a Portaria MS nº. 2914do Ministério da Saúde (BRASIL, 2011), que determina as máximas densidades de cianobactérias e concentrações de cianotoxinas em mananciais. A concentração máxima permitida é de $1 \mu \mathrm{g} . \mathrm{L}^{-1}$ de microcistina, $3 \mu \mathrm{g} . \mathrm{L}^{-1}$ de saxitoxina e $1 \mu \mathrm{g} . \mathrm{L}^{-1}$ de cilindrospermopsina. Os testes de toxicidade são realizados semanalmente quando há densidade de cianobactéria superior a 20.000 células $/ \mathrm{ml}$.

Cylindrospermopsis raciborskii é hábil à produção de duas das cianotoxinas, saxitoxina, uma neurotoxina, e cilindrospermopsina, que é hepatotoxina. A cilindrospermopsina é uma toxina que age principalmente no fígado, devido à tentativa desse órgão em degradá-la, ocasionando lesões tecidulares, por atuar na desorganização do citoesqueleto das células hepáticas, resultando na perda da estrutura do fígado, retração e aumento dos espaços intercelulares choque hipovolêmico e injúrias nos rins. A saxitoxina impede a ação dos neurônios nas células musculares através do bloqueamento dos canais de sódio, o que pode gerar sintomas como a tontura, vômito, fraqueza muscular, taquicardia, entre outros (AZEVEDO, 1998; CALIJURI et al., 2006; CHARMICHAEL, 1994).

Os resultados do estudo realizado por Smith et al. (2008) indicaram que a biodegradação das cilindrospermopsinas em massas de água naturais é um processo complexo que pode ser influenciado por muitos fatores ambientais, alguns dos quais incluem a concentração desta toxina, temperatura, além da presença de algicidas à base de cobre. Por outro lado, as saxitoxinas, sofrem lentas reações de degradação em ambientes escuros e na temperatura ambiente, e os processos de acidificação e fervura da água aumentam a toxicidade dessa substância (CALIJURI et al., 2006).

\subsection{Proposta e hipótese da pesquisa}

Nesta pesquisa, foram realizados ensaios de interação entre duas espécies isoladas do Reservatório de Itupararanga, C. raciborskii e M. contortum, sob diferentes concentrações de ortofosfato dissolvido, simulando o Reservatório de Itupararanga em três diferentes graus de 
trofia. Os graus de trofia estabelecidos são conforme o índice de estado trófico, discutido por Lamparelli (2004), que são: oligotrófico, mesotrófico e supereutrófico.

As duas espécies foram selecionadas baseando-se em estudos realizados no Projeto Temático intitulado, "Contribuição ao conhecimento do ciclo do carbono no Reservatório de Itupararanga como subsídio para a sustentabilidade da Bacia Hidrográfica do Rio Sorocaba (SP)". Também teve importância fundamental a pesquisa de Vargas e Dos Santos (2009) realizada no mesmo reservatório, que observaram domínio e abundância da cianobactéria $C$. raciborskii e da clorofícea M. contortum, respectivamente, desde agosto de 2008, principalmente na região próxima à barragem deste reservatório.

Portanto, verificou-se a hipótese desta pesquisa, que se fundamentou que os parâmetros de crescimento das duas espécies e a interação entre elas iria variar de acordo com o aumento ou diminuição da concentração de nutrientes, favorecendo-as ou não.

Dessa forma, poderá haver maior aprofundamento nas investigações da relação do nível trófico do reservatório com as espécies que nele são abundantes, preocupando-se, principalmente, com o desenvolvimento da cianobactéria, por serem organismos hábeis à produção de cianotoxinas.

Visto que, as cianotoxinas presentes nas águas podem ser prejudiciais à saúde e há domínio da cianobactéria C. raciborskii no Reservatório de Itupararanga, o aumento da concentração de cianotoxinas é uma ameaça à saúde da população, por ser um manancial utilizado para abastecimento público.

Esta pesquisa poderá minimizar tais impactos ao subsidiar informações para previsões do crescimento de $C$. raciborskii e $M$. contortum devido às variações da concentração de nutrientes no reservatório a fim de favorecer seu manejo e conservação do recurso hídrico. 


\section{MATERIAL E MÉTODOS}

\subsection{Caracterização da área de estudo}

A área de drenagem do Reservatório de Itupararanga abrange parcialmente os municípios de Ibiúna, São Roque, Piedade, Mairinque, Votorantim, Alumínio, Vargem Grande Paulista e Cotia, no interior do estado de São Paulo (Figura 4). O reservatório está inserido em uma Área de Proteção Ambiental (APA) e pertence a Bacia Hidrográfica dos Rios Sorocaba e Médio Tietê. A represa é formada pelos rios Sorocabuçu, Sorocamirim e Una, que são os formadores do Rio Sorocaba.

O reservatório está localizado no Planalto Cristalino na Serra de São Francisco, com transição para a Depressão Periférica, com uma altitude de 710 metros, na bacia hidrográfica do Rio Sorocaba. A represa foi construída pela Light em 1911, com funcionamento a partir de 1912, com 20,9 $\mathrm{km}^{2}$ de área, capacidade de volume de aproximadamente $286 \times 10^{6} \mathrm{~m}^{3}$ de água, profundidade média de 7,8 m, e $936,5 \mathrm{~km}^{2}$ de área de drenagem, com vazão máxima de $39,12 \mathrm{~m}^{3} \cdot \mathrm{s}^{-1}$. A barragem está localizada no município de Votorantim com queda bruta de 206 metros (GARCIA et al., 1999).

A água da Bacia Hidrográfica que está inserida a represa é utilizada para o abastecimento, sendo que o fornecimento se dá para cerca de $90 \%$ da região, segundo o comitê da bacia hidrográfica (2010), além de contribuir com a geração de energia, como área de lazer e pesca. Possui uma usina hidrelétrica para geração de energia, a qual é operada pela Votorantim Energia. 


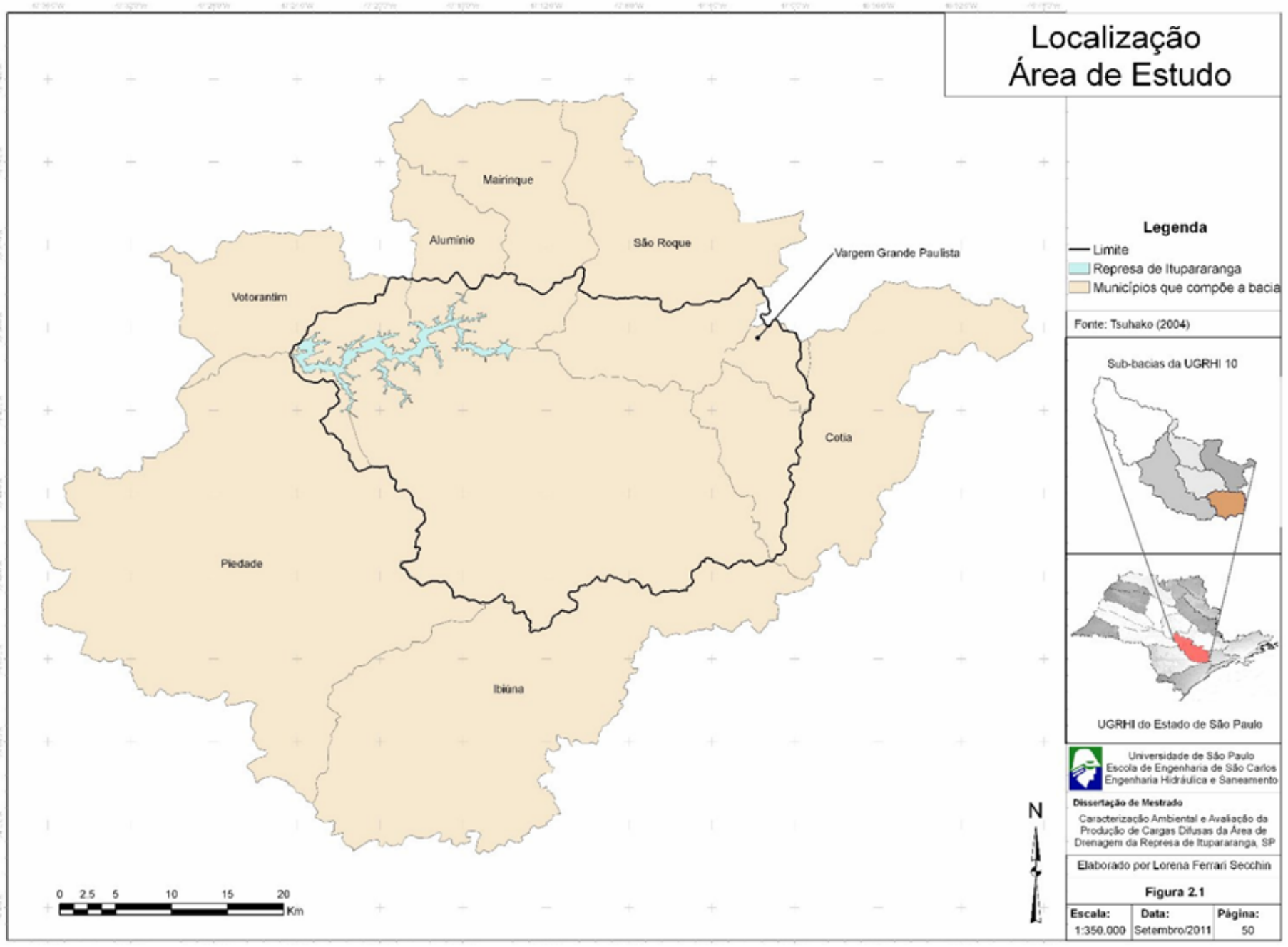

Figura 4: Localização do Reservatório de Itupararanga (SECCHIN, em andamento). 


\subsection{Fluxograma experimental}

Na Figura 5 pode ser observado o fluxograma experimental desta pesquisa. Cada uma das etapas será discutida a seguir, sendo que os itens 4.3. a 4.6. são referentes à preparação dos cultivos para a realização dos experimentos.

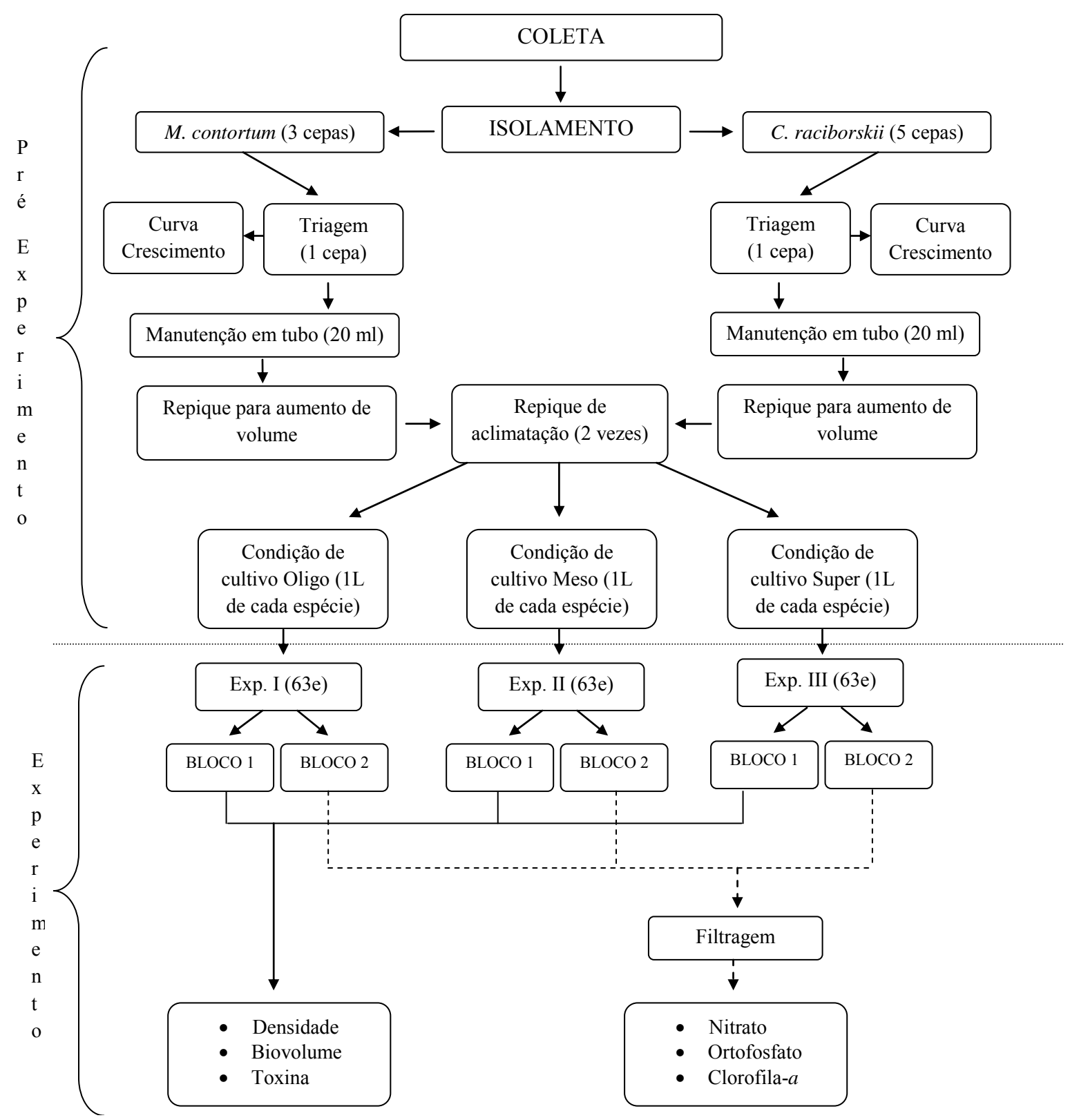

Figura 5: Fluxograma de apresentação das principais etapas desenvolvidas no projeto de pesquisa. Experimento - Exp.; Oligotrófico - Oligo; Mesotrófico - Meso; Supereutrófico - Super. Total de 63 Erlenmeyers em cada experimento, sendo 9 do Bloco 1 e 54 do Bloco 2. 


\subsection{Coleta de amostras}

No Reservatório de Itupararanga foi realizada uma coleta de forma manual e na superfície, em oito estações de amostragem, incluindo a área central do reservatório e os braços, conforme Figura 6. Essa coleta foi feita com frascos transparentes para $200 \mathrm{ml} \mathrm{de}$ água de cada estação. As amostras foram conservadas em condições normais de temperatura e luminosidade e os frascos mantidos semi-abertos para a manutenção de trocas gasosas.

Posteriormente, em laboratório, as oito amostras foram misturadas, para a obtenção de uma amostra composta. Este procedimento foi realizado para não haver influência do ponto de amostragem e, também, para que as espécies trabalhadas possam representar todo o corpo hídrico de maneira aleatória.

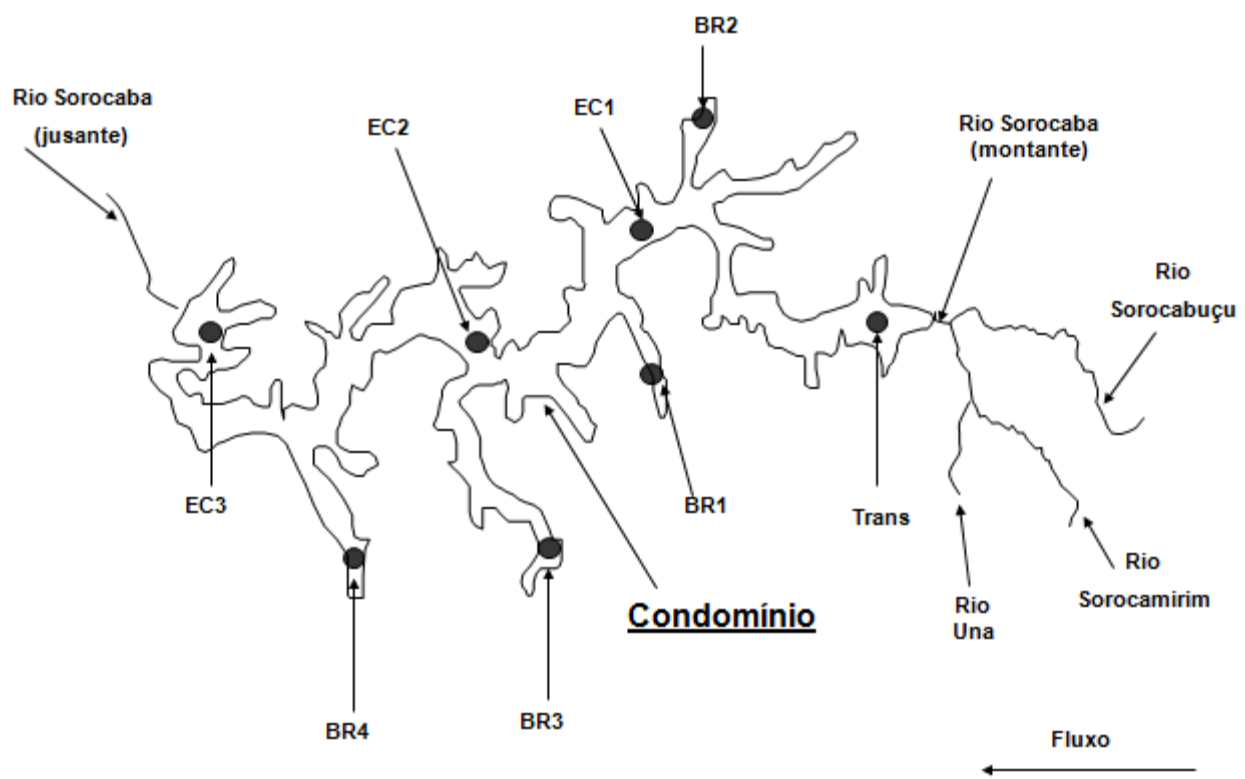

Figura 6: Estações de amostragem das coletas do Reservatório de Itupararanga. EC1 - eixo central ; EC2 - eixo central 2; EC3 - eixo central 3; BR1 - braço 1; BR2 - braço 2; BR3 - braço 3; BR4 - braço 4; Trans - transição dos rios para o reservatório.

\subsection{Isolamento das espécies}

A partir da amostra composta, houve o enriquecimento da mesma nos meios de cultura WC (GUILLARD \& LORENZEN, 1972) (ANEXO A) e ASM-1 (GORHAM et al., 1964 modificado por REYNOLDS \& JAWORSKI, 1978) (ANEXO B), nas concentrações de 25, 50 e $75 \%$ de meio de cultura previamente esterilizado $\left(121^{\circ} \mathrm{C}, 20\right.$ minutos $)$, com pH ajustado 
para 8,0 e tamponado com TRIS $\left(0,5 \mathrm{~g} . \mathrm{L}^{-1}\right)$, totalizando seis frascos, sendo três para cada meio de cultura utilizado.

O meio de cultura WC foi utilizado objetivando o isolamento de Monoraphidium contortum e o ASM-1 para a obtenção de Cylindrospermopsis raciborskii. As diferentes concentrações de meio de cultura e de amostra foram utilizadas para aumentar a probabilidade de crescimento destas duas espécies, já que o fitoplâncton responde diferentemente às condições nutricionais.

As amostras enriquecidas, com total de $100 \mathrm{ml}$ de cultura, foram mantidas em frasco Duran de $500 \mathrm{~mL}$, com tampa parcialmente desrosqueada, em sala climatizada de cultivo com temperatura de $24^{\circ} \mathrm{C}$, fotoperíodo de 12 horas e intensidade luminosa de $60 \mu \mathrm{E} \cdot \mathrm{m}^{-2} \mathrm{~s}^{-1}$ fornecida por lâmpadas tubulares fluorescentes de 20W (OSRAM).

Para a manutenção das amostras, elas foram repicadas mensalmente em condições de assepsia na proporção de 1:10 do seu respectivo meio de cultura autoclavado, nas mesmas condições já citadas.

As metodologias de isolamento para as espécies Cylindrospermopsis raciborskii e Monoraphidium contortum foram realizadas simultaneamente para otimização do tempo, pois alguns métodos de isolamento poderiam não ter resultados positivos.

Foi feito o plaqueamento das amostras enriquecidas em meio de cultura solidificado com Ágar (1\%), utilizando-se o WC e o ASM-1, a partir do método de espalhamento. Repicagens das colônias foram feitas em outras placas a partir do método de estrias até que se obtivesse a colônia pura das espécies desejadas (GUERRERO III \& VILLEGAS, 1982).

Além disso, foi realizado também o método da diluição das amostras enriquecidas e o método da alça e pipetagem da espécie desejada com agulha e alça fina (GUERRERO III \& VILLEGAS, 1982), nos microscópios invertido Olympus CKX41 e Olympus BX51 com câmara de captura de imagem pelo software Image - Pro Plus versão 4.5.1.29.

Especificamente para o isolamento da cianobactéria, $5 \mathrm{ml}$ de cada amostra enriquecida foram inoculadas em tubos de ensaio esterilizados com ASM-1, juntamente com ciclohexamida (70 mg. $\mathrm{L}^{-1}$ ), que inibe o crescimento de células eucarióticas (FURTADO, 2007), seguido de sucessivas repicagens. 


\subsection{Triagem das cepas e testes de cultivo da cianobactéria e da clorofícea}

Após o isolamento da C. raciborskii realizou-se triagens das cepas isoladas da espécie para determinar quais delas eram linhagens tóxicas, a partir do método de Ensaio do Imunoadsorvente Ligado à Enzima (ELISA). A partir dos resultados da triagem foi possível estabelecer qual cepa seria utilizada nos ensaios de interação com M. contortum.

Para a escolha da cepa da cianobactéria adotou-se que seria utilizada aquela que possuísse a maior produção de toxina, e, para a clorofícea, seria escolhida a cepa que crescesse na maior diluição realizada no isolamento pelo método por diluição em série, tendo, portanto, menor concentração de bactéria.

Após esta definição, foram realizados testes de cultivo para estabelecer as melhores condições para ambas as cepas. Foram testados dois meios de cultura utilizados para o isolamento e diferentes condições de $\mathrm{pH}$ e temperatura.

Foi observado que $M$. contortum cresceu semelhantemente no WC e no ASM-1, e $C$. raciborskii obteve melhor desempenho no ASM-1. Portanto, estabeleceu-se que as duas seriam mantidas no ASM-1 para a realização dos experimentos com $\mathrm{pH}$ ótimo para ambas de 7,8 e temperatura de $24^{\circ} \mathrm{C}$.

Além disso, foram realizados testes das cepas escolhidas no meio de cultura ASM-1 modificado para diferentes condições nutricionais, visando verificar o crescimento das mesmas.

Posteriormente aos testes de cultivo e estabelecidas as melhores condições, foram construídas curvas de crescimento das duas espécies em monocultura no ASM-1. Com os dados, foram analisadas as fases de crescimento lag, exponencial, estacionária e de senescência para determinar as taxas de crescimento e estabelecer a duração dos ensaios de interação, bem como o tempo de repique ideal de cada espécie para o início dos experimentos de interação.

\subsection{Manutenção das cepas}

As cepas utilizadas nos experimentos foram mantidas em tubos de ensaio de vidro com tampa em sala climatizada de cultivo com temperatura de $24^{\circ} \mathrm{C}$, fotoperíodo de 12 horas e intensidade luminosa de $60 \mu \mathrm{E} \cdot \mathrm{m}^{-2} \mathrm{~s}^{-1}$ fornecida por lâmpadas tubulares fluorescentes de 20W (OSRAM). 
Os inóculos foram repicados mensalmente em condições de assepsia na proporção de 1:10 de ASM-1 previamente autoclavado à $121^{\circ} \mathrm{C}$, por 20 minutos, com $\mathrm{pH}$ ajustado para 7,8 e tamponado com TRIS $\left(0,5\right.$ g.L $\left.\mathrm{L}^{-1}\right)$.

À medida que os ensaios foram realizados, sucessivos repiques das cepas foram feitos durante as suas fases exponenciais para aumentar o volume dos inóculos (150 ml para 1000 $\mathrm{ml}$ ), com o objetivo de obter volume necessário de cultura e aclimatar a cultura do ASM-1 padrão para o modificado. Os repiques de aclimatação no meio de cultura modificado, de acordo com a condição nutricional do experimento a ser realizado, foram feitos por duas vezes, correspondentes ao de $150 \mathrm{ml}$ para $1000 \mathrm{ml}$ e de $1000 \mathrm{ml}$ para o mesmo volume.

Por exemplo, para a simulação do mesotrófico, as culturas de C. raciborskii e de $M$. contortum, em meio de cultura ASM-1 padrão, sofreram dois repiques sucessivos no meio de cultura modificado para mesotrófico, sendo esta então, a cultura utilizada para os inóculos do experimento.

Os repiques das cepas, assim como o experimento, foram feitos em Erlenmeyers de $2000 \mathrm{ml}$ e $250 \mathrm{ml}$, respectivamente. Estes foram vedados com rolhas de gaze e algodão e agitados diariamente para garantir a troca gasosa da cultura e sua homogeneização.

\subsection{Delineamento experimental}

Foram realizados três experimentos de interação das duas espécies sob variadas condições de concentrações de nutrientes, que compreende a simulação de ambiente oligotrófico, mesotrófico e supereutrófico do Reservatório de Itupararanga, conforme índice proposto por Lamparelli (2004), modificado de Carlson (1977). Mas, nesta pesquisa as concentrações de fósforo correspondem ao ortofosfato dissolvido e de nitrogênio disponível na forma de nitrato, pois correspondem à forma destes macronutrientes disponíveis para o fitoplâncton.

Para o início dos experimentos, foram utilizadas amostras retiradas das culturas de $1000 \mathrm{ml} \mathrm{em}$ fase exponencial, aclimatadas de acordo com suas respectivas condições nutricionais. Os experimentos foram mantidos a $24^{\circ} \mathrm{C}$ em sala climatizada, com fotoperíodo de 12 horas, luminosidade de $60 \mu \mathrm{E} \cdot \mathrm{m}^{-2} \cdot \mathrm{s}^{-1}$, e pH 7,8. Foram feitos em blocos com duração de 15 dias. 
Os experimentos foram realizados em triplicata, constituindo-se de 3 controles para cada espécie e 3 para a interação entre elas em Erlenmeyers de $250 \mathrm{ml}$ com volume total de $100 \mathrm{ml}$ de cultura.

Amostras para análise de densidade e biovolume foram retiradas em condições de assepsia dos de frascos do BLOCO 1 - Figura 7, de dois em dois dias e para a análise de toxina, de três em três dias, coincidindo com os dias de amostragem para análise de nutrientes e clorofila-a.

Enquanto os frascos de cultivo do BLOCO 1 foram mantidos durante todo o experimento, séries de nove frascos de cultivo do BLOCO 2 (três de cada tratamento) foram retirados integralmente a cada três dias e o seu volume amostral utilizado nas análises de nutrientes e clorofila-a (Figura 7).

Apesar de todos os inóculos iniciais terem sido iguais, tanto para os controles quanto para as interações, não foi possível garantir que o crescimento das espécies do bloco 2 fossem iguais aos Erlenmeyers de controle de biovolume (bloco 1, Figura 7). Devido aos blocos 1 e 2 estarem nas mesmas condições, tanto físico-químicas quanto de biovolume, supõem-se que as espécies cresceram de maneira semelhante.

Os Erlenmeyers foram agitados e rearranjados randomicamente, diariamente, para a homogeneização da biomassa e diminuição do efeito de possíveis diferenças da intensidade luminosa. 


\section{Esquema Experimental}
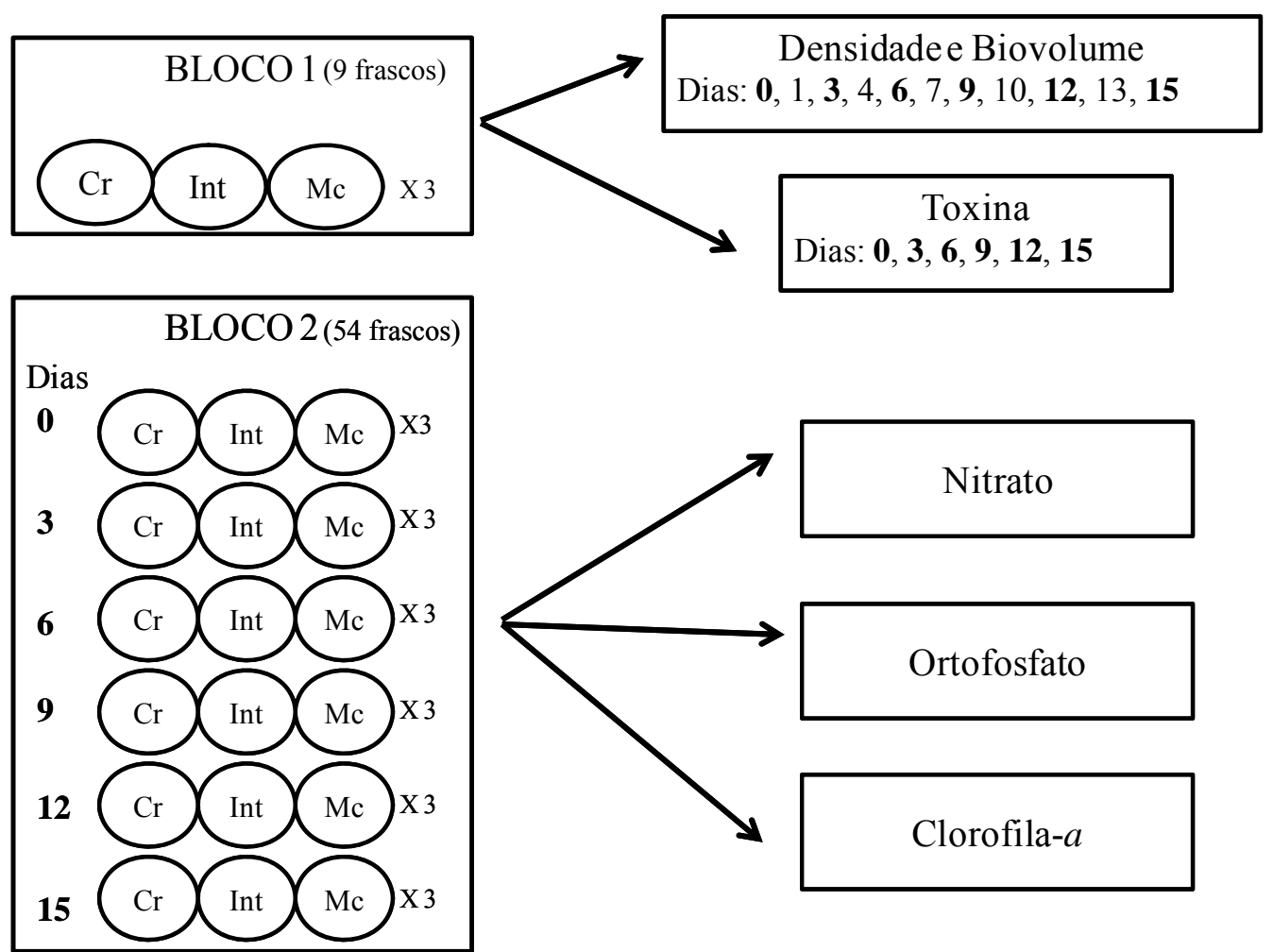

Figura 7: Esquema dos experimentos realizados em triplicata para cada ensaio de simulação de trofia. $\mathrm{Cr}$ monocultura de Cylindrospermopsis raciborskii; Int - Interação das duas espécies; Mc - monocultura de Monoraphidium contortum. Bloco 1 representa unidades experimentais para amostragem de densidade, biovolume e toxina. Bloco 2 representa unidades experimentais para amostragem de nutrientes e clorofila-a. Monoculturas correspondem aos controles das duas espécies.

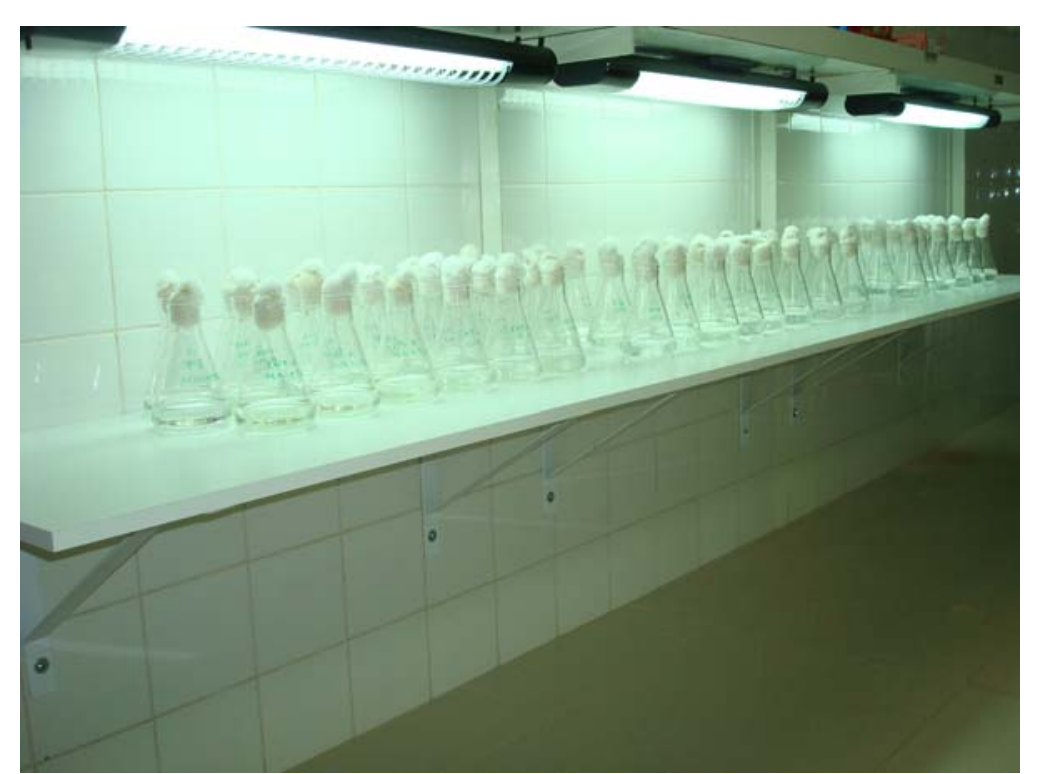

Figura 8: Exposição dos blocos 1 e 2, totalizando 63 Erlenmeyers em cada simulação de trofia. 


\subsubsection{Cálculo do inóculo inicial}

A quantidade ideal de inóculo de cada espécie, necessária para o início dos experimentos de interação, foi calculada a partir do biovolume das culturas aclimatadas sob as condições de trofia de cada experimento. Esta medida foi adotada com o intuito de que a biomassa das espécies fosse semelhante inicialmente, uma vez que estimar o inóculo pela densidade traria um erro quanto à biomassa, pois $M$. contortum possui células menores do que os tricomas de C. raciborskii.

Para o biovolume foi necessário calcular a densidade e a média do volume celular de 30 indivíduos de cada espécie em suas respectivas culturas em fase exponencial. Multiplicando esses resultados, obteve-se uma estimativa do biovolume.

Segundo Hillebrand et al. (1999), M. contortum apresenta morfologia celular de dois cones, cujo volume é calculado conforme a equação (1), e o tricoma de C. raciborskii com morfologia semelhante a um cilindro, o qual se calcula o volume como representado na equação (2).

$$
\text { Volume }=\frac{\pi}{6} \times d^{2} \times \frac{z}{2}
$$

Sendo:

$\mathrm{d}=$ diâmetro

$\mathrm{Z}=$ altura do organismo

$$
\text { Volume }=\frac{\pi}{4} \times d^{2} \times C
$$

Sendo:

$\mathrm{d}=$ diâmetro

$\mathrm{C}=$ Comprimento do organismo

A partir da relação entre os resultados obtidos, considerou-se que para a espécie com menor biovolume seria inoculado $10 \%$ de cultura, correspondendo a $10 \mathrm{ml}$ do total de $100 \mathrm{ml}$ da cultura. A percentagem estabelecida foi para que o crescimento das espécies não fosse prejudicado de acordo com as suas fases de crescimento. 
Para a outra espécie seria inoculado a quantidade calculada a partir da relação do biovolume entre elas. Logo, os inóculos iniciais representaram biovolumes semelhantes para as duas espécies, apesar de densidades diferentes.

Para cada experimento de simulação de trofia, houve a necessidade de realizar esses cálculos de inóculo inicial para as espécies, pois elas respondem de formas distintas às condições nutricionais a que foram submetidas, variando, portanto, suas densidades e volume celular. A quantia de inóculo das culturas em cada experimento calculada segue na Tabela 2.

Tabela 2 - Inóculo e biovolume iniciais das culturas de C. raciborskii e M. contortum para cada ambiente simulado

\begin{tabular}{cccc}
\hline \multirow{2}{*}{$\begin{array}{c}\text { Trofia } / \\
\text { Cultura }\end{array}$} & \multicolumn{2}{c}{ Inóculo inicial (ml) } & $\begin{array}{c}\text { Biovolume inicial calculado } \\
\mathbf{( 1 0}^{-5} \mathbf{\mu m}^{\mathbf{3}} \cdot \mathbf{m l}^{\mathbf{- 1}} \mathbf{)}\end{array}$ \\
\hline Oligotrófico & 1,59 & 10 & 2,48 \\
\hline Mesotrófico & 10 & 7,12 & 5,49 \\
\hline Supereutrófico & 10 & 7,69 & 9,12 \\
\hline
\end{tabular}

\subsection{Condições nutricionais dos experimentos}

As concentrações de nutrientes dissolvidos testadas nos ensaios foram baseadas nos resultados obtidos de Casali (em andamento). Foram utilizadas a soma das médias das concentrações das formas de nitrogênio (nitrito, nitrato e amônia) e de fósforo (ortofosfato total dissolvido), segundo metodologia descrita em APHA (2005), além da média das concentrações dos micronutrientes de coleta realizada em fevereiro de 2011 (Tabela 3), determinadas por espectrometria de absorção atômica, modelo AA240FS Varian, no Laboratório de Sanemanento EESC-USP.

Adotou-se que seriam utilizadas as concentrações de nutrientes dissolvidos, pois são estas as formas prontamente disponíveis na água para os organismos assimilarem. Dessa forma, o cálculo do índice de estado trófico, bem como a definição das concentrações de fósforo em cada experimento, foi baseado apenas no fósforo total dissolvido e não no fósforo total.

De acordo com esses resultados, foram feitas modificações na composição do meio de cultura ASM-1 (GORHAM et al., 1964 modificado por REYNOLDS \& JAWORSKI, 1978) para a simulação do reservatório conforme a condição nutricional do ensaio desejado (oligotrófico, mesotrófico e supereutrófico). 


\subsubsection{Modificações do meio ASM-1 para a simulação de trofia}

Nos meios de cultura elaborados para cada simulação de trofia, as soluções de nitrogênio e micronutrientes do meio ASM-1 foram ajustadas para simular as concentrações do reservatório em todos os ensaios (Tabela 3). Apenas a concentração de fósforo variou entre os experimentos, já que é este, juntamente com a clorofila-a, que determinam o grau de trofia do ambiente aquático.

As concentrações de alguns dos nutrientes do meio de cultura ASM - 1 padrão que foram modificados, bem como as concentrações do reservatório podem ser verificadas na Tabela 3. Os demais componentes da composição do meio ASM-1 não foram alterados, conforme dados do anexo B.

Tabela 3 - Comparação da média dos macronutrientes e micronutrientes do Reservatório de Itupararanga e do meio de cultura ASM - 1 padrão, em mg.. ${ }^{-1}$

\begin{tabular}{|c|c|c|c|}
\hline & Nutrientes & Média do Reservatório (mg.L ${ }^{-1}$ ) & ASM -1 (mg.L ${ }^{-1}$ ) \\
\hline \multirow{2}{*}{ Macronutrientes } & Nitrogênio dissolvido & 0,45 & 28 \\
\hline & Ortofosfato total dissolvido & 0,012 & 6,2 \\
\hline \multirow{6}{*}{ Micronutrientes } & Zinco & 0,0875 & 0,209 \\
\hline & Ferro & 0,2425 & 0,223 \\
\hline & Manganês & 0,021 & 0,384 \\
\hline & Cobre & 0,0135 & 0,000051 \\
\hline & Boro & 0,9 & 0,432 \\
\hline & Cobalto & 0,0075 & 0,00471 \\
\hline
\end{tabular}

Fonte: Os dados das concentrações dos nutrientes do Reservatório de Itupararanga segundo Casali (em andamento).

A relação estequiométrica entre nitrogênio e fósforo (N:P) do meio de cultura ASM -1 é de 10:1. Como houve alterações apenas nas concentrações de fósforo, houve também variação da relação N:P nos meios de cultura modificados para a simulação dos graus de trofia.

As concentrações dos nutrientes utilizados nos meios de simulação dos graus de trofia seguem na Tabela 4, bem como as relações N:P iniciais constituídas. As concentrações de fósforo foram estabelecidas juntamente com o resultado médio da clorofila-a do reservatório da mesma coleta, 31,5 $\mu \mathrm{g} . \mathrm{L}^{-1}$, já que o índice de estado trófico (IET) é estabelecido a partir desses dois parâmetros.

De acordo com os resultados obtidos da coleta referenciada (CASALI, em andamento), o reservatório foi classificado como eutrófico (IET CL $-63,65$; IET $\mathrm{PO}_{4}{ }^{-}-57,5$; IET médio - 60,5), conforme demonstrado na Tabela 5 e cálculos pelas equações 3 e 4 . 
Visto que os relatórios da Cetesb (CETESB, 2008, 2009, 2010), citam o Reservatório de Itupararanga como mesotrófico e os dados do Projeto Temático (item 3.5.), especificamente no período de fevereiro de 2011 (CASALI, em andamento) revelaram índice eutrófico, optou-se por fazer os experimentos de simulação com diferentes índices tróficos, conforme os dados de clorofila-a e de fósforo total dissolvido, estabelecidos conforme Tabela 4.

Tabela 4 - Concentrações de fósforo utilizadas para as simulações dos graus de trofia do Reservatório de Itupararanga e o índice de estado trófico (IET) conforme Lamparelli, 2004

\begin{tabular}{|c|c|c|c|c|c|}
\hline Simulação & $\begin{array}{c}\text { Ortofosfato } \\
\left(\mu g . L^{-1}\right)\end{array}$ & Nitrato (mg.L $\left.{ }^{-1}\right)$ & Micronutrientes & $\mathbf{N}: \mathbf{P}$ & IET \\
\hline Oligotrófico & 3,3 & \multirow{3}{*}{0,45} & Tabela 3 & $302: 1$ & 49,5 \\
\hline Mesotrófico & 8,8 & & Média do & 113:1 & 55,5 \\
\hline Supereutrófico & 35,3 & & reservatório & $28: 1$ & 63,9 \\
\hline
\end{tabular}

Tabela 5 - Classificação do Estado Trófico - IET - de Reservatórios segundo Lamparelli (2004)

\begin{tabular}{|c|c|c|c|c|}
\hline \multicolumn{5}{|c|}{ Classificação do Estado Trófico - Reservatórios } \\
\hline $\begin{array}{c}\text { Categoria } \\
\text { (Estado Trófico) }\end{array}$ & Ponderação & $\begin{array}{c}\text { Secchi }-\mathbf{S} \\
(\mathbf{m})\end{array}$ & $\begin{array}{c}\text { P-total }-\mathbf{P} \\
\left(\mathbf{m g} \cdot \mathbf{m}^{-3}\right)\end{array}$ & $\begin{array}{c}\text { Clorofila a } \\
\left(\mathbf{m g} \cdot \mathbf{m}^{-3}\right)\end{array}$ \\
\hline Ultraoligotrófico & $\mathrm{IET}=47$ & $\mathrm{~S}=2,4$ & $\mathrm{P}=8$ & $\mathrm{CL}=1,17$ \\
\hline Oligotrófico & $47<\mathrm{IET}=52$ & $2,4>\mathrm{S}=1,7$ & $8<\mathrm{P}=19$ & $1,17<\mathrm{CL}=3,24$ \\
\hline Mesotrófico & $52<\mathrm{IET}=59$ & $1,7>\mathrm{S}=1,1$ & $19<\mathrm{P}=52$ & $3,24<\mathrm{CL}=11,03$ \\
\hline Eutrófico & $59<\mathrm{IET}=63$ & $1,1>\mathrm{S}=0,8$ & $52<\mathrm{P}=120$ & $11,03<\mathrm{CL}=30,55$ \\
\hline Supereutrófico & $63<\mathrm{IET}=67$ & $0,8>\mathrm{S}=0,6$ & $120<\mathrm{P}=233$ & $30,55<\mathrm{CL}=69,05$ \\
\hline Hipereutrófico & $\mathrm{IET}>67$ & $0,6>\mathrm{S}$ & $233<\mathrm{P}$ & $69,05<\mathrm{CL}$ \\
\hline
\end{tabular}

$$
\begin{aligned}
& \operatorname{IET}(\mathrm{CL})=10 \times(6-((0,92-0,34 \times(\ln \mathrm{CL})) / \ln 2)) \\
& \operatorname{IET}(\mathrm{PT})=10 \times(6-(1,77-0,42 \times(\ln \mathrm{PT}) / \ln 2))
\end{aligned}
$$

Sendo:

$\mathrm{CL}=$ concentração de clorofila-a medida à superfície da água, em $\mu \mathrm{g} \cdot \mathrm{L}^{-1}$

$\mathrm{PT}=$ concentração de fósforo total à superfície da água, em $\mu \mathrm{g} \cdot \mathrm{L}^{-1}$

$\ln =$ logaritmo natural 


\subsection{Análise quantitativa do crescimento das culturas}

Para evitar a contaminação das culturas, todo o material coletado do Bloco 1 (Figura 7) foi manipulado dentro de capela de fluxo laminar, com bico de Büssen, previamente desinfectada com álcool 70\% e exposta à luz UV por 15 minutos. As coletas foram realizadas com auxílio de material estéril e em horários fixos.

Nos dias estabelecidos, foi retirada alíquota de $500 \mu \mathrm{l}$ de cada frasco de cultivo do Bloco 1 (Figura 7). As amostras foram armazenadas em frasco âmbar e fixadas com lugol.

A partir dessas amostras foram feitos os cálculos da densidade, em câmara de Fuchs Rosenthal, segundo APHA (2005) (eq. 5), e do volume celular de 30 indivíduos de cada espécie (HILLEBRAND et al., 1999). O volume celular das espécies foi calculado conforme descrito no item 4.7.1.

A contagem das células, realizada em microscópio Olympus BX51, e as medidas do volume celular, através do software Image - Pro Plus versão 4.5.1.29, foram realizadas imediatamente após a coleta. Com estes dados, foi possível calcular a biomassa das espécies através do biovolume (eq. 6), tanto para os controles quanto para a interação.

Do Bloco 1, também foram retiradas alíquotas de $2 \mathrm{ml}$ para a determinação de toxina, armazenadas em frascos de vidro vedados e posteriormente congelados em freezer a $-20^{\circ} \mathrm{C}$, conforme os dias estabelecidos e demonstrados na Figura 7.

Com os resultados de densidade e volume celular foram traçadas as curvas de crescimento das espécies a partir do biovolume $\left(\mu \mathrm{m}^{3} \cdot \mathrm{mL}^{-1}\right)$. Baseando-se na fase exponencial de crescimento das espécies foram feitos os cálculos da velocidade específica de crescimento ( $\mu$ ) (eq. 7) e do tempo de duplicação (Td) (eq. 8), conforme descrito por Stein (1973).

$$
D=\frac{N \times A v}{A f \times E \times V}
$$

Sendo:

$\mathrm{D}=$ densidade (ind. $\mathrm{ml}^{-1}$ )

$\mathrm{N}=$ número de organismo

$\mathrm{Ac}=$ área da câmara $\left(\mathrm{mm}^{2}\right)$

Af $=$ área do campo de contagem $\left(\mathrm{mm}^{2}\right)$

$\mathrm{F}=$ número de campos contados

$\mathrm{V}=$ volume da câmara $\left(\mathrm{mm}^{3}\right)$ 


$$
B=D x V
$$

Sendo:

$\mathrm{B}=$ biovolume $\left(\mu \mathrm{m}^{3} \cdot \mathrm{ml}^{-1}\right)$

$\mathrm{D}=$ densidade (ind. $\mathrm{ml}^{-1}$ )

$\mathrm{V}=$ volume celular médio $\left(\mu \mathrm{m}^{3}\right)$

$$
\mu=\frac{\ln \left(\frac{x_{2}}{\mathrm{NQ}}\right)}{\mathrm{t1}-\mathrm{t0}}
$$

Sendo:

$\mu=$ velocidade específica de crescimento

$\mathrm{Ln}=$ logaritmo natural

$\mathrm{N} 1$ = número de organismo ou biomassa no tempo $\mathrm{t} 1$

N0 = número de organismos ou biomassa no tempo t0

$$
T d=\frac{L m 2}{\mu}
$$

Sendo:

$\mathrm{Td}=$ tempo de duplicação

$\mu=$ velocidade específica de crescimento

\subsection{Análise de nutrientes dissolvidos e clorofila-a}

A partir do Bloco 2 (Figura 7), nos dias determinados, toda a cultura dos controles e das interações $(100 \mathrm{ml})$, foram filtradas através de membranas de fibra de vidro Boeco Germany de 1,2 $\mu \mathrm{m}$ de porosidade.

As amostras filtradas foram armazenadas em frascos de PVC e foram congeladas para posteriores análises de nitrato e ortofosfato conforme metodologia descrita em APHA (2005). 
O método utilizado para a determinação de nitrato foi o espectrofotométrico - Método $4500 \mathrm{NO}_{3} \mathrm{~B}$ - através de medições em luz ultravioleta, e o ortofosfato, também espectrofotométrico - Método $4500 \mathrm{P}$ - B - ácido ascórbico, conforme procedimento descrito em APHA (2005).

As membranas utilizadas na filtragem foram secas no escuro, à temperatura ambiente e congeladas para posterior determinação da clorofila-a, pelo método espectrofotométrico e extração com etanol 80\% (NUSH, 1980 modificado por Nederlandse Norm 6520, 1981).

Todas as leituras espectrofotométricas foram realizadas em espectrofotômetro DR4000 UV-VIS (HACH).

\subsection{Análise quantitativa da produção de toxina}

A determinação das toxinas cilindrospermopsina e saxotoxina, que podem ser produzidas pela Cylindrospermopsis raciborskii, foi realizada através do método bioquímico de Ensaio do Imunoadsorvente Ligado à Enzima, ELISA, que se baseia na reação bioquímica entre antígenos, as toxinas, e anticorpos policlonais (CALIJURI et al., 2006; SANTOS, 2009).

São poucas as pesquisas realizadas com este método para a detecção de cilindrospermopsina e saxitoxina, pois o Kit de detecção ELISA para estas toxinas foi disponibilizado recentemente no mercado.

$\mathrm{Na}$ etapa de triagem das cepas, foram detectadas apenas cepas hábeis à produção de saxitoxina. Portanto, as análises para quantificação da produção de toxina nos controles da $C$. raciborskii e na interação, em todos os experimentos, ocorreram apenas para a saxitoxina.

A extração da saxitoxina total (extra e intracelular) foi realizada conforme descrito por Berry \& Lind (2010), Torökne et al. (2004) e Yilmaz et al. (2008), através do congelamento e descongelamento das amostras por quatro vezes antes da realização dos testes, o que permitiu a lise celular e a liberação da toxina intracelular.

Os testes foram realizados em kits de saxitoxina em placa (Beacon Analytical Systems Inc., ME, USA), com procedimentos realizados em lavadora e leitora de microplacas modelos Atlantis e Expert Plus, respectivamente.

De acordo com os resultados obtidos da concentração total de saxitoxina por amostra, em $\mu \mathrm{g} . \mathrm{L}^{-1}$, foi realizada a conversão desta unidade para a concentração de saxitoxina por biovolume de C.raciborskii respectiva à sua amostra. 


\subsection{Análise dos dados}

Inicialmente, foi aplicado o teste de normalidade Kolmogorov_Smirnov em todos os dados dos parâmetros bióticos e físico-químicos para averiguar se os dados eram ou não paramétricos e selecionar os testes estatísticos adequados.

As curvas de crescimento das espécies foram traçadas a partir da média do biovolume das culturas controle e interação ao longo do tempo. A comparação do crescimento foi realizada através de análise estatística por meio do teste $t$-student entre os conjuntos de dados da interação e dos controles das espécies, para cada dia amostrado, assim como para averiguar as diferenças significativas entre as concentrações de toxina.

O teste t-student também foi aplicado para comparar as concentrações da soma da clorofila-a dos controles com a concentração da clorofila-a da interação em seus respectivos dias, e para a comparação do volume celular das espécies no controle e na interação durante os experimentos.

A concentração de nutrientes dentro e entre cada experimento foi comparada com uma ANOVA seguida de um post hoc, o Teste de Tukey. Este mesmo teste foi utilizado com outros parâmetros comparados entre os experimentos precedidos da ANOVA.

Em todos os testes estatísticos foi utilizado o software Origin Pro 8.0 e para indicar diferença significativa dos resultados foi adotado $\mathrm{p} \leq 0,05$. 


\section{RESULTADOS}

5.1. Isolamento e caracterização do crescimento das cepas de C. raciborskii e M. contortum

A partir da amostra composta coletada no Reservatório de Itupararanga, foi feito o isolamento e triagem das cepas no laboratório, do qual foram obtidos no total cinco cepas de Cylindrospermopsis raciborskii e três cepas de Monoraphidium contortum. A representação da comunidade fitoplanctônica do Reservatório de Itupararanga após o enriquecimento pode ser observada na Figura 9.

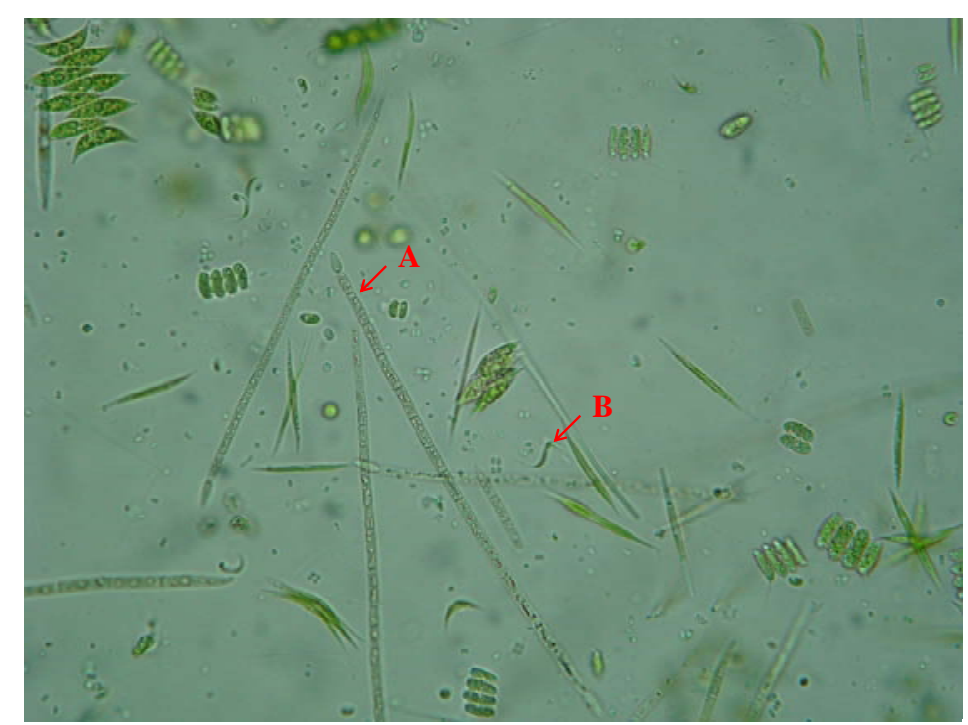

Figura 9: Comunidade fitoplanctônica do Reservatório de Itupararanga após enriquecimento em meio de cultura em aumento de 200x. A - Cylindrospermopsis raciborskii; B - Monoraphidium contortum.

Após o isolamento das cepas das duas espécies, foi realizada a triagem das mesmas. Para C. raciborskii foi realizado o teste ELISA para averiguar quais cepas estavam produzindo toxina. Destas cinco, duas das cepas produziam apenas saxitoxina e as outras três não estavam hábeis à produção de nenhuma das toxinas que a espécie apresenta potencial: saxitoxina e cilindrospermopsina. A cepa escolhida para a realização dos experimentos foi a que apresentou maior concentração de saxitoxina. 
Já a cepa de $M$. contortum selecionada foi a que apresentava menor concentração de bactérias. Esta cepa foi submetida a uma diluição de $10^{-6}$ para reduzir a concentração desses microrganismos.

Foram traçadas curvas de crescimento das cepas escolhidas de C. raciborskii e de $M$. contortum, tanto por densidade (ind. $\left.\mathrm{ml}^{-1}\right)$ quanto por biovolume $\left(\mu \mathrm{m}^{3} \cdot \mathrm{ml}^{-1}\right)$, num período de 30 dias, em triplicata e no meio de cultura ASM-1, conforme representado na Figura 10.

As curvas foram determinadas para caracterizar as fases de crescimento lag, exponencial, estacionária e de senescência, visando estabelecer a duração dos experimentos, bem como os períodos adequados para o repique das culturas.

Como pode ser obervado na Figura 10, tanto na curva de crescimento por densidade, quanto por biovolume, foi possível observar que a fase lag de C. raciborskii ocorreu do dia 0 ao $3^{\circ}$, tendo início, posteriormente, a fase $\log$ do crescimento, que corresponde à fase exponencial da espécie, seguindo até $25^{\circ}$ dia, aproximadamente. Logo após, até o fim do período, dia 30, foi observada a fase estacionária da espécie, não sendo notado o início da fase de senescência.

Nas curvas de $M$. contortum (Figura 10) foi observado um crescimento mais rápido comparado ao da cianobactéria, pois sua fase lag é curta, considerada apenas do dia 0 ao $1^{\circ}$, e a fase exponencial, iniciou-se aproximadamente no $1^{\circ}$ dia e prosseguiu até o $12^{\circ}$ dia. A partir deste último então, inicia-se a fase estacionária até o $30^{\circ}$ dia, notando-se crescimento mais lento. Para esta espécie também não foi observada a fase de senescência.

Devido ao crescimento mais rápido, $M$. contortum iniciou a fase estacionária primeiro do que C. raciborskii. Foi possível notar (Figura 10), que no momento em que a clorofícea estava na fase estacionária, a cianobactéria continuou na fase exponencial, já que esta se iniciou mais tardiamente.

Além disso, foi possível observar também que as duas espécies no primeiro dia das curvas de crescimento apresentaram biovolume semelhante, mas o mesmo não ocorreu com as densidades iniciais das espécies, pois o volume celular de $M$. contortum era menor do que o de C. raciborskii.

Por esse motivo e para melhor precisão dos resultados, o cálculo do inóculo inicial dos experimentos, as curvas de crescimento, a velocidade específica de crescimento e o tempo de duplicação das duas espécies, bem como a concentração de saxitoxina nos controles da cianobactéria e na interação, foram baseados nos resultados dos biovolumes das espécies. Além disso, optou-se em adotar o biovolume semelhante no início dos experimentos, com o 
intuito de evitar grande concentração de biomassa e possível sombreamento, caso fosse considerado o número de células.

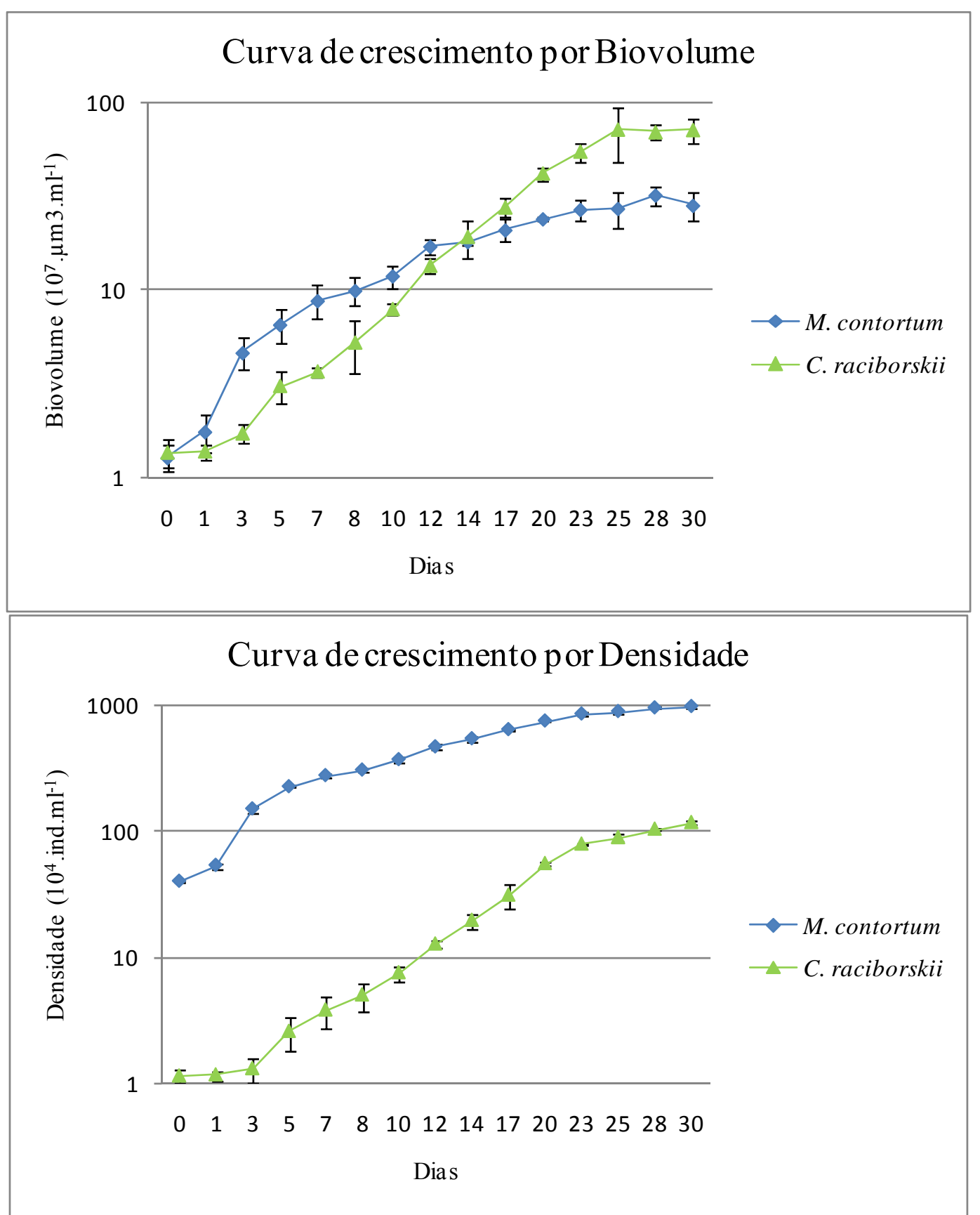

Figura 10: Curvas de crescimento das cepas de M. contortum e C. raciborskii baseadas nas médias da densidade $\left(10^{4}\right.$.ind. $\left.\mathrm{ml}^{-1}\right)$ e do biovolume $\left(10^{7} \cdot \mu \mathrm{m}^{3} \cdot \mathrm{ml}^{-1}\right)$. Barras verticais indicam o desvio padrão $(\mathrm{n}=3)$. 


\subsection{Ensaios de interação: comparação dos parâmetros bióticos e físico-químicos}

A interação de C. raciborskii com M. contortum foi realizada em três diferentes níveis de trofia, conforme a classificação por Lamparelli (2004), simulando o Reservatório de Itupararanga no ambiente oligotrófico, mesotrófico e supereutrófico.

Os resultados estão apresentados na forma de médias das triplicatas dos controles e da interação das espécies para as variáveis bióticas: biovolume $\left(\mu \mathrm{m}^{3} \cdot \mathrm{ml}^{-1}\right)$, velocidade específica de crescimento $(\mu)$, tempo de duplicação (Td) e volume celular $\left(\mu \mathrm{m}^{3}\right)$, e para os físicoquímicos: saxitoxina $\left(\mu \mathrm{g} \cdot \mu \mathrm{m}^{-3}\right)$, clorofila-a $\left(\mu \mathrm{g} . \mathrm{L}^{-1}\right)$, nitrato $\left(\mathrm{mg} . \mathrm{L}^{-1}\right)$ e ortofosfato $\left(\mu \mathrm{g} . \mathrm{L}^{-1}\right)$.

\subsubsection{Caracterização do crescimento das cepas nas simulações de trofia}

As análises estatísticas foram realizadas para comparar o crescimento das culturas de cada espécie no controle e na interação, e entre as espécies na interação, para cada ambiente simulado, a partir do Test $t$-student. Os resultados constam nas Tabelas 6 e 7 e as diferenças significativas estão representadas por símbolos. A análise estatística para comparar cada cultura nos diferentes ambientes simulados foi através do ANOVA e os resultados significativos estão apresentados por letras maiúsculas nas Tabelas 6 e 7. Na Tabela 8 estão apresentados as médias dos biovolumes inicias e finais das espécies em cada cultura dos três ambientes simulados.

Para a simulação do reservatório oligotrófico foi utilizada a concentração inicial de 3,3 $\mu \mathrm{g} . \mathrm{L}^{-1}$ de fósforo e $450 \mu \mathrm{g} . \mathrm{L}^{-1}$ de nitrogênio, estabelecendo uma relação N:P inicial de 302/1.

O inóculo inicial do experimento, baseado em semelhante biovolume para as espécies, foi de densidade média de $5,89 \times 10^{3}$ ind. $\mathrm{ml}^{-1}$ para o controle e $6,41 \times 10^{3}$ ind. $\mathrm{ml}^{-1}$ na interação de $M$. contortum. O controle de C. raciborskii teve como densidade inicial 5,61 x10 $0^{2}$ ind. $\mathrm{ml}^{-1} \mathrm{e}$ $4,83 \times 10^{2}$ ind. $\mathrm{ml}^{-1}$ na interação.

As médias dos biovolumes iniciais foram semelhantes para as duas espécies, sendo $2,0 \times 10^{5} \mu \mathrm{m}^{3} \cdot \mathrm{ml}^{-1}$ e $2,39 \times 10^{5} \mu \mathrm{m}^{3} \cdot \mathrm{ml}^{-1}$ no controle e na interação, respectivamente, de $M$. contortum. Para C. raciborskii correspondeu a $2,52 \times 10^{5} \mu \mathrm{m}^{3} \cdot \mathrm{ml}^{-1}$ no controle e $2,72 \times 10^{5}$ $\mu \mathrm{m}^{3} \cdot \mathrm{ml}^{-1}$ na interação, conforme pode ser observado na Figura 11 e Tabela 8. Não foram observadas diferenças significativas nos biovolumes dos inóculos iniciais ( $\mathrm{p}>0,05)$.

Quanto às curvas de crescimento de $M$. contortum, os resultados do controle e da interação foram semelhantes até o $4^{\circ}$ dia do experimento, com valores aproximados de biovolume. Do $6^{\mathrm{o}}$ dia em diante, esta espécie apresentou diferença significativa em seu 
biovolume, sendo então observados maiores valores no seu controle $\left(p<0,14\right.$ do $6^{\circ}$ ao $15^{\circ}$ dia).

Os valores máximos de biovolume do controle e da interação de $M$. contortum foram $1,6 \times 10^{6} \mu \mathrm{m}^{3} \cdot \mathrm{ml}^{-1}$ no $9^{\circ}$ dia e $1,25 \times 10^{6} \mu \mathrm{m}^{3} \cdot \mathrm{ml}^{-1}$ no $13^{\circ}$ dia. Houve diminuição no biovolume de ambas no $10^{\circ}$ dia devido à uma diminuição do volume celular da espécie, conforme pode ser observado na Figura 14. Embora tenham apresentado biovolumes maiores nestes dias, o M. contortum na interação iniciou a fase estacionária no $4^{\circ}$ dia e teve inicio da fase de senescência a partir do $13^{\circ}$ dia. Em contrapartida, o controle da clorofícea apresentou fase exponencial mais longa, com inicio da fase estacionária no $7^{\circ}$ dia, seguindo até o fim do experimento.

As velocidades específicas de crescimento e os tempos de duplicação de $M$. contortum podem ser observados nas Tabelas 6 e 7, respectivamente. Em ambas as variáveis não houve diferença estatística entre o controle e a interação, embora, para as duas variáveis tenham apresentado $\mathrm{p}=0,06$, próximo ao valor considerado significativo para as diferenças $(\mathrm{p}<$ $0,05)$.

Comparando as curvas de crecimento de C. raciborskii no controle e na interação (Figura 11) foi observado que na interação houve redução significativa do biovolume a partir do $4^{\circ}$ dia do experimento e do $10^{\circ}$ dia em diante esta diferença tornou-se marcante

No controle, o biovolume aumentou até o $6^{\circ}$ dia, correspondendo a fase exponencial, e do $7^{\circ}$ dia em diante a cultura permaneceu na fase estacionária, embora tenha atingido seu maior biovolume no $9^{\circ}$ dia, $2,56 \times 10^{6} \mu \mathrm{m}^{3} \cdot \mathrm{ml}^{-1}$.

Já na interação, o biovolume máximo de C. raciborskii ocorreu no $4^{\circ}$ dia, com $6,49 \times 10^{5} \mu \mathrm{m}^{3} \cdot \mathrm{ml}^{-1}$, do $5^{\mathrm{o}}$ ao $7^{\mathrm{o}}$ dia a cultura permaneceu na fase estacionária e a partir do $8^{\mathrm{a}}$ dia entrou em senescência. Os biovolumes finais das espécies em cada cultura constam na Tabela 8.

Embora haja diferença no crescimento de C. raciborskii no controle e na interação, inclusive ocorrendo senescência da espécie na interação a partir do $8^{\circ}$ dia, não foram observadas diferenças significativas das velocidades específicas de crescimento e do tempo de duplicação entre estas culturas (Tabelas 6 e 7). 


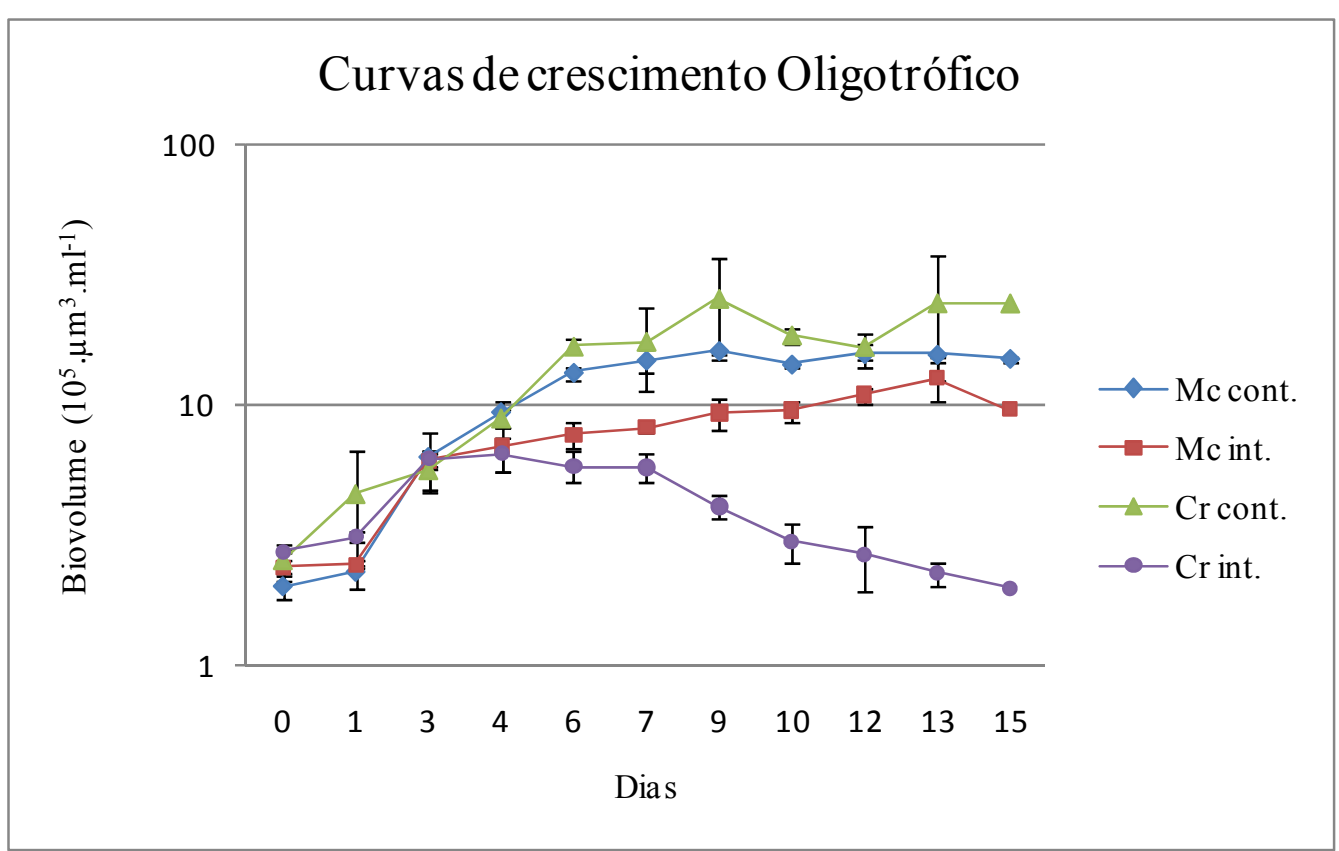

Figura 11: Curvas de crescimento de C. raciborskii e M. contortum baseadas nas médias do biovolume $\left(10^{5} \cdot \mu \mathrm{m}^{3} \cdot \mathrm{ml}^{-1}\right)$ na simulação do ambiente Oligotrófico. Mc cont. - M. contortum controle; Mc int. - M. contortum interação; $\mathrm{Cr}$ cont. - C. raciborskii controle; $\mathrm{Cr}$ int. - C. raciborskii interação. Barras verticais indicam o desvio padrão $(\mathrm{n}=3)$.

Comparando o crescimento das duas espécies quando em interação (Figura 11), verificou-se que a clorofícea apresentou vantagens sobre a cianobactéria, sendo o biovolume de $M$. contortum significativamente maior comparado ao de C. raciborskii a partir do $7^{\circ}$ dia ( $p$ $<0,015$ do $7^{\circ}$ ao $15^{\circ}$ dia). Esta diferença deve-se ao $M$. contortum ter iniciado a fase estacionária a partir do $4^{\circ}$ dias enquanto que C. raciborskii esteve na fase estacionária do $5^{\circ}$ ao $7^{\circ}$ dia, e posteriormente iniciou a fase de senescência.

Houve diferença também nas velocidades específicas de crescimento e tempos de duplicação entre as duas espécies em interação, sendo a velocidade e tempo de duplicação significativamente maior e menor, respectivamente, para M. contortum, conforme Tabelas 6 e 7.

Ambas as espécies foram prejudicadas na interação, pois tiveram crescimento final reduzido quando comparadas ao seu controle. Apesar de não haver diferença das velocidades específicas de crescimento entre o controle e a interação das duas espécies, na interação houve antecipação da chegada da fase estacionária de ambas e, no caso de C. raciborskii, houve senescêscia da cultura.

Ao final do experimento, na interação, $M$. contortum foi a espécie dominante havendo drástica redução do biovolume de C. raciborskii, quando comparado ao seu controle. 
Para a simulação do reservatório mesotrófico foi utilizada a concentração inicial de 8,8 $\mu \mathrm{g} . \mathrm{L}^{-1}$ de fósforo e $450 \mu \mathrm{g} . \mathrm{L}^{-1}$ de nitrogênio, estabelecendo uma relação inicial N:P de 113/1.

O inóculo inicial do experimento, baseando em semelhante biovolume das espécies nas culturas, foi de densidade média de $1,7 \times 10^{4}$ ind. $^{-1}$ no controle e $1,81 \times 10^{4}$ ind. $^{-1}$ na interação para $M$. contortum. O controle e a interação de C. raciborskii apresentaram densidade inicial iguais, $6,25 \times 10^{2}$ ind. $\mathrm{ml}^{-1}$.

Os biovolumes iniciais foram semelhantes para as duas espécies, não apresentando

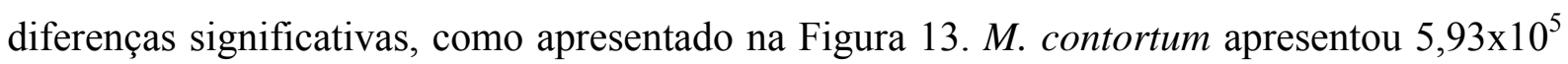
$\mu \mathrm{m}^{3} \cdot \mathrm{ml}^{-1}$ e $6,07 \times 10^{5} \mu \mathrm{m}^{3} \cdot \mathrm{ml}^{-1}$, no controle e na interação, respectivamente. C. raciborskii apresentou biovolume de $6,79 \times 10^{5} \mu \mathrm{m}^{3} \cdot \mathrm{ml}^{-1}$ no controle e $6,76 \times 10^{5} \mu \mathrm{m}^{3} \cdot \mathrm{ml}^{-1}$ na interação (Tabela 8).

As curvas de crescimento de $M$. contortum (Figura 12), no controle e na interação, começaram a apresentar diferença significativa no biovolume a partir do $3^{\circ}$ dia até o final do experimento ( $\mathrm{p}<0,045$ do $3^{\circ}$ ao $15^{\circ}$ dia). No controle, o biovolume foi crescente até o $15^{\circ}$ dia, atingindo o máximo de $1,25 \times 10^{7} \mu^{3} \cdot \mathrm{ml}^{-1}$, ocorrendo no mesmo dia na interação que, apesar de menor, atingiu o máximo de $3,18 \times 10^{6} \mu \mathrm{m}^{3} \cdot \mathrm{ml}^{-1}$. Esta espécie, tanto no controle quanto na interação, entrou na fase exponencial logo no $1^{\circ}$ dia do experimento e permaneceu nesta fase até o $6^{\circ}$ dia, dando inicio, posteriormente a fase estacionária até o final do experimento.

A velocidade específica de crescimento de $M$. contortum foi significativamente maior no controle comparado à interação $(\mathrm{p}=0,027)$ e quanto ao tempo de duplicação não houve essa diferença para esta espécie devido, provavelmente, ao desvio padrão (Tabelas 6 e 7). Mas, nesta comparação do tempo de duplicação entre o controle e a interação, a probabilidade de diferença foi próxima a considerada significativa, $\operatorname{com} \mathrm{p}=0,08$.

Em contrapartida, comparando as curvas de crescimento no controle e na interação de C. raciborskii (Figura 12), não foi observada diferença significativa. No controle, o biovolume máximo foi de $2,59 \times 10^{6} \mu \mathrm{m}^{3} \cdot \mathrm{ml}^{-1}$ e na interação $2,31 \times 10^{6} \mu \mathrm{m}^{3} \cdot \mathrm{ml}^{-1}$, ambos no $15^{\circ}$ dia do experimento (Tabela 8). Dessa forma, a cianobactéria, tanto no controle quanto na interação, permaneceram na fase exponencial do $1^{\mathrm{o}}$ dia até o final do experimento, não apresentando fase estacionária.

Estas informações estão de acordo com os resultados do teste t-student, pois também não houve diferença significativa nas velocidades específicas de crescimento e tempo de 
duplicação entre o controle e a interação para C. raciborskii, conforme Tabelas 6 e 7, respectivamente.

$\mathrm{Na}$ interação, o biovolume de C. raciborskii foi menor do que o de $M$. contortum do $1^{\mathrm{o}}$ dia até o $12^{\circ}$, com $\mathrm{p}<0,034$ para todos os dias, exceto no dia 4, apesar da estatística apresentar valor próximo ao considerado significativo, $\operatorname{com} p=0,052$ (Figura 12). A partir do $13^{\circ}$ dia essa situação é revertida e as duas espécies passam a ter o mesmo biovolume. $M$. contortum se manteve na fase estacionária e C. raciborskii manteve seu crescimento exponencial, atingindo biovolume similar ao da clorofícea. Em relação à velocidade específica de crescimento e ao tempo de duplicação das duas espécies na interação, não foram observadas diferenças significativas.

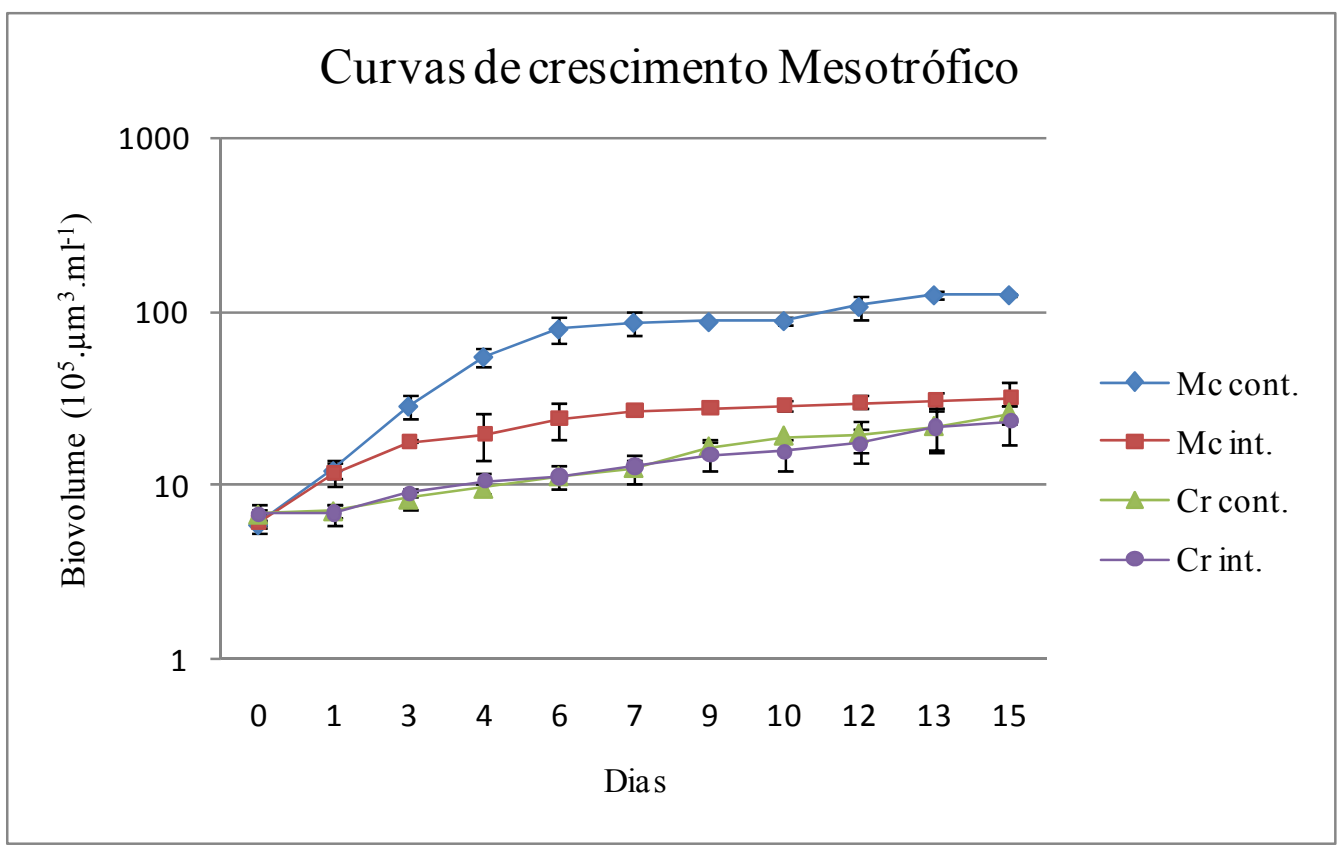

Figura 12: Curvas de crescimento de C. raciborskii e $M$. contortum baseadas nas médias do biovolume $\left(10^{5} \cdot \mu \mathrm{m}^{3} \cdot \mathrm{ml}^{-1}\right)$ na simulação do ambiente Mesotrófico. Mc cont. - M. contortum controle; Mc int. - M. contortum interação; $\mathrm{Cr}$ cont. - C. raciborskii controle; $\mathrm{Cr}$ int. - C. raciborskii interação. Barras verticais indicam o desvio padrão $(\mathrm{n}=3)$.

Esses dados evidenciam que C. raciborskii, em condições mesotróficas, não foi inibida com a presença de $M$. contortum. Em contrapartida, à clorofícea teve seu crescimento inibido pela cianobactéria, pois no controle de $M$. contortum, o crescimento e a velocidade específica de crescimento, foram significativamente maiores comparados à esta espécie na interação.

Embora o crescimento de $M$. contortum tenha sido inibido na interação, houve a coexistência desta com C. raciborskii ao final do experimento. A cianobactéria, no $15^{\circ}$ dia, permaneceu na fase exponencial e a clorofícea na estacionária, o que pode ser um indício de 
que C. raciborskii tenha vantagem competitiva no ambiente mesotrófico, pois esta espécie não teve seu crescimento afetado pela presença de $M$. contortum.

Para a simulação do reservatório supereutrófico, as concentrações iniciais de 35,3 $\mu \mathrm{g} . \mathrm{L}^{-1}$ de fósforo e $450 \mu \mathrm{g} . \mathrm{L}^{-1}$ de nitrogênio foram utilizadas, estabelecendo uma relação N:P inicial de 28/1.

De acordo com o biovolume das culturas das espécies, foi calculado o inóculo inicial

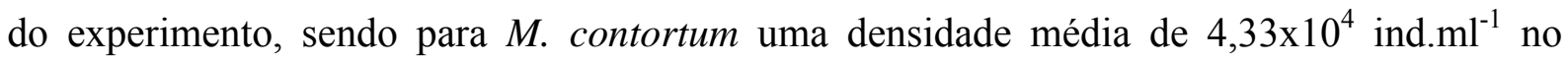

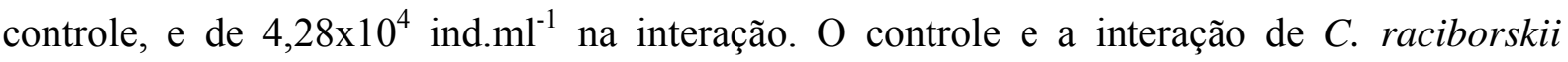
apresentaram como densidade inicial $6 \times 10^{2}$ ind. $\mathrm{ml}^{-1}$.

Os biovolumes iniciais foram semelhantes para as duas espécies nos controles e na interação. M. contortum inicialmente apresentou biovolume de $1,06 \times 10^{6} \mu \mathrm{m}^{3} \cdot \mathrm{ml}^{-1}$ no controle e $1,05 \times 10^{6} \mu \mathrm{m}^{3} \cdot \mathrm{ml}^{-1}$ na interação. C. raciborskii apresentou biovolume de $1,1 \times 10^{6} \mu \mathrm{m}^{3} \cdot \mathrm{ml}^{-1} \mathrm{e}$ $1,03 \times 10^{6} \mu \mathrm{m}^{3} \cdot \mathrm{ml}^{-1}$ no controle e na interação, respectivamente, como pode ser observado na Figura 13 e Tabela 8.

As curvas de crescimento de M. contortum, representadas na Figura 13, demonstraram que, no controle, o biovolume foi crescente até o final do experimento, apresentando valor máximo no $15^{\circ}$ dia: $3,09 \times 10^{7} \mu \mathrm{m}^{3} \cdot \mathrm{ml}^{-1}$. Na interação, ocorreu no mesmo dia, porém atingindo o máximo de $1,29 \times 10^{7} \mu \mathrm{m}^{3} \cdot \mathrm{ml}^{-1}$, ou seja, o crescimento foi menor (Tabela 8). Estas curvas apresentaram diferença significativa a partir do $3^{\circ}$ dia de experimento, prosseguindo até o fim, com $\mathrm{p}<0,04$ em todos os dias, exceto no dia 4, devido ao maior desvio padrão da média, apesar do valor de $p$ ter sido próximo ao considerado significativo $(\leq 0,05): p=0,051$.

A clorofícea, tanto no controle quanto na interação, iniciou a fase exponencial no $1^{\circ}$ dia do experimento, a qual seguiu até o $4^{\circ}$ dia, e posteriormente, teve início a fase estacionária até o final do experimento.

Embora haja diferença nos biovolumes ao longo do experimento, quanto a velocidade específica de crescimento (Tabela 6) e o tempo de duplicação (Tabela 7) não foi observada diferença significativa, além de no controle $M$. contortum ter atingido biovolume maior comparado à interação, indicando inibição em seu crescimento.

Quanto às curvas de crescimento de C. raciborskii (Figura 13), elas apresentaram-se semelhantes, com diferença significativa apenas no $9^{\circ}$ dia $(p=0,007)$ provavelmente devido à redução do volume celular que ocorreu nos tricomas da espécie, como pode ser observado na 
Figura 16. No controle, o biovolume máximo foi de $3,24 \times 10^{6} \mu \mathrm{m}^{3} \cdot \mathrm{ml}^{-1}$ e na interação foi de $2,46 \times 10^{6} \mu \mathrm{m}^{3} \cdot \mathrm{ml}^{-1}$, ambos observados no último dia de experimento, conforme Tabela 8.

Tanto no controle quanto na interação, as curvas da cianobactéria mantiveram-se na fase exponencial do $1^{\circ}$ dia até o final do experimento, não havendo indícios de fase estacionária.

Os dados relacionados ao semelhante crescimento de C. raciborskii no controle e na interação, corroboram com os resultados estatísticos da comparação quanto às suas velocidades específica de crescimento e aos tempos de duplicação, pois não há diferença significativa desses parâmetros entre estas culturas de cianobactéria.

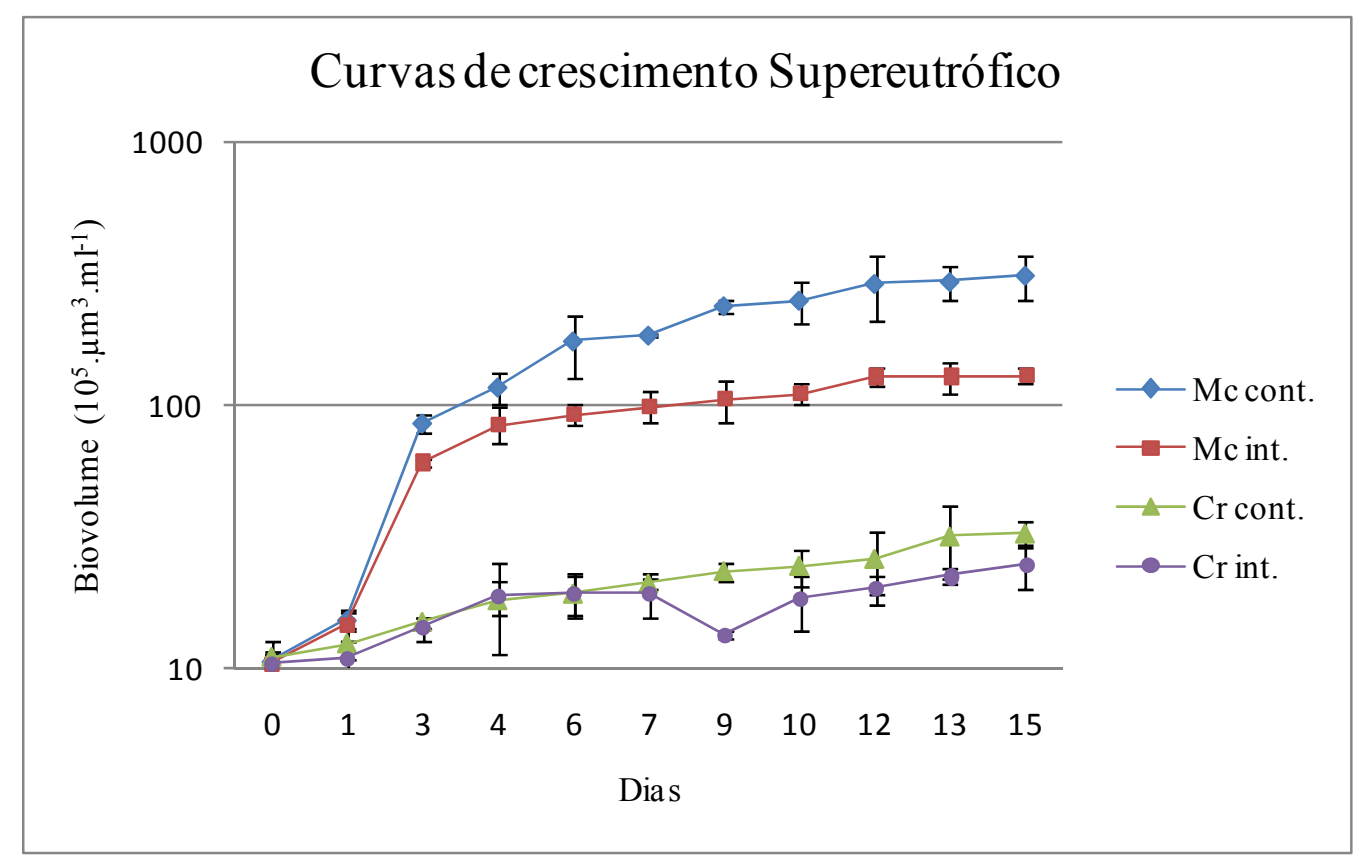

Figura 13: Curvas de crescimento de C. raciborskii e $M$. contortum baseadas nas médias do biovolume $\left(10^{5} \cdot \mu \mathrm{m}^{3} \cdot \mathrm{ml}^{-1}\right)$ na simulação do ambiente Supereutrófico. Mc cont. $-M$. contortum controle; Mc int. $-M$. contortum interação; $\mathrm{Cr}$ cont. - C. raciborskii controle; $\mathrm{Cr}$ int. - C. raciborskii interação. Barras verticais indicam o desvio padrão $(\mathrm{n}=3)$.

$\mathrm{Na}$ interação, as duas espécies iniciaram o experimento com biovolumes semelhantes e ambas apresentaram crescente aumento dessa variável até o final do experimento (Figura 13). No entanto, $M$. contortum apresentou biovolume significativamente maior comparado a $C$. raciborskii, com diferença significativa a partir do $3^{\circ}$ até o fim do experimento $(\mathrm{p}<0,013$ do $3^{\circ}$ ao $15^{\circ}$ dia). Também houve diferença nas velocidades específicas de crescimento e tempo de duplicação das espécies na interação, conforme constatado nas Tabelas 6 e 7, respectivamente. 
De acordo com esses dados observa-se que M. contortum teve seu crescimento inibido na interação com C. raciborskii, quando comparado ao seu controle, embora a clorofícea tenha apresentado biovolume final significativamente maior do que ao da cianobactéria. Porém, quando C. raciborskii na interação é comparada com seu controle, nota-se que o crescimento da espécie foi semelhante, não sendo prejudicado pela presença de $M$. contortum.

Embora M. contortum tenha maior velocidade específica de crescimento e maior crescimento comparada a C. raciborskii na interação, a clorofícea inicia a fase estacionária primeiramente, enquanto a cianobactéria permanece na fase exponencial. Este fato contribui com a vantagem competitiva de C. raciborskii, além de esta não ter o seu crescimento inibido.

Tabela 6 - Comparação das velocidades específicas de crescimento $(\mu)$ (média com desvios padrão, $\mathrm{n}=3$ ), de $M$. contortum $(\mathrm{Mc})$ e C. raciborskii $(\mathrm{Cr})$, e C. raciborskii nos três ambientes simulados: oligotrófico, mesotrófico e supereutrófico

\begin{tabular}{|c|c|c|c|c|}
\hline \multirow{2}{*}{ Simulação / Tratamento } & \multicolumn{4}{|c|}{ Velocidade específica de crescimento $\left(\mathrm{dia}^{-1}\right)$} \\
\hline & Mc - controle & Mc - interação & Cr - controle & Cr - interação \\
\hline Oligotrófico & $0,35 \pm 0,04$ & $\begin{array}{c}0,45 \pm 0,05 \\
\mathrm{C}+\end{array}$ & $\begin{array}{c}0,28 \pm 0,11 \\
\text { E F }\end{array}$ & $\begin{array}{c}0,24 \pm 0,03 \\
\text { G H }\end{array}$ \\
\hline Mesotrófico & $\begin{array}{c}0,37 \pm 0,02 \\
*\end{array}$ & $0,14 \pm 0,08$ & $0,09 \pm 0,01$ & $0,09 \pm 0,03$ \\
\hline Supereutrófico & $\begin{array}{c}0,68 \pm 0,07 \\
\text { A B }\end{array}$ & $\begin{array}{c}0,58 \pm 0,07 \\
\mathrm{D} \dagger\end{array}$ & $0,07 \pm 0,01$ & $0,06 \pm 0,02$ \\
\hline $\begin{array}{l}\text { * Diferença entre Mc contr } \\
\text { † Diferença entre Mc inter } \\
\text { A Diferença de Mc control } \\
\text { B Diferença de Mc control } \\
\text { C Diferença de Mc interaça } \\
\text { D Diferença de } \mathrm{Mc} \text { interaç } \\
\text { E Diferença de } \mathrm{Cr} \text { controle } \\
\text { F Diferença de } \mathrm{Cr} \text { controle } \\
\text { G Diferença de } \mathrm{Cr} \text { interaçã } \\
\text { H Diferença de } \mathrm{Cr} \text { interaçã }\end{array}$ & $\begin{array}{l}\text { le e Mc interaçãc } \\
\text { ção e Cr interaçãc } \\
\text { entre oligotrófic } \\
\text { entre mesotrófic } \\
\text { o entre oligotrófic } \\
\text { o entre mesotrófi } \\
\text { entre oligotrófico } \\
\text { entre oligotrófico } \\
\text { entre oligotrófic } \\
\text { entre oligotrófic }\end{array}$ & $\begin{array}{l}\text { supereutrófico } \\
\text { supereutrófico } \\
\text { e mesotrófico } \\
\text { e supereutrófico } \\
\text { mesotrófico } \\
\text { supereutrófico } \\
\text { mesotrófico } \\
\text { supereutrófico }\end{array}$ & $\begin{array}{l}p=0,027 \\
p<0,007 \\
p<0,001 \\
p<0,001 \\
p=0,003 \\
p<0,001 \\
p=0,031 \\
p=0,019 \\
p=0,001 \\
p<0,001\end{array}$ & \\
\hline
\end{tabular}


Tabela 7 - Comparação dos tempos de duplicação (Td) (média com desvios padrão, $\mathrm{n}=3$ ), de M. contortum $(\mathrm{Mc})$ e C. raciborskii $(\mathrm{Cr})$, e C. raciborskii nos três ambientes simulados: oligotrófico, mesotrófico e supereutrófico

\begin{tabular}{|c|c|c|c|c|}
\hline \multirow{2}{*}{ Simulação / Tratamento } & \multicolumn{4}{|c|}{ Tempo de duplicação (dia) } \\
\hline & Mc - controle & Mc - interação & $\mathrm{Cr}$ - controle & Cr - interação \\
\hline Oligotrófico & $\begin{array}{c}1,98 \pm 0,22 \\
\mathrm{~A}\end{array}$ & $1,54 \pm 0,19$ & $2,76 \pm 1,01$ & $2,90 \pm 0,40$ \\
\hline Mesotrófico & $\begin{array}{c}1,86 \pm 0,13 \\
\mathrm{~B} \\
\end{array}$ & $\begin{array}{c}6,12 \pm 3,20 \\
D \\
\end{array}$ & $\begin{array}{c}7,55 \pm 0,81 \\
\mathrm{E} \\
\end{array}$ & $\begin{array}{c}8,90 \pm 3,64 \\
G \dagger\end{array}$ \\
\hline Supereutrófico & $1,03 \pm 0,10$ & $1,20 \pm 0,13$ & $\begin{array}{c}10,26 \pm 1,67 \\
F\end{array}$ & $\begin{array}{c}11,93 \pm 4,73 \\
\mathrm{H} \dagger\end{array}$ \\
\hline $\begin{array}{l}\text { † Diferença entre Mc inter } \\
\text { A Diferença de } \mathrm{Mc} \text { control } \\
\text { B Diferença de } \mathrm{Mc} \text { control } \\
\text { D Diferença de } \mathrm{Mc} \text { interaç } \\
\text { E Diferença de } \mathrm{Cr} \text { controle } \\
\text { F Diferença de } \mathrm{Cr} \text { controle } \\
\text { G Diferença de } \mathrm{Cr} \text { interaçã } \\
\text { H Diferença de } \mathrm{Cr} \text { interaçã }\end{array}$ & $\begin{array}{l}\text { ão e Cr interaçã } \\
\text { entre oligotrófic } \\
\text { entre mesotrófic } \\
\text { entre mesotrófi } \\
\text { ntre oligotrófico } \\
\text { ntre oligotrófico } \\
\text { entre oligotrófic } \\
\text { entre oligotrófic }\end{array}$ & $\begin{array}{l}\text { supereutrófico } \\
\text { supereutrófico } \\
\text { e supereutrófico } \\
\text { mesotrófico } \\
\text { supereutrófico } \\
\text { mesotrófico } \\
\text { supereutrófico }\end{array}$ & $\begin{array}{l}\mathrm{p}<0,017 \\
\mathrm{p}<0,001 \\
\mathrm{p}=0,002 \\
\mathrm{p}=0,040 \\
\mathrm{p}=0,007 \\
\mathrm{p}<0,001 \\
\mathrm{p}=0,047 \\
\mathrm{p}=0,040\end{array}$ & \\
\hline
\end{tabular}

Tabela 8 - Médias dos biovolumes iniciais e finais de $M$. contortum (Mc) e C. raciborskii (Cr) $\left(10^{5} \cdot \mu \mathrm{m}^{3} \cdot \mathrm{ml}^{-1}\right)$, com desvios padrão $(\mathrm{n}=3)$, nos três ambientes simulados

\begin{tabular}{cccccc}
\hline \multirow{2}{*}{ Trofia } & \multirow{5}{c}{ Beriodolume $\left(\mathbf{1 0}{ }^{5} \mathbf{\mu m}^{3} \cdot \mathbf{m r}^{-1}\right)$} \\
\cline { 2 - 6 } & & Mc controle & Mc interação & Cr controle & Cr interação \\
\hline \multirow{2}{*}{ Oligotrófico } & Inicial & $2,00 \pm 0,22$ & $2,39 \pm 0,29$ & $2,52 \pm 0,27$ & $2,72 \pm 0,16$ \\
\cline { 2 - 6 } & Final & $14,90 \pm 0,46$ & $9,53 \pm 0,12$ & $24,60 \pm 3,08$ & $1,98 \pm 0,52$ \\
\hline \multirow{2}{*}{ Mesotrófico } & Inicial & $5,93 \pm 0,23$ & $6,07 \pm 0,77$ & $6,79 \pm 0,52$ & $6,76 \pm 0,86$ \\
\cline { 2 - 6 } & Final & $125,29 \pm 1,25$ & $31,81 \pm 7,5$ & $25,92 \pm 2,96$ & $23,15 \pm 5,70$ \\
\hline \multirow{2}{*}{ Super eutrófico } & Inicial & $10,59 \pm 0,86$ & $10,47 \pm 0,88$ & $11,03 \pm 1,61$ & $10,35 \pm 0,91$ \\
\cline { 2 - 6 } & Final & $309,42 \pm 61,26$ & $129,34 \pm 9,44$ & $32,45 \pm 3,74$ & $24,61 \pm 4,80$ \\
\hline
\end{tabular}

Diante dos resultados, é possível comparar o crescimento das espécies nos três diferentes ambientes simulados. Foi observado que apenas no oligotrófico o biovolume do controle de C. raciborskii foi superior ao de M. contortum, tanto no controle quanto na interação. Nos ambientes mesotrófico e supereutrófico o biovolume do controle da clorofícea foi superior a todas as outras situações analisadas.

Comparando os biovolumes de $M$. contortum e C. raciborskii quando em interação, observou-se que em todas as simulações o da clorofícea foi superior ao da cianobactéria, apesar de no mesotrófico, no final do experimento, não ter sido encontrado diferença significativa entre o biovolume das espécies, pois $M$. contortum encontrava-se na fase estacionária e C. raciborskii na exponencial. 
Apesar disso, os biovolumes de C. raciborskii na interação não apresentaram diferenças significativas quando comparados aos seus controles, nos ambientes mesotrófico e supereutrófico, demonstrando que $M$. contortum não inibiu o crescimento desta cianobactéria em tais situações. O mesmo não ocorreu no oligotrófico, no qual a cianobactéria teve um pico de crescimento no $4^{\circ}$ dia de experimento e posteriormente iniciou a senescência ao interagir com a clorofícea.

Em compensação, analisando as curvas de crescimento de $M$. contortum, notou-se que nos três níveis de trofia houve diferença significativa no biovolume final da espécie em seu controle comparado à interação demonstrado que, de alguma forma, esta espécie teve uma inibição em seu crescimento pela competição com C. raciborskii.

Nas Tabelas 6 e 7 são apresentadas as comparações e os resultados estatísticos do teste ANOVA das velocidades específicas de crescimento e tempo de duplicação das espécies, em cada cultura, entre os diferentes ambientes simulados.

Foi observado que houve diferença entre as velocidades específicas de crescimento e o tempo de duplicação nos controles e na interação de $M$. contortum do ambiente supereutrófico com os oligotrófico e mesotrófico. As velocidades foram crescentes e os tempos de duplicação decrescentes conforme o aumento da trofia. Essa relação só não foi válida com esta espécie na interação no ambiente mesotrófico, a qual apresentou velocidade específica de crescimento maior e tempo de duplicação menor.

Quanto à velocidade específica de crescimento e tempo de duplicação de $C$. raciborskii, constatou-se que foram superiores e inferiores, respectivamente, no oligotrófico comparadas aos ambientes mesotrófico e supereutrófico, tanto no controle quanto na interação. Entre o mesotrófico e o supereutrófico não houve diferença destes parâmetros.

Embora não tenha ocorrido diferença entre esses dois últimos ambientes, observa-se que C. raciborskii nos controles e nas interações, apresentaram velocidades específicas de crescimento decrescentes em relação ao aumento da trofia e os tempos de duplicação crescentes, sendo o oposto às características de crescimento de M. contortum.

Portanto, de maneira geral, pode-se dizer que a clorofícea possui vantagens competitivas em elevado nível de trofia quanto à maior velocidade específica de crescimento, embora tenha apresentado inibição em seu crescimento em todos os ambientes simulados em competição com a C. raciborskii. Mas, quanto ao crescimento, a cianobactéria tem vantagens 
por permanecer na fase exponencial enquanto $M$. contortum encontrava-se na fase estacionária, e por não ter seu crescimento inibido quando em interação com a clorofícea.

\subsubsection{Volume celular}

Os volumes celulares das espécies em cada experimento foram comparados, entre o controle e a interação com o teste t-student para averiguar se houve diferença significativa nesta variável.

Além disso, foi verificado se houve diferença no volume celular no início, meio e fim dos experimentos (dias 0, 7 e 15), nas curvas de crescimento de $M$. contortum e $C$. raciborskii, dos controles e das interações, através do teste ANOVA, representadas por símbolos nas Tabelas 9 e 10, respectivamente.

No ambiente oligotrófico, conforme Figura 14, o volume celular de M. contortum foi semelhante entre o controle e a interação, não apresentando diferença significativa em nenhum dos dias analisados (teste $t, p>0,05$ ). Também não houve diferença do volume do início ao fim do experimento, tanto no controle quanto na interação (ANOVA, p > 0,05).

O mesmo não ocorreu com C. raciborskii, na qual foi observada uma diminuição significativa do volume celular da espécie na interação do $6^{\circ}$ ao $10^{\circ}$ dia do experimento $(\mathrm{p}<$ 0,001 no $6^{\circ}, 7^{\circ}$ e $9^{\circ}$ dia e $\mathrm{p}=0,003$ no $10^{\circ}$ ) comparada ao controle. A partir do $12^{\circ}$ dia, houve diminuição também do volume celular da cianobactéria no controle, e de acordo com as curvas de crescimento deste experimento, foi notado que o biovolume do controle de $C$. raciborskii no oligotrófico (Figura 11) foi superior às demais situações. Além disso, no $7^{\circ}$ dia, o controle da cianobactéria obteve volume celular significativamente maior comparado aos dias 0 e 15 .

A redução no biovolume da cianobactéria na interação a partir do $6^{\circ}$ dia ocorreu devido à significativa diminuição do volume celular, pois a espécie obteve aumento da sua densidade até o $9^{\circ}$ dia, o que indica uma hipótese de estratégia de sobrevivência desta espécie em competição com a outra.

Ao contrário do que ocorreu na situação anterior, os volumes celulares das espécies na simulação do mesotrófico, apresentados na Figura 15, demonstraram que C. raciborskii não apresentou diferenças significativas em seu controle comparado à interação. Também não ocorreu essa diferença durante os dias de análise, do início ao fim do experimento na 

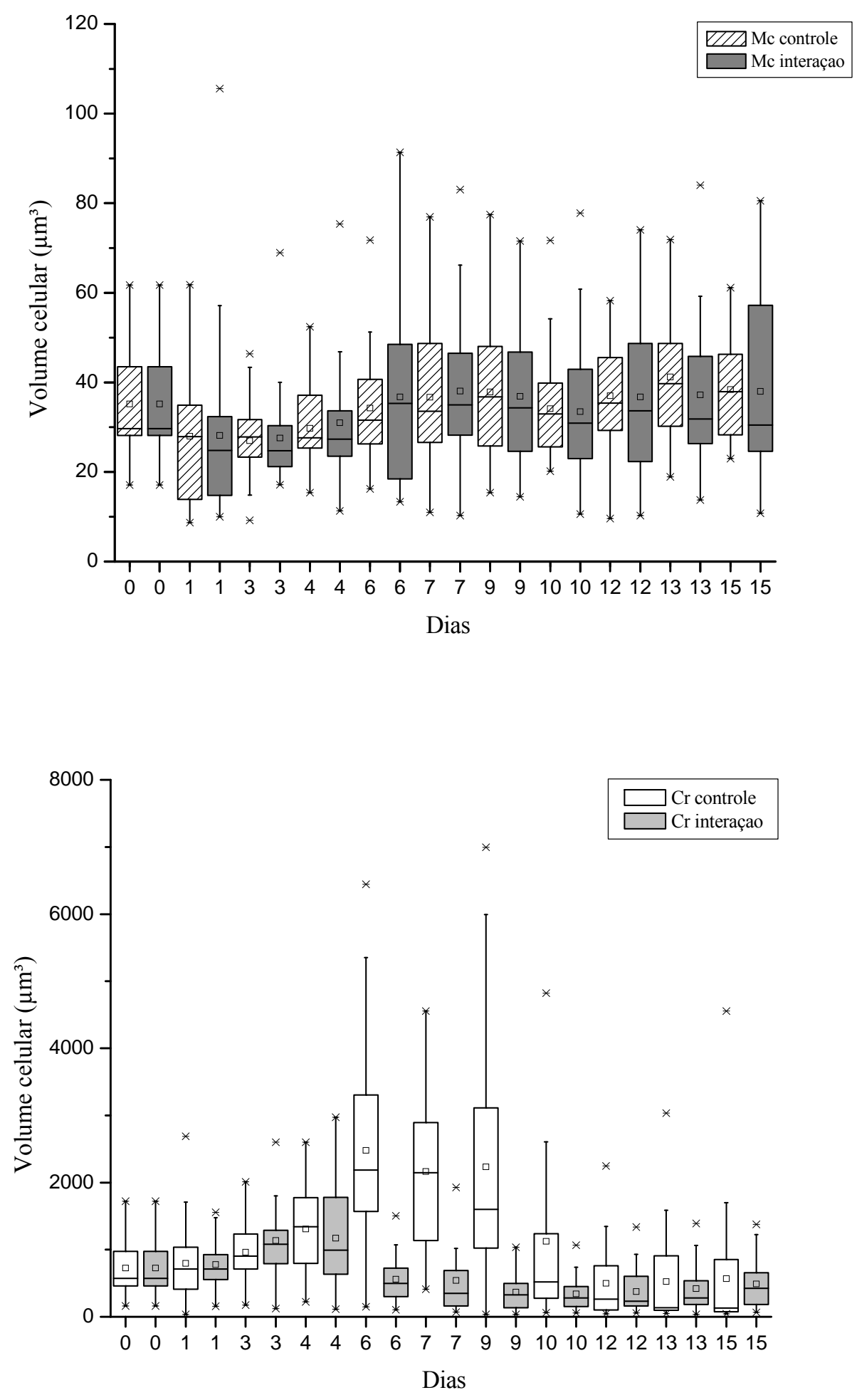

Figura 14: Média dos volumes celulares $\left(\mu \mathrm{m}^{3}\right)$ de M. contortum (Mc) e C. raciborskii $(\mathrm{Cr})$ na simulação do ambiente oligotrófico. " $\mathrm{x}$ " indica máximo e mínimo, retângulo a maior concentração dos volumes e $\square$ dentro do retângulo a média do volume celular $(\mathrm{n}=3)$. 
interação, e no controle, o volume celular no dia 15 foi significativamente maior do que no dia $0(p=0,034$, Tabela 10).

O volume celular do controle de $M$. contortum no $1^{\mathrm{o}}$ dia do experimento foi significativamente menor do que na interação, o que pode ser justificado pelo controle ter tido velocidade específica de crescimento maior $(\mathrm{p}=0,027)$ e tempo de duplicação menor $(\mathrm{p}=$ 0,08) (Tabelas 6 e 7). Além disso, o volume celular no controle da clorofícea encontrou-se significativamente maior no $15^{\circ}$ dia comparada aos dias 0 e 7 (Tabela 9).

Houve também diferença significativa do volume celular da clorofícea nos dois últimos dias de análise, $13^{\circ}$ e $15^{\circ}$, nos quais esta espécie se apresentou com menor volume na interação ( $\mathrm{p}=0,046 \mathrm{e} \mathrm{p}=0,031$, respectivamente). Uma hipótese para essa diminuição do volume celular é devido à competição com $C$. raciborskii, pois não apresentaram diferenças significativas em suas curvas de crescimento na interação nestes dias, conforme analisado anteriormente (Figura 12).

Quanto ao supereutrófico, os volumes celulares estão representados na Figura 16. Não houve diferença significativa entre os volumes celulares de C. raciborskii no controle e na interação nos dias de análise, semelhante ao ocorrido no ambiente mesotrófico. É importante ressaltar que, no $9^{\circ}$ dia de experimento, houve uma diminuição do volume desta espécie na interação próxima ao considerado significativo $(p<0,05)$, com $p=0,069$, o que confirmou a única diferença significativa encontrada entre as curvas de crescimento por biovolume do controle e da interação, conforme demonstrado na Figura13.

Posteriormente a este dia, houve diminuição também do volume celular desta espécie no controle, voltando a aumentar no último dia do experimento, tanto no controle quanto na interação.

Em relação ao volume celular de $M$. contortum, este foi significativamente menor na interação, comparado ao seu controle, a partir do $10^{\circ}$ dia até o final do experimento $(\mathrm{p}=$ $0,003, \mathrm{p}=0,014, \mathrm{p}=0,002$, e $\mathrm{p}=0,007$, respectivamente), sendo que no $9^{\circ}$ dia apresentou diferença próxima ao considerado significativo $(\mathrm{p}=0,056)$, indicando uma provável modificação morfológica devido à competição com a cianobactéria. 

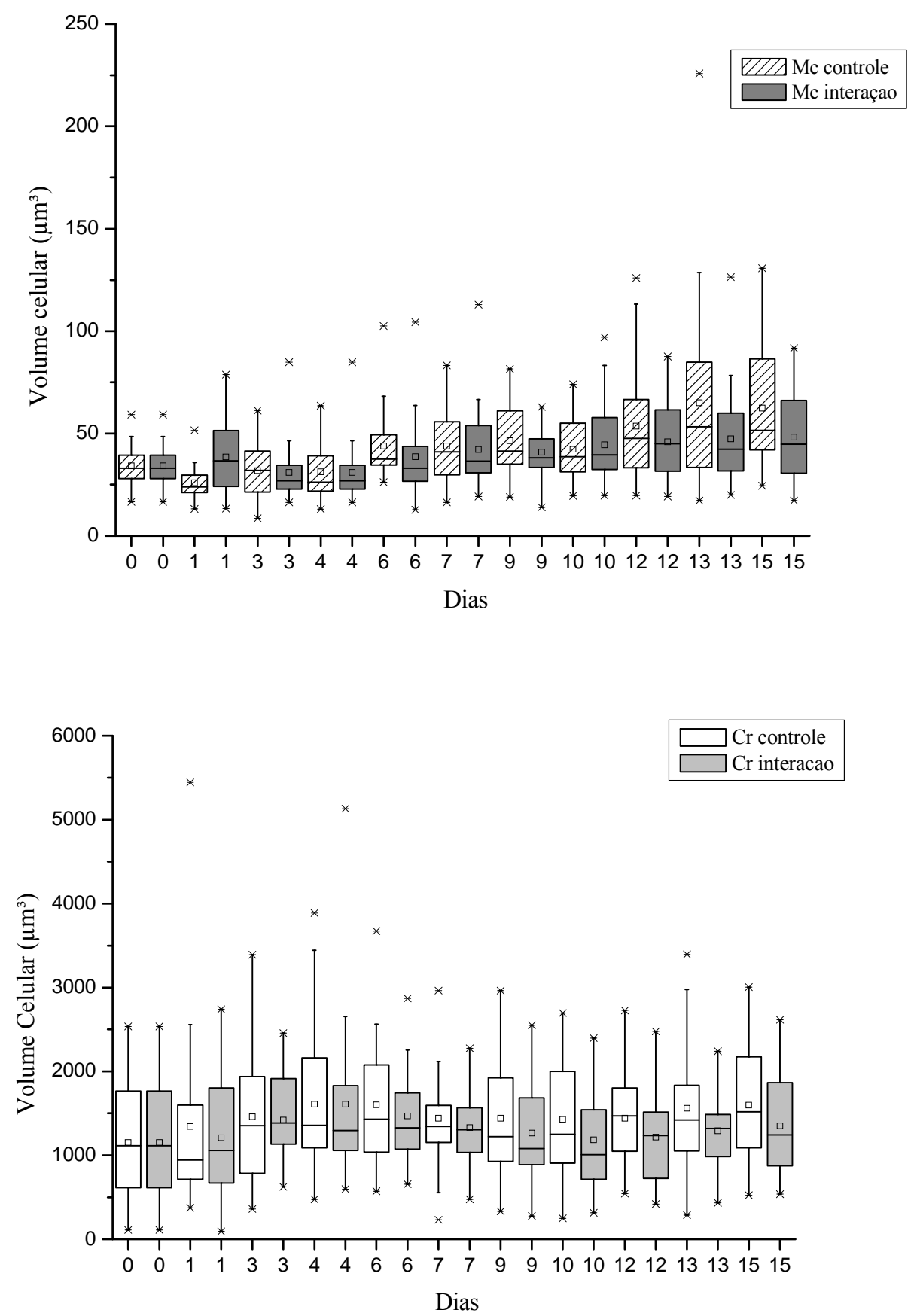

Figura 15: Média dos volumes celulares $\left(\mu \mathrm{m}^{3}\right)$ de $M$. contortum $(\mathrm{Mc})$ e C. raciborskii $(\mathrm{Cr})$ na simulação do ambiente mesotrófico. " $x$ " indica máximo e mínimo, retângulo a maior concentração dos volumes e $\square$ dentro do retângulo a média do volume celular $(\mathrm{n}=3)$. 

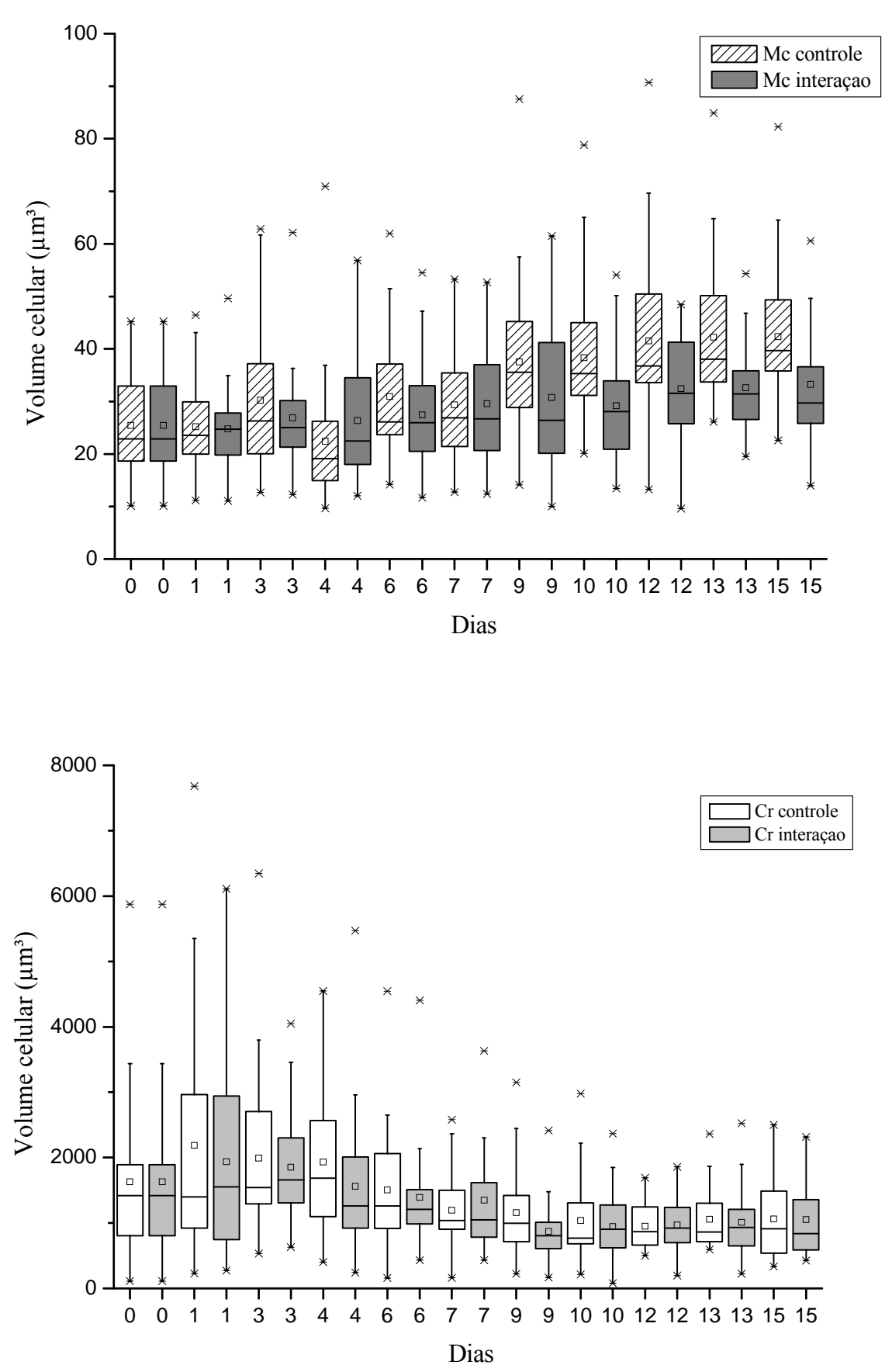

Figura 16: Média dos volumes celulares $\left(\mu \mathrm{m}^{3}\right)$ de $M$. contortum $(\mathrm{Mc})$ e C. raciborskii $(\mathrm{Cr})$ na simulação do ambiente supereutrófico. " $\mathrm{x}$ " indica máximo e mínimo, retângulo a maior concentração dos volumes $\mathrm{e} \square$ dentro do retângulo a média do volume celular $(\mathrm{n}=3)$.

Comparando o controle da clorofícea ao longo do experimento, o dia 15 apresentou volume significativamente maior do que os dias 0 e 7 , e na interação essa diferença só foi observada entre os dias 0 e 15 (Tabela 9). 
No controle, C. raciborskii apresentou diminuição significativa no volume celular entre os dias 0 e 15, sendo maior no início do experimento (Tabela 10). Por outro lado, na interação desta espécie não foi observada diferença significativa em seu volume celular do início ao fim do experimento.

Conforme já constatado nas análises de crescimento, os dados de volume celular reforçam as evidências de que C. raciborskii não teve seu desenvolvimento prejudicado quando em interação com $M$. contortum nas condições mesotrófica e supereutrófica, pois o volume celular da cianobactéria não apresentou diferença significativa entre o controle e a interação. Quanto à $M$. contortum, houve diferença no volume celular entre o controle e a interação nesses dois níveis de trofia, confirmando que a clorofícea teve seu crescimento afetado por C. raciborskii.

Para averiguar se houve diferença dos volumes celulares nos diferentes níveis de trofia, foi feita uma comparação a partir do teste ANOVA entre os controles e entre as interações de cada espécie, em três dias no decorrer do experimento, 0, 7 e 15, exemplificando as diferenças dos volumes celulares no início, meio e fim do experimento. Nas Tabelas 9 e 10 estão representadas as diferenças, com letras, de $M$. contortum e de C. raciborskii, respectivamente.

De maneira geral, quanto ao M. contortum, as diferenças estiveram: nos volumes celulares inicias, dos quais os ambientes oligotrófico e mesotrófico apresentaram volumes significativamente maiores ao supereutrófico, nos controle e na interação; o volume celular do controle de $M$. contortum no mesotrófico foi significativamente maior do que nos outros dois níveis de trofia no final do experimento, dia 15. Na interação essa diferença ocorreu apenas entre o mesotrófico e o supereutrófico, nos dias 7 e 15 (Tabela 9).

No controle de C. raciborskii, o volume celular no $7^{\circ}$ dia foi significativamente maior no oligotrófico comparado aos outros dois níveis de trofia, mas no final do experimento o volume da cianobactéria no ambiente oligotrófico foi significativamente menor comparado ao mesotrófico e supereutrófico. O volume celular do ambiente mesotrófico também foi maior comparado ao supereutrófico. 
Tabela 9 - Médias, com desvios padrão $(\mathrm{n}=3)$, dos volumes celulares de $M$. contortum nos controles e nas interações, nos dias 0,7 e 15 , nos ambientes simulados

\begin{tabular}{|c|c|c|c|c|c|c|}
\hline \multicolumn{7}{|c|}{ Volume celular $M$. contortum $\left(\mu^{3}\right)$} \\
\hline \multicolumn{7}{|c|}{ Controle } \\
\hline Trofia / Dias & $\mathbf{0}$ & & 7 & & 15 & \\
\hline Oligotrófico & $35,14 \pm 11,84$ & $\mathrm{~A}$ & $36,66 \pm 14,34$ & & $38,37 \pm 10,46$ & \\
\hline Mesotrófico & $34,23 \pm 9,38$ & $\mathrm{~B}$ & $43,88 \pm 16,74$ & $\mathrm{C}$ & $62,39 \pm 28,56$ & $* \dagger \mathrm{DE}$ \\
\hline Supereutrófico & $25,41 \pm 9,37$ & & $29,36 \pm 9,81$ & & $42,31 \pm 12,58$ & $* \dagger$ \\
\hline \multicolumn{7}{|c|}{ Interação } \\
\hline Trofia / Dias & $\mathbf{0}$ & & 7 & & 15 & \\
\hline Oligotrófico & $35,14 \pm 11,84$ & $\mathrm{a}$ & $38,02 \pm 16,15$ & & $37,98 \pm 19$ & \\
\hline Mesotrófico & $34,23 \pm 9,38$ & $\mathrm{~b}$ & $42,17 \pm 18,58$ & $\mathrm{c}$ & $48,17 \pm 20,57$ & $* \mathrm{e}$ \\
\hline Supereutrófico & $25,41 \pm 9,37$ & & $29,59 \pm 10,69$ & & $33,23 \pm 12,52$ & $*$ \\
\hline \multicolumn{5}{|c|}{ *Diferença entre dias 0 e 15} & $\mathrm{p}<0,019$ & \\
\hline \multicolumn{5}{|c|}{ † Diferença entre dias 7 e 15} & $\mathrm{p}<0,001$ & \\
\hline \multicolumn{5}{|c|}{ A; a Diferença entre dia 0 do oligotrófico e 0 do supereutrófico } & $\mathrm{p}=0,001$ & \\
\hline \multicolumn{5}{|c|}{ B; b Diferença entre dia 0 do mesotrófico e 0 do supereutrófico } & $\mathrm{p}=0,004$ & \\
\hline \multicolumn{5}{|c|}{ C; c Diferença entre dia 7 do mesotrófico e 7 do supereutrófico } & $\mathrm{p}<0,006$ & \\
\hline \multicolumn{5}{|c|}{ D Diferença entre dia 15 do oligotrófico e 15 do mesotrófico } & $\mathrm{p}<0,001$ & \\
\hline \multicolumn{5}{|c|}{ E; e Diferença entre dia 15 do mesotrófico e 15 do supereutrófico } & $\mathrm{p}<0,004$ & \\
\hline
\end{tabular}

Tabela 10 - Médias, com desvios padrão $(n=3)$, dos volumes celulares de C. raciborskii nos controles e nas interações, nos dias 0,7 e 15, nos ambientes simulados

\begin{tabular}{|c|c|c|c|}
\hline \multicolumn{4}{|c|}{ Volume celular C. raciborskii $\left(\mu^{3}\right)$} \\
\hline \multicolumn{4}{|c|}{ Controle } \\
\hline Trofia / Dias & $\mathbf{0}$ & 7 & 15 \\
\hline Oligotrófico & $725,73 \pm 390,82$ & $2164,3 \pm 1095,65 \#+B$ C & $570,11 \pm 963,44$ \\
\hline Mesotrófico & $1155,12 \pm 690,68$ & $1443,21 \pm 620,93$ & $1599,34 \pm 714,17 * \mathrm{DF}$ \\
\hline Supereutrófico & $1631,22 \pm 1295,56 * \mathrm{~A}$ & $1194 \pm 586,61$ & $1061,31 \pm 573,77 \mathrm{E}$ \\
\hline \multicolumn{4}{|c|}{ Interação } \\
\hline Trofia / Dias & $\mathbf{0}$ & 7 & 15 \\
\hline Oligotrófico & $725,73 \pm 390,82$ & $542,36 \pm 504,6$ & $488,90 \pm 378,87$ \\
\hline Mesotrófico & $1155,12 \pm 690,68$ & $1330,96 \pm 440,4 \mathrm{~b}$ & $1350,33 \pm 553,27 \mathrm{~d}$ \\
\hline Supereutrófico & $1631,22 \pm 1295,56 \mathrm{a}$ & $1347,70 \pm 838,7 \mathrm{c}$ & $1053,77 \pm 575,37 \mathrm{e}$ \\
\hline \multicolumn{3}{|c|}{ \# Diferença entre dia 0 e 7} & 0,001 \\
\hline \multicolumn{3}{|c|}{ *Diferença entre dias 0 e 15} & 0,038 \\
\hline \multicolumn{3}{|c|}{$†$ Diferença entre dias 7 e 15} & 0,001 \\
\hline \multicolumn{3}{|c|}{ A; a Diferença entre dia 0 do oligotrófico e 0 do supereutrófico } & 0,001 \\
\hline \multicolumn{3}{|c|}{ B; b Diferença entre dia 7 do oligotrófico e 7 do mesotrófico } & $<0,002$ \\
\hline \multicolumn{3}{|c|}{ C; c Diferença entre dia 7 do oligotrófico e 7 do supereutrófico } & $<0,001$ \\
\hline \multicolumn{3}{|c|}{ D; d Diferença entre dia 15 do oligotrófico e 15 do mesotrófico } & 0,001 \\
\hline \multicolumn{3}{|c|}{ E; e Diferença entre dia 15 do oligotrófico e 15 do supereutrófico } & $=0,040$ \\
\hline \multicolumn{3}{|c|}{ F Diferença entre dia 15 do mesotrófico e 15 do supereutrófico } & 0,022 \\
\hline
\end{tabular}

$\mathrm{Na}$ interação ocorreu ao contrário do controle de C. raciborskii no $7^{\circ}$ dia, pois o volume celular desta espécie foi significativamente menor no ambiente oligotrófico comparado aos outros (Tabela 10). No dia 15, o ocorrido com o controle foi semelhante à interação, não havendo diferenças apenas nos volumes celulares entre os ambientes mesotrófico e supereutrófico. 
Em relação à morfologia, nos três níveis tróficos simulados, $M$. contortum não apresentou diferenças, e C. raciborskii apresentou diferenças apenas no comprimento do filamento, não apresentou acinetos e heterocistos, exceto no supereutrófico, no qual esta cianobactéria apresentou, em alguns indivíduos, heterocistos. As fotos das espécies podem ser observadas nos apêndices A, B e C, representando os ambientes oligotrófico, mesotrófico e supereutrófico, respectivamente.

\subsubsection{Clorofila-a}

As análises de clorofila-a foram realizadas a partir de amostras coletadas do bloco 2 (Figura 7), em triplicata, de três em três dias, conforme descrito no item 4.7. As análises estatísticas foram realizadas para comparar a concentração de clorofila-a da soma dos controles com a concentração da interação através do teste t-student.

$\mathrm{Na}$ simulação do ambiente oligotrófico, os resultados das concentrações médias da clorofila-a controle e da interação estão apresentados na Figura 17. Comparando estes resultados com as curvas de crescimento, Figura 11, observou-se que a concentração de clorofila-a foi baixa, correspondendo ao baixo crescimento das espécies neste grau de trofia, exceto o controle da cianobactéria, que apresentou maior crescimento.

No dia 0 de experimento, verificou-se que a clorofila-a da interação $\left(7,44 \mu \mathrm{g} . \mathrm{L}^{-1}\right)$ foi igual à soma do resultado do controle de C. raciborskii $\left(1,86 \mu \mathrm{g} . \mathrm{L}^{-1}\right)$ e de $M$. contortum $(5,58$ $\left.\mu \mathrm{g} . \mathrm{L}^{-1}\right)$, confirmando que os inóculos iniciais foram semelhantes.

Apesar de haver diferença significativa do biovolume em alguns pontos na comparação das curvas entre os controles e entre as interações das duas espécies, o mesmo não foi observado para a clorofila-a, não havendo diferença significativa entre a soma dos controles e a interação em nenhum dos dias analisados. O que pode ter ocorrido é a compensação da redução do volume celular de C. raciborskii com o aumento da concentração de clorofila-a em suas células, sendo imperceptível a senescência desta espécie caso o monitoramento da biomassa tivesse sido realizado apenas por este parâmetro.

A concentração de clorofila-a controle atingiu seu máximo no $6^{\circ}$ dia $\left(17,19 \mu\right.$ g.L $\left.\mathrm{L}^{-1}\right)$ que, quando comparadas às curvas de crescimento, correspondeu à fase exponencial dos controles de $M$. contortum e de C. raciborskii. Posteriormente, nos dias 9 e 12 as 
concentrações de clorofila-a foram praticamente constantes com $15,81 \mu \mathrm{g} . \mathrm{L}^{-1}$ e $16,74 \mu \mathrm{g} . \mathrm{L}^{-1}$, respectivamente, havendo diminuição no $15^{\circ}$ dia de experimento.

$\mathrm{Na}$ interação, a concentração máxima de clorofila-a ocorreu no $9^{\circ}$ dia, de $18,12 \mu \mathrm{g} . \mathrm{L}^{-1}$, e a partir do $12^{\circ}$ dia diminuiu, provavelmente, devido ao envelhecimento das células, redução do biovolume das duas espécies e senescência de C. raciborskii.

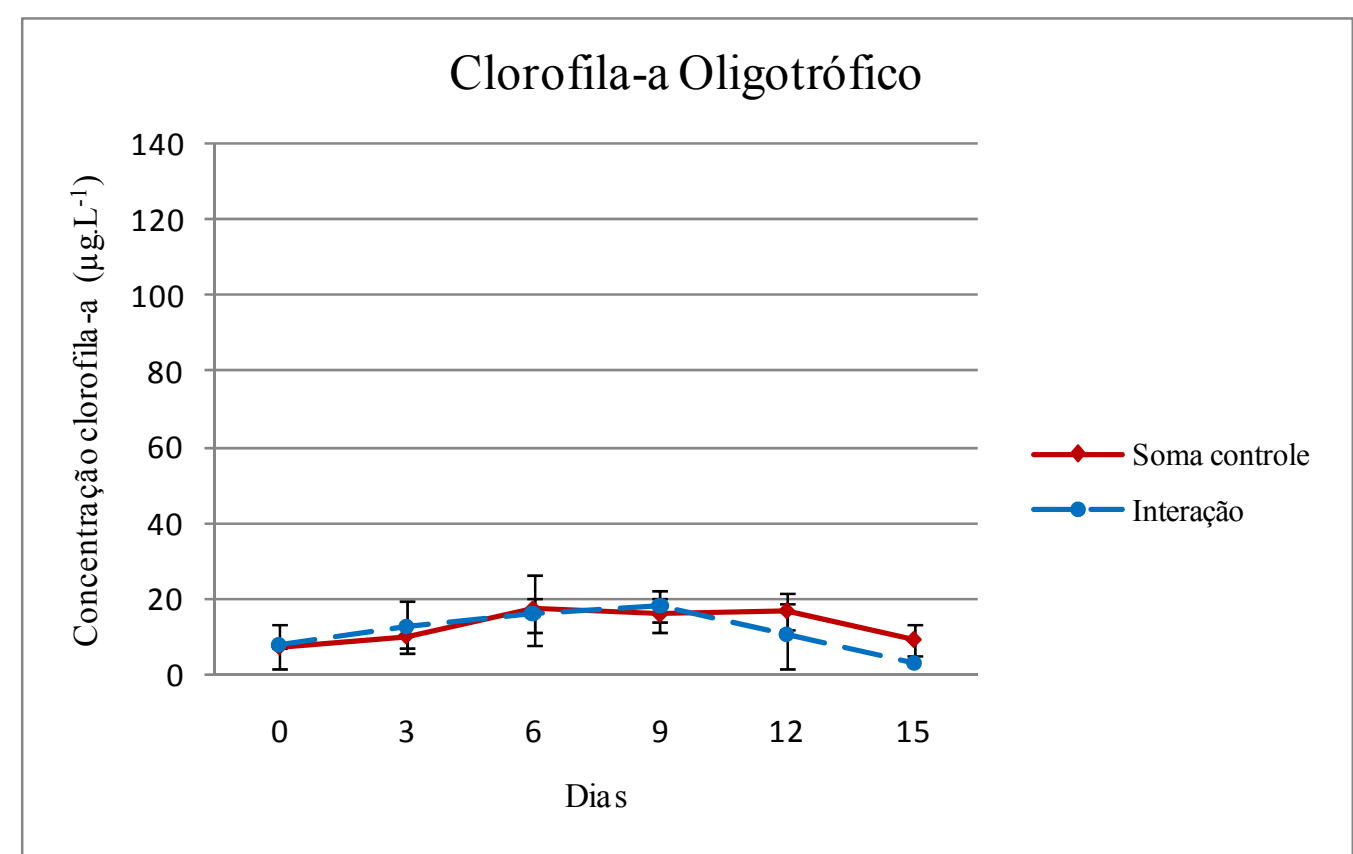

Figura 17: Média da concentração de clorofila-a $\left(\mu \mathrm{g} . \mathrm{L}^{-1}\right)$ da soma dos controles, $M$. contortum e C. raciborskii, e da interação, na simulação do ambiente oligotrófico. As barras verticais indicam o desvio padrão $(n=3)$.

Quanto à simulação do mesotrófico, as médias das concentrações de clorofila-a estão apresentadas na Figura 18. No início do experimento, dia 0, a concentração da interação $\left(11,16 \mu \mathrm{g} . \mathrm{L}^{-1}\right)$ foi igual à soma dos resultados do controle de C. raciborskii $\left(2,79 \mu \mathrm{g} . \mathrm{L}^{-1}\right)$ e de M. contortum $\left(8,37 \mu \mathrm{g} . \mathrm{L}^{-1}\right)$, provando que os inóculos iniciais foram idênticos.

A concentração de clorofila-a dos controles comparadas com a interação foram significativamente maiores a partir do $3^{\circ}$ dia de análise, até o final do experimento $(\mathrm{p}<0,01$ para todos os dias com diferença significativa).

Comparando este dado com as curvas de crescimento, notou-se que, C. raciborskii cresceu igual no controle e na interação, enquanto $M$. contortum cresceu menos na interação comparado ao seu controle. Isso poderia justificar a maior concentração de clorofila-a dos controles em relação à da interação. 


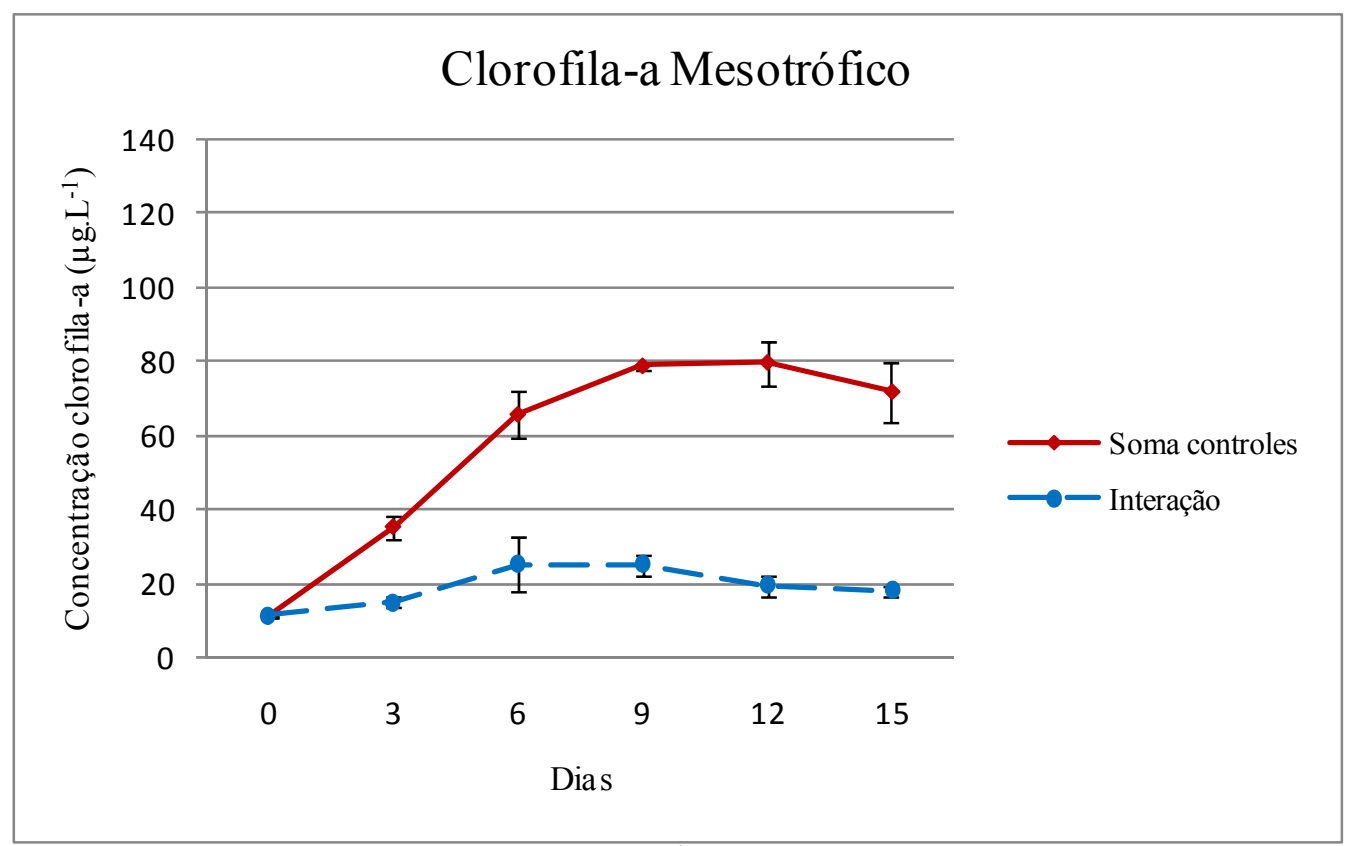

Figura 18: Média da concentração de clorofila-a $\left(\mu \mathrm{g} . \mathrm{L}^{-1}\right)$ da soma dos controles, $M$. contortum e C. raciborskii, e da interação, na simulação do ambiente mesotrófico. As barras verticais indicam o desvio padrão $(\mathrm{n}=3)$.

As concentrações máximas de clorofila-a dos controles ocorreram no $9^{\circ}$ e $12^{\circ}$ dias (78,57 $\mu \mathrm{g} . \mathrm{L}^{-1}$ e 79,49 $\mu \mathrm{g} . \mathrm{L}^{-1}$, respectivamente), que correspondeu ao período da fase estacionária de $M$. contortum e da fase exponencial de C. raciborskii. No $15^{\circ}$ dia de experimento, foi observada redução na concentração de clorofila-a, embora as espécies, nos controles e na interação, tenham atingindo biovolume máximo neste dia.

$\mathrm{Na}$ interação, as concentrações máximas da clorofila-a ocorreram no $6^{\circ}$ e $9^{\circ}$ dias de experimento, com 25,11 $\mu \mathrm{g} . \mathrm{L}^{-1}$, e decaiu no $12^{\circ}$ dia. Apesar de na interação a concentração máxima de clorofila-a e a diminuição da mesma terem sido antecipadas em relação à dos controles, não foi observado relação deste parâmetro com as velocidades específicas de crescimento. No controle de $M$. contortum a velocidade foi maior e o tempo de duplicação menor comparada à esta mesma espécie na interação, embora o mesmo não tenha ocorrido para C. raciborskii, não havendo diferença nas velocidades específicas de crescimento entre o seu controle e a interação.

As menores concentrações de clorofila-a observadas na interação comprovaram que M. contortum teve seu crescimento prejudicado, já que não foi observada diferença entre o controle e a interação de C. raciborskii nas curvas de crescimento, ao contrário do que ocorreu com M. contortum, com biovolume significativamente menor na interação comparado ao seu controle. 
$\mathrm{Na}$ simulação do supereutrófico, as concentrações de clorofila-a são apresentadas na Figura 19. As concentrações de clorofila-a foram mais elevadas e a diminuição delas foi antecipada se comparada às outras duas simulações de trofia. As concentrações de clorofila-a dos controles foram significativamente maiores do que as da interação desde o $3^{\circ}$ dia até o último dia de experimento $(0,05<\mathrm{p}>0,001 \mathrm{em}$ todos os dias com diferença significativa).

Além disso, como não foi encontrada diferença entre as curvas de crescimento no controle e na interação de C. raciborskii demonstrou-se que, da mesma forma que no mesotrófico, as menores concentrações de clorofila-a na interação deveram-se ao menor crescimento de $M$. contortum devido à diferença observada nas suas curvas, o que também justificaria a concentração de clorofila-a dos controles ter sido superior à da interação.

No início do experimento, a concentração da clorofila-a na interação foi de 16,74 $\mu \mathrm{g} . \mathrm{L}^{-1}$, igual à soma das concentrações do controle de C. raciborskii, $4,19 \mu \mathrm{g} . \mathrm{L}^{-1}$ e de $M$. contortum, 12,56 $\mu \mathrm{g} . \mathrm{L}^{-1}$, confirmando que os inóculos iniciais foram semelhantes.

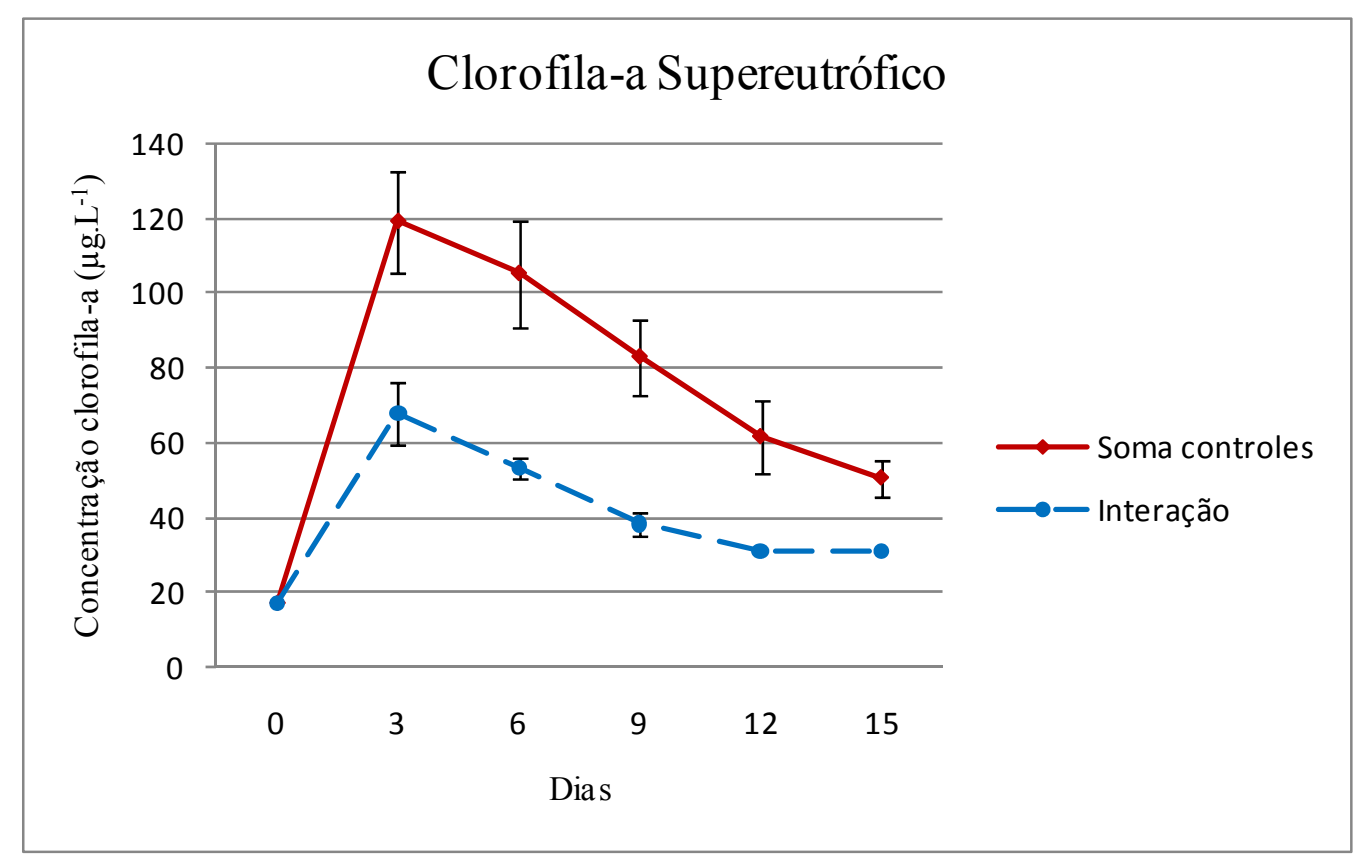

Figura 19: Média da concentração de clorofila-a $\left(\mu \mathrm{g} . \mathrm{L}^{-1}\right)$ da soma dos controles, $M$. contortum e C. raciborskii, e da interação, na simulação do ambiente supereutrófico. As barras verticais indicam o desvio padrão $(n=3)$.

Os controles e a interação atingiram o pico máximo de concentração de clorofila-a no $3^{\text {o }}$ dia do experimento, com $119,04 \mu \mathrm{g} . \mathrm{L}^{-1}$ e $67,89 \mu \mathrm{g} . \mathrm{L}^{-1}$, respectivamente, e a partir do $6^{\circ}$ até o fim do experimento, as concentrações diminuíram, embora, as espécies, tanto nos controles quanto na interação, tenham atingido o seu maior biovolume no $15^{\circ}$ dia de experimento. 
Os picos de clorofila-a no $3^{\circ}$ dia de experimento do supereutrófico podem ter ocorrido devido à velocidade específica de crescimento de $M$. contortum, tanto no controle quanto na interação, terem sido significativamente maiores neste nível trófico comparados ao oligotrófico e mesotrófico ( $\mathrm{p}<0,001$ ), exceto na comparação entre as velocidades na interação dos ambientes oligotrófico e supereutrófico $(p=0,12)$ (Tabelas 9 e 10).

De acordo com o relatado, algumas observações puderam ser feitas para este parâmetro comparando os três diferentes níveis de trofia simulados, apesar de terem inóculos iniciais diferentes quanto ao biovolume das espécies.

As concentrações de clorofila-a comprovaram os resultados obtidos nas velocidades específicas de crescimento de $M$. contortum, tanto no controle quanto na interação, as quais demonstraram que no supereutrófico esta espécie cresceu mais rapidamente do que nos outros experimentos. Além disso, as menores concentrações de clorofila-a na interação, no mesotrófico e no supereutrófico, estiveram relacionadas, provavelmente, ao menor crescimento de M. contortum.

Foi possível observar também que $C$. raciborskii apresentou concentrações menores de clorofila-a comparadas a $M$. contortum, pois nos três ambientes simulados, as duas espécies tiveram biovolumes iniciais semelhantes, e no primeiro dia de análise de clorofila-a, foi possível notar que as concentrações de clorofila-a da cianobactéria foram menores do que as da clorofícea.

Houve semelhança também em todos os experimentos quanto à diminuição da concentração da clorofila-a, uns mais tardiamente do que outros. Uma hipótese para esta ocorrência foi o envelhecimento das células e consequente diminuição da concentração de clorofila-a, pois a quantidade de pigmento das células não necessariamente correspondeu às suas curvas de crescimento, já que, dependendo das condições nutricionais e do tempo, as células envelhecem, perdem pigmentação e consequentemente, diminuem a sua capacidade fotossintética.

Outros fatores que podem estar relacionados à síntese e diminuição das concentrações de clorofila-a, nas três simulações de trofia, são as concentrações de nitrato e ortofosfato.

\subsubsection{Nutrientes}

Foram feitas análises para nitrato e ortofosfato, que representaram as formas de nitrogênio e fósforo, respectivamente, disponíveis para assimilação dos microrganismos. As 
análises dos nutrientes foram feitas a partir de coletas dos Erlenmeyers do bloco 2, conforme Figura 7, de três em três dias.

Os resultados apresentados são médias com desvios padrão e os testes estatísticos foram realizados para comparar o consumo dos nutrientes entre os dias para cada cultura (diferença representada por letras minúsculas) e o consumo pelas três diferentes culturas, controles e interação, em cada dia em que foi realizada a análise (diferença representada por símbolos). Posteriormente, foi realizada uma comparação do consumo dos dois nutrientes nos diferentes níveis de trofia simulados (diferença representada por letras maiúsculas).

\subsubsection{Ortofosfato}

As concentrações iniciais estabelecidas para o ortofosfato foram $3,3 \mu \mathrm{g} . \mathrm{L}^{-1}, 8,8 \mu \mathrm{g} . \mathrm{L}^{-1}$ e 35,3 $\mu \mathrm{g} . \mathrm{L}^{-1}$, para simulação dos ambientes oligotrófico, mesotrófico e supereutrófico, respectivamente. Apesar desta definição e da aclimatação prévia das culturas, nem sempre foi possível obter concentrações de nutrientes iniciais idênticas em todas as culturas (controles e interação). Uma hipótese para explicar tais diferenças iniciais foi a interferência das concentrações pré-existentes nos inóculos e repiques que antecederam os experimentos e, além disso, por as concentrações de ortofosfato, no decorrer dos experimentos, apresentaramse abaixo do limite de detecção do método $\left(10 \mu \mathrm{g} . \mathrm{L}^{-1}\right)$.

No oligotrófico, as concentrações de ortofosfato nos controles e interação foram semelhantes, havendo diferença estatística apenas entre o controle de C. raciborskii e a interação, com maior concentração no primeiro. Os resultados podem ser observados na Tabela 11.

Notou-se que o ortofosfato diminuiu nos controles e na interação no mesmo período. Logo no $3^{\circ}$ dia do experimento houve redução significativa deste nutriente que, posteriormente, permaneceu praticamente constante, tanto nos controles quanto na interação (Tabela 11). As menores concentrações ocorreram no $9^{\circ}$ dia para o controle de C. raciborskii e a interação, e no $3^{\circ}$ dia no controle de $M$. contortum.

A diferença que se observou foi que houve um menor consumo no controle de $C$. raciborskii comparado à interação do início até o $12^{\circ}$ dia de experimento. Essa diferença pode estar relacionada com o controle da cianobactéria ter tido no início concentração de ortofosfato acima dos demais, ou também, pelo consumo na interação ser maior devido à presença de duas espécies. 
$\mathrm{Na}$ interação, verificou-se também, que o consumo pelo nutriente se iniciou logo nas primeiras horas do experimento, pois a concentração foi menor do que a proposta inicial. O consumo mais rápido na interação pode estar relacionado à velocidade específica de crescimento de $M$. contortum ser maior do que a de seu controle, apesar de não haver diferenças significativas entre as velocidades, embora o p seja próximo ao considerado significativo $(\mathrm{p}=0,053)$.

Tabela 11 - Médias, com desvios padrão $(n=3)$, das concentrações de ortofosfato $\left(\mu \mathrm{g} . \mathrm{L}^{-1}\right)$ da simulação do ambiente oligotrófico, nas culturas (Cult.) controle de C. raciborskii $(\mathrm{Cr}-$ cont.), controle de $M$. contortum (Mc - cont.) e interação

\begin{tabular}{|c|c|c|c|c|c|c|}
\hline Cult./Dias & $\mathbf{0}$ & 3 & 6 & 9 & 12 & 15 \\
\hline Cr - cont. & $\begin{array}{c}3,91 \pm 0,43 \\
* \mathrm{a}\end{array}$ & $\begin{array}{c}1,47 \pm 0,13 \\
* \S\end{array}$ & $\begin{array}{c}1,68 \pm 0,11 \\
*\end{array}$ & $\begin{array}{c}1,42 \pm 0,22 \\
*\end{array}$ & $\begin{array}{c}1,7 \pm 0,31 \\
*\end{array}$ & $1,55 \pm 0,11$ \\
\hline Mc - cont. & $\begin{array}{c}3,22 \pm 0,33 \\
\mathrm{a} \\
\end{array}$ & $0,74 \pm 0,25$ & $1,10 \pm 0,40$ & $0,92 \pm 0,13$ & $1,3 \pm 0,32$ & $1,18 \pm 0,15$ \\
\hline Interação & $\begin{array}{c}2,38 \pm 0,27 \\
a\end{array}$ & $0,81 \pm 0,31$ & $0,83 \pm 0,36$ & $0,53 \pm 0,24$ & $0,86 \pm 0,25$ & $0,82 \pm 0,50$ \\
\hline $\begin{array}{l}\text { Diferença } \\
\text { Diferença e }\end{array}$ & $\begin{array}{l}\text { tre controle } \\
\text { ttre controle } \\
\text { tre dia } 0 \text { con }\end{array}$ & dos os or & lias & & $\begin{array}{l}\mathrm{p}<0,0 \\
\mathrm{p}<0,0 \\
\mathrm{p}<0,0\end{array}$ & \\
\hline
\end{tabular}

Da mesma forma que no oligotrófico, as concentrações de ortofosfato no mesotrófico não foram inicialmente iguais em todos os Erlenmeyers, havendo diferença significativa do controle de $M$. contortum com o controle da cianobactéria e com a interação, sendo maior a concentração neste primeiro. Os resultados estão apresentados na Tabela 12.

As concentrações de ortofosfato foram significativamente maiores no início do experimento quando comparados à todos os outros dias nos controles das duas espécies e na interação, havendo diminuição desde o $3^{\circ}$ dia, permanecendo com valores semelhantes e praticamente constantes até o dia 15 do experimento. 
Tabela 12 - Médias, com desvios padrão $(n=3)$, das concentrações de ortofosfato $\left(\mu \mathrm{g} . \mathrm{L}^{-1}\right)$ da simulação do ambiente mesotrófico, nas culturas (Cult.) controle de C. raciborskii $(\mathrm{Cr}-$ cont.), controle de M. contortum (Mc - cont.) e interação

\begin{tabular}{|c|c|c|c|c|c|c|}
\hline Cult./Dias & $\mathbf{0}$ & 3 & 6 & 9 & 12 & 15 \\
\hline \multirow{2}{*}{ Cr - cont. } & $7,2 \pm 0,43$ & \multirow{2}{*}{$1,22 \pm 0,32$} & \multirow{2}{*}{$1,33 \pm 0,54$} & \multirow{2}{*}{$1,18 \pm 0,87$} & \multirow{2}{*}{$0,7 \pm 0,41$} & \multirow{2}{*}{$1,72 \pm 0,51$} \\
\hline & $\mathrm{a}$ & & & & & \\
\hline \multirow{2}{*}{ Mc - cont. } & $10,78 \pm 0,83$ & \multirow{2}{*}{$1,02 \pm 0,07$} & \multirow{2}{*}{$2,03 \pm 0,37$} & \multirow{2}{*}{$1,37 \pm 0,69$} & $2,3 \pm 0,35$ & \multirow{2}{*}{$0,87 \pm 0,55$} \\
\hline & $\S+a$ & & & & $\S$ & \\
\hline \multirow{2}{*}{ Interação } & $6,12 \pm 0,59$ & \multirow{2}{*}{$0,96 \pm 0,19$} & \multirow{2}{*}{$1,49 \pm 0,97$} & \multirow{2}{*}{$0,96 \pm 0,38$} & $1,68 \pm 2,99$ & \multirow{2}{*}{$1,1 \pm 0,36$} \\
\hline & $\mathrm{a}$ & & & & $*$ & \\
\hline \multicolumn{5}{|c|}{ *Diferença entre controle C. raciborskii e Interação } & \multicolumn{2}{|l|}{$\mathrm{p}<0,05$} \\
\hline \multicolumn{5}{|c|}{$\dagger$ Diferença entre controle $M$. contortum e interação } & \multicolumn{2}{|l|}{$\mathrm{p}<0,05$} \\
\hline \multicolumn{5}{|c|}{$\S$ Diferença entre controle $C$. raciborskii e controle $M$. contortum } & \multicolumn{2}{|l|}{$\mathrm{p}<0,05$} \\
\hline \multicolumn{5}{|c|}{ a Diferença entre dia 0 com todos os outros dias } & \multicolumn{2}{|l|}{$\mathrm{p}<0,001$} \\
\hline
\end{tabular}

Entre as culturas, no decorrer dos dias, houve diferença entre as concentrações no $12^{\circ}$ dia, em que o controle de $M$. contortum e a interação apresentaram maiores concentrações que o controle de C. raciborskii. As menores concentrações foram observadas no $12^{\circ}$ dia no controle da cianobactéria, no $15^{\circ}$ no controle da clorofícea e nos dias 3 e 9 na interação.

Em relação às concentrações iniciais de ortofosfato na simulação do supereutrófico, observou-se que os controles e a interação apresentaram diferenças significativas entre si, como demonstrado na Tabela 13, com maiores concentrações no controle de $C$ raciborskii, seguido da interação, e concentrações menores do que as iniciais estabelecidas no controle de M. contortum.

Verificou-se que o consumo do ortofosfato pela monocultura de M. contortum iniciou logo nas primeiras horas de experimento. Na interação também se pode dizer que houve esse rápido consumo, pois em seu inóculo foi adicionada o mesmo biovolume da cianobactéria no controle, que, por sua vez, apresentou concentrações maiores de ortofosfato.

As concentrações diminuíram logo no início do experimento, no $3^{\circ}$ dia, demonstrado pela diferença significativa do dia 0 comparado com todos os outros dias, em todas as culturas. A concentração de ortofosfato foi significativamente maior no dia 3 comparada aos dias 9 e 12 no controle da cianobactéria. Na interação, a concentração foi significativamente maior no $3^{\circ}$ dia também, comparada aos dias 6 e 9 (Tabela 13).

No $15^{\circ}$ dia de experimento, o controle de $M$. contortum e a interação apresentaram diferenças com as concentrações de ortofosfato do dia 9, sendo menores neste dia.

Entre as culturas, houve diferenças também nestes mesmos dias, com concentrações maiores no controle de C. raciborskii comparadas às obtidas na interação e ao controle de $M$. contortum, evidenciando que o consumo de ortofosfato pelo controle de C. raciborskii foi mais lento. Esse fato ocorreu, provavelmente, por a sua concentração inicial ter sido maior e 
por esta espécie apresentar velocidade específica de crescimento menor no ambiente supereutrófico. As menores concentrações ocorreram no $9^{\circ}$ dia de experimento no controle da clorofícea e na interação, e no $12^{\circ}$ dia no controle da cianobactéria.

Os resultados podem também estar relacionados com a velocidade específica de crescimento e tempo de duplicação de $M$. contortum, por ter sido significativamente maior e menor, respectivamente, tanto no controle quanto na interação, quando comparados aos parâmetros de crescimento de C. raciborskii neste ambiente.

Tabela 13 - Médias, com desvios padrão $(n=3)$, das concentrações de ortofosfato $\left(\mu \mathrm{g} . \mathrm{L}^{-1}\right)$ da simulação do ambiente supereutrófico, nas culturas (Cult.) controle de C. raciborskii $(\mathrm{Cr}-$ cont.), controle de M. contortum (Mc - cont.) e interação

\begin{tabular}{|c|c|c|c|c|c|c|}
\hline Cult./Dias & $\mathbf{0}$ & 3 & 6 & 9 & 12 & 15 \\
\hline $\mathrm{Cr}$ - cont. & $\begin{array}{c}67,28 \pm 1,05 \\
* \S \mathrm{a}\end{array}$ & $\begin{array}{c}3,6 \pm 0,57 \\
* \S b\end{array}$ & $2,08 \pm 0,35$ & $\begin{array}{c}1,48 \pm 0,26 \\
* \S\end{array}$ & $1,22 \pm 0,96$ & $2,34 \pm 0,49$ \\
\hline Mc - cont. & $\begin{array}{c}21,51 \pm 0,33 \\
\mathrm{a}\end{array}$ & $1,98 \pm 0,60$ & $1,79 \pm 0,94$ & $0,75 \pm 0,18$ & $1,51 \pm 0,24$ & $\begin{array}{c}2,16 \pm 0,52 \\
\mathrm{c}\end{array}$ \\
\hline Interação & $\begin{array}{c}47,78 \pm 0,78 \\
\dagger \mathrm{a}\end{array}$ & $\begin{array}{c}2,30 \pm 0,32 \\
\mathrm{~d} \\
\end{array}$ & $1,11 \pm 0,14$ & $0,79 \pm 0,26$ & $1,41 \pm 0,32$ & $\begin{array}{c}1,99 \pm 0,52 \\
\mathrm{c} \\
\end{array}$ \\
\hline $\begin{array}{l}\text { *Diferença } \\
\dagger \text { Diferença } \\
\S \text { Diferença } \\
\text { a Diferença } \\
\text { b Diferença } \\
\text { c Diferença } \\
\text { d Diferença }\end{array}$ & $\begin{array}{l}\text { ntre controle } C \\
\text { entre controle } \\
\text { entre controle } C \\
\text { ntre dia } 0 \mathrm{com} \\
\text { entre dia } 3 \mathrm{com} \\
\text { ntre dia } 9 \mathrm{com} \\
\text { entre dia } 3 \mathrm{com}\end{array}$ & $\begin{array}{l}\text { raciborskii e } \\
\text { contortum } \\
\text { raciborskii } \\
\text { odos os outr } \\
9 \text { e } 12 \\
15 \\
6 \text { e } 9\end{array}$ & $\begin{array}{l}\text { nteração } \\
\text { nteração } \\
\text { controle } M . c c \\
\text { dias }\end{array}$ & ortum & $\begin{array}{l}\mathrm{p}<0,05 \\
\mathrm{p}<0,05 \\
\mathrm{p}<0,05 \\
\mathrm{p}<0,001 \\
\mathrm{p}<0,038 \\
\mathrm{p}<0,031 \\
\mathrm{p}<0,042\end{array}$ & \\
\hline
\end{tabular}

As oscilações nas concentrações de ortofosfato na simulação dos três ambientes, após o consumo, no decorrer dos experimentos, devem-se, provavelmente, aos resultados estarem à baixo do limite de detecção do método, ou também, pelas análises terem ocorrido em blocos e não de amostras de um único Erlenmeyer do início ao fim do experimento.

Comparando o consumo de ortofosfato nos três níveis tróficos, pode-se observar que, inicialmente, como planejado, as concentrações iniciais foram todas significativamente diferentes, como demonstrado na Tabela 14.

No dia 3 foi observado que as concentrações no supereutrófico foram significativamente maiores do que nos ambientes oligotrófico e mesotrófico nas três culturas.

Além destas diferenças, houve também concentrações significativamente maiores no controle de $M$. contortum no ambiente mesotrófico comparadas ao oligotrófico e supereutrófico. No $15^{\circ}$ dia, entre os controles de $M$. contortum as concentrações foram 
maiores no ambiente supereutrófico em comparação com o mesotrófico. Neste mesmo dia, houve diferença nas concentrações das interações entre os ambientes oligotrófico e supereutrófico, sendo maior neste ultimo ambiente (Tabela 14).

De maneira geral, não houve diferenças nas concentrações no decorrer dos dias entre os ambientes, dando evidencias de que a assimilação do ortofosfato ocorre de forma semelhante nos diferentes ambientes simulados. 
Tabela 14 - Médias, com desvios padrão $(n=3)$, das concentrações de ortofosfato ( $\left.\mu \mathrm{g} \cdot \mathrm{L}^{-1}\right)$ da simulação dos ambientes oligotrófico, mesotrófico e supereutrófico, nas culturas (Cult.) controle de C. raciborskii $(\mathrm{Cr}$ - cont.), controle de M. contortum (Mc - cont.) e interação, com comparação das culturas em cada dia de análise

\begin{tabular}{|c|c|c|c|c|c|c|}
\hline Trofia & Cult./Dias 0 & 3 & 6 & 9 & 12 & 15 \\
\hline \multirow{3}{*}{ Oligotrófico } & Cr - cont. $3,91 \pm 0,43$ & $1,47 \pm 0,13$ & $1,68 \pm 0,11$ & $1,42 \pm 0,22$ & $1,7 \pm 0,31$ & $1,55 \pm 0,11$ \\
\hline & Mc - cont. $3,22 \pm 0,33$ & $0,74 \pm 0,25$ & $1,10 \pm 0,40$ & $0,92 \pm 0,13$ & $1,30 \pm 0,32$ & $1,18 \pm 0,15$ \\
\hline & Interação $2,38 \pm 0,27$ & $0,81 \pm 0,31$ & $0,83 \pm 0,36$ & $0,53 \pm 0,24$ & $0,86 \pm 0,25$ & $0,82 \pm 0,50$ \\
\hline \multirow{3}{*}{ Mesotrófico } & Cr - cont. $7,20 \pm 0,43 \quad \mathrm{~A}$ & $1,22 \pm 0,32$ & $1,33 \pm 0,54$ & $1,18 \pm 0,87$ & $0,70 \pm 0,41$ & $1,72 \pm 0,51$ \\
\hline & Mc - cont. $10,78 \pm 0,83 \mathrm{D}$ & $1,02 \pm 0,07$ & $2,03 \pm 0,37$ & $1,37 \pm 0,69$ & $2,30 \pm 0,35 \quad \mathrm{DF}$ & $0,87 \pm 0,55$ \\
\hline & Interação $6,12 \pm 0,59 \quad \mathrm{G}$ & $0,96 \pm 0,19$ & $1,49 \pm 0,97$ & $0,96 \pm 0,38$ & $1,68 \pm 2,99$ & $1,10 \pm 0,36$ \\
\hline \multirow{2}{*}{ Supereutrófico } & Cr - cont. $67,28 \pm 1,05 \mathrm{~B} \mathrm{C}$ & $3,6 \pm 0,57 \quad \mathrm{~B} \mathrm{C}$ & $2,08 \pm 0,35$ & $1,48 \pm 0,26$ & $1,22 \pm 0,96$ & $2,34 \pm 0,49$ \\
\hline & Interação $47,78 \pm 0,78 \mathrm{H} \mathrm{I}$ & $2,30 \pm 0,32 \quad \mathrm{H} \mathrm{I}$ & $1,11 \pm 0,14$ & $0,79 \pm 0,26$ & $1,41 \pm 0,32$ & $1,99 \pm 0,52 \mathrm{H}$ \\
\hline \multicolumn{7}{|c|}{ A Diferença dos controles de C. raciborskii entre oligotrófico e mesotrófico $\quad \mathrm{p}<0,003$} \\
\hline \multicolumn{7}{|c|}{ B Diferença dos controles de C. raciborskii entre oligotrófico e supereutrófico $\quad p<0,001$} \\
\hline \multicolumn{4}{|c|}{ C Diferença dos controles de C. raciborskii entre mesotrófico e supereutrófico } & \multicolumn{3}{|c|}{$\mathrm{p}<0,001$} \\
\hline \multicolumn{4}{|c|}{ D Diferença dos controles de $M$. contortum entre oligotrófico e mesotrófico } & \multicolumn{3}{|c|}{$\mathrm{p}<0,016$} \\
\hline \multicolumn{4}{|c|}{ E Diferença dos controles de $M$. contortum entre oligotrófico e supereutrófico } & \multicolumn{3}{|c|}{$\mathrm{p}<0,001$} \\
\hline \multicolumn{4}{|c|}{ F Diferença dos controles de $M$. contortum entre mesotrófico e supereutrófico } & \multicolumn{3}{|c|}{$\mathrm{p}<0,044$} \\
\hline \multicolumn{4}{|c|}{ G Diferença da interação entre oligotrófico e mesotrófico } & \multicolumn{3}{|c|}{$\mathrm{p}<0,001$} \\
\hline \multicolumn{4}{|c|}{ I Diferença da interação entre mesotrófico e supereutrófico } & \multicolumn{3}{|c|}{$\mathrm{p}<0,001$} \\
\hline
\end{tabular}




\subsubsection{Nitrato}

A concentração inicial estabelecida para o nitrato foi igual para todos os experimentos, correspondente à $0,45 \mathrm{mg} \cdot \mathrm{L}^{-1}$. Da mesma maneira como mencionado em relação ao ortofosfato, apesar desta concentração inicial estabelecida para os meios de cultura e da aclimatação prévia das culturas às condições adequadas de cada experimento, nem sempre foi possível obter concentrações iniciais idênticas nos controles e interação, provavelmente devido às concentrações pré-existentes nos inóculos e repiques antecedentes aos experimentos.

$\mathrm{Na}$ simulação do oligotrófico, conforme Tabela 15, as concentrações nos dias 0 e 3 foram significativamente maiores no controle de C. raciborskii e na interação quando comparados ao controle de M. contortum, e nos dias 12 e 15 observou-se menores concentrações na interação do que nos dois controles.

Tabela 15 - Médias, com desvios padrão $(n=3)$, das concentrações de nitrato $\left(m g . L^{-1}\right)$ da simulação do ambiente oligotrófico, nas culturas (Cult.) controle de C. raciborskii $(\mathrm{Cr}-$ cont.), controle de M. contortum (Mc - cont.) e interação

\begin{tabular}{|c|c|c|c|c|c|c|}
\hline Cult./Dias & $\mathbf{0}$ & 3 & 6 & 9 & 12 & 15 \\
\hline \multirow{2}{*}{ Cr - cont. } & $0,47 \pm 0,02$ & $0,46 \pm 0,01$ & \multirow{2}{*}{$0,46 \pm 0,01$} & \multirow{2}{*}{$0,48 \pm 0,02$} & $0,51 \pm 0,01$ & $0,54 \pm 0,01$ \\
\hline & $\S$ & $\S$ & & & $* \mathrm{~b}$ & $* \mathrm{c}$ \\
\hline \multirow{2}{*}{ Mc - cont. } & \multirow{2}{*}{$0,41 \pm 0,0$} & \multirow{2}{*}{$0,4 \pm 0,01$} & \multirow{2}{*}{$0,44 \pm 0,01$} & $0,47 \pm 0,02$ & $0,5 \pm 0,01$ & $0,52 \pm 0,01$ \\
\hline & & & & $\mathrm{e}$ & $\dagger \mathrm{b}$ & $\dagger \mathrm{f}$ \\
\hline \multirow{2}{*}{ Inte ração } & $0,45 \pm 0,02$ & $0,44 \pm 0,01$ & \multirow{2}{*}{$0,45 \pm 0,02$} & $0,47 \pm 0,01$ & \multirow{2}{*}{$0,46 \pm 0,02$} & $0,5 \pm 0,01$ \\
\hline & $\dagger$ & $\dagger$ & & $\mathrm{d}$ & & $c$ \\
\hline \multicolumn{5}{|c|}{ *Diferença entre controle C. raciborskii e Interação } & \multicolumn{2}{|l|}{$p<0,05$} \\
\hline \multicolumn{5}{|c|}{$\dagger$ † Diferença entre controle $M$. contortum e interação } & \multicolumn{2}{|l|}{$\mathrm{p}<0,05$} \\
\hline \multirow{2}{*}{\multicolumn{5}{|c|}{$\begin{array}{l}\text { § Diferença entre controle } C \text {. raciborskii e controle } M \text {. contortum } \\
\text { b Diferenca entre dia } 12 \text { com dias } 0,3 \text { e } 6\end{array}$}} & \multirow{2}{*}{\multicolumn{2}{|c|}{$\begin{array}{l}\mathrm{p}<0,05 \\
\mathrm{n}<0006\end{array}$}} \\
\hline & & & & & \multirow{2}{*}{\multicolumn{2}{|c|}{$\mathrm{p}<0,006$}} \\
\hline & & & \multirow{2}{*}{\multicolumn{2}{|c|}{$p<0,042$}} \\
\hline \multicolumn{5}{|c|}{ d Diferença entre dia 9 com dia 3} & & \\
\hline \multicolumn{5}{|c|}{ e Diferença entre dia 9 com dias 0 e 3} & \multicolumn{2}{|l|}{$\mathrm{p}<0,002$} \\
\hline \multicolumn{5}{|c|}{ f Diferença entre dia 15 com dias $0,3,6$ e 9} & \multicolumn{2}{|l|}{$\mathrm{p}<0,003$} \\
\hline
\end{tabular}

Comparando cada cultura separadamente no decorrer dos dias, notou-se que nos dias 12 e 15 as concentrações de nitrato do controle de C. raciborskii foram maiores do que em todos os outros dias. O mesmo ocorreu com o controle de $M$. contortum. Na interação, no $9^{\circ}$ dia, apresentou-se concentração maior do que no $3^{\circ}$ dia, e no $15^{\circ}$ foi significativamente maior do que em todos os outros dias. Com esses resultados, pode-se dizer então, que o consumo do nitrato ocorreu no $3^{\circ}$ e $6^{\circ}$ dias e posteriormente começou a aumentar nas três culturas. 
Em relação ao mesotrófico, situação semelhante ocorreu, havendo consumo deste nutriente no início e posterior aumento das concentrações no final do experimento, como pode ser observado na Tabela 16. O consumo do nitrato ocorreu mais tardiamente. A concentração no controle da cianobactéria e na interação diminuiu significativamente a partir do $9^{\circ}$ dia e no controle da clorofícea no $6^{\circ}$ dia, dando evidências que o consumo foi mais rápido, seguido de aumento das concentrações em todas as culturas no dia 15.

Além disso, quando se comparou o consumo entre as culturas, notou-se que não houve diferença nas concentrações iniciais. As concentrações deste nutriente foram significativamente maiores no controle de C. raciborskii a partir do $6^{\circ}$ dia, até o final do experimento, comparado ao controle de $M$. contortum. Em relação à interação, o mesmo ocorreu, porém somente nos dias 12 e 15 foi superior ao controle da clorofícea. Portanto, foi possível observar que o consumo de nitrato por C. raciborskii foi mais lento e menor.

Tabela 16 - Médias, com desvios padrão $(\mathrm{n}=3)$, das concentrações de nitrato $\left(\mathrm{mg} \cdot \mathrm{L}^{-1}\right)$ da simulação do ambiente mesotrófico, nas culturas (Cult.) controle de C. raciborskii ( $\mathrm{Cr}-$ cont.), controle de M. contortum (Mc - cont.) e interação

\begin{tabular}{|c|c|c|c|c|c|c|}
\hline Cult./Dias & $\mathbf{0}$ & 3 & 6 & 9 & 12 & 15 \\
\hline \multirow{2}{*}{ Cr - cont. } & $0,46 \pm 0,02$ & $0,45 \pm 0,01$ & $0,44 \pm 0,02$ & $0,37 \pm 0,01$ & $0,35 \pm 0,02$ & $0,38 \pm 0,01$ \\
\hline & $\mathrm{b}$ & $\mathrm{c}$ & $\S d$ & $\S$ & $\S$ & $\S$ \\
\hline \multirow{2}{*}{ Mc - cont. } & $0,47 \pm 0,01$ & $0,41 \pm 0,02$ & $0,36 \pm 0,03$ & \multirow{2}{*}{$0,23 \pm 0,06$} & \multirow{2}{*}{$0,23 \pm 0,01$} & \multirow{2}{*}{$0,28 \pm 0,02$} \\
\hline & $\mathrm{e}$ & $\mathrm{c}$ & $\mathrm{f}$ & & & \\
\hline \multirow{2}{*}{ Inte ração } & $0,44 \pm 0,06$ & $0,41 \pm 0,02$ & \multirow{2}{*}{$0,38 \pm 0,03$} & \multirow{2}{*}{$0,29 \pm 0,02$} & $0,32 \pm 0,02$ & $0,35 \pm 0,03$ \\
\hline & $\mathrm{g}$ & $\mathrm{h}$ & & & $\dagger$ & $\dagger$ \\
\hline \multicolumn{5}{|c|}{ † Diferença entre controle $M$. contortum e interação } & $\mathrm{p}<0,05$ & \\
\hline \multirow{2}{*}{\multicolumn{5}{|c|}{$\begin{array}{l}\S \text { Diferença entre controle } C \text {. raciborskii e controle } M \text {. contortum } \\
\text { b Diferença entre dia } 0 \text { com dias } 9,12 \text { e } 15\end{array}$}} & $\mathrm{p}<0,05$ & \\
\hline & & & & & $\mathrm{p}<0,001$ & \\
\hline \multicolumn{5}{|c|}{ c Diferença entre dia 3 com dias 9, 12 e 15} & $\mathrm{p}<0,002$ & \\
\hline \multicolumn{5}{|c|}{ d Diferença entre dia 6 com dias 9,12 e 15} & $\mathrm{p}<0,006$ & \\
\hline \multicolumn{5}{|c|}{ e Diferença entre dia 0 com dias $6,9,12$ e 15} & $\mathrm{p}<0,008$ & \\
\hline \multicolumn{5}{|c|}{ f Diferença entre dia 6 com dia 9 e 12} & $\mathrm{p}<0,002$ & \\
\hline \multicolumn{5}{|c|}{ g Diferença entre dia 0 com dias 9 e 12} & $\mathrm{p}<0,008$ & \\
\hline \multicolumn{5}{|c|}{ h Diferença entre dia 3 com dia 9} & $\mathrm{p}<0,008$ & \\
\hline
\end{tabular}

$\mathrm{Na}$ simulação do supereutrófico, as concentrações iniciais de nitrato foram significativamente maiores no controle de C. raciborskii, conforme Tabela 17, provavelmente devido à situações mencionadas anteriormente.

Foi observado que em todas as culturas houve diferença nas concentrações do dia 0 com todos os outros dias de análise, demonstrando que houve consumo deste nutriente, apesar deste consumo ocorrer logo no $3^{\circ}$ dia e posteriormente ter um aumento significativo nas 
concentrações do $6^{\circ}$ dia até o final do experimento, tanto nos controles quanto na interação, havendo maiores concentrações no $15^{\circ}$ dia.

Tabela 17 - Médias, com desvios padrão $(n=3)$, das concentrações de nitrato $\left(\mathrm{mg} . \mathrm{L}^{-1}\right)$ da simulação do ambiente supereutrófico, nas culturas (Cult.) controle de C. raciborskii $(\mathrm{Cr}-$ cont.), controle de M. contortum (Mc - cont.) e interação

\begin{tabular}{|c|c|c|c|c|c|c|}
\hline Cult./Dias & $\mathbf{0}$ & 3 & 6 & 9 & 12 & 15 \\
\hline \multirow{2}{*}{ Cr - cont. } & $0,53 \pm 0,0$ & \multirow{2}{*}{$0,12 \pm 0,01$} & $0,23 \pm 0,01$ & $0,24 \pm 0,01$ & $0,23 \pm 0,01$ & $0,25 \pm 0,01$ \\
\hline & $* \S \mathrm{a}$ & & $\mathrm{c}$ & $\mathrm{b}$ & d & $\mathrm{e}$ \\
\hline \multirow{2}{*}{ Mc - cont. } & $0,43 \pm 0,01$ & $0,18 \pm 0,03$ & $0,25 \pm 0,01$ & $0,27 \pm 0,01$ & $0,27 \pm 0,02$ & $0,3 \pm 0,01$ \\
\hline & $\mathrm{a}$ & $\S \dagger$ & $\dagger \mathrm{c}$ & $\S \mathrm{b}$ & $\S d$ & $\S+g$ \\
\hline \multirow{2}{*}{ Inte ração } & $0,5 \pm 0,01$ & \multirow{2}{*}{$0,12 \pm 0,01$} & $0,22 \pm 0,01$ & $0,25 \pm 0,01$ & $0,26 \pm 0,02$ & $0,27 \pm 0,02$ \\
\hline & $\dagger \mathrm{a}$ & & $\mathrm{c}$ & $\mathrm{b}$ & $\mathrm{f}$ & $\mathrm{g}$ \\
\hline \multicolumn{5}{|c|}{ *Diferença entre controle C. raciborskii e Interação } & $\mathrm{p}<0,05$ & \\
\hline \multicolumn{5}{|c|}{ † Diferença entre controle $M$. contortum e interação } & $\mathrm{p}<0,05$ & \\
\hline \multicolumn{5}{|c|}{$\S$ Diferença entre controle $C$. raciborskii e controle $M$. contortum } & $\mathrm{p}<0,05$ & \\
\hline \multicolumn{5}{|c|}{ a Diferença entre dia 0 com todos os outros dias } & $\mathrm{p}<0,001$ & \\
\hline \multicolumn{5}{|c|}{ b Diferença entre dia 3 com dia 9} & $\mathrm{p}<0,001$ & \\
\hline \multicolumn{5}{|c|}{ c Diferença entre dia 3 com dia 6} & $\mathrm{p}<0,001$ & \\
\hline \multicolumn{5}{|c|}{ d Diferença entre dia 3 com dia 12} & $\mathrm{p}<0,001$ & \\
\hline \multicolumn{5}{|c|}{ e Diferença entre dia 15 com dias $3,6,9$ e 12} & $\mathrm{p}<0,03$ & \\
\hline \multicolumn{5}{|c|}{ f Diferença entre dia 12 com dias 3 e 6} & $\mathrm{p}<0,01$ & \\
\hline \multicolumn{5}{|c|}{ g Diferença entre dia 15 com dias 3 e 6} & $\mathrm{p}<0,009$ & \\
\hline
\end{tabular}

No $3^{0}$ dia em que foram observadas as menores concentrações, ressalta-se que no controle de C. raciborskii e na interação, as concentrações foram significativamente menores do que no controle de $M$. contortum. Embora a partir do $6^{\circ}$ dia as concentrações se elevaram, foi observado que no controle da clorofícea as concentrações foram maiores do que comparadas ao controle da cianobactéria do $9^{\circ}$ dia até o final do experimento. Essa diferença entre o controle de $M$. contortum e a interação só foi observada no $6^{\circ}$ dia, e entre a interação e o controle de C. raciborskii não houve diferenças nas concentrações de nitrato nos dias analisados.

O consumo do nitrato do início ao $3^{\circ}$ dia de experimento pode estar relacionado com o pico de clorofila-a que ocorreu, nesse mesmo dia de análise, no ambiente supereutrófico.

Comparando os três experimentos, pode-se observar que houve maior consumo de nitrato no supereutrófico e, tanto neste quanto no oligotrófico, o consumo ocorreu logo no $3^{\circ}$ dia de experimento. No mesotrófico, este consumo foi mais lento, iniciando entre os dias 6 e 9. A Tabela 18 representa as diferenças das concentrações de cada cultura nos três níveis tróficos por dia de análise.

A semelhança entre os três experimentos foi o aumento da concentração de nitrato, que no mesotrófico ocorreu no final do experimento e no oligotrófico e supereutrófico do 
meio para o fim do experimento progressivamente, em todas as culturas, controles e interação. Uma hipótese para esta ocorrência foi a presença de bactérias nitrificantes, que são capazes de fixar o nitrogênio aerobiamente, transformando nitrito a nitrato.

De acordo com os resultados foi possível notar também que o consumo do nitrato foi maior conforme o aumento do nível de trofia, ou seja, havendo menor consumo no ambiente oligotrófico e maior no supereutrófico. Este fato pode estar relacionado com a limitação de fósforo, pois a assimilação do nitrogênio é menor devido ao baixo metabolismo das células sob a limitação deste nutriente.

Outra evidência para sustentar essa hipótese são as concentrações de clorofila-a, que também foram crescentes à medida que a concentração de fósforo aumentava.

Por isso, no ambiente oligotrófico, a maior concentração de nitrato no final do experimento, comparado aos outros ambientes, pode ser justificada pelo menor consumo de nitrato devido à baixa concentração de ortofosfato. Conseqüentemente, a concentração mais elevada do nitrato tornou-se mais aparente devido à ocorrência de fixação de nitrogênio pelas bactérias, embora em todas as simulações tenha ocorrido este aumento. 
Tabela 18 - Médias, com desvios padrão $(n=3)$, das concentrações de nitrato $\left(m g . L^{-1}\right)$ da simulação dos ambientes oligotrófico, mesotrófico e supereutrófico, nas culturas (Cult.) controle de C. raciborskii $(\mathrm{Cr}$ - cont.), controle de M. contortum (Mc - cont.) e interação, com comparação das culturas em cada dia de análise

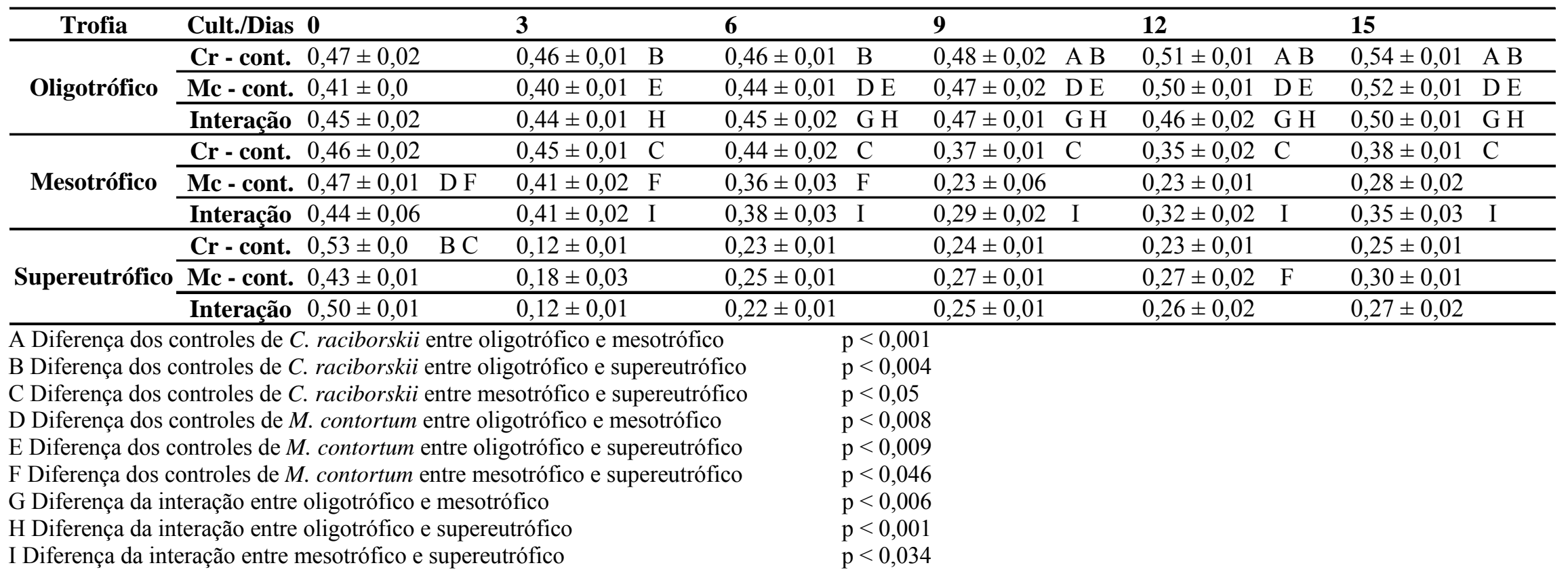




\subsubsection{Relação $N: P$}

Para melhor comparação da relação da assimilação de nitrato e ortofosfato nos diferentes ambientes simulados, segue na Tabela 19 as relações N:P a partir dos resultados de nitrato e ortofosfato no início (dia 0$)$ e fim $\left(15^{\circ}\right.$ dia) dos experimentos de cada cultura.

Tabela 19 - Relação N:P inicial e final de cada cultura nos ambientes simulados baseada na média das concentrações de nitrato e ortofosfato $(\mathrm{n}=3)$ nos controles de M. contortum $(\mathrm{Mc}-$ controle) e de C. raciborskii ( $\mathrm{Cr}$ - controle) e interação.

\begin{tabular}{|c|c|c|c|}
\hline \multicolumn{4}{|c|}{ Relação N:P } \\
\hline Trofia & Cultura/Período & Inicial & Final \\
\hline \multirow{3}{*}{ Oligotrófico } & Mc - controle & $282: 1$ & $976: 1$ \\
\hline & $\mathrm{Cr}$ - controle & $266: 1$ & $771: 1$ \\
\hline & Interação & 418:1 & 1350:1 \\
\hline \multirow{3}{*}{ Mesotrófico } & Mc - controle & $97: 1$ & $713: 1$ \\
\hline & $\mathrm{Cr}$ - controle & $141: 1$ & 489:1 \\
\hline & Interação & $159: 1$ & $704: 1$ \\
\hline \multirow{3}{*}{ Supereutrófico } & Mc - controle & $44: 1$ & $307: 1$ \\
\hline & $\mathrm{Cr}$ - controle & $17: 1$ & $237: 1$ \\
\hline & Interação & $23: 1$ & $300: 1$ \\
\hline
\end{tabular}

\subsubsection{Toxina}

As análises de toxina total foram feitas apenas para saxitoxina devido aos testes preliminares com a cepa utilizada de $C$. raciborskii, que constataram que não havia produção de cilindrospermopsina, apenas saxitoxina. As análises foram realizadas a partir de coletas dos Erlenmeyers dos controles da cianobactéria e da interação, ambos do bloco 1, conforme Figura 7.

Os resultados apresentados são médias com desvios padrão das concentrações de saxitoxina em relação ao biovolume dos seus respectivos dias, conforme demonstrado na Tabela 20, nos três diferentes níveis tróficos simulados. As análises estatísticas foram para comparar a diferença da concentração de saxitoxina entre os dias para cada cultura, representada por letras minúsculas, e a diferença entre o controle de C. raciborskii e interação, em cada dia em que foi realizada a análise, representada por símbolos. Posteriormente, foi 
realizada uma comparação da concentração de saxitoxina de cada cultura nos diferentes níveis de trofia simulada, indicada por letras maiúsculas na Tabela 21.

No oligotrófico as maiores concentrações de saxitoxina ocorreram no $3^{\mathrm{o}}$ dia do experimento, com $2,05 \times 10^{-10} \mu \mathrm{g} . \mu \mathrm{m}^{-3}$ no controle e no $15^{\circ}$ dia na interação, $4,73 \times 10^{-10}$ $\mu \mathrm{g} . \mu \mathrm{m}^{-3}$. A menor concentração no controle ocorreu no $9^{\circ}$ dia, $3,87 \times 10^{-11} \mu \mathrm{g} \cdot \mu \mathrm{m}^{-3}$, e na interação no dia 0 de experimento, $1,28 \times 10^{-10} \mu \mathrm{g} \cdot \mu \mathrm{m}^{-3}$.

No controle houve diferença significativa apenas das concentrações nos dias 0 e 3 comparadas com todos os outros dias analisados, sendo que a partir do $6^{\circ}$ dia de experimento as concentrações de saxitoxina diminuíram e não apresentaram diferenças. Na interação, houve diferença da concentração apenas no último dia de experimento, ocorrendo o aumento da concentração devido, provavelmente, a antecipação das fases estacionária e de senescência de C. raciborskii na interação. Comparando as concentrações de saxitoxina entre o controle e a interação, houve aumento significativo na interação a partir do sexto dia até o final do experimento, exceto no $9^{\circ}$ dia, apesar da análise resultar em um $p=0,096$. As concentrações maiores na interação se devem, provavelmente, pelo biovolume de $C$. raciborskii ter sido significativamente menor na interação do que no seu controle, além de antecipação da fase de senescência devido à competição com M. contortum.

Em relação ao mesotrófico, as maiores e menores concentrações de saxitoxina, tanto no controle quanto na interação, ocorreram nos dia 0 e 15 , respectivamente, com resultados de $1,97 \times 10^{-10} \mu \mathrm{g} \cdot \mu \mathrm{m}^{-3}$ e $8,56 \times 10^{-11} \mu \mathrm{g} \cdot \mu \mathrm{m}^{-3}$ no controle, e $1,61 \times 10^{-10} \mu \mathrm{g} \cdot \mu \mathrm{m}^{-3}$ e $9,45 \times 10^{-11}$ $\mu \mathrm{g} \cdot \mu \mathrm{m}^{-3}$, na interação. Nos dias analisados, entre o controle e a interação, não foi observada diferença significativa nas concentrações de saxitoxina.

Apesar de as menores concentrações terem ocorrido no final do experimento, foi neste dia que C. raciborskii atingiu o biovolume máximo, tanto no controle quanto na interação. Ou seja, a relação toxina/biovolume diminuiu conforme a cianobactéria avançou na fase exponencial, sendo coincidente, tanto no controle quanto na interação, as fases de crescimento e a produção de saxitoxina.

Entre os dias do controle, houve diferença significativa das concentrações de saxitoxina nos dias 0 e 6 comparados a todos os outros dias analisados, exceto diferença entre eles (0 e 6 não apresentaram diferença). Na interação, não houve diferença da concentração entre os dias, embora tenha apresentado diminuição das concentrações no final do experimento. 
Tabela 20 - Média, com desvio padrão $(n=3)$, das concentrações de saxitoxina por biovolume $\left(10^{-10} \mu \mathrm{g} . \mu \mathrm{m}^{-3}\right)$ das culturas (Cult.) controle de C. raciborskii ( $\mathrm{Cr}-$ cont.) e interação (Int.), nos três ambientes simulados, oligotrófico (oligo), mesotrófico (meso) e supereutrófico (super)

\begin{tabular}{|c|c|c|c|c|c|c|}
\hline \multicolumn{7}{|c|}{ Concentração de saxitoxina $\left(10^{-10} \mu g . \mu m^{-3}\right)$} \\
\hline Cult/Dias & $\mathbf{0}$ & 3 & 6 & 9 & 12 & 15 \\
\hline \multicolumn{7}{|c|}{ Oligotrófico } \\
\hline Cr -cont. & $1,41 \pm 0,27 \mathrm{a}$ & $2,05 \pm 0,22 \mathrm{~b}$ & $0,44 \pm 0,05$ & $0,39 \pm 0,13$ & $0,63 \pm 0,18$ & $0,45 \pm 0,10$ \\
\hline Int. & $1,28 \pm 0,89$ & $1,5 \pm 0,82$ & $1,38 \pm 0,31 *$ & $1,55 \pm 0,07 *$ & $2,44 \pm 0,39 *$ & $4,73 \pm 1,26 * \mathrm{e}$ \\
\hline \multicolumn{7}{|c|}{ Mesotrófico } \\
\hline Cr -cont. & $1,97 \pm 0,40 \mathrm{c}$ & $1,14 \pm 0,18$ & $1,8 \pm 0,21 \mathrm{~d}$ & $1,28 \pm 0,24$ & $1,06 \pm 0,07$ & $0,86 \pm 0,1$ \\
\hline Int. & $1,61 \pm 0,40$ & $1,44 \pm 0,26$ & $1,54 \pm 0,15$ & $1,36 \pm 0,47$ & $1,2 \pm 0,17$ & $0,9 \pm 0,23$ \\
\hline \multicolumn{7}{|c|}{ Supereutrófico } \\
\hline Cr -cont. & $0,32 \pm 0,17$ & $0,40 \pm 0,07$ & $0,32 \pm 0,06$ & $0,27 \pm 0,08$ & $0,25 \pm 0,06$ & $0,32 \pm 0,19$ \\
\hline Int. & $0,32 \pm 0,06$ & $0,27 \pm 0,11$ & $0,21 \pm 0,05$ & $0,30 \pm 0,08$ & $0,35 \pm 0,05$ & $0,18 \pm 0,09$ \\
\hline $\begin{array}{l}\text { * Diferença } \\
\text { a Diferença } \\
\text { b Diferença } \\
\text { c Diferença } \\
\text { d Diferença } \\
\text { e Diferença }\end{array}$ & $\begin{array}{l}\text { entre controle } \\
\text { entre dia } 0 \text { cor } \\
\text { entre dia } 3 \text { cor } \\
\text { entre dia } 0 \text { cor } \\
\text { entre dia } 6 \text { cor } \\
\text { entre dia } 15\end{array}$ & $\begin{array}{l}\text { C. raciborskii } \\
\text { todos os outr } \\
\text { todos os outr } \\
\text { dias } 3,9,12 \text {, } \\
\text { dias } 3,9,12 \\
\text { m todos os out }\end{array}$ & $\begin{array}{l}\text { Interação } \\
\text { s dias } \\
\text { dias } \\
15 \\
15 \\
\text { os dias }\end{array}$ & & $\begin{array}{l}p<0,05 \\
p<0,00 \\
p<0,00 \\
p<0,00 \\
p<0,02 \\
p<0,05\end{array}$ & \\
\hline
\end{tabular}

$\mathrm{Na}$ simulação do supereutrófico foi observado que, no controle, a maior concentração de saxitoxina ocorreu no $3^{\circ}$ dia, 4,01 x $10^{-11} \mu \mathrm{g} \cdot \mu \mathrm{m}^{-3}$, e a menor no $12^{\circ}$ dia do experimento, $2,51 \times 10^{-11} \mu \mathrm{g} \cdot \mu \mathrm{m}^{-3}$. Na interação, a maior concentração foi notada no $12^{\circ}$ dia, $3,48 \times 10^{-11}$ $\mu \mathrm{g} . \mu \mathrm{m}^{-3}$, e a menor no $15^{\circ}$ dia de experimento, $1,78 \times 10^{-11} \mu \mathrm{g} . \mu \mathrm{m}^{-3}$.

Apesar da diferença dos dias em que ocorreram as maiores e menores concentrações entre o controle e a interação, não foi observada diferença das concentrações de saxitoxina nesta comparação. Além disso, do início ao final do experimento, também não foi encontrada diferença significativa nas concentrações de saxitoxina entre os dias de análise no controle da cianobactéria e na interação.

De forma semelhante ao observado no mesotrófico, as menores concentrações de saxitoxina ocorrem no final do experimento, quando a relação toxina/biovolume diminuiu e a cianobactéria avançou na fase exponencial. No controle essa concentração foi menor no $12^{\circ} \mathrm{e}$ na interação no $15^{\circ}$ dia, provavelmente, porque o tempo de duplicação de C. raciborskii no controle foi menor do que na interação (Tabela 7). 
Para analisar as diferenças das concentrações de saxitoxina dos controles de $C$. raciborskii e das interações entre os diferentes níveis tróficos, foram comparados os resultados por dia de análise, como representado na Tabela 21.

Entre os controles de C. raciborskii, foi observado que a concentração de saxitoxina foi significativamente maior no ambiente mesotrófico comparada as dos ambientes oligotrófico e supereutrófico, exceto no $3^{\circ}$ dia de análise quando no ambiente oligotrófico ocorreram concentrações significativamente maiores dos demais ambientes. Entre os ambientes oligotrófico e o supereutrófico também houve diferença nas concentrações nos dias 0,3 e 12 .

Tabela 21 - Comparação das médias, com desvios padrão $(n=3)$, das concentrações de saxitoxina $\left(\mu \mathrm{g} . \mathrm{L}^{-1}\right)$ entre os controles de C. raciborskii e entre as interações, nas diferentes simulações de níveis tróficos

\begin{tabular}{|c|c|c|c|c|c|c|}
\hline \multicolumn{7}{|c|}{ Concentração de saxitoxina no controle $C$. raciborskii $\left(10^{-10} \mu \mathrm{g} \cdot \mu^{-3}\right)$} \\
\hline Ambiente/Dia & $\mathbf{0}$ & 3 & 6 & 9 & 12 & 15 \\
\hline Oligo & $\begin{array}{c}1,41 \pm 0,27 \\
\text { B }\end{array}$ & $\begin{array}{c}2,05 \pm 0,22 \\
\text { D E }\end{array}$ & $0,44 \pm 0,05$ & $0,39 \pm 0,13$ & $\begin{array}{c}0,63 \pm 0,18 \\
\mathrm{~N}\end{array}$ & $0,45 \pm 0,10$ \\
\hline Meso & $\begin{array}{c}1,97 \pm 0,40 \\
\text { A C }\end{array}$ & $\begin{array}{c}1,14 \pm 0,18 \\
F \\
\end{array}$ & $\begin{array}{c}1,8 \pm 0,21 \\
\text { G I }\end{array}$ & $\begin{array}{c}1,28 \pm 0,24 \\
\mathrm{~J} \mathrm{~L}\end{array}$ & $\begin{array}{c}1,06 \pm 0,07 \\
\mathrm{M} \mathrm{O}\end{array}$ & $\begin{array}{c}0,86 \pm 0,1 \\
\text { P R } \\
\end{array}$ \\
\hline Super & $0,32 \pm 0,17$ & $0,40 \pm 0,07$ & $0,32 \pm 0,06$ & $0,27 \pm 0,08$ & $0,25 \pm 0,06$ & $0,32 \pm 0,19$ \\
\hline \multicolumn{7}{|c|}{ Concentração de saxitoxina na interação $\left(10^{-10} \mu \mathrm{g} \cdot \mu^{-3}\right)$} \\
\hline Ambiente/Dia & $\mathbf{0}$ & 3 & 6 & 9 & 12 & 15 \\
\hline Oligo & $1,28 \pm 0,89$ & $1,5 \pm 0,82$ & $\begin{array}{c}1,38 \pm 0,31 \\
\mathrm{H} \\
\end{array}$ & $\begin{array}{c}1,55 \pm 0,07 \\
\mathrm{~K}\end{array}$ & $\begin{array}{c}2,44 \pm 0,39 \\
\mathrm{M} \mathrm{N}\end{array}$ & $\begin{array}{c}4,73 \pm 1,26 \\
\mathrm{PQ} \\
\end{array}$ \\
\hline Meso & $1,61 \pm 0,40$ & $1,44 \pm 0,26$ & $\begin{array}{c}1,54 \pm 0,15 \\
I\end{array}$ & $1,36 \pm 0,47$ & $\begin{array}{c}1,2 \pm 0,17 \\
O\end{array}$ & $0,9 \pm 0,23$ \\
\hline Super & $0,32 \pm 0,06$ & $0,27 \pm 0,11$ & $0,21 \pm 0,05$ & $0,30 \pm 0,08$ & $0,35 \pm 0,05$ & $0,18 \pm 0,09$ \\
\hline
\end{tabular}

A Diferença entre dia 0 do oligotrófico e 0 do mesotrófico

B Diferença entre dia 0 do oligotrófico e 0 do supereutrófico

C Diferença entre dia 0 do mesotrófico e 0 do supereutrófico

D Diferença entre dia 3 do oligotrófico e 3 do mesotrófico

E Diferença entre dia 3 do oligotrófico e 3 do supereutrófico

F Diferença entre dia 3 do mesotrófico e 3 do supereutrófico

G Diferença entre dia 6 do oligotrófico e 6 do mesotrófico

H Diferença entre dia 6 do oligotrófico e 6 do supereutrófico

I Diferença entre dia 6 do mesotrófico e 6 do supereutrófico

J Diferença entre dia 9 do oligotrófico e 9 do mesotrófico

K Diferença entre dia 9 do oligotrófico e 9 do supereutrófico

L Diferença entre dia 9 do mesotrófico e 9 do supereutrófico

M Diferença entre dia 12 do oligotrófico e 12 do mesotrófico

N Diferença entre dia 12 do oligotrófico e 12 do supereutrófico

O Diferença entre dia 12 do mesotrófico e 12 do supereutrófico

P Diferença entre dia 15 do oligotrófico e 15 do mesotrófico

Q Diferença entre dia 15 do oligotrófico e 15 do supereutrófico

$\mathrm{R}$ Diferença entre dia 15 do mesotrófico e 15 do supereutrófico $\mathrm{p}=0,037$

$\mathrm{p}=0,002$

$\mathrm{p}<0,001$

$\mathrm{p}=0,001$

$\mathrm{p}<0,001$

$\mathrm{p}=0,004$

$\mathrm{p}<0,001$

$\mathrm{p}<0,001$

$\mathrm{p}<0,001$

$\mathrm{p}=0,001$

$\mathrm{p}=0,045$

$\mathrm{p}<0,001$

$\mathrm{p}<0,01$

$\mathrm{p}<0,017$

$\mathrm{p}<0,013$

$\mathrm{p}<0,027$

$\mathrm{p}<0,001$

$\mathrm{p}=0,007$ 
Comparando as concentrações de saxitoxina das interações nos diferentes níveis tróficos, nota-se que não houve diferenças nos dias 0 e 3 entre os ambientes, ao contrário do que ocorreu na comparação dos controles. Esse fato deve-se, provavelmente, ao maior desvio padrão destas análises. A partir do $6^{\circ}$ dia até o fim do experimento, o ambiente oligotrófico apresentou concentrações significativamente maiores comparadas ao supereutrófico, sendo o mesmo observado na comparação com o mesotrófico nos dias 12 e 15 do experimento. A diferença entre os ambientes mesotrófico e supereutrófico ocorreu apenas no $6^{\circ}$ e $12^{\circ}$ dias.

De acordo com esses resultados, observa-se que nos controles a maior concentração de saxitoxina ocorreu no ambiente mesotrófico e na interação, no ambiente oligotrófico. Embora haja essa diferença, foi apenas no ambiente oligotrófico que ocorreu aumento significativo das concentrações na interação comparada ao seu controle, com diferença a partir do $6^{\circ}$ dia do experimento. No mesotrófico e supereutrófico essa diferença entre controles e interação não foi observada.

Quando se comparou a concentração de saxitoxina do ambiente oligotrófico com as curvas de crescimento da cianobactéria no controle e na interação (Figura 11), observou-se que o biovolume desta espécie na interação foi menor do que o seu controle a partir do $4^{\circ}$ dia de experimento. Esta é uma possível evidência de que aumento da síntese de saxitoxina e diminuição do volume celular (Figura 14) podem ser estratégias de sobrevivência de $C$. raciborskii na competição com a clorofícea, além de relação com a antecipação das fases estacionária e senescência que não ocorreram no controle desta espécie.

\section{3. $\quad$ Síntese dos resultados e considerações gerais}

De acordo com todos os resultados apresentados dos três experimentos realizados, simulando ambientes oligotrófico, mesotrófico e supereutrófico, com médias e desvios padrão, foi feita uma síntese dos principais resultados, conforme Tabela 22, com o intuito de comparar, de maneira geral, as principais diferenças entre os experimentos.

O crescimento de M. contortum foi maior no supereutrófico, tanto no controle quanto na interação, apresentando maior velocidade específica de crescimento e menor tempo de duplicação, sendo, portanto, as velocidades crescentes com o aumento da trofia. Com $C$. raciborskii, no controle e na interação, ocorreu ao contrário, sendo as velocidades específicas de crescimento decrescentes à elevação do nível de trofia. 
A cianobactéria, no controle, apresentou melhor desempenho no ambiente oligotrófico, apesar de neste ambiente, na interação com a clorofícea, ter tido seu crescimento afetado, evidenciado pela diminuição do volume celular e maiores concentrações de saxitoxina comparado ao seu controle.

No mesotrófico e no supereutrófico, C. raciborskii apresentou desempenho semelhante no controle e na interação, sem diferenças significativas no biovolume, volume celular e produção de saxitoxina, demonstrando que a cianobactéria não foi afetada quando em interação com a clorofícea. O mesmo não ocorreu com $M$. contortum, que, nos três experimentos, apresentou crescimento menor na interação comparado ao seu controle. 
Tabela 22 - Síntese dos resultados, médias com desvios padrão (n=3), das culturas controle (Cont.) e interação (Int.), nos três ambientes simulados: oligotrófico (oligo), mesotrófico (meso) e supereutrófico (super)

\begin{tabular}{|c|c|c|c|c|c|c|c|c|c|c|c|}
\hline \multirow[t]{2}{*}{ Trofia } & \multirow{2}{*}{\multicolumn{2}{|c|}{ Cultura }} & \multirow{2}{*}{$\begin{array}{c}\text { Biovolume } \\
\text { final } \\
\left(10^{-6} \mathrm{\mu m}^{3} \cdot \mathrm{ml}^{-1}\right)\end{array}$} & \multirow{2}{*}{$\begin{array}{c}\mu \\
\left(\operatorname{dia}^{-1}\right)\end{array}$} & \multirow{2}{*}{$\begin{array}{c}\text { Td } \\
\text { (dia) }\end{array}$} & \multirow{2}{*}{$\begin{array}{c}\text { Redução } \\
\text { Significativa do } \\
\text { Vol. Celular } \\
\left(\mu^{3}\right) \\
\end{array}$} & \multicolumn{2}{|c|}{ Relação N:P } & \multirow{2}{*}{$\begin{array}{l}\text { Clorofila } \\
\text { máxima } \\
\left(\mu g . L^{-1}\right)\end{array}$} & \multicolumn{2}{|c|}{ 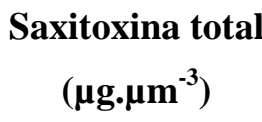 } \\
\hline & & & & & & & Inicial & Final & & Difer. & Perc.* \\
\hline \multirow{4}{*}{ Oligo } & \multirow{2}{*}{ Cont. } & M.c. & $1,49 \pm 0,05$ & $0,35 \pm 0,04$ & $1,98 \pm 0,22$ & $\mathrm{~N}$ & $282: 1$ & $976: 1$ & \multirow{2}{*}{$17,19 \pm 4,26$} & \multirow{2}{*}{$\mathrm{S}$} & \multirow{4}{*}{$1051 \%$} \\
\hline & & C.r. & $2,46 \pm 0,31$ & $0,28 \pm 0,11$ & $2,76 \pm 1,01$ & $12^{\circ} \mathrm{dia}$ & $266: 1$ & $771: 1$ & & & \\
\hline & \multirow{2}{*}{ Int. } & M.c. & $0,95 \pm 0,01$ & $0,45 \pm 0,05$ & $1,54 \pm 0,19$ & $\mathrm{~N}$ & \multirow{2}{*}{ 418:1 } & \multirow{2}{*}{ 1350:1 } & \multirow{2}{*}{$18,12 \pm 4,19$} & \multirow{2}{*}{$\mathrm{S}$} & \\
\hline & & C.r. & $0,20 \pm 0,05$ & $0,24 \pm 0,03$ & $2,90 \pm 0,40$ & a partir do $6^{\circ}$ dia & & & & & \\
\hline \multirow{4}{*}{ Meso } & \multirow{2}{*}{ Cont. } & M.c. & $12,53 \pm 0,12$ & $0,37 \pm 0,02$ & $1,86 \pm 0,13$ & $1^{\mathrm{o}} \mathrm{dia}$ & $97: 1$ & $713: 1$ & \multirow{2}{*}{$79,49 \pm 6,10$} & \multirow{2}{*}{$\mathrm{N}$} & \multirow{4}{*}{ - } \\
\hline & & C.r. & $2,59 \pm 0,30$ & $0,09 \pm 0,01$ & $7,55 \pm 0,81$ & $\mathrm{~N}$ & $141: 1$ & 489:1 & & & \\
\hline & \multirow{2}{*}{ Int. } & M.c. & $3,18 \pm 0,75$ & $0,14 \pm 0,08$ & $6,12 \pm 3,20$ & $13^{\circ}$ e $15^{\circ}$ dia & \multirow{2}{*}{ 159:1 } & \multirow{2}{*}{$704: 1$} & \multirow{2}{*}{$25,11 \pm 2,79$} & \multirow{2}{*}{$\mathrm{N}$} & \\
\hline & & C.r. & $2,31 \pm 0,57$ & $0,09 \pm 0,03$ & $8,90 \pm 3,64$ & $\mathrm{~N}$ & & & & & \\
\hline \multirow{4}{*}{ Super } & \multirow{2}{*}{ Cont. } & M.c. & $30,94 \pm 6,13$ & $0,68 \pm 0,07$ & $1,03 \pm 0,10$ & $\mathrm{~N}$ & $44: 1$ & $307: 1$ & \multirow{2}{*}{$119,04 \pm 13,76$} & \multirow{2}{*}{$\mathrm{N}$} & \\
\hline & & C.r. & $3,24 \pm 0,37$ & $0,07 \pm 0,01$ & $10,26 \pm 1,67$ & $\mathrm{~N}$ & $17: 1$ & $237: 1$ & & & \\
\hline & \multirow{2}{*}{ Int. } & M.c. & $12,93 \pm 0,94$ & $0,58 \pm 0,07$ & $1,20 \pm 0,13$ & a partir do $10^{\circ}$ dia & \multirow{2}{*}{$23: 1$} & $300 \cdot 1$ & $6789+852$ & $\mathrm{~N}$ & \\
\hline & & C.r. & $2,46 \pm 0,48$ & $0,06 \pm 0,02$ & $11,93 \pm 4,73$ & $9^{\circ}$ dia & & & & & \\
\hline
\end{tabular}

M.c. - Monoraphidium contortum; C.r. - Cylindrospermopsis raciborskii; $\mu$ - velocidade específica de crescimento; Td - tempo de duplicação; N - não houve; S - sim; Difer

- diferença; Perc. - Percentual

* Percentual de diferença máxima no aumento de concentração de saxitoxina entre o controle de C. raciborskii e interação 
Em relação aos nutrientes, nos três ambientes, o consumo do ortofosfato ocorreu no início do experimento, no $3^{\circ}$ dia, e permaneceu praticamente constante, em todas as situações, até o final. Quanto ao nitrato, houve o consumo seguido de aumento das concentrações em todas as culturas e níveis tróficos, o que pode ter sido devido à presença de bactérias nitrificantes. Além disso, o maior consumo do nitrato ocorreu com a elevação das concentrações de fósforo, bem como, o aumento das concentrações de clorofila-a.

A seguir, serão discutidas algumas hipóteses das diferenças nos parâmetros de crescimento das espécies e a influência dos fatores físico-químicos, nos diferentes ambientes simulados. Além de hipóteses relacionadas às modificações observadas e aos possíveis impactos sobre a comunidade fitoplanctônica, associados ao aumento de trofia do Reservatório de Itupararanga. 


\section{DISCUSSÃO}

Há várias pesquisas de interação entre organismos fitoplanctônicos relacionadas à competição por nutrientes limitantes e em diferentes formas de disponibilidade e concentrações, principalmente tratando-se de fósforo e de nitrogênio. As interações estudadas são principalmente entre cianobactérias (DE NOBEL et al., 1997; DUCOBU et al., 1998; SANTOS, 2009), mas entre cianobactérias e clorofíceas (HYENSTRAND et al., 2000; KEARNS \& HUNTER, 2000; ZHU et al., 2010) são mais escassas. Há também pesquisas que demonstram a relação dos nutrientes e micronutrientes com a morfologia e o crescimento de algumas cianobactérias e microalgas (KENESI et al., 2009; KIM et al., 2007; LEAL, 2006; RODRIGO et al., 2009; SOMMER, 1989; VUORIO et al., 2005).

A partir destas pesquisas e de acordo com os resultados aqui apresentados, pode-se entender melhor como o crescimento da clorofícea $M$. contortum e da cianobactéria $C$. raciborskii ocorreram em interação, bem como a produção de saxitoxina por esta última. Dessa forma, verificou-se o que favoreceu ou não o crescimento destas espécies em diferentes concentrações de nutrientes sob limitação de fósforo a partir de simulações baseadas em dados obtidos por Casali (em andamento).

É importante lembrar que todas as culturas utilizadas nos experimentos, para as duas espécies, foram não axênicas e, por isso, a presença de bactérias pode ter influenciado no crescimento desses organismos (WETZEL, 1993), em monocultura ou interação. Em contrapartida, a presença delas aproxima os experimentos realizados às condições ambientais simuladas, uma vez que C. raciborskii e M. contortum foram isolados do reservatório estudado e, provavelmente, as bactérias presentes nas culturas pertenciam à este ecossistema.

Zhu et al. (2010) estudaram diferentes níveis de nutrientes com diferentes concentrações e relações de nitrogênio e fósforo, simulando oligotrofia, eutrofia e hipereutrofia, em culturas puras e mistas de Microcystis aeruginosa (cianobactéria) e Scenedesmus quadricauda (clorofícea), por 10 dias à $24^{\circ} \mathrm{C}$ e fotoperíodo de 12 horas. As relações N:P utilizadas foram 10:1, 15:1 e 20:1 para os três níveis tróficos simulados. No oligotrófico, as concentrações de nitrogênio foram $0,1,0,15$ e $0,2 \mathrm{mg} . \mathrm{L}^{-1}$ e $0,01 \mathrm{mg} . \mathrm{L}^{-1}$ de fósforo; no mesotrófico foram utilizadas as concentrações de 2, 3 e $4 \mathrm{mg}$. $\mathrm{L}^{-1}$ para nitrogênio e $0,02 \mathrm{mg}$. $\mathrm{L}^{-1}$ para fósforo; e no hipereutrófico foram considerados 10,15 e $20 \mathrm{mg} . \mathrm{L}^{-1}$ de 
nitrogênio e $1 \mathrm{mg}$. $\mathrm{L}^{-1}$ de fósforo. Estas concentrações foram estabelecidas de acordo com dois lagos estudados pelos autores, na China, e foram considerados os nutrientes totais e não os na forma dissolvida.

Em contrapartida, nesta pesquisa, tem-se como vantagem a utilização de nutrientes dissolvidos, nitrato e ortofosfato, que são as formas prontamente disponíveis na água para assimilação pelos organismos (WETZEL, 1993).

As pesquisas realizadas em campo por Zhu et al. (2010) demonstraram que águas com elevadas concentrações de nitrogênio e fósforo favorecem as clorofíceas e com baixas concentrações, as cianobactérias. Porém, de acordo com os experimentos, constataram que as melhores condições de crescimento e reprodução para as duas espécies ocorreram no eutrófico e, quando em competição, $M$. aeruginosa apresentou vantagens em condições de menores concentrações de nutrientes, enquanto que $S$. quadricauda em concentrações mais elevadas de nutrientes.

Os resultados obtidos por Zhu et al. (2010) são similares ao desta pesquisa, visto que os controles comportaram-se de maneira semelhante ao ocorrido com o estudo de campo desses autores, onde, em concentrações baixas de nutrientes as cianobactérias foram favorecidas e, em altas, foram favorecidas as clorofíceas. É válido ressaltar que as concentrações de fósforo e nitrogênio e as relações N:P foram diferentes entre as pesquisas devido ao uso dos nutrientes totais em uma e ao uso de dissolvidos em outra.

No oligotrófico, foi observado que o controle de C. raciborskii obteve velocidade de crescimento significativamente maior e tempo de duplicação menor comparado aos controles dos outros níveis tróficos, sendo decrescente e crescente, respectivamente, conforme o aumento do nível de trofia. O biovolume final foi semelhante em todas as simulações, embora esta espécie tenha iniciado o experimento com biovolume inferior no oligotrófico, demonstrando seu melhor desempenho.

Além disso, M. contortum, apresentou velocidade específica de crescimento crescente do ambiente oligotrófico para o supereutrófico e tempos de duplicação menores nos maiores níveis tróficos, corroborando com o autor e as informações referenciadas anteriormente, pois as clorofíceas apresentaram melhor desempenho no crescimento em condições com maiores concentrações de nutrientes.

No entanto, referente aos ensaios de interação, não houve semelhanças entre as pesquisas. Zhu et al. (2010) verificaram vantagem competitiva de $M$. aeruginosa nas menores concentrações de nutrientes ao passo que nesta pesquisa, no ambiente oligotrófico, $C$. 
raciborskii foi prejudicada na competição pois diminuiu sua biomassa e entrou em senescência a partir do $8^{\circ}$ dia de experimento.

Em maiores concentrações de nutrientes, a vantagem na interação foi de M. contortum, confirmando o ocorrido nos experimentos de Zhu et al. (2010) em que a clorofícea $S$. quadricauda foi beneficiada, nesta mesma situação, em interação com a cianobactéria $M$. aeruginosa. Mas, é válido lembrar que nesta pesquisa, no ambiente mesotrófico, $M$. contortum e C. raciborskii não apresentaram diferenças em seus biovolumes finais, além de a clorofícea apresentar diferenças significativas nos parâmetros cinéticos de crescimento comparados ao seu controle.

Em contrapartida, a interação entre cianobactéria e clorofícea investigada por Rodrigo et al. (2009), apresentou resultados mais semelhantes aos encontrados nesta pesquisa. Os autores realizaram experimentos com 8 espécies de fitoplâncton, incluindo duas cianobactérias filamentosas, Limnothrix redekei e Planktothrix agardhii, a clorofícea $M$. contortum, entre outras. Os experimentos consistiram em analisar o crescimento dessas espécies em monocultura em condições oligotróficas e eutróficas, a $20^{\circ} \mathrm{C}$, fotoperíodo de 12 horas, luz de $30 \mu \mathrm{E} \cdot \mathrm{m}^{-2} \cdot \mathrm{s}^{-1}$, por 36 dias. Analisaram também a interação de $M$. contortum com as outras sete espécies em meio oligotrófico com culturas utilizadas na fase estacionária, aos 40 dias, para averiguar a capacidade de recuperação de cada espécie. Para os experimentos foram utilizados nutrientes na forma dissolvida, sendo que no oligotróficos foram utilizadas as concentrações de 6,2 $\mu \mathrm{g} . \mathrm{L}^{-1}$ de fósforo e $152 \mu \mathrm{g} . \mathrm{L}^{-1}$ de nitrogênio e no eutrófico, $62 \mu \mathrm{g} . \mathrm{L}^{-1}$ de fósforo e $1520 \mu \mathrm{g} . \mathrm{L}^{-1}$ de nitrogênio estabelecendo uma relação N:P de 25:1.

As concentrações de fósforo e nitrogênio utilizadas na pesquisa de Rodrigo et al. (2009) foram mais próximas às desta pesquisa do que às de ZHU et al. (2010), apesar de as concentrações de nitrogênio não terem variado e as relações $\mathrm{N}: \mathrm{P}$ serem diferentes nos três ambientes simulados.

Os cultivos das monoculturas nas duas condições de trofia realizados por Rodrigo et al. (2009) evidenciaram que o crescimento e a biomassa de $M$. contortum foram maiores no eutrófico. Em contrapartida L. redekei apresentou melhores resultados na condição oligotrófica, tanto em densidade quanto biomassa, e $P$. agardhii não apresentou diferença entre os tratamentos. 
Estes dois estudos confirmaram os resultados desta pesquisa, em que, a cianobactéria obteve melhor crescimento em menores concentrações de nutrientes e as clorofíceas em maiores, embora as espécies estudadas tenham sido diferentes.

Os experimentos de interação, no oligotrófico, entre M. contortum e L. redekei e entre esta clorofícea e P. agardhii, demonstraram que o crescimento de $M$. contortum foi superior ao das duas cianobactérias e estas não se desenvolveram. O mesmo foi observado no oligotrófico desta pesquisa, no qual C. raciborskii, além de diminuir sua biomassa, apresentou senescência. Com outras espécies nas mesmas condições de trofia, os autores constataram que M. contortum apresentou melhor desempenho quando em interação com Cosmarium contractum e Euglena gracilis, demonstrando que, apesar de maior crescimento de $M$. contortum, as cianobactérias influenciaram o desenvolvimento desta clorofícea.

Além disso, Rodrigo et al. (2009) observaram que dos oito organismos estudados, os que eram de menor tamanho e de mais rápido crescimento se desenvolveram melhor no eutrófico, como M. contortum, e com eficiência fotossintética quatro vezes maior comparado aos organismos de melhor crescimento no oligotrófico, que foi caracterizado por organismos maiores e de crescimento lento, como a cianobactérias filamentosa Limnothrix redekei.

Dessa forma, observou-se nesta pesquisa semelhanças aos resultados obtidos por Rodrigo et al. (2009), pois M. contortum apresentou crescimento maior do que C. raciborskii nas interações dos ambientes oligotrófico e supereutrófico, e no mesotrófico, as espécies apresentaram crescimento final semelhante. Porém, $M$. contortum reduziu a sua biomassa na presença de C. raciborskii, visto que seus parâmetros de crescimento foram significativamente menores se comparados aos seus controles nos três níveis tróficos simulados.

Portanto, considerando os três ambientes simulados, M. contortum, de maneira geral, teve maior crescimento de biomassa em todas as interações com C. raciborskii. É importante ressaltar que apenas no oligotrófico a cianobactéria foi prejudicada, pois nos dois outros níveis tróficos, C. raciborskii não apresentou diferença significativa de crescimento entre interação e controle.

Segundo Reynolds (2006), na escala evolutiva, alguns organismos desenvolvem estratégias fisiológicas e morfológicas que podem aumentar a sua aptidão em determinados ambientes, embora nenhuma espécie seja bem adequada para todas as condições ambientais. Uma morfologia favorável à rápida troca de nutriente ocorre nos organismos que possuem maior relação área/volume, ou seja, possuem tamanhos menores, neste caso, M. contortum. Já os organismos de tamanho maior, C. raciborskii, possuem vantagens no armazenamento de 
nutrientes, motilidade e persistência. Dessa forma, os diferentes ambientes podem ser mais favoráveis para algumas espécies do que para outras.

De acordo com os trabalhos discutidos e conforme Odum (1988) há nove diferentes tipos de interações entre as espécies, das quais se destaca a competição por um recurso limitado e o amensalismo. A competição é a interação entre duas ou mais espécies em um ecossistema e que se sobrepõem, afetando o crescimento e o desenvolvimento das espécies, principalmente devido ao uso de recursos. Segundo Reynolds (2006), neste tipo de competição há exclusão de uma ou mais espécies, pois dois verdadeiros competidores não podem coexistir. O amensalismo é uma interação na qual uma espécie é inibida e a outra não é afetada, havendo a coexistência das espécies, pois a espécie inibida não é excluída.

Comparando o comportamento das espécies colocadas em interação nesta pesquisa com as relações propostas por Odum (1988) e o relatado por Reynolds (2006), apresentou-se a hipótese que no oligotrófico ocorreu interação do tipo competição por recurso limitado, pois o crescimento de $M$. contortum e de C. raciborskii foi menor comparado aos seus controles, ocorrendo até mesmo diminuição da biomassa da cianobactéria e sua senescência. No mesotrófico e supereutrófico, pode-se dizer que a relação entre as espécies foi de amensalismo, pois somente o crescimento da clorofícea foi inibido e C. raciborskii apresentou comportamento semelhante aos seus controles, como já mencionado. No entanto, não se pode afirmar que essas duas espécies tenham competido pelo recurso limitante, o fósforo, nestes dois níveis tróficos, pois há possibilidade da existência de outro fator que tenha provocado a inibição do crescimento da clorofícea.

Entretanto, mesmo com algumas semelhanças relacionadas à investigação de Zhu et al. (2010), os tipos de interação ocorridas nesta pesquisa não estiveram relacionados com o que estes observaram. Os autores relataram que a concorrência e inibição do crescimento entre as duas espécies estudadas, clorofícea e cianobactéria, ocorreram em altas concentrações de nutrientes. Quando a concentração foi baixa e houve maior relação N:P, provavelmente, ocorreu simbiose e estimulação entre as duas espécies.

A teoria da competição, relatada por Tilman et al. (1982), é definida pela competição por recursos entre duas espécies. A teoria retrata que se essas duas espécies, com semelhantes taxas de crescimento forem cultivadas juntas, com concentrações de recursos limitados, a espécie que obtiver a maior taxa de captação de nutriente é capaz de crescer mais rapidamente do que a outra. Porém, a espécie que obteve menor crescimento consegue manter seu 
crescimento a partir de outro recurso, mesmo em baixas concentrações. Quando estes dois recursos combinados são limitantes, uma das espécies será favorecida. Quando as concentrações destes dois recursos são elevadas, as duas espécies podem coexistir no mesmo ambiente.

Outra estratégia das espécies fitoplanctônicas na competição por recursos é o aumento da relação área/volume do organismo. Esta estratégia é principalmente observada em ambientes oligotróficos, visto que nestes a disponibilidade de um ou mais recursos é deficiente e as espécies com alta afinidade de assimilação do nutriente limitante são beneficiadas. Estas espécies são, geralmente, organismos pequenos, por ter maior relação área/volume, eliminando as espécies de tamanho grande (REYNOLDS, 2006).

Segundo Reynolds (1988), as clorofíceas são classificadas como C - esrategistas (competidoras), que se caracterizam por serem organismos pequenos, com alta relação área/volume e atividade metabólica, além de serem espécies adaptadas e com habilidade de excluir outras espécies e dominarem o ambiente ao encontrarem condições ideias. As cianobactérias encontram-se no grupo $\mathrm{S}$ - estrategista ("stress" tolerante), no qual estão inseridos os organismos grandes, com baixa relação área/volume, taxa de crescimento e atividade metabólica, embora sobrevivam em ambientes com reduzida concentração de nutrientes.

Conforme simulação do ambiente oligotrófico, C. raciborskii apresentou diminuição significativa em seu volume celular na interação comparado ao seu controle a partir do $6^{\circ}$ dia de experimento, o que demonstrou, de acordo com o discutido, que pode ser uma estratégia da espécie para aumentar sua relação área/volume e melhorar a assimilação de recursos escassos. Desta maneira, C. raciborskii adaptou-se para sobreviver com M. contortum, que possui vantagens fisiológicas e morfológicas sobre a cianobactéria, pois consegue capturar mais rapidamente os nutrientes devido ao seu volume celular reduzido e ter velocidade de crescimento maior. Happey-Wood (1988) afirma que as clorofíceas pequenas possuem vantagem adaptativa importante em ambientes oligotróficos por ter maior relação área/volume que aumenta a capacidade de absorção de nutrientes.

No controle, C. raciborskii também diminuiu o seu volume celular, mais tardiamente do que na interação, no $12^{\circ}$ dia, demonstrando também que pode ser estratégia da espécie no ambiente com menor disponibilidade de nutrientes. A diminuição do volume celular desta espécie mais tardiamente no controle pode ser explicada por ter havido maiores concentrações de nitrato e ortofosfato no controle de C. raciborskii, devido aos repiques de aclimatação, comparado à interação. 
Houve também uma diminuição do volume celular de C. raciborskii no mesotrófico e no supereutrófico da metade ao final do experimento, tanto no controle quanto na interação. Por isso, além de redução do volume celular para melhoria de assimilação de nutrientes, como ocorrido no ambiente oligotrófico, a diminuição do volume celular também estaria associada à permanência da espécie na fase exponencial de crescimento.

Além do volume celular, outro fato que pode estar relacionado à estratégia de $C$. raciborskii na competição com $M$. contortum no oligotrófico é o aumento da produção de saxitoxina, pois as concentrações foram significativamente maiores na interação comparadas ao controle, que será discutido adiante. Essa diferença entre controle e interação não foi observada no mesotrófico e no supereutrófico.

Nesta pesquisa, os ensaios realizados ocorreram sob a disponibilidade do fósforo como recurso limitante, por estar desbalanceado em relação ao nitrogênio. O crescimento do fitoplâncton, em grande parte das águas doces, é regulado pela disponibilidade fósforo (KENESI et al., 2009) e por ser constituinte das células estruturais desses organismos, assim como o nitrogênio também, podem interferir no desenvolvimento deles (TAVARES \& ROCHA, 2003).

Lee e Jones-Lee (1998) discutiram os fatores limitantes para o crescimento de algas em reservatórios e relataram que quando a relação da concentração de nitrogênio inorgânico (amônia e nitrato) com ortofosfato for superior a 7,5:1, o ambiente é limitado por fósforo. Nos três experimentos houve a limitação por fósforo e todas as relações $\mathrm{N}: \mathrm{P}$ foram superiores à considerada por estes autores, sendo na simulação do oligotrófico 302:1, 113:1 no mesotrófico e 28:1 no supereutrófico.

Vuorio et al. (2005) pesquisaram o impacto do enriquecimento de nutrientes na comunidade fitoplanctônica do Mar Báltico nas proporções N:P de 1:1 e 7:1, e constataram que, nesta segunda relação, a produção primária e a biomassa foram superiores à primeira, principalmente devido ao abundante crescimento das clorofíceas, inclusive de $M$. contortum. O enriquecimento com nutrientes não teve efeito significativo na biomassa total de cianobactérias fixadoras de nitrogênio e nenhum efeito sobre a toxicidade deste grupo de organismos. Porém, tratando-se de Anabaena spp (cianobactéria), observou-se maior biomassa na relação N:P baixa, confirmando a hipótese de Smith (1983) e Stal et al. (2003), que afirmam que em menores relações $\mathrm{N}: \mathrm{P}$ as cianobactérias tendem a predominar. 
Em estudo realizado por Smith (1983), em 17 lagos do mundo, o autor sugeriu que a proporção relativa de cianobactérias no epilimnion foi dependente da relação nitrogênio e fósforo totais nesta região, sendo raramente encontradas quando esta relação é superior a 29:1.

Kim et al. (2007) pesquisaram o efeito dos nutrientes limitantes e a relação N:P no crescimento da comunidade fitoplanctônica em um reservatório hipereutrófico. As cianobactérias dominaram o local estudado que se encontrava limitado por fósforo e, a partir de bioensaios, a adição de fósforo e nitrogênio na comunidade fitoplanctônica, diminuiu a relação N:P e favoreceu o crescimento das cianobactérias. Os autores afirmaram que muitos outros fatores ambientais poderiam estar relacionados com o florescimento das cianobactérias em locais eutrofizados, como luz e temperatura.

Além de aumentar o predomínio das cianobactérias em ambientes em que a relação $\mathrm{N}: \mathrm{P}$ é reduzida, Odum (1988) afirmou que cianobactérias fixadoras de nitrogênio iniciam a fixação de nitrogênio atmosférico para elevar a razão entre esses nutrientes.

Portanto, de acordo com esses autores e conforme as relações N:P desta pesquisa, no supereutrófico, que foi o experimento com menor relação N:P (28:1), C. raciborskii não apresentou deficiência em seu crescimento quando em interação com $M$. contortum. Conforme as fotos no apêndice $\mathrm{C}$, esta cianobactéria apresentou heterocistos em seus controles e na interação. O mesmo não foi observado no oligotrófico e mesotrófico, o que é uma evidência de que a cianobactéria iniciou a fixação do nitrogênio quando a relação N:P diminuiu.

Em relação às concentrações iniciais de nitrogênio na forma de nitrato, elas foram iguais nos três experimentos e em todas as culturas. Nos resultados pode-se observar que o consumo do nitrato, de modo geral, foi semelhante entre os controles e interação nos três níveis tróficos simulados. Nos três ambientes houve consumo deste nutriente no início do experimento e no final um aumento em sua concentração, embora o consumo tenha sido maior quanto mais elevado o nível de trofia.

A hipótese para o aumento da concentração de nitrato é a existência de bactérias nitrificantes nas culturas das duas espécies estudadas, uma vez que $M$. contortum e $C$. raciborskii foram isoladas do Reservatório de Itupararanga, e em análises preliminares de sua água o teste para tais organismos foi positivo. Além disso, análises ${ }^{1}$ a partir do método

\footnotetext{
${ }^{1}$ Análise microbiológica realizada no Laboratório de Microbiologia Ambiental na Universidade Federal de São Carlos - Campus Sorocaba.
} 
descrito por Schmidt e Belser (1984, modificado - ANEXO C) confirmaram a presença de bactérias nitrificantes nas culturas. É possível também que tenha ocorrido a presença de bactérias púrpuras não sulforosas, pois estas também são hábeis à fixação de nitrogênio atmosférico. Os dois grupos de bactérias referenciados pertencem ao filo Proteobacteria, que se caracteriza por serem organismos gram-negativos e possuírem grande diversidade metabólica (MADIGAN et al., 2004).

As bactérias nitrificantes são capazes de fixar nitrogênio atmosférico transformando-o em amônia e, posteriormente, à nitrito e nitrato, e como já relatado. Estes microrganismos possuem funções essenciais na ciclagem do nitrogênio. Os principais gêneros são Nitrosomonas e Nitrobacter, que se caracterizam por serem aeróbios e em sua maioria são organismos quimiolitotróficos e capazes de crescer autotroficamente. Estas bactérias são abundantes em ecossistemas aquáticos que recebem esgotos ou outros dejetos (MOAT \& FOSTER, 1988; MADIGAN et al. 2004), o que foi observado no reservatório em estudo devido ao uso e ocupação do solo em seu entorno (BEU et al., 2011).

De acordo com pesquisas realizadas por Sundareshwar et al. (2003), há relação da disponibilidade de fósforo com a fixação de nitrogênio pelas bactérias. Nos experimentos em que eram adicionadas concentrações de fósforo, as bactérias fixavam menores quantidades de nitrogênio, embora na literatura não tenham encontrado relação com o ocorrido. Em analogia, nesta pesquisa, o resultado foi semelhante, pois no experimento oligotrófico houve as maiores concentrações de nitrato no final do experimento e menor consumo deste nutriente.

Assim como as bactérias, os micronutrientes também podem ter influenciado o crescimento de M. contortum e de C. raciborskii. Alguns estudos, como de Lukac \& Aegerter (1993), Utkilen \& Gjǿlme (1995), Vuorio et al. (2005) e Quiblier et al. (2008), demonstraram a influência dos micronutrientes no crescimento de espécies fitoplanctônicas e na produção de toxina por algumas cianobactérias, sendo o ferro e o zinco os elementos mais significantes na influência na síntese destes compostos. Além disso, os micronutrientes também podem ser fatores limitantes para um determinado ambiente, inclusive podem limitar a fotossíntese (ODUM, 1988; WETZEL, 1993; REYNOLDS, 2006).

Nesta pesquisa, as concentrações iniciais dos micronutrientes utilizadas em todos os experimentos foram baseadas nas concentrações do Reservatório de Itupararanga, modificando os elementos que constam no meio de cultura ASM-1, que são o zinco, ferro, manganês, cobre, boro e cobalto, conforme Tabela 3, apresentada no item 4.8.1. Comparando 
as concentrações dos micronutrientes do meio de cultura com as determinadas no reservatório, observou-se que para zinco e manganês foram utilizadas concentrações 2,39 e 18,29 vezes menores, respectivamente; o ferro permaneceu praticamente inalterado $\left(0,242 \mathrm{mg} . \mathrm{L}^{-1}\right.$ no reservatório e $0,223 \mathrm{mg} . \mathrm{L}^{-1}$ no meio de cultura ASM-1); e as concentrações do cobre, boro e cobalto foram superiores ao meio de cultura, sendo 264,71, 2,08, e 1,59 vezes maiores, respectivamente (Tabela 3).

Para os seres autótrofos, os elementos mais importantes são ferro (Fe), manganês $(\mathrm{Mn})$, cobre $(\mathrm{Cu})$, zinco $(\mathrm{Zn})$, boro $(\mathrm{B})$, silício $(\mathrm{Si})$, molibdênio $(\mathrm{Mo})$, cloro $(\mathrm{Cl})$, vanádio $(\mathrm{V})$ e cobalto (Co). Eles podem se agrupar de acordo com as suas principais funções, como aqueles que são necessários para a fotossíntese, $\mathrm{Mn}, \mathrm{Fe}, \mathrm{Cl}, \mathrm{Zn}$ e V; para o metabolismo do nitrogênio, Mo, B, Co, Fe; e os utilizados para outras funções metabólicas, Mn, B, Co, Cu e Si (ODUM, 1988).

Wetzel (1993) relata que as concentrações relativas de micronutrientes nas águas doces podem ter efeito sobre a capacidade competitiva das espécies da comunidade fitoplanctônica. Os micronutrientes metálicos, quando em excesso ou quando formam complexos orgânicos superiores aos limites de tolerância, são considerados muito tóxicos. $\mathrm{O}$ cobre, por exemplo, é utilizado como herbicida para controlar o crescimento do fitoplâncton, e sua concentração na água do reservatório é muito elevada, o que pode ter afetado o desenvolvimento das espécies em estudo.

Embora a concentração do cobre esteja alta em relação ao meio ASM-1, a Portaria MS $n^{\circ}$. 2914 do Ministério da Saúde (BRASIL, 2011) admite concentração máxima nas águas de consumo de $2 \mathrm{mg} . \mathrm{L}^{-1}$, e no Reservatório de Itupararanga a concentração encontrava-se inferior $\left(0,0135 \mathrm{mg} . \mathrm{L}^{-1}\right)$. Este elemento pode ser proveniente de sais de cobre utilizados em fungicidas e também de fertilizantes (BRAGA et al. 2005; PIVELI \& KATO, 2006), visto que é uma região que há grande ocupação do solo por agricultura (BEU et al. 2011).

Além disso, as concentrações de manganês estiveram abaixo das do meio de cultura ASM-1, e, conforme relatado por Odum (1988), este elemento é necessário para a fotossíntese, juntamente com o zinco, que também teve concentração inferior, e o ferro, que apresentou concentrações semelhantes.

Uma vez que a fotossíntese está relacionada com a absorção de luz pela clorofila-a e a sua concentração com a biomassa, pode-se dizer que estes micronutrientes referenciados podem ter limitado a fotossíntese de $M$. contortum e de C. raciborskii. Dessa forma, esses fatores podem ter contribuído para a diminuição da concentração de clorofila-a nos três experimentos realizados. No oligotrófico e mesotrófico a concentração diminuiu no final do 
experimento e no supereutrófico, a partir da metade do período considerado, embora as biomassas por biovolume tenham sido crescentes, exceto quanto à cianobactéria na interação do oligotrófico.

Além da relação dos micronutrientes com a menor síntese de clorofila-a, outra explicação para a diminuição deste pigmento é a sua relação com diminuição da concentração do ortofosfato observada em todas as culturas de todos os experimentos. Para a ocorrência da primeira fase da fotossíntese, que é a conversão da energia luminosa em energia química, é necessária a utilização de fósforo inorgânico para a fosforilação do ADP em ATP, que fornecerá energia para as células (LEHNINGER, 2000).

Foi observado também que as concentrações de clorofila-a foram maiores quanto mais elevado o nível trófico. A maior disponibilidade de fósforo no meio e conseqüente assimilação pelos microrganismos, gera maior energia disponível às células para assimilação do nitrato e sintetização de clorofila-a, uma vez que está é normalmente associada a proteína específica (LEHNINGER, 2000).

Nesta pesquisa, a maior assimilação de nitrato e maiores concentrações de clorofila-a ocorreram no ambiente supereutrófico, no qual, foi observado que houve diminuição significativa nas concentrações de nitrato e pico de concentração de clorofila-a no $3^{\circ}$ dia de experimento, nos controles e na interação.

As investigações de Hou et al. (2007), Lai et al. (2011) e Moore et al. (2008) corroboram com a hipótese de que sob limitação de nutrientes a síntese de clorofila-a é menor. Resultados demonstraram que a menor síntese deste pigmento ocorre principalmente quando há deficiência de nitrogênio nas células dos organismos, embora Lai et al. (2011) afirmem que tanto o fósforo quanto o nitrogênio são essenciais no metabolismo celular e a deficiência de qualquer um deles afeta a síntese de pigmentos. Por esse motivo, explica-se, nesta pesquisa, as concentrações de clorofila-a terem sido crescentes conforme o aumento do nível de trofia.

Para averiguar se as concentrações do ortofosfato e da clorofila-a estiveram correlacionadas no desenvolvimento desta pesquisa e confirmar o que foi discutido anteriormente, foi feita a correlação de Pearson entre esses parâmetros, do início ao fim dos três experimentos, considerando correlação linear fraca com $r$ entre 0,0 e 0,3 , moderada, $r$ entre 0,3 e 0,6 , relação forte com $r$ de 0,6 a 0,9 , e muito forte com valores de $r$ superiores a 0,9 (CALLEGARI-JACQUES, 2003). 
No oligotrófico, as relações foram consideradas moderadas, sendo $r=-0,54$, no controle de $C$. raciborskii, $\mathrm{r}=-0,53$ no controle de $M$. contortum e $\mathrm{r}=-0,42$ na interação. No mesotrófico, a relação foi moderada para o controle da cianobactéria $(r=-0,43)$ e forte na interação e no controle da clorofícea $(r=-0,6$ e $r=-0,78$, respectivamente). Na simulação do supereutrófico, todas as correlações foram fortes: no controle de C. raciborskii $(r=-0,84)$, na interação $(r=-0,6)$ e no controle de $M$. contortum, $(r=-0,68)$. Esses resultados corroboraram com o que foi discutido, demonstrando que houve uma relação inversamente proporcional entre as concentrações de ortofosfato e clorofila-a, mesmo havendo diminuição da concentração desta. Este fato demonstra a incorporação do ortofosfato à biomassa dos organsimos.

Deve-se considerar que há outros pigmentos que realizam esta captação de luz além deste analisado. Lee (2008) afirmou que há vários pigmentos que absorvem luz para a realização da fotossíntese pelos seres autótrofos, sendo quatro tipos de clorofila, $a, b, c$ e $d$, carotenóides e ficobiliproteínas. As clorofíceas possuem principalmente clorofilas $a$ e $b$ em seus complexos de captação de luz e as cianobactérias possuem as ficocianinas e aloficocianinas, que são dois tipos de ficobiliproteínas, como principais captores de luz, embora também possuam a clorofila-a.

Estes diferentes pigmentos nesses dois grupos de organismos fitoplanctônicos justificam a diferença inicial da concentração de clorofila-a entre os controles de $M$. contortum e de C. raciborskii em todos os experimentos. Ainda que tenham apresentado biovolumes semelhantes em todos os inóculos, a cianobactéria teve menores concentrações deste pigmento analisado comparado à clorofícea.

Conforme o que foi referenciado e as vantagens e desvantagens observadas nas duas espécies em seus controles e na interação, pode-se comparar as ocorrências e o desempenho de $M$. contortum e de C. raciborskii nos experimentos realizados com a mais atual classificação funcional por códons dos organismos fitoplanctônicos, proposta por Reynolds et al. (2002) e Padisák et al. (2008), contribuindo com as evidências já relatadas.

M. contortum e as demais espécies deste gênero são classificadas no códon $\mathrm{X} 1$, caracterizado por algas de ambiente raso e de transição do eutrófico para o hipereutrófico, tolerantes às estratificações e sensíveis à deficiência de nutrientes. C. raciborskii está inserida no códon $\mathrm{S}_{\mathrm{N}}$, que é caracterizada por indivíduos que estão presentes em ambientes mistos e quentes, embora não tenham provas suficientes para classificá-las neste grupo, pois se alguma espécie do gênero Cylindropermopsis for menos tolerante à sombra do que C. raciborskii, elas devem pertencer ao grupo H1. Além disso, C. raciborskii pode ocorrer em grandes 
profundidades e, por este motivo, poderia ser agrupada no grupo R, ou ainda no grupo MP, com espécies inseridas em ambientes frequentemente agitados e turvos. Esta cianobactéria é tolerante à ambientes deficientes de luminosidade e nitrogênio (REYNOLDS et al., 2002; PADISÁK et al. 2008).

Há evidências da ocorrência de C. raciborskii desde reservatórios oligotróficos, em regiões subtropicais, até em lagos hipereutróficos tropicais (PADISÁK, 1997). Os resultados desta pesquisa corroboraram com a literatura de que em ambientes mais eutrofizados esta cianobactéria tende a predominar, o que é preocupante na perspectiva de qualidade da água, por se tratar de uma espécie hábil à produção de toxinas (Saker et al., 2003).

O sucesso de C. raciborskii em diversos ambientes deve-se às grandes vantagens adaptativas que possui, à sua elevada eficácia na atividade fotossintética, na absorção de carbono inorgânico dissolvido, na absorção e transformação do fósforo inorgânico, à baixa exigência de luz, capacidades de migração da espécie na coluna da água, alta absorção de amônia e fixação do nitrogênio atmosférico, como também à resistência à herbivoria, entre outros fatores (PADISÁK, 1997; CHELLAPA et al., 2008; WU et al., 2009).

As causas para a produção de toxinas pelas cianobactérias não estão muito bem esclarecidas ainda, mas há hipóteses de que essas substâncias têm funções protetoras contra o grazing, e podem estar relacionadas à competição por recurso e às condições de crescimento (CALIJURI et al., 2006). Para investigar a síntese destes compostos e as suas causas, pesquisas de interações entre diferentes comunidades foram realizadas por diversos estudiosos, como por exemplo, interações entre clorofíceas e cianobactérias (KEARNS \& HUNTER, 2000), entre cianobactérias (SANTOS, 2009), cianobactéria e zooplâncton (FERRÃO-FILHO et al., 2009; SOARES et al., 2009; BERRY \& LIND, 2010), como também o desenvolvimento de pesquisas em genética molecular para investigar os genes envolvidos na síntese de toxinas (FURTADO, 2007; RASMUSSEN et al., 2008).

Kearns \& Hunter (2000) em estudo de interação entre a cianobactéria Anabaena flosaquae e a clorofícea Chlamydomonas reinhardtii, e cada uma dessas espécies com o substrato da outra, em tratamentos de 12 dias a $25^{\circ} \mathrm{C}$, verificaram que C. reinhardtii cresceu cinco vezes menos quando em contato com a cianobactéria, e vinte vezes menos quando era adicionado apenas o substrato de A. flos-aquae, quando comparado ao seu controle. Já a cianobactéria apresentou crescimento ligeiramente reduzido com a presença da clorofícea e o substrato desta não afetou o crescimento de A. flos-aquae. Os autores observaram que, quando 
em interação com a clorofícea, a cianobactéria produzia até duas vezes mais toxina, anatoxina e microcistina, embora houvesse diminuição desta concentração no final do experimento devido à limitação por nutrientes. Constatou também que apenas a microcistina inibiu o crescimento de C. reinhardtii, causando senescência desta.

Em estudo de interação entre cianobactérias realizado por Santos (2009) investigou-se a produção e a influência da microcistina produzida por $M$. aeruginosa em duas diferentes cepas de C. raciborskii. Foi constatado que a cepa de C. raciborskii, cuja toxicidade não foi determinada, foi mais competitiva do que as cepas tóxicas e não tóxicas de M. aeruginosa. Por outro lado, esta espécie tóxica apresentou vantagem competitiva quando em interação com a cepa não tóxica de C. raciborskii. Tais observações levaram o pesquisador a concluir que a síntese de toxina pode atuar na competição por interferência, produção de alelopáticos e comunicação química, reforçando as evidências de que, além das condições físico-químicas, as variáveis biológicas também contribuem para a produção de toxinas.

Considerando as três simulações de trofia realizadas nesta pesquisa, houve aumento significativo da produção de saxitoxina entre controle e interação da cianobactéria apenas no ambiente oligotrófico. Nos outros dois experimentos, a síntese de saxitoxina foi semelhante entre essas culturas.

De acordo com estas evidências e conforme os estudos investigativos da síntese de toxinas pelas cianobactérias, o aumento da síntese de saxitoxina no ambiente oligotrófico poderia estar vinculado a pelo menos dois fatores. Um seria atribuído à estratégia de defesa e sobrevivência da espécie, corroborando com Santos (2009) que afirmou que as variáveis biológicas também contribuem para a produção destes compostos e que podem até mesmo atuar como alelopáticos. Outro fator estaria relacionado à modificação do perfil de crescimento de C. raciborskii na interação, já que houve diminuição do volume celular e da biomassa de C. raciborskii, antecipação da fase estacionária e indução da fase de senescência a partir do $8^{\circ}$ dia de experimento.

A presença de cepas tóxicas e não tóxicas de cianobactérias em um ambiente pode estar relacionado à competição entre as populações e à dinâmica populacional, além de a toxicidade poder estar relacionada à algum estressor ambiental presente (CALIJURI et al., 2006).

C. raciborskii é uma espécie potencialmente tóxica e, no decorrer deste trabalho, foram isoladas cepas tóxicas e não tóxicas desta cianobactéria do Reservatório de Itupararanga. Embora esta espécie seja hábil à produção de cilindrospermopsina e saxitoxina, o teste ELISA detectou que as cepas tóxicas isoladas sintetizavam apenas saxitoxina. As 
saxitoxinas são alcalóides carbamatos e atuam no bloqueamento dos canais de sódio, impedindo a interrupção na comunicação entre as células musculares e os neurônios (ROSET et al., 2001).

As concentrações detectadas nos três experimentos foram inferiores ao limite admitido nos ecossistemas aquáticos brasileiros. A Portaria MS no 2914 do Ministério da Saúde (BRASIL, 2011) recomenda que as concentrações de saxitoxina nas águas potáveis não deve ser superior a $3 \mu \mathrm{g} \cdot \mathrm{L}^{-1}$.

Embora as concentrações da água do Reservatório de Itupararanga estejam abaixo do permitido pela legislação $\left(0,11 \mu \mathrm{g} . \mathrm{L}^{-1}\right.$, dado referente a coleta de fevereiro de 2011 , segundo CASALI, em andamento) a situação deste reservatório é preocupante por ser utilizado prioritariamente para o abastecimento público. Os resultados desta pesquisa deixaram claro que o aumento do nível trófico favoreceu a competitividade de C. raciborskii em relação ao M. contortum, apesar desta clorofícea ter sido mais abundante nos três ambientes simulados, houve apenas tendência à exclusão competitiva de C. raciborskii no ambiente oligotrófico.

Por isso, o fato de no ambiente oligotrófico a C. raciborskii ter velocidades específicas de crescimento maiores comparadas aos outros ambientes, esta não é uma característica que favorece esta espécie na competição. Considerando que foram nos ambientes mesotrófico e supereutrófico que a cianobactéria não teve seu crescimento inibido por $M$. contortum e permanceu na fase exponencial enquanto a clorofícea já se encontrava na fase estacionária.

Apenas recentemente as cianotoxinas nas águas são amplamente reconhecidas como um problema para a saúde pública (BARTRAM et al., 1999). No Brasil, há alguns registros de intoxicação em populações humanas pelo consumo de água contaminada por cianotoxinas. Um dos casos mais graves foi o ocorrido em Caruaru em 1996, onde pacientes de uma clínica de hemodiálise apresentaram intoxicação hepática, causada pelo uso da água contaminada por cianotoxinas, acarretando na morte de metade deles (AZEVEDO, 1998).

É válido lembrar que esta pesquisa foi embasada nas características de duas espécies que são, de maneira geral, as mais abundantes no Reservatório de Itupararanga. Outras espécies ou mudanças ambientais podem influenciar a comunidade fitoplanctônica e modificar os indivíduos que ali dominam, bem como aumentar a produção de cianotoxinas. Segundo Calijuri et al. (2006) e Wetzel (1993) essa alteração da comunidade é decorrente das interações de diversos fatores, como por exemplo, luz, temperatura, $\mathrm{pH}$, concentrações dos 
macronutrientes e micronutrientes, competição pelos recursos, predação, ciclo hidrológico, hidrodinâmica dos reservatórios, entre outros.

Portanto, as populações de C. raciborskii e $M$. contortum no Reservatório de Itupararanga podem sofrer influências em seus crescimentos e domínios devido à diversos fatores, os quais não puderam ser previstos nesta pesquisa. Porém, de acordo com os relatórios da CETESB (CETESB, 2008, 2009, 2010), a qualidade da água deste ecossistema está diminuindo, tornando-se cada vez mais eutrofizada.

Por isso, o aumento do grau de trofia poderia incrementar a competitividade de $C$. raciborskii no reservatório num cenário de crescente domínio desta cianobactéria, além de possível aumento na síntese de cianotoxinas.

A preocupação não se deve apenas com o aumento da liberação dessas cianotoxinas na água, pois o potencial tóxico dessas substâncias e a ação nos organismos podem sofrer influências por vários fatores após se dispersarem no ambiente. Exemplos são a interação com outras substâncias, as vias de contaminação e o tempo de contato com os organismos, o transporte entre os compartimentos do ecossistema, o processo de degradação, entre outros (SIVONEN \& JONES, 1999; CALIJURI et al., 2006).

De acordo com o discutido, a crescente degradação ambiental em torno do Reservatório de Itupararanga e dada a importância deste manancial à região e à Bacia Hidrográfica do Sorocaba e Médio Tietê, deve haver incentivos à pesquisas no local a fim de realizar ações de planejamento ambiental na área para favorecer o manejo e conservação deste recurso hídrico, com o intuito de que este reservatório continue sendo potencialmente utilizado em beneficio da população. 


\section{CONCLUSÕES}

De acordo com os experimentos realizados de interação entre C. raciborskii e $M$. contortum, simulando o Reservatório de Ituparanga nos ambientes oligotrófico, mesotrófico e supereutrófico, pode-se concluir que:

- As velocidades específicas de crescimento de M. contortum foram crescentes com o aumento do nível de trofia, enquanto que os tempos de duplicação foram decrescentes. $\mathrm{O}$ contrário ocorreu com C. raciborskii, com velocidades decrescentes e tempo de duplicação crescente de acordo com a elevação da trofia.

- Houve evidências de que C. raciborskii reduziu o crescimento de M. contortum, independente do ambiente simulado. Embora, no ambiente oligotrófico, a cianobactéria tenha antecipado as fases estacionária e senescência. No entanto, devido às variações detectadas nas concentrações de nutrientes entre controle e interação, mais estudos com condições controladas de nutrientes seriam necessários para reforçar esta hipótese.

- A redução do volume celular pode ser estratégia de sobrevivência de C. raciborskii em ambientes oligotróficos, visto que houve diminuição acentuada desta característica nos ensaios de interação. Esta modificação estaria relacionada ao aumento da relação área/volume celular e consequente aumento da assimilação de nutrientes e explicaria a maior abundância de $M$. contortum em todos os ensaios de interação realizados, já que o volume celular desta espécie foi sempre menor do que da cianobactéria.

- O consumo de ortofosfato e nitrato foram semelhantes nos três ambientes em todas as culturas. A concentração de ortofosfato diminuiu desde o início do experimento e permaneceu baixa e praticamente constante até o final. O nitrato foi consumido no início e, posteriormente, sua concentração aumentou no fim dos experimentos, devido, provavelmente, à presença de bactérias nitrificantes nas culturas.

- A assimilação do nitrato foi maior, pelas duas espécies, quanto mais elevado o nível trófico. Esta relação dá-se devido à maior disponibilidade de fósforo para os microrganismos. Consequentemente, as maiores concentrações de clorofila-a também ocorreram em ambientes com maiores concentrações e assimilação de nutrientes. 
- A simulação do ambiente oligotrófico favoreceu a síntese de saxitoxinas e mudou o perfil de crescimento de C. raciborskii, tornando-a menos competitiva do que M. contortum. Tais evidências não foram observadas nos demais ambientes simulados.

- Considerando que C. raciborskii não apresentou inibição em seu crescimento pela presença de $M$. contortum e que esta clorofícea apresentou melhor desempenho em seu crescimento em ambientes mais eutrofizados, o crescimento de $M$. contortum deverá ser acelerado no Reservatório de Itupararanga, porém, C. raciborskii continuará persistindo e afetando o desenvolvimento desta clorofícea, já que a clorofícea inicia mais rapidamente a fase estacionária enquanto a cianobactéria permanece na fase exponencial.

- Além dos nutrientes, muitos outros fatores físicos, químicos e biológicos, que não são possíveis de serem previstos nesta pesquisa, podem interferir no desenvolvimento da comunidade fitoplanctônica, podendo sofrer alterações neste reservatório no decorrer dos anos.

- A situação da qualidade da água do Reservatório de Itupararanga é preocupante para a saúde pública devido a $C$. raciborskii ser uma espécie potencialmente tóxica e este corpo hídrico ser utilizado para o abastecimento público. As degradações ambientais e inadequado uso e ocupação do solo em seu entorno estão contribuindo com o aceleramento da eutrofização da água e com o possível aumento das concentrações de cianotoxinas.

Portanto, incentivos às pesquisas e ações de planos de manejo são essenciais para contribuir com a conservação do recurso hídrico e da biodiversidade da fauna e flora deste importante manancial para região e à Bacia Hidrográfica do Sorocaba e Médio Tietê. 


\section{REFERÊNCIAS BIBLIOGRÁFICAS}

APHA, American Public Health Association. 1995. Standart methods for the examination of water and wastewater. $19^{\text {th }}$ ed., Washington: Byrd Prepess Spingfield.

AZEVEDO, S.M.F.O. 1998. Toxinas de cianobactérias: causas e conseqüências para a saúde pública. Medicina On Line, v. 1, Ano 1, n. 3.

BARTRAM, J. et al. 1999. Introduction. In: CHORUS, I.; BARTRAM, J. (Ed). Toxic cyanobacteria in water: a guide to their public health consequences, monitoring and management. London and New York: St Edmundsbury. p. 1-14.

BERRY, J.P.; LIND, O. 2010. First evidence of "paralytic shellfish toxins" and cylindrospermopsin in a Mexican freshwater system, Lago Catemaco, and apparent bioaccumulation of the toxins in "tegogolo"snails (Pomacea patula catemacensis). Toxicon, v. 55, p. $930-938$.

BEU, S.E; MISATO, M.T.; HAHN, C.M. 2011. APA de Itupararanga. In: BEU, S.E.; DOS SANTOS, A.C.A.; CASALI, S.P. Diversidade na APA Itupararanga: Condições atuais e perspectivas futuras. $1^{a}$ Ed. - São Paulo: SMA/ FF/ UFSCar/ CCR - Via Oeste. p. 33-49.

BICUDO, C.E.M. e MENEZES, M. 2006. Gêneros de Algas de Águas Continentais do Brasil: chave para identificação e descrições. Ed. Rima, 489p.

BOUVY, M.; FALCÃO, D.; MARINHO, M. PAGANO, M.; MOURA, A. 2000. Occurrence of Cylindrospermopsis (Cyanobacteria) in 39 Brazilian tropical reservoirs during the 1998 drought. Ecologia de Microrganismos aquáticos, v. 23, p.13-27.

BRAGA, B. Et al. 2005. O meio aquático. In: . Introdução à Engenharia Ambiental: o desafio do desenvolvimento sustentável. Ed. Pearson Prentice Hall, $2^{a}$ ed, São Paulo: p. 73 124.

BRASIL. 2005. Resolução CONAMA 357/05. Disponível em: <http://www.mma.gov.br>. Acesso em: outubro/2011.

BRASIL. 2011. Portaria do Ministério da Saúde no . 2914. Disponível em: < http://www.agenciapcj.org.br/novo/images/stories/portaria-ms-2914.pdf >. Acesso em: janeiro/2012.

BRIAND, J.F., ROBILLOT, C., QUIBLIER-LLOBÉRAS, C., HUMBERT, J.F., COUTÉ, A., BERNARD, C. 2002. Environmental context of Cylindrospermopsis raciborskii (Cyanobacteria) blooms in a shallow pond in France. Water Research, v. 36, p. 3183-3192.

CALIJURI, M.C.; ALVES, M.S.A.; DOS SANTOS, A.C.A. 2006. Cianobactérias e cianotoxinas em águas continentais. São Carlos: Rima, 109p. 
CALIJURI, M.C.; CUNHA, D.G.F.; POVINELLI, J. 2010. Sustentabilidade: um desafio na gestão dos recursos hídricos. São Carlos: EESC-USP. 80 p.

CALlEGARI-JACQUES, S.M. 2003. Bioestatística - Princípios e Aplicações. Ed. Artmed, $1^{\mathrm{a}}$ ed, Porto Alegre: $256 \mathrm{p}$.

CARLSON, R.E. 1977. A trophic state index for lakes. Limnology and Oceanography, v. 22, p. 361-380.

CASALI, S.P. A comunidade fitoplanctônica no Reservatório de Itupararanga (Bacia do Rio Sorocaba - S.P.). Em andamento. Tese (Doutorado em Hidráulica e Saneamento). Escola de Engenharia de São Carlos da Universidade de São Paulo, São Carlos.

CETESB - Companhia de Tecnologia de Saneamento Ambiental. 2008. Relatório de qualidade de águas interiores no Estado de São Paulo. Série relatórios. 531 p. Disponível em $<\mathrm{http}: / /$ www.cetesb.sp.gov.br>. Acesso em outubro/2011.

CETESB - Companhia de Tecnologia de Saneamento Ambiental. 2009. Relatório de qualidade de águas interiores no Estado de São Paulo. Série relatórios. 312 p. Disponível em $<$ http://www.cetesb.sp.gov.br>. Acesso em outubro/2011.

CETESB - Companhia de Tecnologia de Saneamento Ambiental. 2010. Relatório de qualidade de águas interiores no Estado de São Paulo. Série relatórios. 300 p. Disponível em $<$ http://www.cetesb.sp.gov.br>. Acesso em outubro/2011.

CARMICHAEL, W.W. 1994. An overview of toxic cyanobacterial research in the United States. In Proc. Of Toxic Cyanobacteria - A Global Perspective. Adelaide, South Australia Centre for Water Quality Research.

CARMICHAEL, W.W.; et al. 2001. Human fatalities from cyanobacteria: chemical and biological evidence for cyanotoxins. Environmental Health Perspectives, v. 109, p. 663-668.

CHELlAPPA, N.T., BORBA, J.M., ROCHA, O. 2008. Phytoplankton community and physical-chemical characteristics of water in the public reservoir of Cruzeta, RN, Brazil. Brazilian Journal of Biology, v. 68, n. 3, p. 477-494.

COMITÊ DA BACIA HIDROGRÁFICA DOS RIOS SOROCABA E MÉDIO TIETÊ. 2010. Relatório de situação. 38 p.

DE NOBEL, W.T.; et al. 1997. Competition for phosphorus between the nitrogen-fixing cyanobacteria Anabaena and Aphanizomenon. Microbiology Ecology, v. 24, p. 259-267.

DUCOBU, H.; HUISMAN, J.; JONKER, R.R.; MUR, L.R. 1998. Competition between a prochlorophyte and a cyanobacterium under various phosphorus regimes: comparison with the droop model. Journal of Phycology, v. 34, p. 467-476.

FERRÃO-FILHO, A.S., et al. 2009. Florações de cianobactérias tóxicas no Reservatório do Funil: dinâmica sazonal e conseqüências para o zooplâncton. Oecologia Brasiliensis, v.13, n.2, p. 346-365. 
FERREIRA, R.M. Efeitos da limitação de fósforo na eficiência fotossintética, na morfologia e no crescimento de Cylindrospermopsis raciborskii. 2007. Dissertação (Mestrado em Ecologia Aplicada ao Manejo e Conservação dos Recursos Naturais) - Universidade Federal de Juiz de Fora, MG.

FURTADO, A.L.F.F. Isolamento, morfologia, análises moleculares e testes toxicológicos de cianobactérias em lagoa facultativa de sistema de estabilização (Cajati/SP). 2007. 152 f. Tese (Doutorado em Hidráulica e Saneamento). Escola de Engenharia de São Carlos da Universidade de São Paulo, São Carlos, 2007.

GARCIA, J. P. M.; FREITAS, N. P.; FILHO, N. L. S. 1999. Caracterização geo-ambiental da Represa de Itupararanga. Disponível em $<$ http://IPE.ibrc.unesp.br/cbhsmt/projeto.html $>$ Acessado em 30.jul.2010.

GORHAM, P.R.; McLACHLAN, J.; HAMMER, U.T. 1964. Isolation and culture of toxic strains of Anabaena flos-aquae (Lyngb.) de Bréb. Verhandlungen des Internationalen Verein Limnologie, v.15, p. 796-804.

GUERRERO III, R.D.; VILLEGAS, C.T. 1982. Report of the training course on growing food organism for fish hatcheries. Phillippines, South China Sea Fisheries Development/Coordinating Programam.

GUILLARD, R.R.L.; LORENZEN, C.J. 1972. WC Medium. In: ANDERSEN, R.A. Algal culturing techniques. Academic Press, 2005. 578p.

HAPPEY-WOOD, C.M. 1988. Ecology of freshwater planktonic green algae. In: SANDGREEN, C.D. (ed). Growth and reprodutive strategies os freshwater phytoplankton. New York: Cambridge University Press. p. 175-226.

HILLEBRAND, H.; DÜRSELEN, C.D.; KIRSCHTEL, D. 1999. Biovolume calculations for pelagic and benthic microalgae. Journal of Phycology, v. 35, p. 403-424.

HOU, J.J; et al. 2007. Effects of nutrient limitation on pigments in Thalassiosira weissflogii and Prorocentrum donghaiense. Journal of Integrative Plant Biology, v. 49, n. 5, pg 686-697.

HUSTON, M. 1979. A general hypothesis in species diversity. American Naturalist, v. 113, p. 81-101.

HYENSTRAND, P.; BURKERT, U.; PETTERSSON, A.; BLOMQVIST, P. 2000. Competition between the green alga Scenedesmus and the cyanobacterium Synechococcus under different modes of inorganic nitrogen supply. Hydrobiologia, v. 435, n. 9, p. 91-98.

KEARNS, K.D.; HUNTER, M.D. 2000. Green algal extracellular products regulate antialgal toxin production in a cyanobacterium. Environmental Microbiology, v. 2, n. 3, p. 291-297.

KENESI, G., et al. 2009. Effect os nitrogen forms on growth, cell composition and $\mathrm{N}_{2}$ fixation of Cylindrospermopsis raciborskii in phosphorus-limited chemostat cultures. Hydrobiologia, v. 623, p. 191-202. 
KIM, H.S.; et al. 2007. Effects of limiting nutrients and N:P ratios on the phytoplankton growth in a shallow hypertrophic reservoir. Hydrobiologia, v. 581, p. 255-267.

KOMÁRKOVÁ-LEGNEROVÁ, J. 1969. The systematics and ontogenesis of the genera Ankistrodesmus Corda and Monoraphidium gen. nov. In: FOTT, B. Ed. Studies in Phycology. Stuttgart: E. Schweizerbart'sche Verlagsbuchhandlung (Nägele und Obermiller). p. 75-140.

LAI, J.; et al. 2011. Responses of the growth and biochemical composition of Prorocentrum donghaiense of different nitrogen and phosphorus concentrations. Journal of experimental marine biology and ecology, v. 405, p. 6-17.

LAMPARELLI, M.C. Grau de trofia em corpos d'água do estado de São Paulo: Avaliação dos métodos de monitoramento. 2004. 238 f. Tese (Doutorado em Ciências na Área de Ecossistemas Terrestres e Aquáticos). Instituto de Biociências da Universidade de São Paulo, São Paulo, 2004.

LEHNINGER, A.L. 2000. Bioquímica: catabolismo e a produção da energia das ligações de fosfato. Vol.2. Tradução da 2a ed. Americana. São Paulo: Ed. Edgard Blücher Ltda. 436 p.

LEE, G. F. and JONES-LEE, A. 1998. Determination of Nutrient Limiting Maximum Algal Biomass in Waterbodies. Report G. Fred Lee \& Associates, El Macero, CA. Disponível em $<$ http://www.gfredlee.com/nut_limit.html $>$ Acessado em outubro/2011.

LEE, R.E. 2008. Phycology. $4^{\mathrm{a}}$ ed. New York: Cambridge University Press. 561 p.

LUKAC, M.; AEGERTER, R. 1993. Influence of trace metals on growth and toxin production of Microcystis aeruginosa. Toxicon, v. 31, p. 293-305.

MAKULLA, A., SOMMER, U. Relationships between resource ratios and phytoplankton species composition during spring in five north German lakes. 1993. Limnology and Oceanography, v. 38, n. 4, p. 846-856.

MADIGAN, M.T.; MARTINKO; J.M.; PARKER, J. 2004. Diversidade Procariótica: Bacteria. In: . Microbiologia de Brock. 10a ed. São Paulo: Prentice Hall. p. 333-421.

MOAT, A.G.; FOSTER, J.W. 1988. Nitrogen Metabolism. In: $2^{\mathrm{a}}$ ed. USA: John Wiley \& Sons. p. 251-283. . Microbial Physiology.

MOORE, C.M.; et al. 2008. Relative influence of nitrogen and phosphorus availability on phytoplankton physiology and productivity in the oligotrophic sub-tropical North Atlantic Ocean. Limnology and Oceanography, v. 53, n. 1, p. 291-305.

NEDERLANDSE NORM. 1981. Norm 6520: water spectrophotometric determination of chlorophyll a content. Delft: NEN.

NUSH, E.A. 1980. Comparison of different methods for chlorophyll and phaepigment. Arch. Hydrobiol. Bech. Sttutgart, v.14, p. 14-36. 
ODUM, E.P. 1988. Ecologia. Rio de Janeiro: Ed. Guanabara Koogan S.A. 434 p.

PADISÁK, J. 1997. Cylindrospermopsis raciborskii (Woloszynska) Seenayya et Subba Raju, an expanding, highly adaptative cyanobacterium: worldwide distribution and review os its ecology. Archiv für Hydrobiologie, v. 107, p. 563-593.

PADISÁK, J., BORICS, G., GRIGORSZKY, I., SORÓCZKI-PINTÉR, E. 2006. Use of phytoplanktom assemblages for monitoring ecological status os lakes within the Water Framework Directive: the assemblage index. Hydrobiologia, v. 553, p.1-14.

PADISÁK, J., CROSSETTI, L.O., NASELLI-FLORES, L. Use and misuse in the application of the phytoplankton functional classification: a critical review with updates. 2008. Hydrobiologia, Review Paper.

PIVELI, R.P.; KATO, M.T. 2006. Qualidade das águas e poluição: aspectos físico-químicos. São Paulo: ABES. 285p.

QUIBLIER, C. et al. 2008. Phytoplankton growth control and risk of cyanobacterial blooms in the lower Senegal River delta region. Water Research, v. 42, n. 4-5, p.1023-1034.

RASMUSSEN, J.P.; et al. 2008. Development and field testing of a real-time PCR assay for cylindrospermopsin-producing cyanobacteria. Journal of Applied Microbiology, v. 104, p. $1503-1515$.

REDFIELD, A.C., 1958. The biological control of chemical factors in the environment. American Scientist, v. 46, p. 205-221.

REYNOLDS, C.S. 1984. The ecology of freshwater phytoplankton. New York: Cambridge University Press. 384p.

REYNOLDS, C.S. 1988. Functional morphology and the adaptive strategies of freshwater phytoplankton. In SANDGREN, C.D. (ed). Growth and reprodutive strategies os freshwater phytoplankton. New York: Cambridge University Press. p. 388-433.

REYNOLDS, C.S. 2006. The ecology of phytoplankton: Ecology, Biodiversity, and Conservation. New York: Cambridge University Press. 551p.

REYNOLDS, C.S.; et al. 2002. Review: Towards a functional classification of the freshwater phytoplankton. Journal of Plankton Research, v. 24, n.5, p. 417-428.

REYNOLDS, C.S.; JAWORSKI, G.H.M. 1978. Enumeration of natural Mycrocystis populations. British Phycological Journal, v.13, p. 269-277.

RODRIGO, M.A.; et al. 2009. Mechanisms of microalgae selection during the assembly of a planktonic community. Aquatic Ecology, v. 43, p. 61-72.

ROSET, J., AGUAYO, S., MUÑOZ, M.J. 2001. Detéccion de cianobactérias y toxinas. Una revisión. Ver. Toxicología, v.18, p. 65-71. 
SAKER, M.L., et al. 2003. First report and toxicological assessment of the cyanobacterium Cylindrospermopsis raciborskii from Portuguese freshwaters. Ecotoxicology and Environmental Safety, v. 55, p. 243-250.

SANTOS, P.V. Interação entre Cylindrospermopsis raciborskii e Microcystis aeruginosa: implicações no crescimento de culturas e na produção de microcistinas. 2009. $94 \mathrm{f}$. Dissertação (Mestrado em Hidráulica e Saneamento). Escola de Engenharia de São Carlos da Universidade de São Paulo, São Carlos, 2009.

SÃO PAULO. 1998. Lei Estadual $n^{\circ}$. 10.100, de $1^{\text {o }}$ de dezembro de 1998. Disponível em: $<$ www.ambiente.sp.gov.br>. Acessado em: outubro/2011.

SCHMIDT, E. L.; BELSER, L. W. 1984. Nitrifying Bacteria. In Methods of Soil Analysis - Chemical and Microbiological Properties. Estados Unidos: Wisconsin, n. 9, Part 2, $4^{a}$ Ed. p. 1027-1042.

SIVONEN, K.; JONES, G. 1999. Introduction. In: CHORUS, I.; BARTRAM, J. (Ed). Toxic cyanobacteria in water: a guide to their public health consequences, monitoring and management. London and New York: St Edmundsbury. p. 42-111.

SMITH, M.J.; SHAW, G.R.; EAGLESHAM, G.K.; HO, L.; BROOKES, J.D. 2008. Elucidating the factors influencing the biodegradation of cylindrospermopsin in drinking water sources. Environmental Toxicology, v. 23, p. 413-421.

SMITH, V.H. 1983. Low nitrogen to phosphorus ratios favor dominance by blue-green algae in Lake Phytoplankton. Science, v. 221, p. 669-771.

SOARES, M.C.S.; LÜRLING, M.; PANOSSO, R.; HUSZAR, V. 2009. Effects of the cyanobacterium Cylindrospermopsis raciborskii on feeding and life-history characteristics of de grazer Daphnia magna. Ecotoxicology and Environmental Safety, v. 72, p. 1183-1189.

SOARES, R.M.; et al. 2006. Sub-lethal exposure from microcystins to renal insufficiency patients in Rio de Janeiro-Brazil. Environmental Toxicology, v. 21, p. 95-103.

SOMMER, U. Nutrient status and nutrient competition od phytoplankton in a shallow, hypertrophic lake. 1989. Limnology and Oceanography, v. 34, n. 7, p. 1162-1 173.

STAL, L.J.; et al. 2003. BASIC: Baltic Sea cyanobacteria. An investigation of the structure and dynamics of water blooms of cyanobacteria in the Baltic Sea-responses to a changing environment. Continental Shelf Research, v. 23, p. 1695- 1714.

STEIN, J.R. 1973. Handbook of Phycological Methods: Culture methods and growth measurements. Ed. Cambridge University Press, New York, USA. 448 p.

SUNDARESHWAR, P.V.; et al. 2003. Phosphorus limitation of Coastal Ecosystem Processes. Science, v. 299, p. 563-565.

TAVARES, L.H.S.; ROCHA, O. 2003. Produção de plâncton (Fitoplâncton e Zooplâncton) para alimentação de Oragnismos Aquáticos. São Carlos: Rima. 106 p. 
THOMANN, R.V.; MUELLER, J.A. 1987. Principles of surface water quality modeling and control. Harper International Edition. 644 p.

TILMAN, D., KILHAM, S.S., KILHAM, P., 1982. Phytoplankton community ecology: the role of limiting nutrients. Annual Review of Ecology and Systematics, v. 13, p. 349-372.

TÖRÖKNE, A, et al. 2004. Interlaboratory comparison trial on cylindrospermopsin measurement. Analytical Biochemistry, v. 332, n. 2, p. 280-284.

TORTORA, G.J., FUNKE, B.R. e CASE, C.L. 2004. Microbiologia. $8^{\text {a }}$ ed. Porto Alegre: Editora Artmed. 920 p.

TREBON, J.K.; PRAHA, B.F. 1983. Das Phytoplankton des SüBwassers: Systematik und Biologie. Germany: Stuttgart. 1043p.

UTKILEN, H.; GJØLME, N. 1995. Iron-Stimulated toxin production in Microcystis aeruginosa. Applied and Environmental microbiology, v. 61, n. 2, p. 797-800.

VARGAS, S.R.; DOS SANTOS, A.C.A. 2009. Caracterização da comunidade fitoplanctônica no Reservatório de Itupararanga, Votorantim, S.P.. In: XVII Congresso de Iniciação Científica da UFSCar, 2009, São Carlos. Anais do XVII Congresso de Iniciação Científica da UFSCar.

VON SPERLING, M. 1996. Introdução à qualidade das águas e ao tratamento de esgotos: princípios do tratamento biológico de águas residuárias - Vol $1-2^{\mathrm{a}}$ ed. Departamento de Engenharia Sanitária e Ambiental - DESA - Universidade Federal de Minas Gerais. Belo Horizonte. 243 p.

VUORIO, K., LAGUS, A.; LEHTIMÄKI, J.M.; SUOMELA, J.; HELMINEN, H. 2005. Phytoplankton community responses to nutrient and iron enrichment under different nitrogen to phosphorus ratios in the northern Baltic Sea. Journal of Experimental Marine Biology and Ecology, v. 322, p. 39-52.

WETZEL, R. G.1993. Limnologia. Lisboa: Editora Fundação Calouste Gulbenkian. p. 919.

WU, Z.; SHI, J.; LI, R. 2009. Comparative studies on photosynthesis and phosphate metabolism os Cylindrospermopsis raciborskii with Microcystis aeruginosa and Aphanizomenon flos-aquae. Harmful Algae. 6p.

YILMAZ, M., et al. 2008. A comparative study of Florida strains of Cylindrospermopsis and Aphanizomenon for cylindrospermopsin production. Toxicon, v. 51, p. 130-139.

ZHU, W.; WAN, L.; ZHAO, L. 2010. Effect of nutrient level on phytoplankton community structure in different water bodies. Journal of Environmental Sciences, v. 22, n. 1, p. 32-39. 


\section{ANEXOS}


ANEXO A - Meio de cultura WC (GUILLARD \& LORENZEN, 1972)

Tabela 23 - Composição do meio de cultura WC

\begin{tabular}{|c|c|c|c|}
\hline Componentes & $\begin{array}{c}\text { Solução } \\
\text { estoque (g.L- } \\
\left.1 \mathbf{d H}_{2} \mathbf{O}\right)\end{array}$ & $\begin{array}{c}\text { Qtd } p / 1 \mathrm{~L} \\
\text { WC }\end{array}$ & $\begin{array}{l}\text { Concentração } \\
\text { final no meio } \\
(M)\end{array}$ \\
\hline $\mathrm{NaNO}_{3}$ & 85,01 & $1 \mathrm{ml}$ & $3,78 \times 10^{-3}$ \\
\hline $\mathrm{CaCl}_{2} \cdot 2 \mathrm{H}_{2} \mathrm{O}$ & 36,76 & $1 \mathrm{ml}$ & $4,13 \times 10^{-3}$ \\
\hline $\mathrm{MgSO}_{4} .7 \mathrm{H}_{2} \mathrm{O}$ & 36,97 & $1 \mathrm{ml}$ & $1,00 \times 10^{-3}$ \\
\hline $\mathrm{NaHCO}_{3}$ & 12,6 & $1 \mathrm{ml}$ & $2,50 \times 10^{-4}$ \\
\hline $\mathrm{Na}_{2} \mathrm{SiO}_{3} .9 \mathrm{H}_{2} \mathrm{O}$ & 28,42 & $1 \mathrm{ml}$ & $1,50 \times 10^{-4}$ \\
\hline $\mathrm{K}_{2} \mathrm{HPO}_{4}$ & 8,71 & $1 \mathrm{ml}$ & $1,50 \times 10^{-4}$ \\
\hline $\begin{array}{c}\text { Solução de metais } \\
\text { traço }\end{array}$ & Tabela 24 & $1 \mathrm{ml}$ & $1,00 \times 10^{-3}$ \\
\hline $\begin{array}{l}\text { Solução de } \\
\text { vitaminas }\end{array}$ & Tabela 25 & $1 \mathrm{ml}$ & $5,00 \times 10^{-5}$ \\
\hline
\end{tabular}

Tabela 24 - Composição da solução de metais do meio de cultura WC

\begin{tabular}{cccc}
\hline Componentes & $\begin{array}{c}\text { Solução } \\
\text { estoque (g.L- } \\
\text { 1dH2O) }\end{array}$ & $\begin{array}{c}\text { Qtd usada } \\
\mathbf{1 L}\end{array}$ & $\begin{array}{c}\text { Concentração } \\
\text { final no meio } \\
(\boldsymbol{M})\end{array}$ \\
\hline $\mathrm{Na}_{2} \mathrm{EDTA} \cdot 2 \mathrm{H}_{2} \mathrm{O}$ & --- & $4,36 \mathrm{~g}$ & $1,17 \times 10^{-5}$ \\
\hline $\mathrm{FeCl}_{2} \cdot 6 \mathrm{H}_{2} \mathrm{O}$ & --- & $3,15 \mathrm{~g}$ & $1,17 \times 10^{-5}$ \\
\hline $\mathrm{CuSO}_{4} \cdot 5 \mathrm{H}_{2} \mathrm{O}$ & 10 & $1 \mathrm{ml}$ & $4,01 \times 10^{-8}$ \\
\hline $\mathrm{ZnSO} 4 \cdot 7 \mathrm{H} 2 \mathrm{O}$ & 22 & $1 \mathrm{ml}$ & $7,65 \times 10^{-8}$ \\
\hline $\mathrm{CoCl}_{2} \cdot 6 \mathrm{H}_{2} \mathrm{O}$ & 10 & $1 \mathrm{ml}$ & $4,2 \times 10^{-8}$ \\
\hline $\mathrm{MnCl}_{2} \cdot 4 \mathrm{H}_{2} \mathrm{O}$ & 180 & $1 \mathrm{ml}$ & $9,1 \times 10^{-7}$ \\
\hline $\mathrm{Na}_{2} \mathrm{MoO}_{4} \cdot 2 \mathrm{H}_{2} \mathrm{O}$ & 6 & $1 \mathrm{ml}$ & $2,48 \times 10^{-8}$ \\
\hline $\mathrm{H}_{3} \mathrm{BO}_{3}$ & --- & $1 \mathrm{~g}$ & $1,62 \times 10^{-5}$ \\
\hline
\end{tabular}


Tabela 25 - Composição da solução de vitaminas do meio de cultura WC

\begin{tabular}{cccc}
\hline Componentes & $\begin{array}{c}\text { Solução } \\
\text { estoque (g.L- } \\
\left.\mathbf{1 d H}_{\mathbf{2}} \mathbf{O}\right)\end{array}$ & $\begin{array}{c}\text { Qtd usada } \\
\mathbf{1 L}\end{array}$ & $\begin{array}{c}\text { Concentração } \\
\text { final no meio } \\
(\boldsymbol{M})\end{array}$ \\
\hline $\begin{array}{c}\text { Thiamine. } \mathrm{HCl} \\
\left(\text { vitamin } \mathrm{B}_{1}\right)\end{array}$ & --- & $100 \mathrm{mg}$ & $2,96 \times 10^{-7}$ \\
\hline Biotin (vitamin $\mathrm{H})$ & 0,5 & $1 \mathrm{ml}$ & $2,05 \times 10^{-9}$ \\
\hline $\begin{array}{c}\text { Cyanocobalamin } \\
\left(\text { vitamin } \mathrm{B}_{12}\right)\end{array}$ & 0,5 & $1 \mathrm{ml}$ & $3,69 \times 10^{-10}$ \\
\hline
\end{tabular}

ANEXO B - Meio de cultura ASM-1 (GORHAM et al., 1964 modificado por REYNOLDS \& JAWORSKI, 1978)

Tabela 26 - Composição do meio de cultura ASM-1

\begin{tabular}{|c|c|c|c|}
\hline Solução & Reagente & $\begin{array}{c}\text { Reagente } \\
\text { (g)/100ml } \\
\text { solução } \\
\end{array}$ & Solução (ml)/L de ASM-1 \\
\hline \multirow{4}{*}{ A } & $\mathrm{NaNo}_{3}$ & 0,85 & \multirow{4}{*}{20} \\
\hline & $\mathrm{MgCl}_{2} \cdot 6 \mathrm{H}_{2} \mathrm{O}$ & 0,205 & \\
\hline & $\mathrm{MgSO}_{4} \cdot 7 \mathrm{H}_{2} \mathrm{O}$ & 0,245 & \\
\hline & $\mathrm{CaCl}_{2} \cdot 2 \mathrm{H}_{2} \mathrm{O}$ & 0,145 & \\
\hline \multirow{2}{*}{ B } & $\mathrm{KH}_{2} \mathrm{PO}_{4}$ & 0,87 & \multirow{2}{*}{2} \\
\hline & $\mathrm{Na}_{2} \mathrm{HPO}_{4} \cdot 12 \mathrm{H}_{2} \mathrm{O}$ & 1,78 & \\
\hline \multirow{6}{*}{$\mathrm{C}$} & $\mathrm{H}_{3} \mathrm{BO}_{3}$ & 2,48 & \multirow{6}{*}{0,1} \\
\hline & $\mathrm{MnCl}_{2} \cdot 4 \mathrm{H}_{2} \mathrm{O}$ & 1,39 & \\
\hline & $\mathrm{FeCl}_{3} \cdot 6 \mathrm{H}_{2} \mathrm{O}$ & 1,08 & \\
\hline & $\mathrm{ZnCl}_{2}$ & 0,335 & \\
\hline & $\mathrm{CoCl}_{2} \cdot 6 \mathrm{H}_{2} \mathrm{O}$ & 0,019 & \\
\hline & $\mathrm{CuCl}_{2} \cdot 2 \mathrm{H}_{2} \mathrm{O}$ & 0,0014 & \\
\hline $\mathrm{D}$ & EDTA. $\mathrm{Na}_{2}$ & 1,86 & 0,4 \\
\hline
\end{tabular}


ANEXO C - Metodologia da análise de detecção de bactérias nitrificantes (Schmidt \&Belser, 1984).

A determinação do NMP das bactérias nitrificantes foi realizada em duas etapas: o NMP das bactérias oxidadoras de amônia e o NMP das bactérias oxidadoras de nitrito. A composição dos meios de cultura utilizados em cada etapa encontra-se nas tabelas 27 e 28 . Após o seu preparo, o pH foi ajustado para 7,5 com bicarbonato de sódio.

$\mathrm{Na}$ primeira etapa, que é a determinação de bactérias oxidadoras de amônia, foi adicionado $9 \mathrm{ml}$ de meio de cultura em cada tudo de ensaio, sendo utilizados 5 tubos para cada diluição. Os tubos foram tampados com rolhas de algodão envolvidos por gaze e autoclavados por 20 minutos sob pressão de $1 \mathrm{~atm}$ e temperatura de $120^{\circ} \mathrm{C}$. Posteriormente, foi adicionado $1 \mathrm{ml}$ de amostra previamente diluída, sob condições de assepsia, em cada tubo. Feito isto, os tubos foram encubados a $30^{\circ} \mathrm{C}$ por 30 dias.

Para a determinação de nitrito após a incubação, foi realizado um teste para verificar se o nitrogênio amoniacal havido sido consumido. De cada tubo foi retirado uma alíquota de $0,5 \mathrm{ml}$ e transferidas para outro tubo. Neste foram adicionados 2 gotas da solução A e em seguida 2 gotas da solução $B$, descritas a abaixo:

Solução A - dissolver 0,5g de sulfanilamida em $100 \mathrm{ml}$ de ácido clorídrico ( $\mathrm{HCl}$ ) 2,4 N. Armazenar em frasco escuro sob refrigeração.

Solução B - dissolver 0,3g de N-naftil-etilenodiamina hidrocloreto em $100 \mathrm{ml}$ de ácido clorídrico $(\mathrm{HCl})$ 0,12 N. Armazenar em frasco escuro sob refrigeração.

Após a adição das soluções verificou-se a cor apresentada nos frascos. A coloração rosa e vermelha significa presença de nitrito e, portanto, pode haver a presença de bactérias oxidadoras de amônia (resultado positivo).

Para a segunda etapa, que é a determinação da presença de bactérias oxidadoras de nitrito, foi realizado igual procedimento da primeira etapa. Após a adição das soluções A e B posteriormente aos 30 dias de incubação, a ausência de coloração significa que o nitrito foi consumido e, portanto, pode haver a presença de bactérias oxidadoras de nitrito (resultado positivo) e a coloração rosa significa presença de nitrito (resultado negativo para a presença dessas bactérias). 
Tabela 27 -Composição do meio de cultura para determinação de bactérias oxidadoras de amônia e nitrito.

\begin{tabular}{|c|c|c|c|}
\hline Componentes & $\begin{array}{c}\text { Solução estoque } \\
(100 \mathrm{ml})\left(\mathrm{g} \cdot \mathrm{ml}^{-1}\right. \\
\left.\mathrm{dH}_{2} \mathrm{O}\right)\end{array}$ & $\begin{array}{l}\text { Qtd }(\mathrm{ml}) \mathrm{p} / \\
500 \mathrm{ml} \text { para } \\
\text { bactérias } \\
\text { oxidadoras } \\
\text { amônia }\end{array}$ & $\begin{array}{c}\text { Qtd p/ } \\
500 \mathrm{ml} \text { para } \\
\text { bactérias } \\
\text { oxidadoras } \\
\text { nitrito }\end{array}$ \\
\hline$\left(\mathrm{NH}_{4}\right)_{2} \mathrm{SO}_{4}$ & 5 & 0,5 & --- \\
\hline $\mathrm{CaCl}_{2} \cdot 2 \mathrm{H}_{2} \mathrm{O}$ & 1,34 & 0,5 & 0,5 \\
\hline $\mathrm{NaNO}_{2} / \mathrm{KNO}_{2}$ & 0,69 & $\begin{array}{ll}-- \\
\end{array}$ & 0,5 \\
\hline $\mathrm{MgSO}_{4} \cdot 7 \mathrm{H}_{2} \mathrm{O}$ & 4 & 0,5 & 2,5 \\
\hline Azul de Bromotimol & 0,04 & 0,5 & --- \\
\hline $\mathrm{K}_{2} \mathrm{HPO}_{4}$ & 3,48 & 2 & $\begin{array}{c}-- \\
-1\end{array}$ \\
\hline $\mathrm{KH}_{2} \mathrm{PO}_{4}$ & 2,72 & 3,75 & 0,5 \\
\hline Ferro quelante & Tabela 28 & 0,5 & 0,5 \\
\hline Solução de metais traço & Tabela 28 & 0,5 & 0,5 \\
\hline
\end{tabular}

Tabela 28 - Composição das soluções ferro quelante e metais traço

\begin{tabular}{|c|c|c|}
\hline Solução estoque & Componentes & $\begin{array}{c}\text { Solução } \\
\text { estoque } \\
(100 \mathrm{ml})\left(\mathrm{g} \cdot \mathrm{ml}^{-1}\right. \\
\left.\mathrm{dH}_{2} \mathrm{O}\right) \\
\end{array}$ \\
\hline \multirow{2}{*}{ Ferro quelante } & Fe. $\mathrm{SO}_{4} .7 \mathrm{H}_{2} \mathrm{O}$ & 0,246 \\
\hline & EDTA dissolvido & 0,331 \\
\hline \multirow{5}{*}{ Metais traço } & $\mathrm{Na}_{2} \mathrm{MoO}_{4} \cdot 2 \mathrm{H}_{2} \mathrm{O}$ & 0,01 \\
\hline & $\mathrm{MnCl}_{2}$ & 0,02 \\
\hline & $\mathrm{CoCl}_{2} \cdot 6 \mathrm{H}_{2} \mathrm{O}$ & 0,0002 \\
\hline & $\mathrm{ZnSO} 4.7 \mathrm{H}_{2} \mathrm{O}$ & 0,01 \\
\hline & $\mathrm{CuSO}_{4} \cdot 5 \mathrm{H}_{2} \mathrm{O}$ & 0,002 \\
\hline
\end{tabular}


APÊNDICES 
APÊNDICE A - Fotos experimento de simulação ambiente oligotrófico

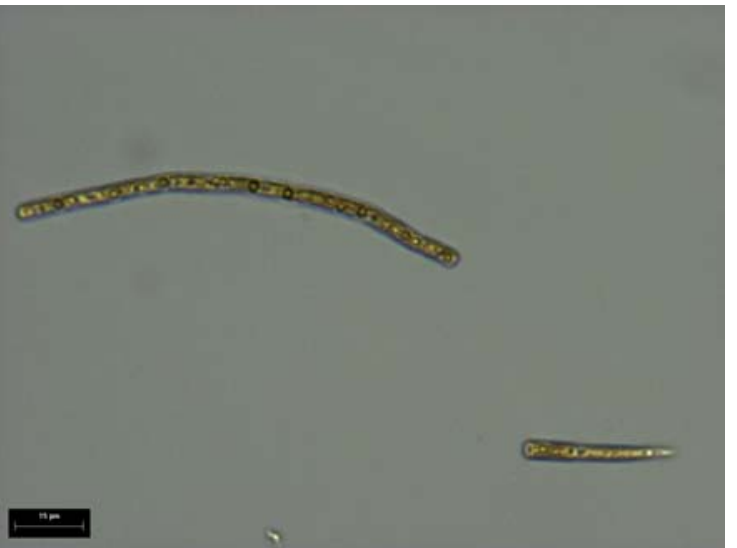

Figura 20: Controle C. raciborskii dia 0. Aumento de 400x. Escala de $15 \mu \mathrm{m}$.

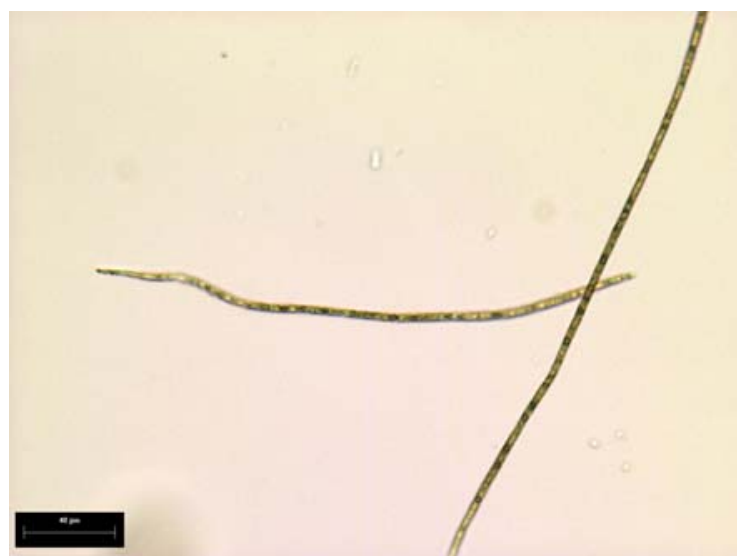

Figura 21: Controle C. raciborskii dia 7. Aumento de 200x. Escala de $40 \mu \mathrm{m}$.

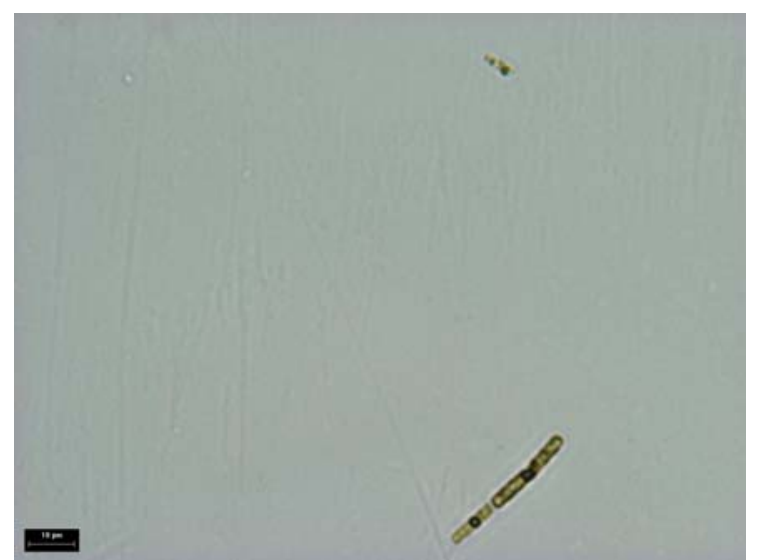

Figura 22: Controle C. raciborskii dia 15. Aumento de 400x. Escala de $10 \mu \mathrm{m}$. 


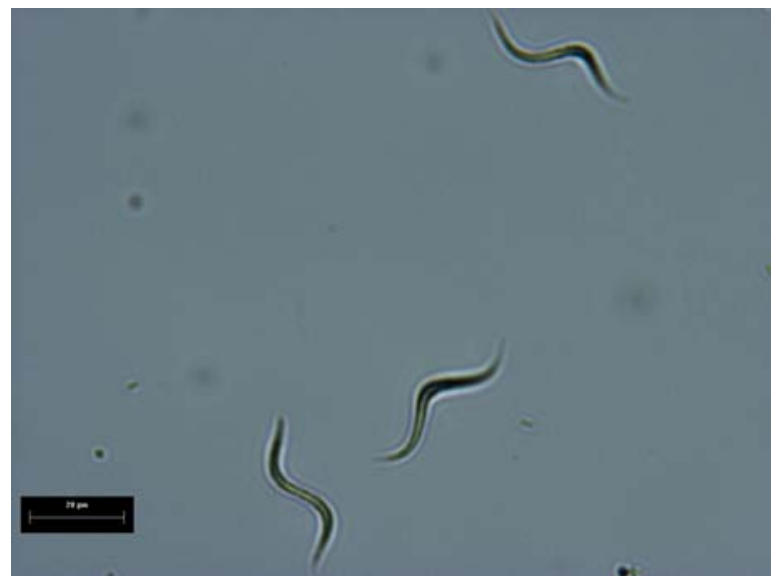

Figura 23: Controle M. contortum dia 0. Aumento de 400x. Escala de $20 \mu \mathrm{m}$.

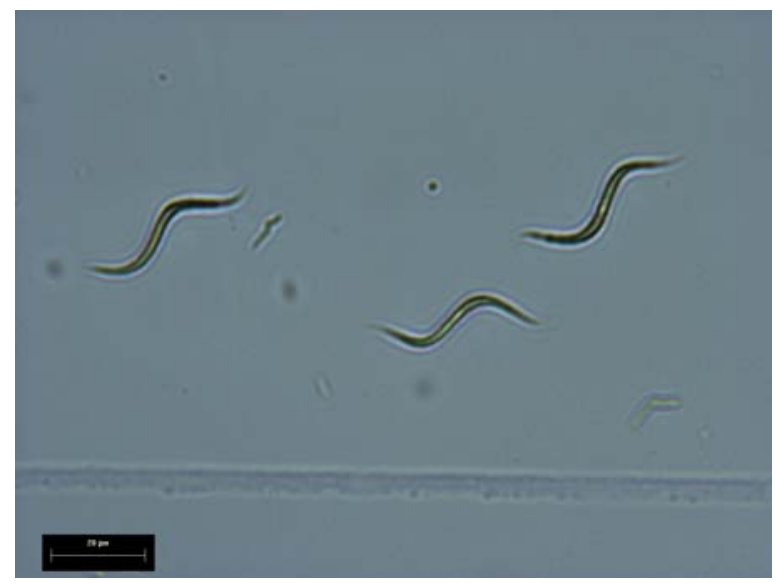

Figura 24: Controle M. contortum dia 7. Aumento de 400x. Escala de $20 \mu \mathrm{m}$.

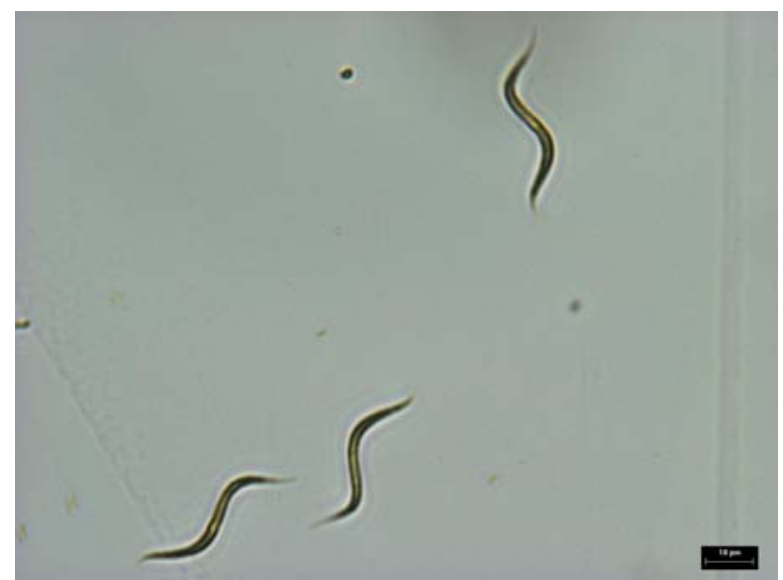

Figura 25: Controle $M$. contortum dia 15. Aumento de 400x. Escala de $10 \mu \mathrm{m}$. 


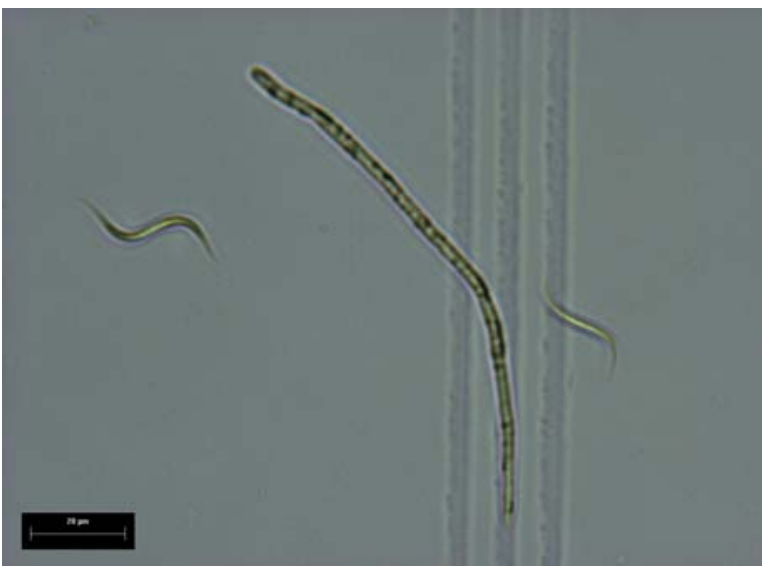

Figura 26: Interação dia 0. Aumento de 400x. Escala de $20 \mu \mathrm{m}$.

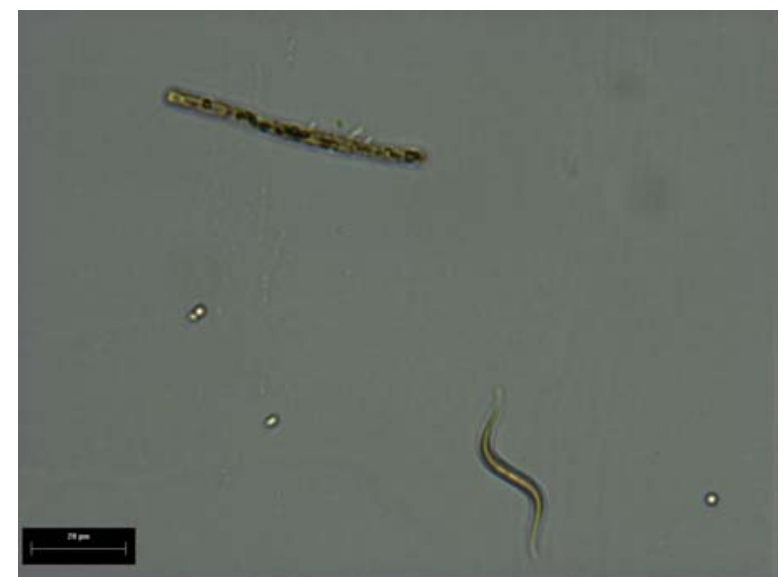

Figura 27: Interação dia 7. Aumento de 400x. Escala de $20 \mu \mathrm{m}$.

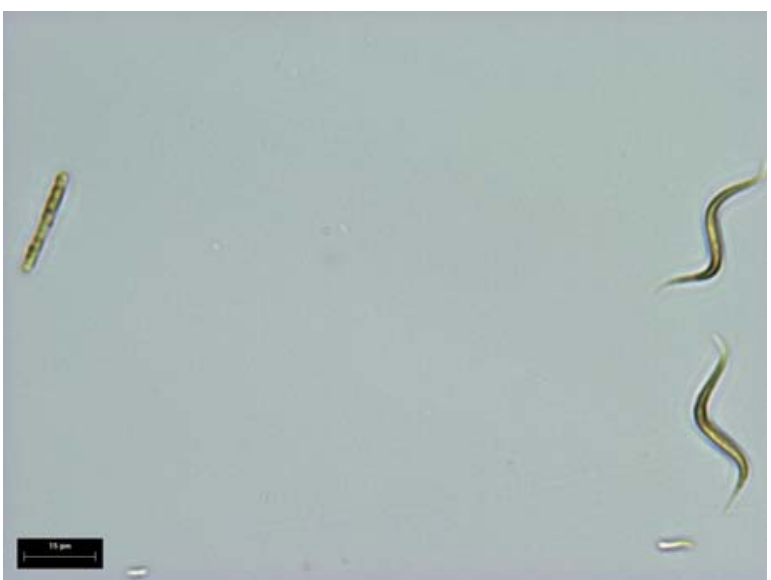

Figura 28: Interação dia 15. Aumento de 400x. Escala de $15 \mu \mathrm{m}$. 
APÊNDICE B - Fotos experimento de simulação ambiente mesotrófico

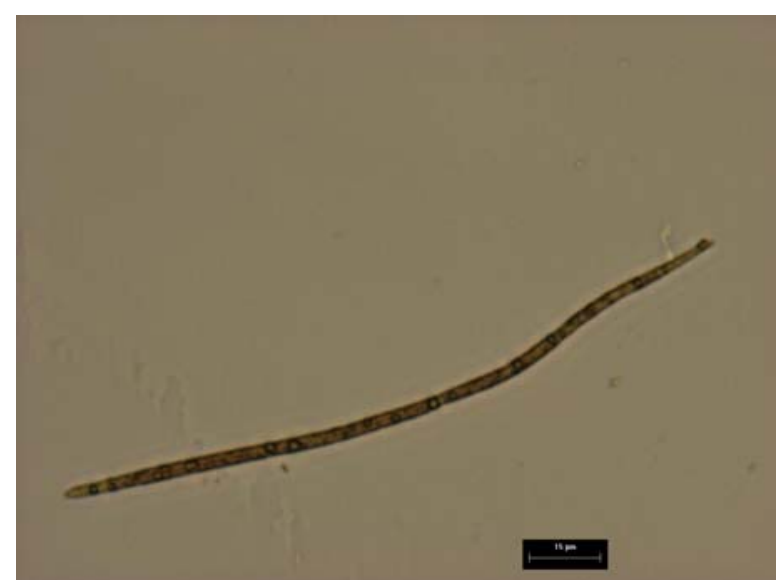

Figura 29: Controle C. raciborskii dia 0. Aumento de 400x. Escala de $15 \mu \mathrm{m}$.

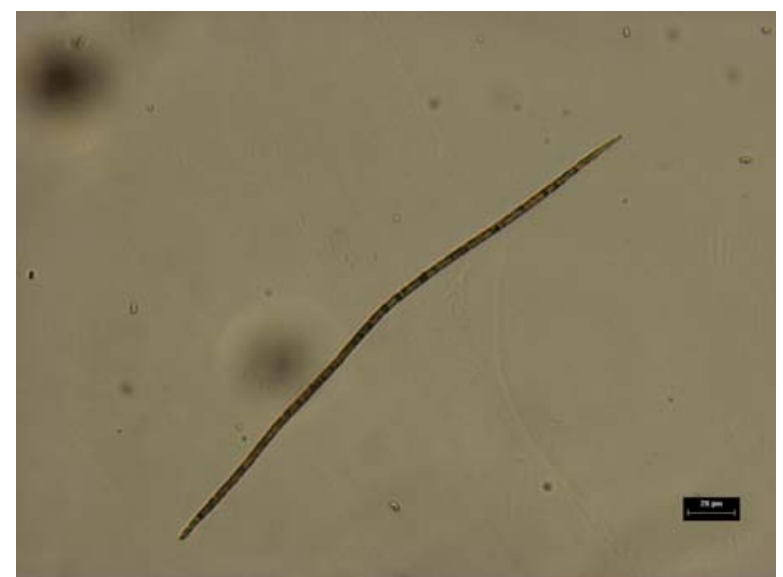

Figura 30: Controle C. raciborskii dia 7. Aumento de 200x. Escala de $20 \mu \mathrm{m}$.

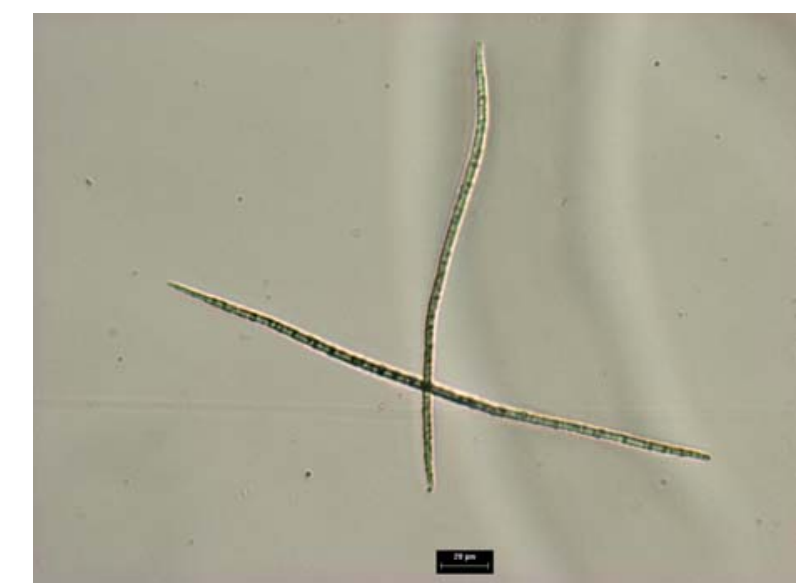

Figura 31: Controle C. raciborskii dia 15. Aumento de 200x. Escala de $20 \mu \mathrm{m}$. 


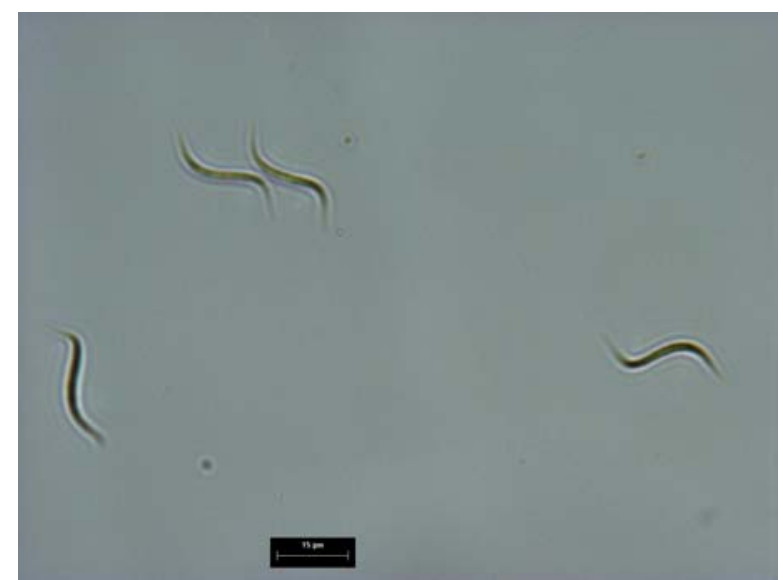

Figura 32: Controle M. contortum dia 0. Aumento de 400x. Escala de $15 \mu \mathrm{m}$.

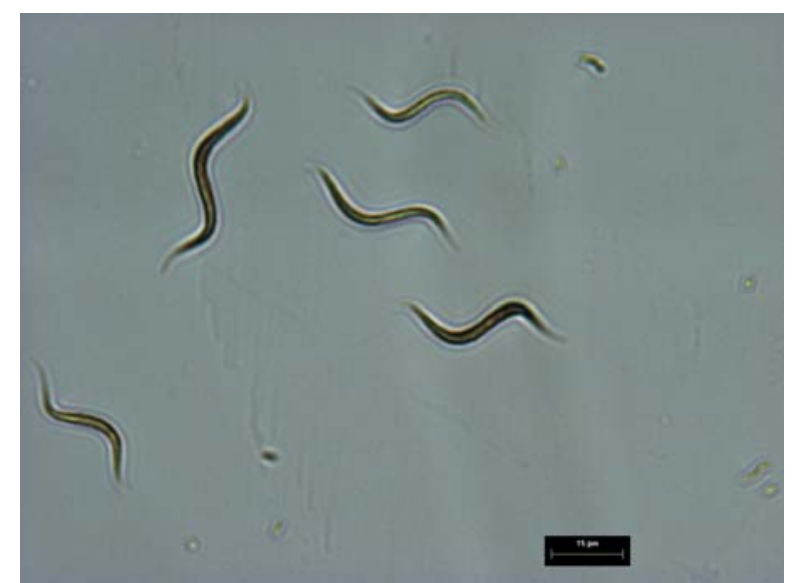

Figura 33: Controle M. contortum dia 7. Aumento de 400x. Escala de $15 \mu \mathrm{m}$.

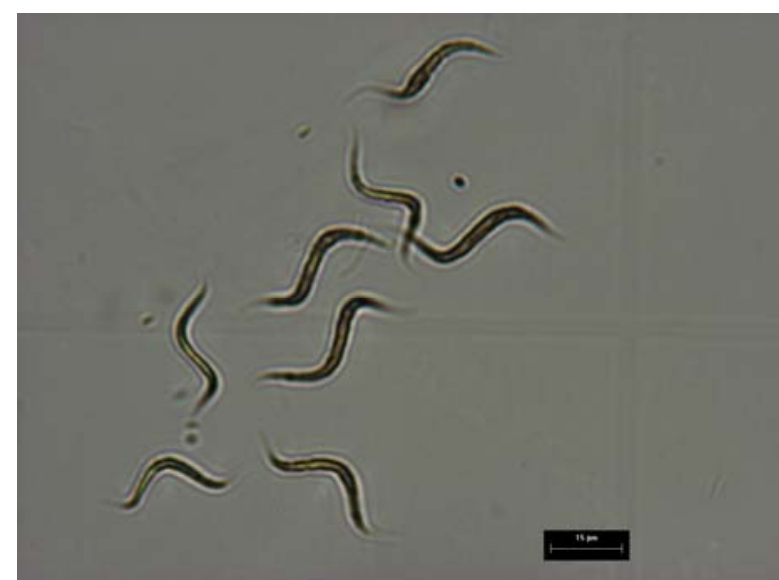

Figura 34: Controle M. contortum dia 15. Aumento de 400x. Escala de $15 \mu \mathrm{m}$. 


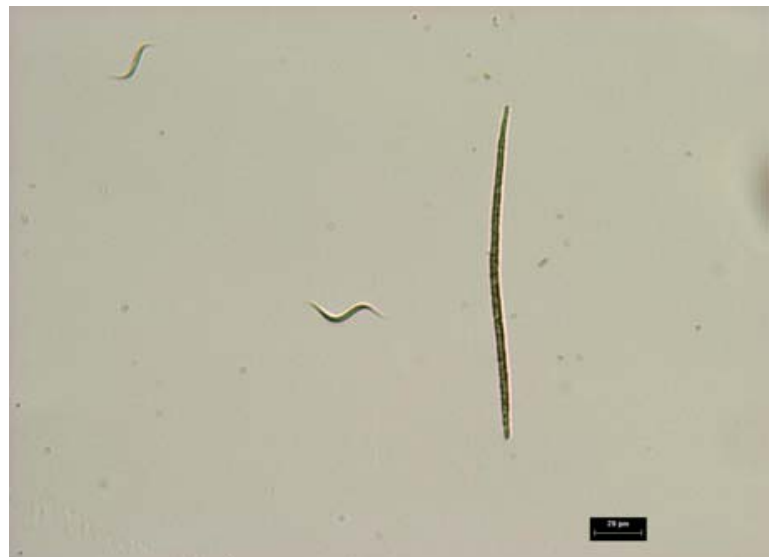

Figura 35: Interação dia 0. Aumento de 200x. Escala de $20 \mu \mathrm{m}$.

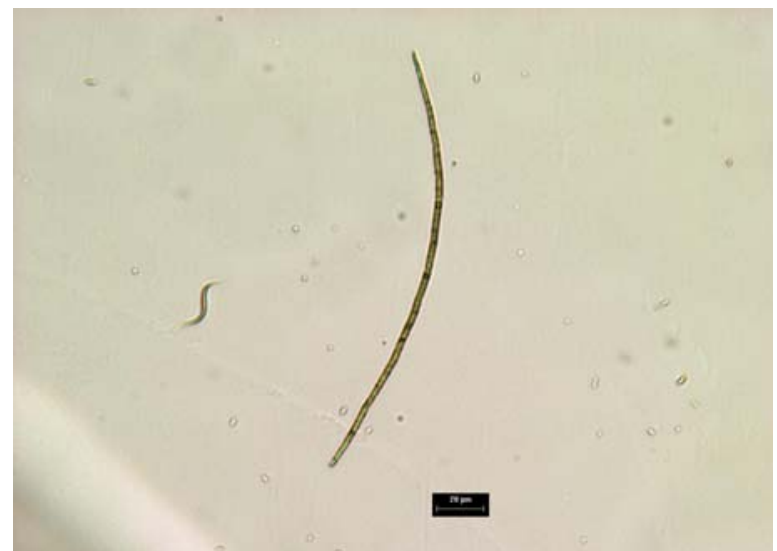

Figura 36: Interação dia 7. Aumento de 200x. Escala de $20 \mu \mathrm{m}$.

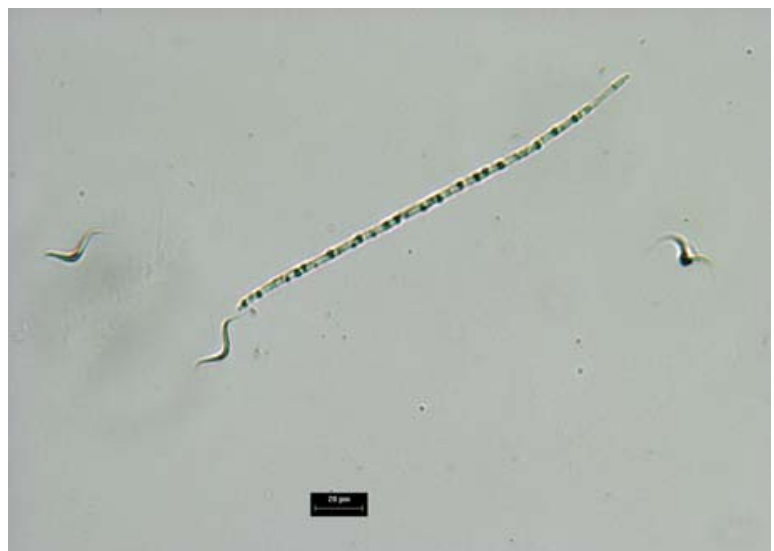

Figura 37: Interação dia 15. Aumento de 200x. Escala de $20 \mu \mathrm{m}$. 
APÊNDICE C - Fotos experimento de simulação ambiente supereutrófico

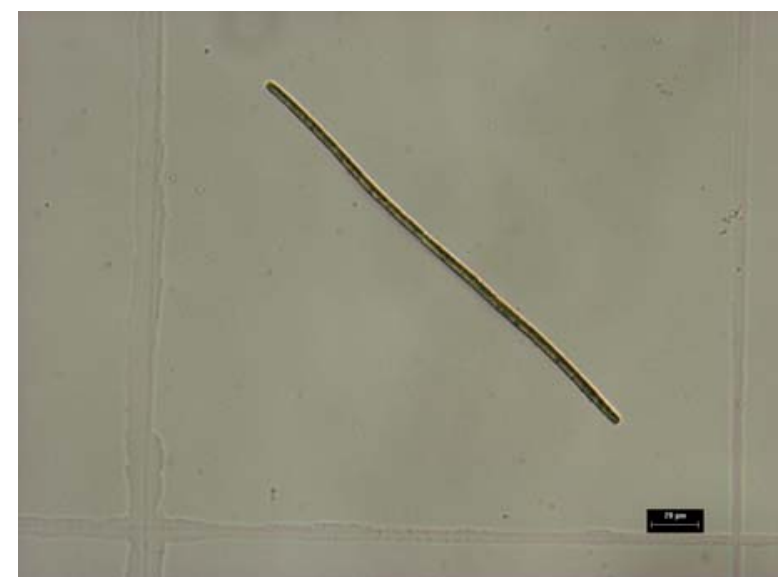

Figura 38: Controle C. raciborskii dia 0. Aumento de 200x. Escala de $20 \mu \mathrm{m}$.

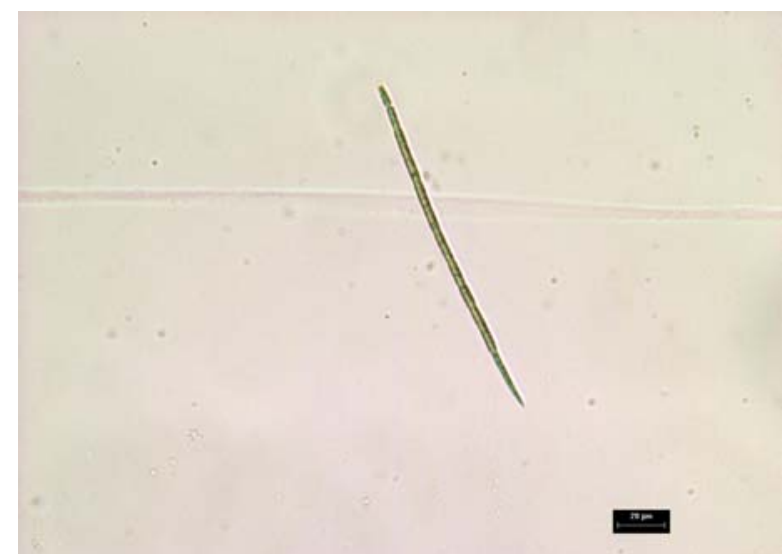

Figura 39: Controle C. raciborskii dia 7, com heterocito. Aumento de 200x. Escala de $20 \mu \mathrm{m}$.

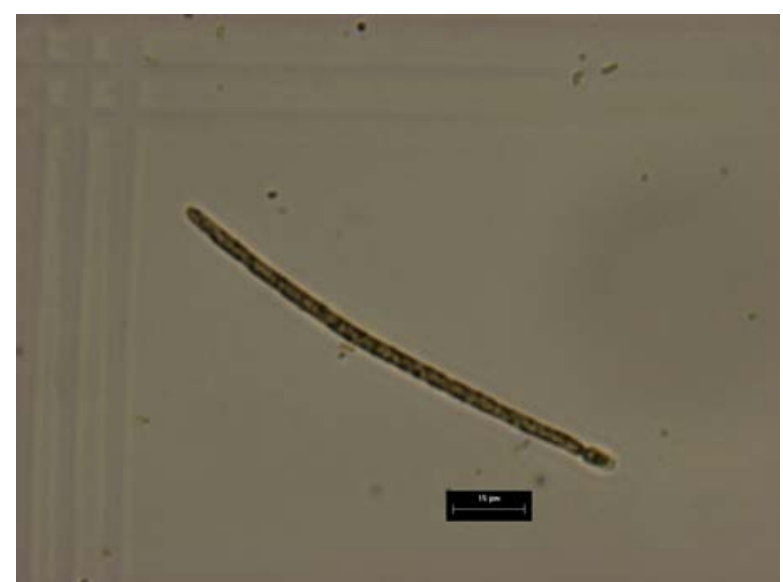

Figura 40: Controle C. raciborskii dia 15, com heterocito. Aumento de 400x. Escala de $15 \mu \mathrm{m}$. 


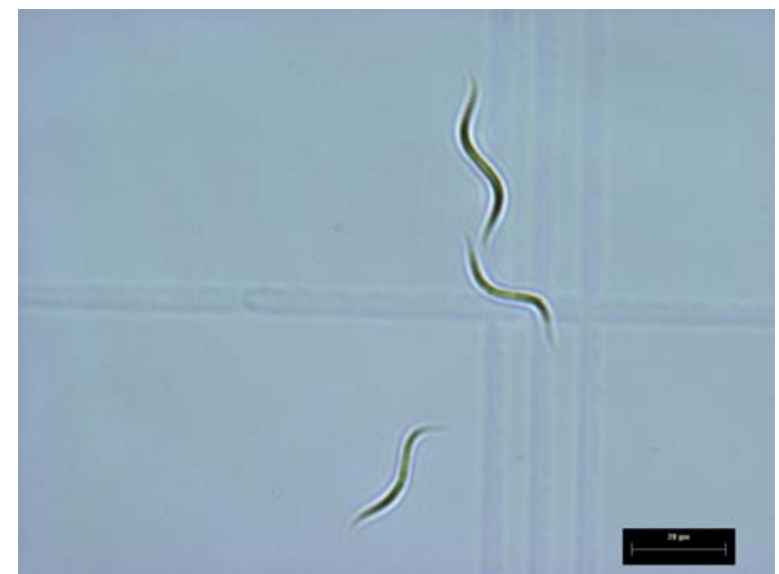

Figura 41: Controle $M$. contortum dia 0. Aumento de 400x. Escala de $20 \mu \mathrm{m}$.

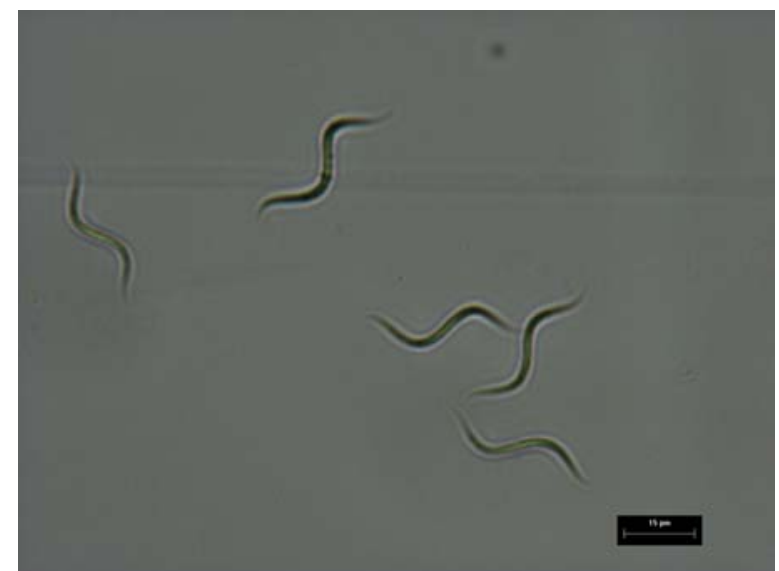

Figura 42: Controle $M$. contortum dia 7. Aumento de 400x. Escala de $15 \mu \mathrm{m}$.

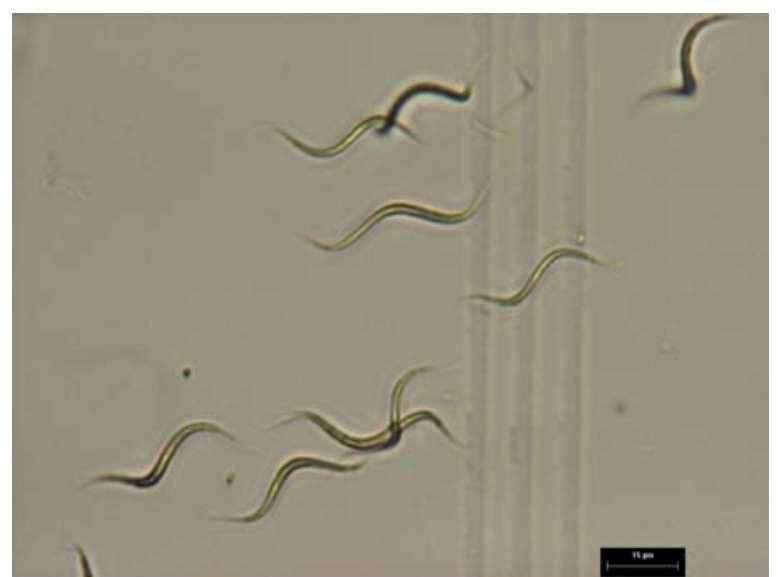

Figura 43: Controle M. contortum dia 15. Aumento de 400x. Escala de $15 \mu \mathrm{m}$. 


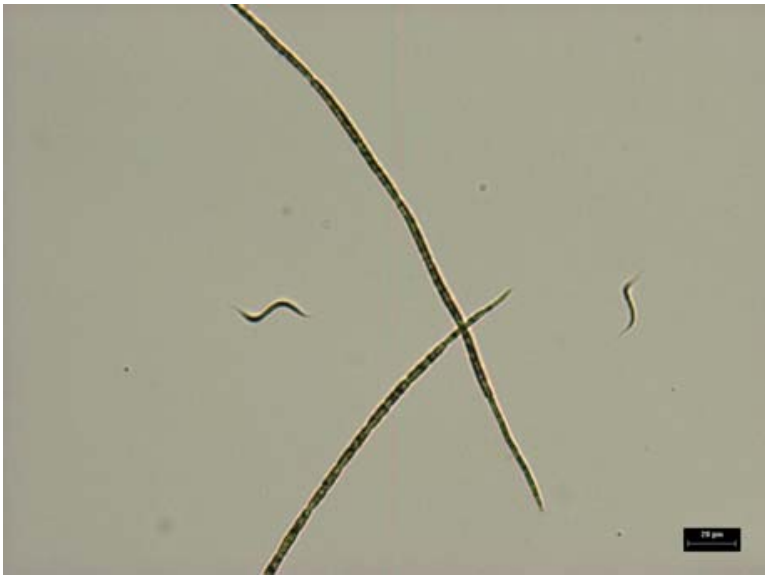

Figura 44: Interação dia 0. Aumento de 200x. Escala de $20 \mu \mathrm{m}$.

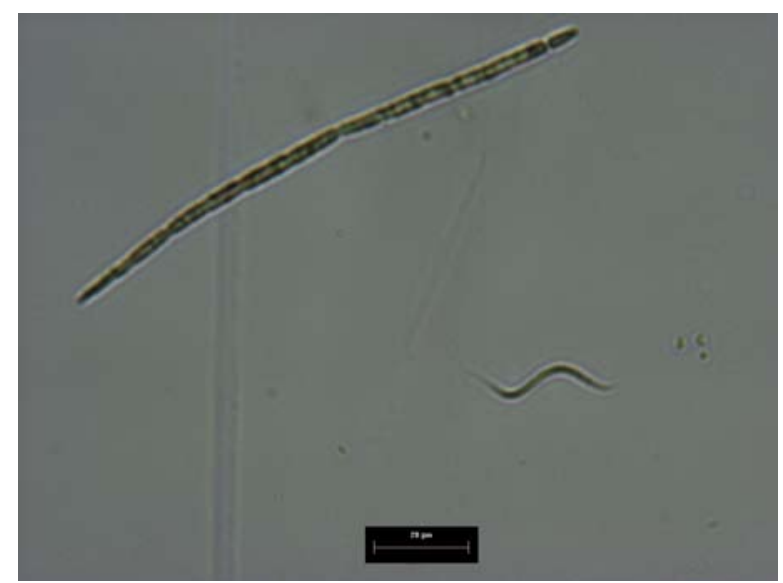

Figura 45: Interação dia 7, C. raciborskii com heterocito. Aumento de 400x. Escala de $20 \mu \mathrm{m}$.

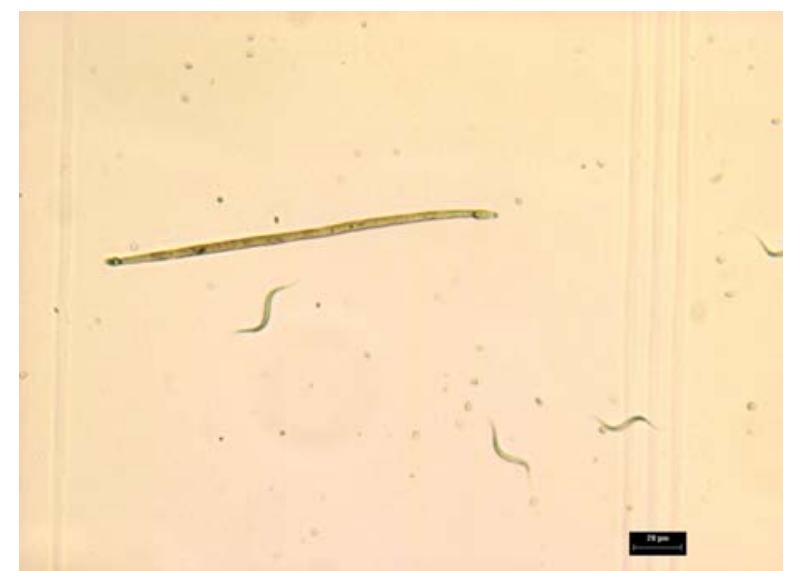

Figura 46: Interação dia 15, C. raciborskii com heterocito. Aumento de 200x. Escala de $20 \mu \mathrm{m}$. 